\title{
Gene expression profiling in cardiac hypertrophy and heart failure : a jey role for mitochondrial energy metabolism
}

Citation for published version (APA):

van den Bosch, B. J. C. (2005). Gene expression profiling in cardiac hypertrophy and heart failure : a jey role for mitochondrial energy metabolism. [Doctoral Thesis, Maastricht University]. Universiteit Maastricht. https://doi.org/10.26481/dis.20051007bb

Document status and date:

Published: 01/01/2005

DOI:

10.26481/dis.20051007bb

Document Version:

Publisher's PDF, also known as Version of record

\section{Please check the document version of this publication:}

- A submitted manuscript is the version of the article upon submission and before peer-review. There can be important differences between the submitted version and the official published version of record.

People interested in the research are advised to contact the author for the final version of the publication, or visit the DOI to the publisher's website.

- The final author version and the galley proof are versions of the publication after peer review.

- The final published version features the final layout of the paper including the volume, issue and page numbers.

Link to publication

\footnotetext{
General rights rights.

- You may freely distribute the URL identifying the publication in the public portal. please follow below link for the End User Agreement:

www.umlib.nl/taverne-license

Take down policy

If you believe that this document breaches copyright please contact us at:

repository@maastrichtuniversity.nl

providing details and we will investigate your claim.
}

Copyright and moral rights for the publications made accessible in the public portal are retained by the authors and/or other copyright owners and it is a condition of accessing publications that users recognise and abide by the legal requirements associated with these

- Users may download and print one copy of any publication from the public portal for the purpose of private study or research.

- You may not further distribute the material or use it for any profit-making activity or commercial gain

If the publication is distributed under the terms of Article $25 \mathrm{fa}$ of the Dutch Copyright Act, indicated by the "Taverne" license above, 


\section{Gene expression profiling in cardiac hypertrophy and heart failure}


(c) Bianca J.C. van den Bosch, Maastricht 2005 ISBN 90-6464-255-9

Cover drawing

Robert Bruls

Cover design

Bianca van den Bosch

Printed by Grafisch bedrijf Ponsen \& Looijen B.V. 


\section{Gene expression profiling in cardiac hypertrophy and heart failure}

\section{a key role for mitochondrial energy metabolism}

\section{Proefschrift}

ter verkrijging van de graad van doctor aan de Universiteit Maastricht, op gezag van de Rector Magnificus, Prof. mr. G.P.M.F. Mols

volgens het besluit van het College van Decanen,

in het openbaar te verdedigen,

op vrijdag 7 oktober 2005 om 12.00 uur

door

Bianca Jozefina Catharina van den Bosch

geboren te Heerlen op 23 oktober 1976 


\section{Promotores}

Prof. dr. J.P.M. Geraedts

Prof. dr. P.A.F.M. Doevendans (Hart-Long Instituut Utrecht)

\section{Co-promotor}

Dr. H.J.M. Smeets

\section{Beoordelingscommissie}

Prof. dr. M. Daemen (voorzitter)

Prof. dr. M.H. Hofker

Dr. Y.M. Pinto

Prof. dr. G.J. van der Vusse

Dr. M. Zeviani (National Institute of Neurology "C. Besta", Italy)

The studies described in this thesis were supported by a grant of the Netherlands Heart Foundation (NHF-99.122) and performed at the Department of Genetics and Cell Biology, Cardiovascular Research Institute Maastricht (CARIM), Maastricht University, The Netherlands.

Financial support by the Netherlands Heart Foundation for the publication of this thesis is gratefully acknowledged. Additional financial support was granted by the Dr. Ir. van de Laar Stichting, Corning Life Sciences B.V. and Transgenomic Ltd. 
If you think you can, you can. And if you think you can't, you're right! 



\section{Contents}

Chapter 1 Introduction

Aims and outline of this thesis

Chapter 2 Mitochondrial cardiomyopathy

Chapter 3 Mutation analysis of the entire mitochondrial DNA using Denaturating High Performance Liquid Chromatography

Chapter 4 Increased risk for cardiorespiratory failure associated with the $\mathrm{A3302 \textrm {C }}$ mutation in the mitochondrial DNA encoded tRNA ${ }^{\text {Leu(UUR) }}$ gene

Chapter 5 Regional absence of mitochondria causing energy depletion in the myocardium of MLP knockout mice

Chapter 6 Methods in molecular cardiology: microarray technology

Chapter 7 Early and transient changes in gene expression compensate pressure overload induced cardiac hypertrophy in mice

Chapter 8 The early genetic profile of maladaptive hypertrophy in CMyBP-C knockout mice

Chapter 9 General discussion

Summary

Samenvatting

Dankwoord

\section{Curriculum Vitae}

\section{Publications}

\section{Abbreviations}





\section{CHAPTER}

\section{Introduction}




\section{Introduction}

\section{Heart failure and cardiac hypertrophy: causes and consequences}

\section{Heart failure}

For many years, cardiovascular disease (CVD) has been the primary cause of death in modern Western societies. ${ }^{1,2}$ About 11\% of the total number of CVD deaths are due to heart failure (HF), which is associated with high morbidity and mortality. Prognosis for patients with $\mathrm{HF}$, with a prevalence of $1-2 \%$ of the Dutch population ${ }^{2}$, is poor with a median survival of 1.7-3.2 years after onset. ${ }^{3,4} \mathrm{HF}$ can be defined as a clinical syndrome due to a structural or functional disorder, in which the heart fails to maintain cardiac function commensurate with the requirements of the body. ${ }^{5}$ It is characterized by low cardiac output due to systolic and/or diastolic dysfunction ${ }^{5,6}$ and symptoms including dyspnea, fatigue, weakness, palpitations, exercise intolerance and peripheral edema. The failing heart is characterized by different degrees of cardiomyocyte hypertrophy, fibrosis, cardiomyocyte necrosis and/or apoptosis, genetic re-programming resembling the fetal heart, mitochondrial dysfunction, alterations at the level of the cytoskeletal architecture and abnormal calcium cycling., ${ }^{4,7}$

The etiology of HF is complex and in humans it is most often the end-stage of various forms of cardiovascular disease, such as myocardial infarction (MI), hypertension, coronary and valvular disease, arrhythmias and hereditary cardiomyopathies. ${ }^{8-11}$ Human CVD is genetically and clinically heterogeneous, which indicates that HF will develop most likely due to a combination of genetic and environmental factors. Dilated cardiomyopathy (DCM) is the most common primary cause of HF. DCM is defined by ventricular dilation and diminished contractile function (Figure 1), but may differ in morphology and pathogenesis. Regardless of the etiology, the clinical course is nearly always progressive and associated with a high risk of sudden death due to ventricular arrhythmias and pump failure. About $25-35 \%$ of individuals with DCM have a familial form of the disease with autosomal dominant inheritance as the predominant pattern of transmission, with or without accompanying features such as cardiac conduction system disease, skeletal muscle disease and deafness. ${ }^{12 \cdot 14} \mathrm{~A}$ large number of genes and gene defects have been identified either by linkage analysis or candidate gene screening, but no common gene defect seems to exist. The discovery of these defects has had a enormous impact on unraveling the pathogenic processes involved. ${ }^{15-17}$ 

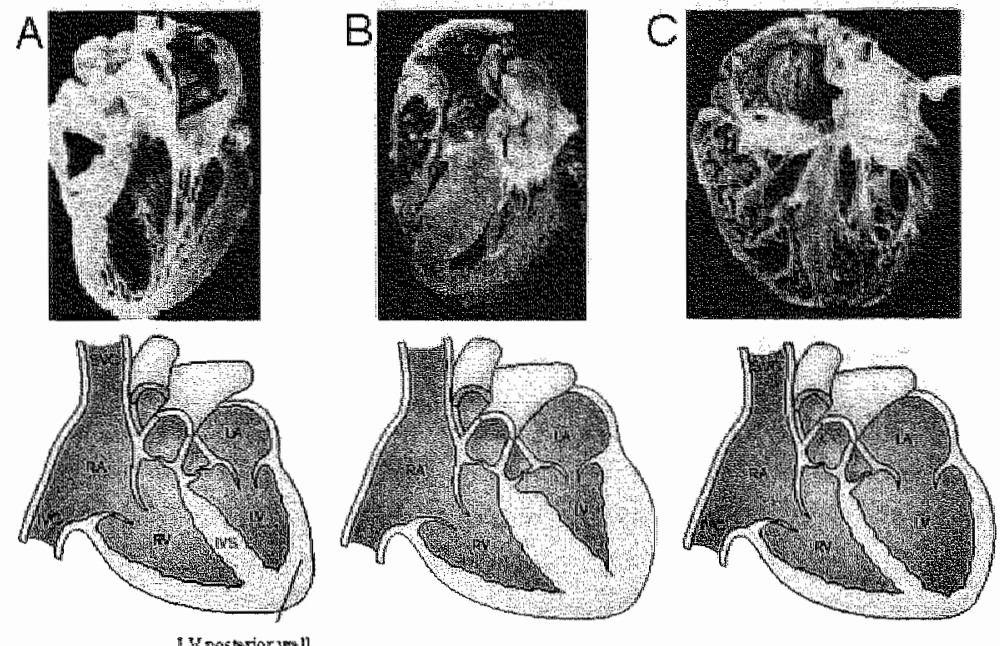

Figure 1: The normal, hypertrophic and failing heart. A. Normal heart. B. Hypertrophic heart, showing severe thickening of the interventricular septum (IVS) and a decreased left ventricular chamber size; $C$. Dilated heart, showing an increase in left ventricular cavity size with thin ventricular walls. Abbreviations: IWC, inferlor vena cava: NS, interventricular septum; LA, left atrium, LV, left ventricle; RA, right atrium "RV "right wentricle; $5 V C$, superior vena cava. Adapted from Seidman $\mathrm{BC}$ et al. ${ }^{16}$

\section{Cardiac hypertrophy}

A common early event in the clinical course of HF is myocardial hypertrophy, which can occur in response to a number of mechanical, hemodynamic, hormonal and pathologic stimuli or due to genetic defects. Hypertrophy can be defined as an increase in heart size resulting from the enlargement of existing cardiomyocytes. ${ }^{18}$ In this way, the heart is able to adapt to increased workload, injury or defects in contractile performance. ${ }^{18}$ Hypertrophy does not necessarily lead to heart failure and can be a compensating physiological adaptation that occurs after birth and by physical exercise. However, while in many cases compensatory cardiac remodeling seems beneficial at first, myocardial hypertrophy is recognized as an important risk factor for subsequent cardiac morbidity and mortality. ${ }^{19,20}$ Pathological hypertrophy is often associated with an accumulation of collagen in the myocardium, combined with an increase in ventricular wall thickness. ${ }^{21}$ In addition, a number of biomarkers, such as BNP (brain natriuretic peptide), have been identified, which discriminate physiological from pathologicall hypertrophy ${ }^{22.23}$, but similar changes in gene expression have also been identified. ${ }^{24}$ These data suggest that adaptive and maladaptive hypertrophy differ at the molecular level, but that certain genes and/or pathways may be involved in all 
forms of cardiac hypertrophy or may be altered transiently. ${ }^{25}$ Cardiac hypertrophy frequently occurs secondary to hypertension or aortic stenosis, which can both be regarded as external hypertrophic stimuli leading to pressure overload. This adaptation is associated with concentric hypertrophy, characterized by thickening of the myocardial walls without increasing left ventricular (LV) lumen size (increased ratio wall thickness/chamber dimension). ${ }^{26}$ Volume-overload, caused by situations in which cardiac output is increased while pressure remains normal, like aortic valve regurgitation, leads to eccentric hypertrophy which is characterized by thickening of the walls associated with increased LV cavity size (decreased ratio wall thickness/chamber dimension). ${ }^{26}$ Familial or genetic hypertrophic cardiomyopathy (HCM) is characterized by hypertrophy of the left (and sometimes right) ventricles with myocyte disarray and hypertrophy, myofibrillar disarray and interstitial fibrosis. ${ }^{14}$ The hypertrophy is most often asymmetric and often with particular involvement of the interventricular septum (Figure 1). ${ }^{27}$ As a consequence, the left ventricular chamber volumes are diminished. Pump function is usually supranormal in affected patients. ${ }^{15}$

\section{Inherited human cardiomyopathies}

Monogenic cardiomyopathies can be classified into hypertrophic cardiomyopathy (HCM), dilated cardiomyopathy (DCM), restrictive cardiomyopathy (RCM) and arrhytmogenic right ventricular dysplasia/cardiomyopathy (ARVD).$^{28} \mathrm{HCM}$ is an autosomal dominant disease with a wide range of clinical features from benign to severe, and is the most common cause of sudden death in atherwise healthy individuals. More than 100 different disease-causing mutations have been identified in 11 genes encoding sarcomeric proteins. Most frequently affected are the $\beta$-myosin heavy chain $(\mathrm{MYH} 7)^{29}$, cardiac troponin $\mathrm{T}(\mathrm{TNNT2})^{30}$ and cardiac myosin binding protein-C (MYBPC3/CMyBP-C) ${ }^{31}$. Cardiac MyBP-C mutations account for about $20 \%$ of all mutations in $\mathrm{FHC}^{31 \cdot 35}$ Due to a founder mutation, this frequency is even higher in the Netherlands. ${ }^{36}$ Other sarcomeric genes mutated in HCM are $\alpha$-tropomyosin $(T P M 1)^{30}$, regulatory and essential myosin light chain (MYL2 and MYL3) ${ }^{37}$, cardiac troponin I (TNNI3) $)^{38}$, titin $(\text { TTN })^{39}$, cardiac $\alpha$-actin $(\mathrm{ACTC})^{40}$ and cardiac troponin $C$ (TNNC1). ${ }^{41}$ Recently, mutations in the muscle LIM protein (MLP/CRP3) were identified as well. ${ }^{42} \mathrm{HCM}$, often in conjunction with other cardiac and non-cardiac phenotypes, can also be caused by alterations in non-sarcomeric genes such as dystrophia myotonica-protein kinase $(\mathrm{DMPK})^{43}, \gamma 2$-regulatory subunit of AMP-activated protein kinase (PRKAG2) 44 , LAMP2 (lysosomal membrane glycoprotein 2) 45 $^{45}$ and frataxin (FRDA). ${ }^{46}$ Gene mutations involved in mitochondrial FA oxidation or mutations in the 
tRNA genes, rRNA genes or other protein encoding genes of the mitochondrial DNA (mtDNA) (see chapter 2 and 4), can also cause HCM. Mutations in all of these genes together account for about $50-70 \%$ of all cases of HCM (Table 1), indicating that a substantial number of genes and mutations remain to be elucidated. ${ }^{14}$

Autosomal dominant DCM without conduction system disease (CDDC) has been associated with mutations in cardiac actin ${ }^{47}$, desmin (DES) ${ }^{48}$, TNNT2 $2^{49}, \mathrm{MYH}^{49}$, MYBPC $3^{50}, \delta$-sarcoglycan (SGCD) $)^{51}, \beta$-sarcoglycan (SGCB) ${ }^{52}, \mathrm{TPM}^{5}{ }^{53}, \mathrm{TTN}^{54}$, MLP/CRP3 $3^{55}$, telethonin $(\mathrm{T} \text {-cap) })^{55}$, metavinculin $(\mathrm{VCL})^{56}$, phospholamban (PLN) $)^{57}$ and Cypher/Zasp. ${ }^{58}$ In autosomal dominant DCM families with CDDC or with additional skeletal myopathy, lamin A/C (LMNA) mutations have been identified..$^{59-62} X$-linked, autosomal recessive and mitochondrial inheritance are less common. ${ }^{13,62}$ For $X$-linked DCM, mutations have been identified in dystrophin ${ }^{63}$ and $\operatorname{tafazzin}^{64}$. No genes have yet been identified in autosomal dominant DCM with sensorineural hearing loss or in autosomal recessive DCM. ${ }^{14}$ Mutations in the mtDNA have been identified in maternally inherited cardiomyopathies. ${ }^{65}$ In about $50 \%$ of cases, a specific cause cannot be identified. These cases are often referred to as idiopathic dilated cardiomyopathy (IDC). Furthermore, several genetic loci have been associated with different forms of DCM, but the genes involved are yet unknown (Table 1). ${ }^{14,66}$ Most cases of DCM can be considered as a primary disease of the cytoskeleton and/or sarcolemma, leading to defects in muscle contraction, which requires effective force and energy generation, but also transmission to the cytoskeleton and the extracellular matrix. ${ }^{66}$

ARVD is a complex disorder characterized by gradual loss of myocytes and replacement by fatty and fibrous tissue. ${ }^{67}$ To date, 9 loci have been identified in families with autosomal dominant inherited ARVD, i.e. ARVD1-9 (Table 1). Three disease-causing genes have been identified: the cardiac ryanodine receptor (RYR2, ARVD2 locus) ${ }^{68}$, desmoplakin (DSP, ARVD8 locus) ${ }^{69}$ and plakophilin-2 (PKP2). ${ }^{70}$ RYR2 plays an important role in calcium homeostasis, which is required for appropriate excitation-contraction coupling, and DSP and PKP-2 are key components of desmosomes. Additional causative genes remain to be identified. Autosomal recessive inheritance (Naxos disease) has been found to be caused by mutations in plakoglobin (JUP), which is just like DSP a component of desmosomes and adherens junctions. ${ }^{71}$ RCM is the least common of the four categories of cardiomyopathies, but has the worst prognosis and is characterized by normal ventricular shape with impaired diastolic filling. Although several inherited and acquired disorders may cause RCM, many cases remain idiopathic. ${ }^{14}$ As disease-causing genes, $\mathrm{DES}^{72}$ and $\mathrm{TNN} / 3^{73}$ have been identified 
(Table 1), although RCM is a relatively infrequent manifestation of desmin-related myopathies. ${ }^{14}$ Other causative genes have not yet been characterized.

The penetrance of HCM is variable and carriers of the gene defect can remain asymptomatic throughout life, while others develop progressive symptoms with or without HF or sudden death, and $10-20 \%$ develops DCM. ${ }^{14}$ The same genes can be involved in either HCM or DCM, indicating common pathways that include cytoskeletal proteins and the sarcomere. The specific functional domain involved or the extent of contractilic deficit might determine whether a mutation results primary in HCM or DCM. $^{24}$ The observed variability in extent of hypertrophy exists not only among members of different families, but even among family members of the same family ${ }^{p 4}$, pointing to the involvement of other factors than the causal mutation. Some of these factors, determining the variation in phenotypic expression and the severity of clinical manifestations in HCM and DCM, have been elucidated, but the picture is \|argelly incomplete and most likely environmental factors and genetic background (modifier genes) will be involved. Also, carriers of two mutated alleles, like double heterozygotes or compound heterozygotes, develop in general a more severe cardiac phenotype in generall. This has been observed in patients with mutations in the MYBPC 3 gene. ${ }^{75,76} \mathrm{~A}$ critical factor may also be inherited or acquired defects in energy metabolism. ${ }^{14}$ Point mutations and deletions in the mtDNA have been described in syndromic and nonsyndromic cardiac abnormalities (see chapters 3 and 4), such as adult-onset hypertrophy and childhood-onset DCM. Primary or acquired mtDNA mutations leading to OXPHOS (oxidative phosphorylation) defects can play a primary or secondary role in the pathogenesis of cardiac disease (see also chapter 2)..$^{5,77}$ In addition, many experimental and clinical studies in the hypertrophied and failing heart have reported defects in energy metabolism ${ }^{78}$, which suggest that the failing heart is an energycompromised organ. ${ }^{78,79}$

In spite of all these findings, the exact molecular program underlying cardiac hypertrophy and heart failure remains largely elusive. A broad variety of factors, like genetic background, environment and drug treatment, can be involved..$^{62}$ It is evident that, except for the genetic forms, the human patient population will be largely heterogeneous. Thus, to get further insight into the underlying pathological processes, animal models are advantageous, because they are genetically and environmentally homogeneous and can be studied more easily. 
Tiable 1 . Cenetic and clinical heterogeneity of human cardiomyopathites

\begin{tabular}{|c|c|c|c|c|}
\hline Phenatype & Inheritance & Chromosoma locus & Gene symbol & Proteińn \\
\hline \multirow[t]{14}{*}{ HCM } & \multirow[t]{11}{*}{ Dominant } & 1932 & TNN12 & Troponin T \\
\hline & & 2931 & TTN & Thtim \\
\hline & & $3 p 211.3-p 14.3$ & TNNC1 & Troponin 6 \\
\hline & & $11 p 11.2$ & MYBPCS & Myosin binding protein- $C$ \\
\hline & & $11 p 15: 1$ & CSRP3 $_{3}$ & Muscle LIM protein \\
\hline & & $12 q 23-924.3$ & MYL2 & Regulatory myosin light thain \\
\hline & & $14 q 12$ & MYH7 & p-myosing heawy chalin \\
\hline & & $15 q 11-q 14$ & $\mathrm{ACTC}$ & a-actim \\
\hline & & 15922.1 & TPM1 & a- Hropamyasin \\
\hline & & $19 p 13.4$ & TNNI3 & Troponin 1 \\
\hline & & $20 \mathrm{pq} 13.3$ & MYLK2 & Myosin light chain kinase 2 \\
\hline & Dom, or recessive & $3 p 21.3-p 21.2$ & MYLB & Essential myosin light chain \\
\hline & Unknown & 14912 & MYHG & $\alpha-$ myasin heavy chain s \\
\hline & Maternal & Mitochondriall IDNA & MIDNA & Respiratory chain proteins \\
\hline HCM+WPW syndrome & Domiruant & 7936 & PRKAG 2 & y2-regullatory subunit of AMPK \\
\hline Myotonic dystr.HCM & Dominant & $19 q 133$ & DMPK & Dystrophia myotonics prot kínase \\
\hline HCM+arrihythmias & xanked & $x q 24$ & LAMP2 & Lysosomal membrane glycoprot 2 \\
\hline Friedreich's ataxia & Recessive & $9 q 13-q \mid 21.1$ & FROA & Frataxin \\
\hline \multirow[t]{19}{*}{ DCM } & \multirow[t]{17}{*}{ Domimant } & 1932 & TNINT2 & Troponin T \\
\hline & & $2 q 31$ & $\operatorname{TTN}$ & Titin \\
\hline & & 2935 & DES & Dresmin \\
\hline & & 4912 & SGCB & P-sarcogflycan \\
\hline & & $5 q 33-934$ & SGCD & s-siancoglycan \\
\hline & & $6 q 12-q 16$ & 7 & $?$ \\
\hline & & $6 q 22.1$ & PLN & Phospholamban \\
\hline & & $9 q 13-q 22$ & ? & $?$ \\
\hline & & $9922-931$ & $?$ & $?$ \\
\hline & & $109211-423$ & $?$ & $?$ \\
\hline & & $\log 22,1-\operatorname{qg} 23$ & VCL & Metavinculin \\
\hline & & 11 p11 & MYBPC 3 & Myosin binding protein-C \\
\hline & & $11 p 15.2$ & MLP & Muscle LM protein \\
\hline & & $14 q 12$ & MYHT & 3-myosin heavy chalu \\
\hline & & $15 q 14$ & ACTC & a-actin \\
\hline & & 15922 & TPHM 1 & autropornyosin \\
\hline & & 17912 & Truap & Telethonin \\
\hline & X-linked & $x p 21$ & DMD & Dystrophin \\
\hline & Maternal & Mitochonidrial DNA & MIDNA & Respiratory chain proteins \\
\hline DCM.rventr.tachycard. & Dom or sporadic & $12 \mathrm{p} 12.1$ & SUR.2 & Sulfonylurea receptor 2 \\
\hline DCMEIINIVM & Dominant & $10922.3-923.2$ & CypheriZASP & Cypher/ZASP \\
\hline \multirow[t]{3}{*}{ DCMACSD } & \multirow[t]{3}{*}{ Dominant } & $1 q 21.2$ & LMNA & Lamin A.C \\
\hline & & $2 q 14-q 22$ & $?$ & $?$ \\
\hline & & $3 p 22 \cdot p 25 ?$ & ? & 7 \\
\hline \multirow[t]{2}{*}{$D C M+5 k M 4 C S D$} & \multirow[t]{2}{*}{ Dominamt } & $1 q 21.2$ & LMMMA & Lămin $A r C$ \\
\hline & & 6923 & $y$ & 7 \\
\hline DCM+Sens.Deafmess & Dominant & $6 q_{23} 3 \cdot q_{24}$ & $?$ & 7 \\
\hline DCM with $A R$ R'D & Dominant & 6p24 (ARVD8) & WSP & Desmoplakin: \\
\hline
\end{tabular}


Table 1. Cenetic and dinical heterogeneily of humain cardionyopathies (continued)

\begin{tabular}{|c|c|c|c|c|}
\hline Phenotype & linheritance & Chiromosomial locus & Gene symbol & Protein \\
\hline DCMit Naxos disease & Dominant & 17921 & JUP & Plakoglobin \\
\hline DCM tath ryndrome & Xlinked & $x 028$ & 64.5 & Tafazzin \\
\hline \multirow[t]{8}{*}{$A R V D$} & Dominant & 1942 (ARVD2) & RYR2 & Pyanodine receptar \\
\hline & & 2932 (ARVD4) & $?$ & $?$ \\
\hline & & $3 p 23(A R V D S)$ & $?$ & $?$ \\
\hline & & 6P24 (ARVD8) & DSP & Desmoplakin \\
\hline & & $10 p 12-p 14$ (ARVD6) & $?$ & $?$ \\
\hline & & $12 p 11$ & PKP2 & Plakophilina.2 \\
\hline & & $14 q 23-924$ (ARVD1) & $?$ & $?$ \\
\hline & & $14 q 12-922$ (ARVD 3 ) & $?$ & $?$ \\
\hline ARVD+ myofibr myop. & Dominant & $10 q 22($ ARVD7) & $?$ & $\gamma$ \\
\hline ARVD+Naxos disease & Recessive & $17 q 21$ (ARVD9) & JUP & Plakoglobin \\
\hline \multirow[t]{2}{*}{ RCM } & & 2935 & DES & Desmin \\
\hline & & $19 q 13$ & TNNI3 & Troponin I \\
\hline
\end{tabular}

dom, dominant; dystr., dystrophin; prot, protein; ventr. tachycard, ventricular tachycardia; SkM, skeletall myopathy; Sens., sensorineural; myofibr. myop., myfibrillar myopathy. Modified and updated from Fatkin D et al. ${ }^{\text {Hat }}$ For the remainder af the abbrevations, see the list of abbreviations at the end of this thesis.

\section{Mouse models of cardiac hypertrophy and heart failure}

The mouse is a suitable experimental system for genetic manipulation because of the small size, rapid gestation (21 days), large litter sizes, stable germline transmission of mutations and well characterized genetics and development, which makes them advantageous to larger mammalian species. ${ }^{80,81}$ Although murine cardiac physiology is fundamentally different from that of humans, mice have been shown to be valid models for studying cardiovascular diseases, as features and disease course are often similar in mice and humans. ${ }^{82}$ Generation and characterization of mouse models have already greatly advanced our knowledge of the molecular mechanisms underlying the pathogenesis of cardiac hypertrophy and heart failure. ${ }^{18,25,83,84}$ In general, there are three kinds of models used for studying cardiac hypertrophy and failure: pharmacologically induced models, genetic models and mechanical models.

\section{Pharmacological models}

Cardiac hypertrophy and HF induced in a pharmacological way can be achieved by treatment of animals with isoproterenol (ISO) or angiotensin II (Ang II). ${ }^{85.86}$ An advantage of these pharmacological models is the possibility not only to study the induction, but also the regression of hypertrophy in vivo. Genes whose expression is altered specifically during this regression might suggest novel strategies to limit hypertrophy and its progression to HF. Moreover, acute and chronic effects of a certain treatment could reveal different gene expression patterns, as has recently been described for Ang $\|$ treatment in mice. ${ }^{86}$ 


\section{Genetic models}

Most genetic mouse models that exist are not spontaneous mutant mice, but genetically altered mouse models of cardiac hypertrophy and failure. These include defects in contractile proteins, cytoskeletal proteins and $\mathrm{Ca}^{24}$-regulatory proteins, cell surface receptors, cell-signaling molecules, transcription factors, growth factors and mitochondria. ${ }^{81}$ The combination of heart specific mutations and the technologies to evaluate the effects of these mutations on cardiac function at the cellular, organ and intact animal levels has already provided novel insights into the molecular mechanisms of hypertrophy and HF. The two genetic mouse models used in our studies are the MLP (Muscle LIM Protein) knockout (KO) mouse (chapter 5) and the CMyBP-C KO mouse (chapter 8 ) that respectively resemble morphological and clinical features of human $D C M^{87}$ and $\mathrm{HCM}^{88}$ Cardiac LIM domain protein MLP is a conserved positive regulator of cardiac muscle development and located at the Z-disc. ${ }^{87}$ The Z-disc is involved in sarcomeric organization, force generation and transmission and acts as an interface between contractile proteins, other cytoskeletal elements and signaling molecules. ${ }^{89}$ MLP deficient mice exhibit disorganization of the $Z$-lines and myofibrils and develop DCM with myocyte hypertrophy and HF. ${ }^{87,90}$ Also, human MLP mutations were recently found to be associated with $D C M^{55.91}$ and $H C M .^{42}$ Cardiac MyBP $C$ is a large and abundant myofibrillar protein with both structural and regulatory functions. ${ }^{92}$ It can be a target for phosphorylation by CAMP-dependent protein kinase (PKA) $)^{93}$ and calcium/calmodulin-dependent protein kinase $1 /$ (CAMKZA) ${ }^{94}$ depending on intracellular calcium levels and $\beta$-adrenergic stimulation. This affects the potential for interaction between myosin heads and actin ${ }^{95}$, which makes it a possible sarcomeric regulator of contractile function. ${ }^{96}$ In comparison to other sarcomeric proteins in which mutations have been found, considerably less is known about the precise structure and function of this protein. ${ }^{96}$ Homozygous CMyBP-C KO mice develop eccentric left ventricular hypertrophy (LVH) with decreased fractional shortening (FS) and impaired relaxation. Heterozygous mice develop asymmetric septal hypertrophy ${ }^{\text {Bg }}$ "which is a major feature of human $\mathrm{FHC}{ }^{97.986}$ Moreover, the mice show no impairment of LV function, as has also been described in human $\mathrm{HCM}^{16}$ Both types of $\mathrm{KO}$ mice do not seem to show a transition to HF, at least not at the time points they were investigated, i.e. 10-11 months of age.

\section{Mechanical models}

The Transverse Aortic Constriction (TAC) model has been used as a mechanically induced mouse model of cardiac hypertrophy. It has been frequently used to study the process of hypertrophy in general or the effect of pressure overload hypertrophy in 
genetically altered mice compared to wild-type animals. ${ }^{99}$ Within these mice, a stenosis in the thoracic aorta ( $40 \%$ of normal aortic diameter) is established, leading to pressure overload (Figure 2). TAC triggers a hypertrophic response in the heart, which is most pronounced in the left ventricle of the animal. ${ }^{100}$ TAC can result in compensated cardiac hypertrophy, although it can also lead to decompensated hypertrophy or induction of HF. This may be dependent on the degree and duration of the banding, but may also be influenced by animal species or strain differences between the mice, as some species or strains of mice rapidly develop heart failure after TAC ${ }^{101-103}$, while others remain compensated even until many months after banding. ${ }^{104-}$ ${ }^{106}$ These differences may shed light on genetic pathogenic and protective factors in the transition of cardiac hypertrophy to heart failure. The TAC model closely resembles the clinical symptoms observed in patients with coarctation of the aorta and is similar to that in patients with aortic stenosis or systemic hypertension. ${ }^{100}$

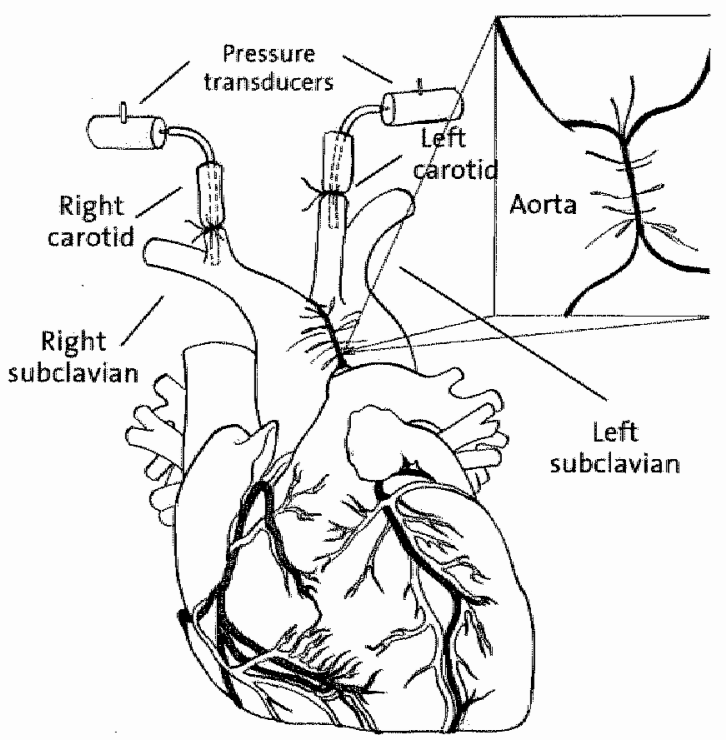

Figure 2. Schematic presentation of the surgical Transverse Aortic Constriction (TAC) procedure." The aorta is being isolated between the first and second truncus of the aortic arch. The transverse aorta is then constricted by 7.0 silk ligature tied against a 0,4 millimeter canula, of which the latter is then removed. The hemodynamic response to the barding can be evaluated by measurement of the presstre difference between the right and left carotid arteries. The banding is created in such a way that it results in a $45 \mathrm{mmHg}$ gradient. Modified from Rockman HA et âd. 
Table 2. Genetically altered mouse models of cardiac hypertrophy and theart failure*

\begin{tabular}{|c|c|c|c|}
\hline i & Cene & Genotype & Phenotype \\
\hline \multirow{21}{*}{ 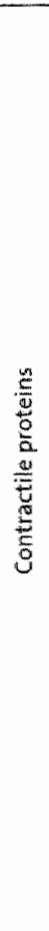 } & W-MHC & W-MHC $(-1-)$ & Death at E11 12 d of gross heart defects \\
\hline & & $a-M H C(+t)$ & $\mathrm{CH}_{2}$ depressed function, fibrosis and sarcomeric abromallias \\
\hline & & Arg $4030 \ln (-1-)$ & Death at 1 week of age \\
\hline & & $\operatorname{Arg} 4030 \ln (+/-)$ & CH, cardiomyopathy, disarray and fibrosis increased with age \\
\hline & BMAEHC & R4030 overexpression & CH that progressed to DCM \\
\hline & $a-a c t i m$ & a-action $(x / 0)$ & $60 \%$ dead at E12.5 and $40 \%$ at 2 wh of age \\
\hline & Troponin T & Truncated TnT & $\begin{array}{l}\text { Cardiomyopathy with smaller hearts, increased morbidity and } \\
\text { mortality; mice die within } 24 \text { hof birth (at high levels) }\end{array}$ \\
\hline & & R920 mutant & Diastolic dysfunction, interstitial fibrosis, shorter sarcomere length \\
\hline & Troponin I & $\operatorname{Tn}(-\beta)$ & Born with normal heart but died of acute MF at 18 days of age \\
\hline & & Truncated Tnl1-193 & $\begin{array}{l}\text { Ventricular dilation, diminished contractility, decreased myofilament } \\
\text { response to calcium, similar to the phemotype of stunned myocardium }\end{array}$ \\
\hline & & Arg1.4.5Gly & Early death, cardiomyocyte disarray and intererstitial fibros is \\
\hline & a-tropomyosin & Asp175,Asn & Wild CH with imparred function and myocyte disorganization \\
\hline & & Giln180Gly & Severe hypertrophy, fibrosis, cardiomyopathy and premature death \\
\hline & & $\alpha-\operatorname{TM}\left(-\alpha_{-}\right)$ & Embryonic lethality \\
\hline & Tropomodulin & Overexpression & DCM in fuvenile mice with severe myofibril disorganization \\
\hline & MYBP-C & Truncated $M y B P-C$ & Decreased power output, sarcomere disorganization and dysgenesis \\
\hline & & Truncated mutant $(-1 /)$ & Meonatal-onset progressive DCM, myocyte hypertrophy and disarray \\
\hline & & MyBP-C (-1-) & $\begin{array}{l}\text { HOMOLVH, decreased FS, impaired relaxation }-H E T \text { :asymmetic septal } \\
\text { hypertiophy }\end{array}$ \\
\hline & ELC & Met149 $\mathrm{Val}$ & Papillary muscle hypertrophy mirroring thuman disease \\
\hline & MLC2V & $\operatorname{MLC} 2 v(-1)$ & Death at E12.5 d with sarcomeric assembly defects and DCM \\
\hline & & $\begin{array}{l}\text { Non-phosphorylatabile } \\
\text { mutant MLC2v }\end{array}$ & $\begin{array}{l}\text { Cardiomyopathic phenotype with structural abnormalities atriall } \\
\text { inypertrophy, dilation, and severe tricuspid walve insufficiency }\end{array}$ \\
\hline \multirow{10}{*}{ 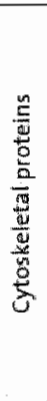 } & MLP & MLP $(\mu-)$ & DCM, CH, disrupted myocyte cytoarchiterture and HF after birth \\
\hline & ALP & ALP $(-1-)$ & Right ventricle DCM \\
\hline & Desmin & Dominant negative & Desmin-related cardionyopathy \\
\hline & $\begin{array}{l}\text { Dystrophin and } \\
\text { Myod }\end{array}$ & Double knockout & $\begin{array}{l}\text { Severe cardiomyopathy with } \mathrm{CH} \text { and areas of necrosis, but dystrophin } \\
(-(-) \text { alone rarely dewelops cardiac abnormalities }\end{array}$ \\
\hline & NMHACHB & $\mathrm{NMMHC} \cdot \| \mathrm{B}(-/ n)$ & $65 \%$ died embryonically: others died of $\mathrm{HF}$ at 1 day of age \\
\hline & $C P$ & CPM. powerexpression & Severe myofibril disarriay and juvenile lethality \\
\hline & & $C P^{9} \beta_{1}$ mutant & Myofibril disruption and intercalated disc remadeling \\
\hline & $\mathrm{SGGB}$ & $\operatorname{SGCB}(-y)$ & Severe cardiomyopathy ${ }^{10 r}$ \\
\hline & 5600 & $\operatorname{sGcos}(\alpha t)$ & Severe cardiomyopathy latia \\
\hline & SIGCD & $\operatorname{sGCD}(-\pi)$ & Severe cardiomyopathy 1 ing \\
\hline \multirow{11}{*}{ 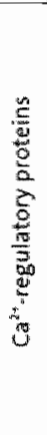 } & PLB & Superinfubitory mutant & $\mathrm{CH}$ and $\mathrm{DCM}$ with interstitial fibrosis and remodeling leading to $\mathrm{HF}$ \\
\hline & & Overexpression & Decreased contractility, overt HF and premature mortallty on alging \\
\hline & $\operatorname{csQ}$ & Overexpression & Concentric left ventricular hypertrophy and progresive HF \\
\hline & MCX & $N C X-1(-1-1)$ & Embryonic lethally due to myofibril disarray, apoptosis, no heartbeat \\
\hline & SERCA2 & $5 \operatorname{ERCA2}(\%)$ & Embryonic lethality \\
\hline & Calreticulin & Overexpression & $\begin{array}{l}\text { Decreased comtractility with chamber dilation and wall thinning. } \\
\text { sudden cardiac death and complete heart block }\end{array}$ \\
\hline & & Callreticulin $(-/-)$ & Decreased ventricular wall thickness \\
\hline & Triadin-1. & Dverexpression & Hypertrophy with depressed contractillity \\
\hline & L-type Ca channel & Overexpression & $\mathrm{CH}$ with progressive remodeling. fibrosis and apoptos is \\
\hline & FKBP12 & FKBPP12 $(-1-)$ & Severe DCM and ventricular septal defects \\
\hline & Ryk-2 & RyR-2 $(-1-)$ & Death at E1o d with theart tube abnormalities \\
\hline
\end{tabular}


Table 2 Genetically altered mosse models of cardlac hypentrophy and heart fallure (continued)

\begin{tabular}{|c|c|c|c|}
\hline & Gene & Geinotype & Phenotype \\
\hline \multirow{11}{*}{ 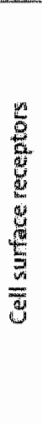 } & $\beta 2-\mathrm{A} A$ & Overexpluession & Enhanced contractile function of progressive DCM (at high lewel) \\
\hline & & Thr164the mutant & Decreased heart rate and cardiac function, blunted responsie to iso \\
\hline & $M i-A R$ & Overexpression & $\mathrm{CH}$ and progressive HF \\
\hline & & BLAR $(-1-)$ & Majority die preniatally \\
\hline & $a_{1 i} \mathrm{AR}$ & Overexpression & $\mathrm{CH}$ and $\mathrm{DCM}$ \\
\hline & fin-ARK1 & BARKI $1 / 1$ & Embryonic lethalty because of ventricular hypoplasia and HF \\
\hline & B. Antegrin & Dominant negative & Some die perinatally of fibrosis; $\mathrm{CH}$ and impaired cardiac function \\
\hline & & Constiturively artive & Cardionyopathy, ECG abnormalities and death within 1 mo of liffe \\
\hline & ATI-R & Owerexpression & $\mathrm{CH}$ and remodeling resulting in $\mathrm{HF}$ \\
\hline & $5 \cdot H T(2 B)-R$ & $5+H T(2 B)-R(-1-)$ & DCM with abnormal contractile protein organization \\
\hline & B2 receptor & B2 receptor $(-1)$ & $\mathrm{CH}_{1} \mathrm{DCM}$, and fibrosis \\
\hline \multirow{24}{*}{ 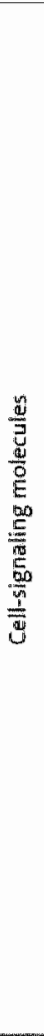 } & Gol & Conditional expression & Lethal cardiomyopathy with a whide ORS complex arrihythmia \\
\hline & Gros: & Owerexpression & LWH; fibrosis and myocyte atrophy in elderly mice \\
\hline & $G a q$ & Overexpression & $\mathrm{CH}$ and congestive $\mathrm{HF}$ \\
\hline & & Consititutively actike & $\mathrm{CH}$ and $\mathrm{DCM}$ \\
\hline & PKA & Consititutively actiwe & DCM, reduced cardiac contractility, arrhythmias, sudden death ${ }^{120}$ \\
\hline & $\mathrm{PKC} \beta 2$ & Owerexpression & $\mathrm{CH}$, decreased finction, myacyte necrosis, fibrosis, cardiomyopathy \\
\hline & PKCE & Mutant overexpression & Cardioprotective (at modest lewel), $\mathrm{CH}$ and $\mathrm{HF}$ (at high level) \\
\hline & Calcineurin & Constitutiwely active & $\mathrm{CH}$ and $\mathrm{HF}$ \\
\hline & Calmodulin & Owerexpression & Cardiomyocyte hypertrophy and hyperplasia \\
\hline & CaMkIV & Owerexpression & $\mathrm{CH}$ with decreased cardiac function \\
\hline & Rac1 & Constitutively active & Lethal DCM, focall adheslan reorganization or transient $\mathrm{CH}$ with age: \\
\hline & Ras. & Owerexpression & LWH and cardiomyopathy with myofibril disarray \\
\hline & TAK1 & Constitutively active & $\mathrm{CH}$, HF with interstitial fibrosis, severe apoptosis and early death \\
\hline & MEK 5 & Constitutively active & Eccentric cardiac hypertrophy that progressed to DCM \\
\hline & RhoA & Owerexpression & W dilation, contractile failure with AV nodal dysfunction \\
\hline & Annexin VI & Owerexpression & Decreased cardiac function, chamber dilation, myocarditis, fibrosis \\
\hline & $P_{2} P_{2}$ & Dominamt negative & DCM that frequently leads to premature death \\
\hline & $\mathrm{IL}-6$ and $\| \mathrm{L}-6 \mathrm{R}$ & Overexpresision & $\mathrm{CH}$ through the gp130 signailing pathway \\
\hline & Gip 130 & Conditionall $(-\mu)$ & $\begin{array}{l}\text { Decreased myocyte diameter, thinning of the left and right } \\
\text { ventricular walls; quick transition into HF on pressure owerload }\end{array}$ \\
\hline & SmgGDS & SmgGDS $(-1)$ & $\begin{array}{l}\text { Died of HF shortly after birth because of enhanced myocyte } \\
\text { apoptosils triggered by cardiovascular overload }\end{array}$ \\
\hline & Plak & Comsititutively artive & Myocardial mypertrophy \\
\hline & $\begin{array}{l}\text { MKK }>0 \\
(\text { UNK }=\text { target })\end{array}$ & Indwucible overexpression & Progressive cardiomyopathy ${ }^{19 .}$ \\
\hline & $\begin{array}{l}\text { Mkk3bE/MKK6bE } \\
\text { (p3:8 arget) }\end{array}$ & Inducible owerexpression & Restrictive cardiomyopathy and heterogeneous myocyle atrophy $y^{418}$ \\
\hline & $p 38 a$ & Dont. neg overexpression & $\mathrm{HCM}^{13}$ \\
\hline \multirow{6}{*}{ 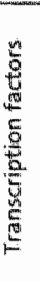 } & NIFAT3 & Constitutively active & Death at $30 \mathrm{~d}$ of life of $\mathrm{CH}$ and $\mathrm{HF}$ \\
\hline & $C l R E B$ & Dominant negative & DCM with Hypertrophlied fibers and interstitial fibrosis. \\
\hline & GATAM. & Overexpmessian & Progressive $\mathrm{CH}$ and cardiomyopathy \\
\hline & MEF2C & $\operatorname{MEF} 2 C(-1-)$ & $\begin{array}{l}\text { Heart development halted at E9.0 d; lack of right ventricle formation } \\
\text { and cardiomyocyte differentiation }\end{array}$ \\
\hline & SRF & Ovarexpression & $\begin{array}{l}\text { DCM with 4-chamber dilation, cardiomyocyte hypertropihy, collagen } \\
\text { deposition and interstitial fibrosis }\end{array}$ \\
\hline & $1 \times 4$ & $\ln \times 4(-1-1)$ & Adult-onset cardiomyopathy with $\mathrm{CH}$ \\
\hline
\end{tabular}


Table 2. Genetically aitered mouse models of cardiac hypertropby and heant failure (contimued)"

\begin{tabular}{|c|c|c|c|}
\hline & Gene & Genotype & Phenotype \\
\hline \multirow{9}{*}{ 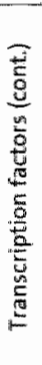 } & TEF-1 & TEF-1 $(-1-)$ & Death at E11-12 d with enlarged pericardial cavity, bradycardia $a_{\text {ind }}$ \\
\hline & & & abnormally thin ventricular wall \\
\hline & STAT3 & Overexpression & Myocardial hypertropliny \\
\hline & MyoD & Overexpression & Death at E16 to 18.5 d exhibiting mish hapen heart \\
\hline & Bmyits & Overexpression & $\mathrm{CH}$ and progressive DCM with fibrosis \\
\hline & C.5X/Nkx 2.5 & $1183 \mathrm{P}$ mutant & Progressive and profound cardiac conduction defects and HF \\
\hline & RXRica & $\operatorname{RXR} \alpha(-1-)$ & Embryonic deatlin from ventricular defects \\
\hline & & Overexpression & $\begin{array}{l}\text { DCM with myofibrillar abnormalities and spectic deficiencies in } \\
\text { respiratory chailn complexes } \mid \text { and } \|\end{array}$ \\
\hline & RAR & Constitutively active & DCM and congestive HF with biventricular dilation: \\
\hline \multirow{9}{*}{$\frac{\frac{n}{5}}{\frac{G}{6}}$} & BGH & Overexpression & Myocardial hypertrophy \\
\hline & TNFa & Overexpression & DCM, Iymphocyte infiltrate, myocyte necrosis and apoptosis \\
\hline & TGF- $\beta 1$ & Constitutively active & Overt fibrosis in atria but not in vertricles. \\
\hline & TGF-Preceptor 1 & Activated form (ALKS) & Linear, dilated, hypoplastic heart tube with disrupted looping \\
\hline & ANP & $\operatorname{ANP}(-/-)$ & $\mathrm{CH}$ \\
\hline & VEGF-A & Conditional $(\% / \alpha)$ & Embryon ic death with a dilated form of ischemic cardionyopathy \\
\hline & VEGF164 and & Knockout $(-1-)$ & Ischemic cardiomyopathy, decreased contractility, sarcomere \\
\hline & VEGF188 & & breakdown and eventual death from $\mathrm{HF}$ \\
\hline & IGF-1 & Overexpression & $\mathrm{CH}$ with decreased systolic function and increased fibrosis \\
\hline \multirow{6}{*}{ 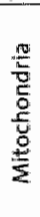 } & METFA & $\operatorname{MtTFA}(-1-)$ & Mitochondrial cardiomyopathy during embryogenesis; $75 \%$ \\
\hline & & & meonatal death and $25 \%$ died of DCM at several months of agge \\
\hline & Core 2 GICNAC-T & Overexpression & Progiressive $\mathrm{CH}$ and diabetic cardiomyopathy \\
\hline & ANT1 & ANTI $(n / \mu)$ & $\mathrm{CH}$ and mitochondrial cardiomyopathy \\
\hline & GLUT4 & GIUT4 $4(-1-)$ & $\mathrm{CH}$ with abnormalities in glucose and lipid metabolism \\
\hline & Mnsod & $\operatorname{SOD} 2(-1-)$ & Died within 10 days of life from DCM \\
\hline \multirow{4}{*}{ 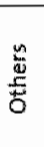 } & Connexin 43 & Conditional $(-/-)$ & Sudden cardiac death with ventricular arrhythmaias \\
\hline & MMP-1 & Constitutively active & Myocyte hypertrophy with impaired cardiac function \\
\hline & LANP $_{2}$ & $\operatorname{LAMP}-2(-1-)$ & Cardiomyopathy with accumulation of ant tophagic vacuoles \\
\hline & Frataxim & Conditional $(-/-)$ & Progressive $\mathrm{CH}$ and cardiomyopathy \\
\hline
\end{tabular}

"Modified and updated from Chu et al." Their review contains all the references for the different mouse models. For the mouse models added to this table, references axre shown in the referance list at the ernd of this chapter. Homo, homozygous mice; HET, heterozygous mice. For the remainder of the abbreviations, see the list of abbreviations at the end of this thesis. 


\section{Identification of molecular pathways}

In the past years, knowledge of intracellular signaling cascades and regulation of the hypertrophic response have increased rapidly. A growing number of intracellular signaling pathways have been characterized as important mediators of cardiac hypertrophy. Recently, the view that hypertrophy is a useful adaptation of the heart to increased workload has been challenged by the findings that some transgenic animal models lack a hypertrophic response without deterioration of cardiac function ${ }^{1.4416}$ and that some mice subjected to pressure overload develop hypertrophy with progression to HF. However, these results likewise support the view that cardiac hypertrophy is mediated by multiple signaling pathways that operate as interdependently cross-talking networks to evoke a hypertrophic response. The idea is that not hypertrophy per se is damaging, but that the hypertrophic process can be maladaptive or beneficial, depending on the specific signaling cascades involved. ${ }^{4.126-118}$ In this regard, identification of mechanisms counteracting hypertrophy might be as important as the mechanisms favoring cardiac hypertrophy. The analysis of such complex networks requires global gene expression approaches, such as microarray analysis, or a well-defined thematic approach, in which one already has some ideas regarding the processes involved.

Gene expression profiling: a powerful tool for the identification of pathogenic processes The number of characterized human and mouse genes has increased considerably and genome technology for transcriptomics has developed and improved rapidly. This combination creates a unique opportunity to apply gene expression profiling studies for deciphering the underlying molecular pathways of a disease, the classification of tumors, the discovery and evaluation of new therapeutic targets or the monitoring of disease progression.

Application of microarray technology offers the possibility to screen and monitor thousands of different genes simultaneously on a broader genomic scale and thus enables the study of genes in their genetic context. It can provide important clues about regulatory mechanisms and biological processes underlying the disease or condition investigated. Moreover, it makes it possible to identify novel genes, not previously known to be associated with the process of interest. This non-targeted approach has the advantage over targeted approaches, such as Northern blot analysis or real-time $P C R$, as these techniques are more suited for the evaluation of known pathways and the use of a limited number of transcripts. Although there are many 
protocols and types of systems available for gene expression profiling (reviewed in chapter 6), the basic principle involves comparison of the amount of messenger RNAs (mRNA) between samples in the normall or reference and the disease or test state. ${ }^{319}$ Briefly, mRNA levels are compared for each gene on the microarray by labeling the mRNAs with different fluorescently labeled nucleotides ( $\mathrm{Cy} 3$ or $\mathrm{Cy} 5$ ) for the test and reference samples. After hybridization to the microarray, the relative amounts a a particular gene transcript in the two samples can be determined by measuring the signal intensities for the fluorescent groups and calculating signal ratios. Also, single color platforms are being used, which require a high reproducibility of the microarray and the data. The advantage is that each array can be compared with every other array, which facilitates the design and data analysis.

One recent example underlining the value of gene expression profiling in the clinic, is the identification of an expression signature that can predict the formation of metastases in patients with breast tumors. ${ }^{120}$ Another example elucidating pathogenic processes is the study by Mootha et al., which described a coordinately decreased expression of genes involved in OXPHOS in human diabetic muscle. An important role for PGC-1 $\alpha$ (peroxisome proliferator activated receptor gamma co-activator 1a) was proposed in this process. This indicates clinically important variation in energy metabolism associated with type 2 diabetes. ${ }^{121}$ Furthermore, their study illustrates elegantly that not only large differences in gene expression, but also subtle but coordinated changes in gene expression might indicate relevant biological pathways or co-regulated gene sets. Alterations in gene expression patterns assessed by microarray were also demonstrated in heart muscle from patients with HCM, DCM and HF. ${ }^{122-126}$ Each of the processes identified can play a role in the symptoms of disease, the progression to $\mathrm{HF}$ or the possible protection against it. Analysis of human myocardial tissue is complicated by different etiologies, medication and individual course of the disease, which may explain differences in results reported by human cardiac studies. These studies are further limited because of small sample sizes due to the scarcity of human tissue available, especially with respect to control tissue. Also, the use of different gene collections and study designs (e.g. cDNA versus oligonucleotides, pooled tissue versus samples from individual patients) complicate the comparison between microarray studies.

One of the major challenges in the field of gene expression profiling lies in the development of tools to analyze the large amounts of data generated by microarray experiments. An adequate experimental microarray design is indispensable to ensure 
good use of the available resources, avoidance of obvious biases and the possibility to answer the primary questions of interest. ${ }^{127}$ Replication is essential to reduce variability and false detection rates of gene expression change. ${ }^{228} \mathrm{~A}$ common form of replication is spotting replicates of the same gene (CDNA transcript) on each slide, while replication can also refer to the use of mRNA from the same extraction (technical replicates) or hybridizations involving mRNA from different extractions or from different individuals (biological replicates). ${ }^{129}$ Next to replication, there is also the issue of dye-swap experiments in two color arrays, in which each hybridization is performed twice, with the dye assignments reversed in the second hybridization. This is done to reduce the bias due to systemic differences in the red (Cy5) and green (Cy3) intensities. ${ }^{129}$ All of these measures are necessary to minimize the influence of natural variation in gene expression, the variability between subjects (e.g. age, sex, strain), but also experimental variation (e.g. spotting artefacts, microarray quality), as these variables may mask the detection of real changes in gene expression. The need for comparable and reproducible data sets has led to the establishment of a set of guidelines: the Minimum information About a Microarray Experiment (MIAME), which describes the minimum information required to ensure that microarray data can be easily interpreted and that results can be independently verified. ${ }^{130}$

As far as the analysis of microarray data is concerned, there is at present no single solution available. Difficulties of data analysis include potentiall sources of random and systemic measurement (which can be minimized to a certain extent by using an appropriate experimental and array design) and the combination of a small number of samples relative to a large number of probes (transcripts). This complicates the interpretation of the data and endangers the validity of microarray findings. ${ }^{131}$ Therefore, it is important to confirm gene expression changes by additional methods, such as real-time PCR or Northern blot analysis. It should also be kept in mind that the transcript level of a gene does not necessarily indicate a causal role of that gene in the process under consideration. A small change in a certain gene can sometimes produce a large biological effect. ${ }^{128}$ In addition, alterations in transcript levels are not necessarily associated with changes at the protein level. Subsequent protein studies and/or functional studies are necessary to determine the role of a certain gene or process in the disease of interest. Nevertheless, by optimizing all stages of the microarray experiments, including the data analysis, and taking note of all the possible pitfalls, microarray analysis is a powerful tool to improve our understanding of complex diseases in a global way. For unraveling the pathogenesis of a disease, it can 
best be regarded as a guiding, hypothesis generating tool that leads to new insights and pathways to be studied in further detail.

\section{Aims and outline of this thesis}

The aim of this thesis was to elucidate pathogenic genetic pathways in cardiac hypertrophy and HF by gene expression profiling. To circumvent the heterogeneity and scarcity of human biopsies, we have initially focused on three mouse models to study different forms of cardiac hypertrophy and HF: the TAC model to investigate compensated hypertrophy which is mechanically induced, and two genetic models, i.e. the MLP KO model to study the processes underlying DCM and the possible transition to $\mathrm{HF}$, and the CMYBPC KO model to examine HCM. Unraveling the processes involved in these mouse models will reveal different pathogenic routes, which can be studied for significance in human pathology.

The results of our initial gene expression studies in TAC and MLP KO mice showed differential gene expression of mitochondrial encoded OXPHOS genes, which pointed to an important role for OXPHOS defects. As primary OXPHOS defects have also been reported to be associated with cardiomyopathies, we decided to investigate the role of the OXPHOS system in cardiomyopathies more closely. Many mtDNA mutations have been identified by now, both in young and older patients with cardiomyopathy, emphasizing the role of mtDNA mutations both in maternally inherited cardiomyopathies and in cardiac disease which develops later during life as an (acquired) risk factor. In chapter 2 of this thesis, the role of mitochondrial DNA (mtDNA) mutations in cardiomyopathies is being discussed. ${ }^{132}$ To study whether mtDNA defects are a possible cause of mitochondrial cardiomyopathy in patients, we screened the entire mtDNA of these patients for mutations. For this purpose we have established a method using DHPLC (Denaturing High Performance Liquid Chromatography), which is a highly sensitive method to detect heteroplasmic (mixture of normal and mutant mtDNA) mutations in the mtDNA. This method and the results of the screening in patients are extensively described in chapter $3 .{ }^{133}$ One of these patients with mitochondrial myopathy and cardiomyopathy revealed the $T 3271 \mathrm{C}$ mutation in mtDNA encoded TRNA $A^{\text {leul(Uur) }}$ and another patient the $A 3302 \mathrm{G}$ mutation in the same gene. This latter patient died from cardiorespiratory falure. A possible relationship between this mitochondrial tRNA mutation and the increased risk for cardiorespiratory failure will be discussed in chapter $4 .{ }^{134}$ Chapter 5 of this thesis studies the OXPHOS abnormalities secondary to a cytoskeletal defect at the gene 
expression and functional level. Biochemical and morphological studies revealled an OXPHOS defect in the MLP KO mice at the DCM stage preceding HF and showed the functional significance of the observed alterations in gene expression. ${ }^{135}$

The second part of this thesis describes our approach to identify new genes and important biological processes involved in cardiac hypertrophy and HF by gene expression profiling. Chapter 6 compares several technical approaches for the development of in-house microarray technology, using commercially available cDNA collections. An overview of possible pitfalls and possibilities is presented. This chapter also briefly introduces the use of the technology in the context of our project to determine gene expression differences in normal, hypertrophic and failing hearts. ${ }^{136}$ Chapter 7 describes the actual identification of several biological processes, molecular pathways and genes involved in the different stages of compensated pressure overload hypertrophy in TAC mice (at 48 hours, 1 week, 2, 3 and 8 weeks after banding). For this purpose, a 15K cDNA collection of embryonic arigin was spotted on the microarrays, as the reactivation of a fetal expression program is a halimark of cardiac hypertrophy. Subsequently, the same cDNA collection was used to perform gene expression profiling in both heterozygous and homozygous CMyBP-C KO mice, which respectively develop asymmetric septal hypertrophy (a major feature of human $\mathrm{FHC}$ ) and eccentric left ventricular hypertrophy with decreased fractional shortening and impaired relaxation. The gene expression differences between wild-type mice, heterozygous and homozygous CMyBP-C KO mice are reported in chapter 8 . In chapter 9 , the significance of our data and processes identified are being evaluated in the light of issues regarding model organisms and microarray studies. The impact of some of these processes, including energy metabolism, for mice and human pathology is discussed in further detail.

\section{References}

1. Koek ML, Grobbee DE, Bots ML. [Trends in cardiowascular morbidity and mortality in the Netherllands, 1980 200ol. Ned Tijduchr Ceneeskd, 2004;148:27-32.

2. Mosterd A, Hoes AW, de Bruyne MC, et al. Prevalence of heart fallure and left ventricular dysfumction in the general propulation; The Rotterdam Study. Eur Heart J. 1999:20:447-455.

3. Ho KK, Anderson KM, Kannel WB, et al. Survival after the onset of congestive heart failure in Framingham Hearth Study siubjects. Circulation. 1993;88:107-115.

4. Ritter $O_{11}$ Neyses L. The molecullar basis of myocardial hypertrophy and heart failure. Trends Mol Med. $2003 ; 9: 323-321$.

5. Felker GM, Adams KF, Jr., Konstam MA, et al. The problem of decompensated heart fallure: nomenclature, classification, and risk stratification. Am Heart $1.2003,145: 518-25$. 


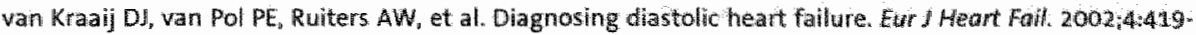
430.

Lips D, deWindt $U_{3}$, van Kraaij DI, et al. Molecullar determinants of myocardial hypeitrophy and fallure: altemative pathways for beneficial and maladaptive hypertrophy. Eur Heart J. 2003;24:883-896.

Cowie MR, Wood DA, Coats AJ, et al. Incidence and aetiology of heart fallure; a population-based study. Eur Heart 1. 1999;20:421-428.

Havranek EP, Masoudi FA, Westfall KA, et all. Spectrum of heart failure in alder patients: results firom the National Heart Failure project. Am Heart J. 2002;143:412-417.

Lloyd-Jones DM, Larson MC, Leip EP, et al. Lifetime risk for developing congestive heart failure: the Framingham Heart Study. Circulation. 2002;106:3068-3072.

Schwartz K, Mercadier JJ. Molecular and cellular biology of heart failure. Curr Opin Cardiol. $1996 ; 11: 22 \%$. 236.

Keeling PJ, Gang Y, Simith $G$, et al. Familial dilated cardiomyopathy in the United Kingdom. Br Heart $d$. 1995:73:417-421.

Grunig $\mathrm{E}$, Tasman JA, Kucherer $\mathrm{H}$, et al. Frequency and phenotypes of familial dilated cardiomyopathy. I Am Coll Cardiol. 1998; 31:186-194.

Fatkin D, Graham RM. Molecular mechanisms of inherited cardiomyopathies. Physiol Rew. 2002;82:945-980. Steenman $M_{8}$ Chen $Y W_{2}$, Le Cunff $M$, et al. Transcriptomal analysis of failing and nonfailing human hearts. Physiol Genomics. 2003;12:97-112.

Seidman JG, Seidman $C$. The genetic basis for cardionyopathy: from mutation identification to mechanistic paradigms. Cell. 2001;104:557-567.

Wang $D_{y}$ Urisman $A_{n}$ Litu VT, et al. Viral discovery and sequence recovery using DNA microarrays. Plos Biol. 2003;1:E2.

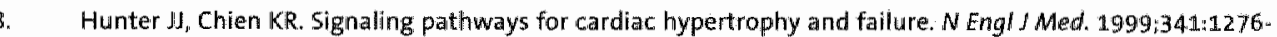
1283.

Agabiti-Rosei E, Muiesan ML. Prognostic signifieance of left ventricular hypertrophy regression. Adv Exp Med Biol. 1997;432:199-205.

Brown DW, Giles $W H$, Croft JB. Left ventricular hypertrophy as a predictor of coronary heart disease mortality and the effect of hypertension. Am Heart J. 2000;140:848-856.

Medugorac 1. Collagen content in different areas of normal and hypertrophied ratt myocardium. Cardiovasc Res. 1980;14:5:51-554.

lemitsw M, Miyauchi T, Maeda 5, et all. Physiological and pathological cardiac hypertrophy induce different molecular phenotypes in the rat. Am I Physiol Regul lotegr Comp Physiol, 2001;281:R2029-2036.

3. Kinugawa $K$, Yonekura $K$, Ribeiro RC, et al. Regulation of thyroid hormone receptor isoforms in physiological and pathological cardiac hypertraphy. Circ Re5, 2001;89:591-598.

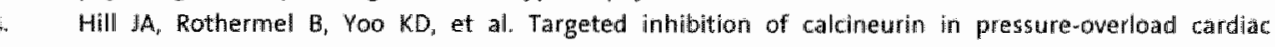
hypertrophy. Preservation of systolic function. I Biol Chem. 2002;277:10251-10255.

Frey N, Olson EN. Cardiac hypertrophy: the good, the bad, and the ugly. Annu Rev Physiol. 2003;65:45-79.

Lorell BH, Carabello BA. Left ventricular hypertrophy: pathogenesis, detection, and prognosis. Circulation. 2000; 10:2:470-479.

7. Carrier $L_{0}$ Jongbloed RJE, Smeets HIM $\mathrm{H}_{i}$ et al. Hypertrophic Cardiomyopathy, In: Doevendans PA, Wilde AA, eds. Cardiovascular Gemetics for Clinicians. Dardrecht, The Netherlands: Klawer Academic Publishers; 2001:139-154.

8. Richardson $P_{1}$ Mckenna $W$, Bristow $M_{4}$ et al. Report of the 1995 World Health Organization/International Society and Federation of Cardiology Task Force on the Definition and Classification of Cardionyopathies. Circulation. 1996;93:841-842.

9. Geisterfer-Lowrance $A A$, Kass 5 , Tanigawa $G_{0}$ et al. $A$ molecular basis for familial hypertrophic cardiomyopathy: a beta cardliac myosin heavy chain gene missense mutation. Cell. 1990;62:999-1006. 
30. Thierfether $L_{x}$ watkins $H_{3}$ Machae $C$, et al. Alpha-tropomyosin and cardiac troponin $T$ mutations cause familial hypertrophic cardionyopathy: a disease of the sarcomere. Cell. 1994:77:701-712.

31. Bonne $G_{4}$ Carrier $L$, Bercowic , et al. Cardiac myosin binding protein-C gene splice acceptor site mutation is associated with fantial hypertrophic cardiomyopathy. Nat Genet. 1995;11:438-440.

32. Watkins $H$, Comer $D$, Thierfelder $L$, et al. Mutations in the cardiac myosin binding protein-C gene on chromosome 11 cause familial hypertropinc cardiomyopathy. Nat Genet $1995 ; 11 * 434-437$.

33. Nimura $H$, Bachinski $L$, Sangwatanalioj 5 , al. Mutations in the gene for cardiac imyosin-binding prote in $C$ and llate -oriset familial hypertrophic cardiomyopathy. N Engl Med. 1998;338:1248-1257.

34. Bonne $G$, Carrier $L$, Richard $P$, et all. Familial hypertrophic cardiomyopathy: from mutations to functional defects, Circ kes, 1998;83:580-593.

35. Carrier $L$, Bonne $G$, Bahrend $E_{1}$ et al. Organization and sequemce of human cardiac myosin binding protein $C$ gene (MYBPC3) and identification of mutationis predicted to produce truncated proteins in familial hypertirophic cardiomyopathy. Circ Res. 1997;80:427-434.

36. Alders $M$, Jongbloed $\mathbb{R}$, Deelen $W$, et al. The 2373 ins $G$ mutatiom in the MYBPC3 gene is a founder mutation, which accounts for nearly one-fourth of the HCM cases in the Netherlands. Eur Heart J. 2003;24:18481853 .

37. Poetter $K$, Jiang $H$, Hassanzadeh $S$, et al. Mutations in either the essential or regulatory light chains of myosin are associated with a rare myopathy in humian heart and skeletal muscle. Nat Genet. 1996; 13:6369.

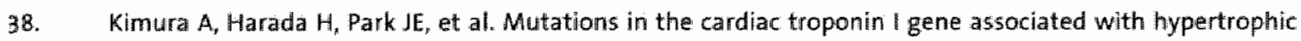
cardiamyopathy. Nat Gienet. 1997;16:379-382.

39. Satoh $M$. Takahashi $M$. Sakamoto $T$, et al. Structural analysis of the titin gene in hypertrophic cardiomyopathy: Identification of a novel disease gene. Biochem Bjophys Res Commun. 1999:26:2:411-417.

40: Olson TM, Doan TP, Kishimoto NY, et al. Inherited and de novo mutations in the cardiac actin gene cause hypertrophic cardiomyopathy. J Mol Cell Cardiol. 2000;32:1687-1694.

41. Hoffmann B, Schmidt-Traub H, Perrot A, et al. First mutation in cardiac troponin $\mathrm{C}, \mathrm{L} 29 \mathrm{Q}$, in a patient with hypertrophic cardlomyopathy. Hum Mutat. 2001; $17: 524$.

42. Geier $C$. Perrot $A$, Ozcelik $C$, et al. Mutations in the human muscle LM protein gene in families with hypertropthic cardiomyopathy. Circulation. 2003:107:1390-1395.

43. Phillips MF, Harper PS. Cardiac disease in myotonic dystirophy. Cardiovasc Res. 1997;33:13-22.

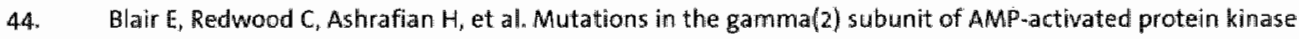
cause familial hypertrophic cardiomyopathy: evidence for the centrall role of energy compromise in disease pathogenesis. Hum Mol Geriet. 2001;10:1215-1220.

45. Arad M. Maron BH, Gorham JM, et al. Glycogen storage diseases presenting as hypertrophic cardiomyopathy. N Engl/ Med. 2005;352:362-372.

46. Bit-Avragim $N_{*}$ Perrot $A_{i}$ Schols $L_{\text {, }}$ et al. The GAA repeat expension in intron 1 of the frataxin gene is related to the severity of cardiac manifestation in patients with Friedreich's ataxia. J Mol Med. 2001:78:626-632.

47. Olson TM, Michels VV, Thibodeau SN, et al. Actin mutations in dilated cardiomyopathy, a heritable form of heart failure Science. 1998;280:750-752.

48. U D. Tapscoft $T$, Gonzalez $O$, et al. Desmin mutation responsible for idliopathic dilated cardiomyopathy. Circulation. 1999:100:451-464.

49. Kamisago M, Sharma SD, DePalma SR, et al. Mutations in sarcomere protein genes as a cause of dilated cardionyopathy. N Engl Med. 2000;343:1688-1696.

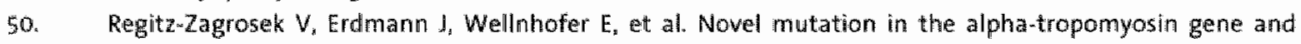
transition from hypertrophic to hypocontractile dilated cardiomyopathy. Circulation. 2000;102: E112-11,6.

51. Tsubata $S$, Bowles $K R$, Vatta $M$, et al. Mutations in the human delta-sarcoglycan gene in familial and sporadic dilated cardiomyopathy. J Clin Invest. 2000; 106:655-662.

52. Barresi R, Di Blasi C. Negri T, et al. Disruption of heart sarcoglycan complex and severe cardiomyopathy caused by beta sarcoglycan mutations. J Med Genet. 2000;37:102-107. 
53. Olson TM, Kishimoto NY, Whitby FG, et al Mutations that alter the sufface charge of alpha-tropomyosm are associated with dillated cardiomyopathy. I Mol Cell Candol: $2001,33: 723732$.

54. Gerull B, Gramlich $M_{3}$ Atherton 1, et al. Mutations of TIN, encoding the giant musele filament titin, cause fimmlial dilated cardiomyopathy. Nat Genet. 2002:30:201-204.

55. Knoll $R$, Hoshijma $M$, Hoffman $H M_{s}$ et al. The cardiac mechanical stretch sensor machinery involves $Z$ disc complex that is defective in subset of human dilated cardomyopathy Cell 2002:111:943-955.

56. Olson $T M$, illenberger 5 , Kishimoto $N Y_{*}$ et al. Netavinculin mutations alter actin interaction in dilated cardiomyopathy. Circulation. 2002;105:431-437.

57. Schmitt JP, Kamisago M. Asahi M, et al. Ditated cardiomyopathy and heart falure calused by a mutation in phospholamban. Science. 2003;299:1410-1413.

58. Vatta M, Mohapatra $B$, Jimenez $S$, et al. Mutations in Cypher/ZASP in patients with dilated cardiomyopat thy and left ventricular non-compaction. I Am Coll Cardiol, 2003;42:2014-2027.

59. Fatkin D, MacRae C, Sasiaki T, et al. Missense mutations in the rod domain of the lamin $A / C$ gene as causes of dilated cardiomyopathy and conduction×system disease. NEngl/ Med. 1999;341:1715-1724.

60. Bonne $G$, Di Barletta MR, Varnous $S$, et al. Mutations in the gene encoding lamin A/C cause autosomal dominant Emery-Dreifiuss muscular dystrophy. Not Genet. 1999;21:285-288.

61. Muchir A, Bonne $G$, van der Kooi AJ, et al. Identification of mutations in the gene encoding lamins. A/C in autosomal dominant limb gindle muscular dystrophy with atriowentricular conduction disturbances (LCMD1B). Hum Mol Genet. 2000:9:1453-1459.

62. Marcelis $C_{*}$ Doevendans $P_{*}$ Bonne G. Dilated Cardiomyopathy" In: Doevendans PA, Wilde AA, eds Cardiovascular Genetics for Clinicians. Dordrecht, The Netherlands: KKluwer Academic Publishers; 2001:155168.

63. Towbin JA, Hejtmancik JF, Brink $P$, et al. X-linked dillated cardiomyropathy. Molecular genetic evidence of linkage to the Duchenne muscular dystrophy (dystrophin) gene at the Xp21 locus. Circulation. $1993 ; 87: 1854-1865$.

64. D'Adamo P, Fassone L, Gedeon $A_{\text {, }}$ et al. The $X$ winked gene $G 4.5$ is responsible for different infantille dilated cardiomyopathies. Am / Hum Genet. 1997:61:862-867.

65. Marin-Garcha $J$, Goldenthal M. Understanding the impact of mitochondrial defects in cardiovascular disease: a revilew. J Card Fail. 2002;8:347-361.

66. Towbin JA, Bowles NE. The failing heart. Nature. 2002;415:227-233.

67. Corrado D, Basso $C$, Thiene $G$, et al. Spectrum of dinicopathologic manifesitations of arrhythmogenic right ventricular cardiomyopathy/dysplasia: a multicenter study. IAm Coll Cardiol. 1997;30:1512-1520.

68. Tiso N, stephan DA, Nawa A, et al. Identification of mutations in the cardiac ryanodine receptor gene in families affected with arrhythmogenic right ventricular cardiomyopathy type 2 (ARVD2). Hum Mol Genet. 2001:10:189-194.

69. Alcala $R$, Metzger $S$, Rosenheck $S$, et al. A recessive mutation in desmoplakin catuses arrhythmogenic right ventricular dysplasia, skin disorder, and woolly hair. Am Coll Cardiol, 2003;42:319-327.

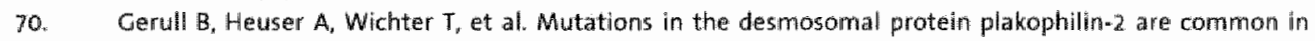
arrhythmogenic right wentricular cardiomyopathy. Nat Genet. 2004;36:1162-1164.

71. Mckoy $G$, Protonotarios $N$, Crosby $A_{a}$ et al. Identification of a deletion in plakoglobin in antiythmogenic right ventricular cardiamyopathy with palmoplantar keratodema and woolly hair (Naxos disease). Lancet. 2000;355:2119-2124.

72. Goldfarb LG, Park KY, Cervenakova L, et al Missense mutations in desmim associated with famillial cardiac and skeletal myopathy. Nat Cenet. 1998;19:402*403.

73. Mogensen 1, Kruse TA, Borglum AD. Assignmert of the human cardiac troponin I gene (TNNi3) to chromosome 19913.4 by radiation hybrid mapping. Cyptogenet Cell Genet. 1997:79:272-273.

74. Marian AJ. On genetic and phenotypic wariability of hypertrophic cardiomyopathy: nature ver sus rurture $J$ Am Cofl Cardiol. 2001:38:331-334. 
is:

76.

77.

78

79

80

Wichard $p_{*}$ isnard $\mathrm{R}_{\text {. Carrer }} \mathrm{L}_{*}$ al. Double heterozygosity for mutations in the beta-myosin heavy chain and in the cardiac riyosin binding protein $C$ genes in a family with hypertraphic cardiomyopathy. $J$ Med cenet. $1999,36,5,42-545$

Richard $P$, Chatron $P$, Leclercq $C$, et al. Homozygotes for a $R 869 G$ mutation in the bieta -myosin heavy chain gene have a severe form of familial hypertrophic cardiomyopathy. 1 Mol Cell Cardiol 2000;32:1575-1583.

Arbustini E, Diegoli M, Fasani R, et al Mitochondrial DNA mutations and mitochomdral abnomalities in dilated cardiomyopathy. An I Pathol. 1998;153:1501-1510.

wan Bilsen $\mathrm{A}$, smeets $\mathrm{PJ}$, Gilde $\mathrm{A}_{i}$ et al. Metabolic remodelling of the falling hearti: the cardiac burn-out syndrome? Cardiovasc Res. $2004,61: 218-226$.

9. Dzeja PP, Redfield MM, Burnett $J C$, et al. Failing energetics in failing hearts. Curr Cardiol Rep. 2000;2:212. 217.

Takeishi $Y$, Walsh RA. Cardiac hypertrophy and failure: lessons learned from genetically engineered mice. Acta Physiol Scand. 2001;173:103-111.

Chu $G$. Haghighi $K$, Kranias $E G$. From mouse to man: understanding heart failure through genetically altered mouse models. J Card Fail. 2002;8:5432-449.

Chien KR. Genes and physiology: molecullar physiology in genetically engineered araimals. 1 Clin Invest. 1996;97:901-909.

Chien KR. Stress pathways and heart failure, Cell 1999:98:555-558.

Molkentin JD, Dorn IG, 2nd. Cytoplasmic signaling pathways that regulate cardliac hypertrophy. Annu Rev Physiol. 2001;63:391:426.

Friddle $C$, Koga $T$, Rubin EM, al. Expresstom profiling reveals distinct sets of genes altered during induction and regression of cardiac hypertrophy. Proc Natl Acad Sci U S A. 2000:97:6745-6750.

Larkin JE, Frank BC, Gaspard RM, et al. Cardiac transicriptional pesponse to acute and chronic angiotensin II treatments. Physiol Genomics. 2004;18:152-166.

Arber 5, Hunter JJ, Ross 1, Ir., et al. MLP-deficient mice exhibit a disruption of cardiac cytoarchitectural organization, dilated cardiomyopathy, and heart failure. Cell. 1997:88:393-403.

Carrier $L$, Knoll $R$, Wignier $N$, et al. Asymmetric septal hypertrophy in heterozygous cMyBP-C null mice. Cardiovasc Res. 2004;63:293-304.

Erwasti JM. Costameres; the Achilles' heel of Hercullean muscle J Biol Chem, 2003;278:13591-13594.

Esposito $G$, Santana LF, Dilly $K$, et al. Cellular and functional defects in a mouse model of heart failure. Arm Physiol Heart Circ Physiol. 2000.279:H3101-3112.

1. Mohapatra B, Jimenex $\mathrm{S}$, Lin $\mathrm{VH}$, et al. Mutations in the muscle LIM protein and alpha-actinin-2 genes in diated cardionyopathy and endocardial fibroelastosis. Mol Genet Metab. 2003:80:207-215.

Cruen M, Giautel M. Mutations in beta-myosin $\$ 2$ that cause familial hypertrophic cardiomyopathy (FHC) abolish the irteraction with the regulatory domain of myosim-binding protein-C. M Mol Biod. 1999;286:933949.

G. Gutel M, Zuffardi O. Freiburg A, et al. Phosphorylation switches specific for the cardiac isoform of imyosin binding protein-C: a modulator of cardiac contraction? Embo 1 1995:14:1952-1960.

4. Schlender KK, Beam U. Phosphorylation of chicken cardiac C-protein by calcium/callmodulin-dependent protein kinase II. J Bial Chem. 1991:266:2811-2817.

5. Hofmann PA, Hartzell HC, Moss. RL. Alterations in Ca2+ sensitive tension due to partial extraction of Cprotein from rat skinned cardiac myocytes and fabbit skeletal muscle fibers. I Gen Physiol. 1991:97:1141. 1163.

Washman E, Redwood C, Moolman-Smook J, et al. Cardiarc myosin binding protein Cx its role in physiology and disease. Circ Res. 2004:94:1279-1289.

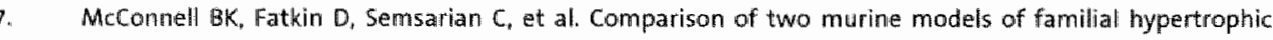
cardiomyopathy. Circ Res. 2001;88:383-389.

Harris SP, Bartley CR, Hacker TA, et al. Hypertrophic cardiomyopathy in cardiac myosin binding protein-C knockout mice Circ Res. 2002;90:594-601. 
99

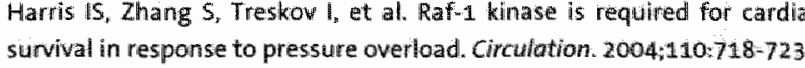

100

101

102.

203

104

105

106

107

108

109.

110

111.

112

113.

124. $1991 ; 88: 82777-8281$ capacity in rat failing cardiac and skeletal muscles. J Physiol. 2003;551:491-501. myocyte apoptosis. Circulation. 2004;110:705 712 . induced hypertrophic cardiomyopathy. Circulation. 2003:108:1133-1138. ventricular genomic response to pressure overload. Physiol Genomics. 2003;12:113-127. Constriction in Mice. Physiol Genomics. 2004. complexity of limb-girdle muscular dystrophy type 2E. Mol Cell. 2000;5:141-15:1. apoptosis independent of dystrophin. J Cell Biol. 1998;142:1279-1287. activation of protein kinase a. Circ Res. 2001;89:997-1004. via cre-lloxP-mediated DNA recombination. Faseb I. 2003;17:749-751. restrictive cardiomyopathy. Proc Nati Acad Sci U S A. 2001;98:12283-12288. through upregulation of calcineurin-MFAT signaling. J Clin invest. 2003:111:1475-1486. Circ Res. 1998;82:186-194. myocyte enlargement during in vivo pressure averlaad. J Clin invest. 2000;106:R1-5. convergence and divergence. Cardiovase Res. 2004;63:373-380.

Butte A. The use and analysis of microarray data. Nat Rev Drug Discov. 2002;1:951-960. cancer. Nature. 2002:415:530-536.

Rockman HA, Ross RS, Harris AN, et al. Segregation of atrial-specific and inducible expression of an atrial matriuretic factor transgene in an in vivo murine model of cardiac hypertrophy. Proc Natl Acod Sci US A.

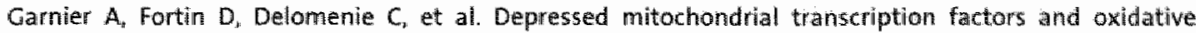

Okada $K_{3}$ Minamino T. Tsukamoto $Y_{4}$ et al. Prolonged endoplasmic reticulum stress in hypertraphic alnd failing heart after aortic constriction: possible contribution of endoplasmic reticulum stress to cardiac

Liao Y, Takashima S, Asano Y, et al. Activation of adenosine Al receptor attenuates cardiac hypertrophy and prevents heart failure in murine left ventricular pressure-overload model. Circ Res. 2003;93:759-766.

Schmitt JP, Semsarian C, Arad $M$, et al. Consequences of pressure overload on sartomere protein mutatian.

Weinberg EO, Mirotsou M, Gannon J, et al. Sex dependence and temporal dependence of the left

Zhao M, Chow A, Powers J, et al. Microarray Analysis of Gene Expression after Transwerse Acrtic

Durbeej $M$. Cohn RD, Hrstka RF, et al. Disruption of the beta-sarcoglycan gene reveals pathogenetic

Hack AA, Ly CT, Jiang F, et al. Gamma-sarcoglycan deficiency leads to muscle membrane defects, and

Coral-Vazquez $\mathrm{R}_{n}$ Cohn RD, Moore SA, et al. Disruption of the sarcoglycan-sarcospan complex in wascular smooth muscle: a novel mechanism for cardiomyopathy and muscular dystrophy. Cell. 1999:98:46:5-474.

Antos $\mathrm{CL}$, Frey $\mathrm{N}$, Marx SO, et al. Dilated cardiomyopathy and sudden death resulting from constitutive

Petrich BG, Molkentin JD, Wang Y. Temporal activation of $\mathrm{c}$-Jun $\mathrm{N}$-terminal kinase in adult transgenic heart

Liao P, Georgakopoulos. D, Kovars A, et al. The in vivo role of P38 MAP kinases in cardiac femodeling and

Braz JC, Bueno OF, Liang $\mathrm{Q}$, et al. Targeted inhibition of p38 MAPK promotes typertrophic cardiomyopathy

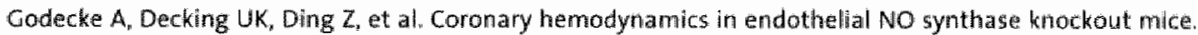

Senbonmatsu T, Ichihara S. Price $E_{0}$ J.. et al. Evidence for angiotensin II type 2 receptor-mediated cardiac

Esposito $G$, Rapacciuolo A, Naga Prasad SV, et al. Genetic alterations that inhibit in wivo pressure-overloand hypertrophy prevent cardiac dysfunction despite increased wall stress. Circulation. 2002;105:85-92.

Brancaccio M, Fratta L, Notte A, et al. Melusin, a muscle-specific integrin beta1-interacting protein, is required to prevent cardiac failure in response to chronic pressure overload. Nat Med. 2003:9:68-75.

Selwetella $G_{\text {, Hirsch }}$. Notte $A$, et al. Adaptive and maladaptive hypertrophic pathways: points of

van 't veer $U$, Dai $H$, van de Vijver $M$, et al. Gene expression profiling predicts clinical outcome of breast

Mootha VK, Lindgren $C M$, Eriksson KF, et al. PGC-1alpha-responsive genes involved in oxidative phosphorylation are coordinately downregulated in human diabetes. Nat Genet. 2003;34:267-273.

Lim DS. Roberts R, Marian AJ. Expression profiling of cardiac genes in human hypertrophic cardiomyopathy. insight into the pathogenesis of phenotypes. IAm Coll Cardiol. 2001;38:1175-1180. 


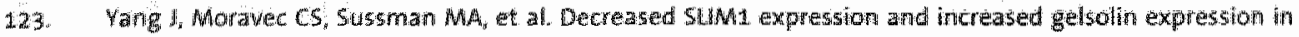

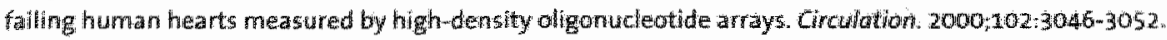

124. Hwarg 13 , Allen pD, Tseng $\mathrm{GC}$, et al. Micronay gere expresion profiles in dilated and hypertrophic cardiomyopathic end-stage heart failure. Physiol Genowics. 2002,10:31-44.

125. Barrans 10, Alem PD, Stamatiou D, et al. Clobal gene expresson prohning of end-stage dilated

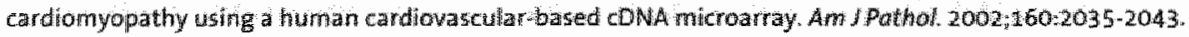

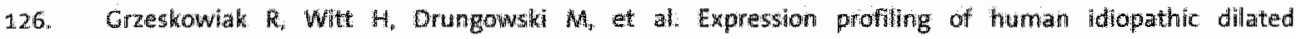
cardiomyopathy. Cardovase Rer. 2003459400411 .

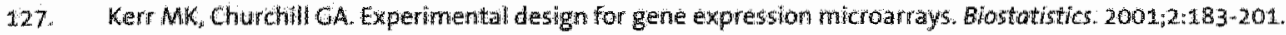

228. Wapoli $C$, Lerman 10, sica $V_{\text {, }}$ al. Microarray analysis novel research topl for caidiovascular scientists. and physicians Heart. 2003,89:597-604.

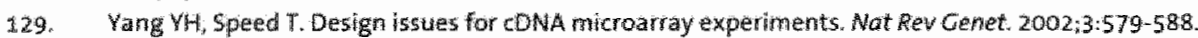

30. Bratma $A_{*}$ Higamp $P_{n}$ Quackenbush $\%$ et al. Minimum information about a microarray experiment (WIAMC)-toward standards for microarray data. Nat Genet. 2001.29:365-371.

131. Muter A, Gath A, Shmookter-Reis R. Anterpretation, design, and analysis of gene array expression

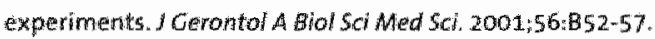

132. Jongtoed RIF, wan den Bosch BJC, de Coo IFM, al. Mitochondrial Cardiomyopathy, Mn Doevendans PA, Whde AA, eds. Cardiovascular Cenetics for Chinicins. Dardrecht, The Netherlands: Kluwer Academic Putulishers: 2001:127-137.

133. war Den Bosch BI, de Coo RF, Schotte HR, et al. Nutation analysis of the entire mitochondrial genome using denaturing high performance liquid chromatography. Nucleic Acids Res. 2000;28:589.

134. vat den Bosch BA, de Coo IF, Hendrickx AT, et al hereased risk for cardiorespiratory failure associated with the A3302G mutation in the mitochondrial DNA encoded tRNALeu(UUR) gene. Neuromuscul Disord. $2004: 14603-688$.

135. van den Bosch $\mathrm{B} \mathrm{J}_{\mathrm{N}}$ van den Burg $\mathrm{CM}$, Schoonderwoerd $\mathrm{K}_{\mathrm{n}}$ et al. Regional absence of mitochondria causing energy depletion in the myocardum of muscle RM protein knockout mice. Cardiovasc Res. 2005:65:411418 .

136. Van den Bosch B), Doevendans: PA, Lips. Df, et at. Methods in molecilar cardialogy: microarray technology. Neth Heart $1.2003 ; 112213-220$. 




\section{CHAPTER}

\section{Mitochondrial myopathy}

R.I.E. Jongbloed ${ }^{1}$, B.J.C. van den Bosch' ${ }^{1}$, I.F.M. de CoO ${ }^{2}$, H.I.M. Smeets ${ }^{2}$

- Cardowascular Research Institute Mastricht (CARIM), Dept of Cenetics \& Cell Bology, Mastricht University. The Netherlands

2 Dept. of Child Neurology, Erasmus MC-Uniwersity Medical Centre Rotterdam. The Netherlands

Mitochondriall cardiomyopathy. In: Doevendans, P.A. Wilde, A.A.M, eds. Cardiovascular Gernetics for

Clinicians. Dordrecht, The Nerherlands: Kuwer Academic Publishers, 2001:127-137 


\section{Mitochondria}

One of the important functions of mitochondria is the production of ATP by the process of oxidative phosphorylation (OXPHOS). " OXPHOS defects become clinically manifest if the ATP production falls below a tissue specific threshold level. Based on energy consumption, the organs most likely to be affected are the central nervous system, skeletal and cardiac muscle, pancreas islets, liver and kidney. In case of the heart, OXPHOS defects may lead to hypertrophic (HCM), dilated (DCM) or hypertrophic dilated cardiomyopathy (HDCM), often as part of specific syndromes, but also as the sole expression of the defect. ${ }^{2}$ Especially, when cardiomyopathies are identified by echocardiography in infants, mitochondrial dysfunction has been reported and should be specifically evaluated. ${ }^{3}$ Appropriate tests include oral glucose tolerance (high prevalence of diabetes) and lactate and creatine kinase level in blood (often raised). Urine organic and amino acids may also be abnormal. Histochemical analysis of skeletal muscle biopsies may show subsarcolemmal accumulations of mitochondria (Ragged Red Fibres) or cytochrome $c$ oxidase deficiency. Studies of activities of the respiratory chain enzyme complexes involved in OXPHOS should also be performed. OXPHOS is generated by 5 enzyme complexes, which are located in the inner membrane of the mitochondria. Deficiencies of the OXPHOS complexes have frequently been reported in HCM and $D C M .^{4-6}$ Thirteen of the subunits of the enzyme complexes are encoded by the mitochondrial DNA (mtDNA), a small, circular DNA molecule of $16.6 \mathrm{~kb}$ (figure 1). It has a genetic code which differs from the nuclear DNA and also encodes 22 transfer RNAs and 2 ribosomal RNAs. The remaining subunits and all other proteins involved in protein trafficking, unfolding and assembly or in mtDNA replication, transcription and translation, are encoded by nuclear genes. Genetic defects causing mitochondrial disease can therefore either be found in mitochondrial or nuclear genes.

\section{Mitochondrial DNA and mutations}

Defects in the mtDNA (figure 1) differ in a number of aspects from the defects in nuclear genes.' Firstly, the mtDNA and mtDNA diseases segregate maternally and are transmitted through the cytoplasm of the oocyte to the offspring. Secondly, each cell contains several hundreds to thousands of mitochondria, each with 2 to 10 copies of mtDNA. Defects in mtDNA only become manifest if the percentage mutated mtDNA (heteroplasmy), exceeds a tissue specific threshold level. Thirdly, mitochondria are randomly segregated to daughter cells during replication and changes in the percentage mutated mtDNA can occur among daughter cells and tissues. This somatic 
variation in family members who are carrying the same mutations, can lead to different clinical manifestations of the same mutation. For example, the mtDNA 3243 mutation can either manifest as Mitochondrial Encephalopathy Lactic Acidosis and Stroke-like episodes (MELAS), deafness, HCM, renal failure or diabetes mellitus (figure 2) $)^{8-11}$

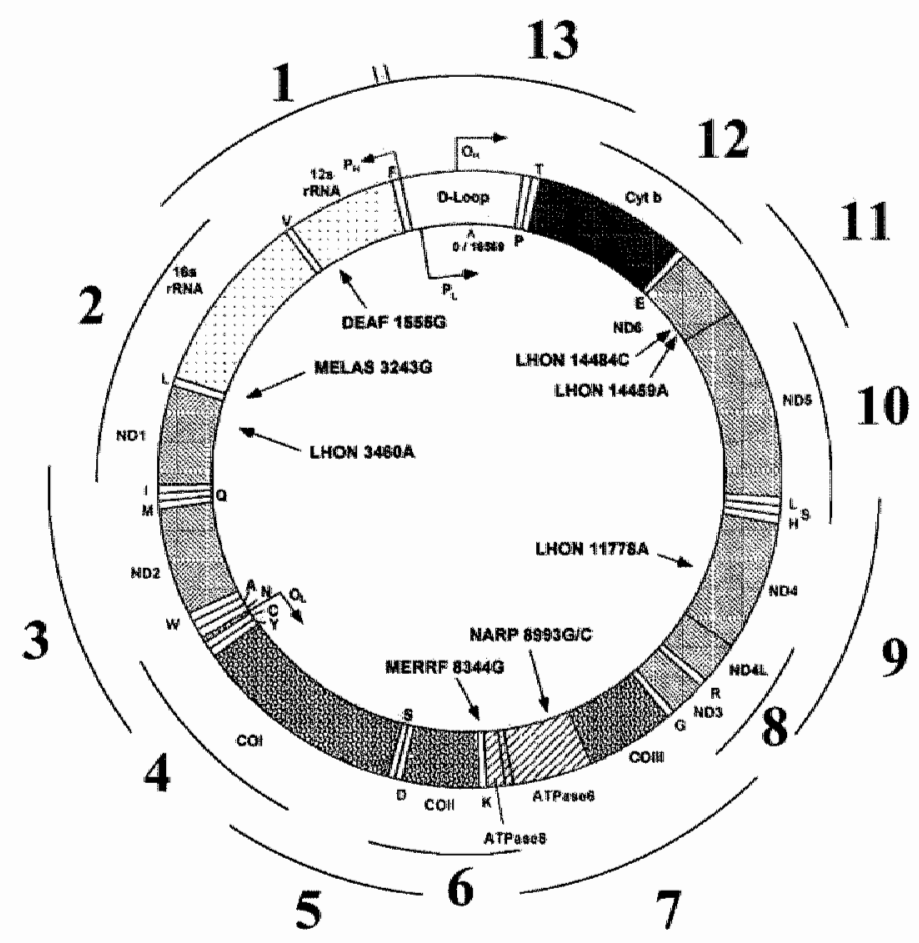

Figure 1. The circular mitochondrial DNA, adapted from Brandon MC et al. ${ }^{127}$ Indicated are the protein encoding and RNA genes and the origin of heawy and light strand replication (O) and promoters (P) for transcription. Arrows within the circle indicate a number of common point mutations. Numbers 1-13 on the outside of the circle are the fragments generated for DHPLC analysis (figure 5).

Extreme variations in mutation load occur during oogenesis, because the number of mtDNA molecules reduces drastically. The number of transmission units mentioned in literature varies between 1 and $>100$, which subsequently repopulate the oocyte and embryo. ${ }^{13.14}$ Finally, the mutation rate of mtDNA is about 10-20 times higher than the nuclear DNA, because free radicals generated during OXPHOS are highly mutagenic and mitochondria have only limited repair mechanisms. ${ }^{15}$ As the mtDNA lacks protecting histones and does not have large introns or intergenic regions, mutations will often have a pathogenic effect. 


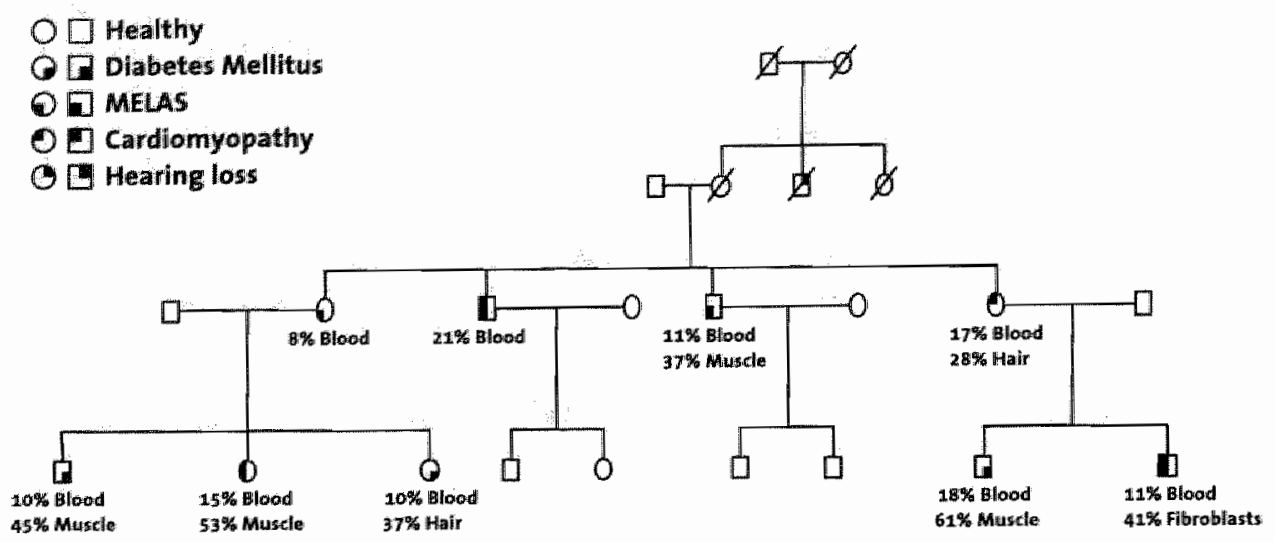

Figure 2. Fictitious familly with the MELAS A3243G mutation based on own and literature data. The disealse segregates solely through the maternal lineage and the clinical manifestations and percentage of the mutation vary broadly. Clinicians should be aware that these clinical features are caused by the same genetic defect.

The mode of inheritance of mitochondrial cardiomyopathy depends on the genetic defect involved. Single large deletions in the mtDNA are sporadic and are rarely, if ever, transmitted to the offspring. Point mutations in the RNA or in protein encoding genes of the mtDNA show a maternal segregation pattern. ${ }^{16}$ Although mutations in the mtDNA can be the sole DNA defect involved, it is also possible that the mutated mtDNA acts a risk factor contributing to the development of HCM or DCM by exaggerating the effect of nuclear gene mutations. ${ }^{17}$ With respect to this, it is noteworthy that the high mutation rate in the mIDNA may lead to somatic OXPHOS impairment and may contribute to ageing and related diseases. Mutations in nuclear genes with a mitochondrial function or mutations causing a mtDNA defect (multiple deletions or reduced number (depletion) of mtDNA molecules) can either be autosomal dominant or recessive, or $X$-linked. ${ }^{18}$

\section{Mitochondrial DNA mutations in cardiomyopathies}

Most mtDNA mutations associated with cardiomyopathy have been identified in tRNA genes. These molecules have a triplet RNA code on one site complementary to MRNA, and carry an amino acid in a different domain. After amino acid delivery to a growing peptide, the tRNA will pick up a new free amino acid. Therefore, the tRNAs are crucial components in the translation process and a mutation in one of the tRNA genes may impair the dynamics of translation in general. Mutations have been identified in a number of tRNA 
genes: tRNA ${ }^{\text {Leu(uve), }}$, which is a known 'hot spot' for pathogenic mutations ${ }^{19,20}$ (e.g. $A 3243 G^{21}, A 3260 G^{22}$ and $C 3303 T^{23}$ ), tRNA $A^{\text {Hle }}$ (e.g. $A 4269 \mathrm{G}^{24}, A 4295 \mathrm{C}^{25}$ and $\mathrm{A} 4300 \mathrm{G}^{26}$ ), tRNA $A^{\text {iys }}$ (e.g. $A 8344 G^{27}$ and $G 8363 A^{28}$ ) and tRNA ${ }^{\text {Gly }}$ (e.g. T9997 ${ }^{29}$ ). Mutations have also been described in the mtDNA rRNA genes (e.g. $A 1555 \mathrm{C}^{30}$ ) and protein encoding genes, for example as a rare association of Leigh disease (T8993G in the ATPase 6 gene $^{31}$ ) or Parkinsonism/MELAS overlap syndrome ( 4 bp deletion cytochrome b gene)..$^{32}$

The A3243G mutation in the TRNA for leucine, is commonly associated with MELAS syndrome. ${ }^{21}$ Cardiac involvement occurs in $20-30 \%$ of the patients with the full-blown MELAS syndrome, usually in the form of $\mathrm{HCM}$, but also sometimes as Wolf-ParkinsonWhite syndrome. The A3243G mutation has also been described in a large pedigree with maternally inherited diabetes mellitus, sensorineural deafness, HCM and renal failure. ${ }^{8 \cdot 11}$ Rarely, HCM is the predominant manifestation of this mutation. The C3303T mutation was described in a family with severe infantile cardiomyopathy, but presentation can range from moderate severe cardiomyopathy to isolated myopathy. ${ }^{23}$ The A4300C mutation was described in a large Italian family with the heart as the only affected organ.$^{26}$ The A8344G mutation is associated with MERRF syndrome, named according to the presenting symptoms, Myoclonic Epilepsy with Ragged Red Fibers. ${ }^{27}$ A review of 62 patients showed that $33 \%$ had cardiac problems. The A1555G mutation in the 125 rRNA gene is usually associated with maternally inherited deafness, but has also been found in a family with maternally inherited restrictive cardiomyopathy. ${ }^{30}$

Single large mtDNA rearrangements (deletion/duplication) are found in Kearns-Sayre syndrome patients, $20 \%$ of whom have cardiac involvement, typically consisting of conduction defects and DCM. ${ }^{33}$ The clinical appearance of the Kearns-Sayre syndrome includes myopathy, ptosis, progressive external ophthalmoplegia and abnormal retinal pigmentation. A comprehensive database for the human mIDNA is MITOMAP (http://www.mitomap.org/). ${ }^{19}$ The database uses the mtDNA sequence as the unifying element for bringing together information on mitochondrial genome structure and function, pathogenic mutations and their clinical characteristics, population associated variation, and gene-gene interactions.

\section{Detection of known mitochondrial DNA mutations}

Large deletions and duplications usually occur in the mtDNA of patients with specific syndromes, like Chronic Progressive External Ophthalmoplegia (CPEO), Kearns-Sayre syndrome, Pearson syndrome and diabetes mellitus with deafness. Deletions and 
duplications can also co-exist. More than 100 rearrangements have been described in mitochondrial disease in general, which can be detected either by Southern blot analysis or long range polymerase chain reaction (PCR) (figure 3). For Southern blotting, the circular mtDNA is digested by a restriction enzyme (Pvull), which cleaves only once and linearizes the mtDNA. Size fractionation by gel electrophoresis, transfer to a nylon membrane (blotting) and screening with specific mtDNA probes will reveal if deletions are present and will show which part of the mtDNA is deleted. Long range $P C R^{34}$ has recently become a rapid and sensitive alternative (figure 3 ). The entire 16.6 $\mathrm{kb}$ mtDNA molecule is amplified and the length of the PCR fragments is determined on an agarose gel. As PCR preferentially amplifies shorter fragments, it is not a reliable method to determine the mutation load from this assay and Southern blot analysis has to be performed in addition to quantify the amount of deleted mtDNA. Also, discrimination between deletions and duplications can only be determined by Southern blot analysis. Sometimes multiple deletions can be observed, especially in CPEO, which are caused by nuclear gene defects. ${ }^{18}$

Over a 100 different point mutations affecting protein encoding, tRNA and rRNA genes in the mtDNA have been described in patients with various manifestations of mitochondrial disease, of which about $20 \%$ included cardiomyopathies. As the number of mtDNA mutations accumulates, protocols were developed to determine which specific mutation should be tested in which case. The information used includes clinical presentation, metabolic measurements, OXPHOS function and mitochondrial morphology. A broad variety of technologies exists to check for known mutations in a highly sensitive way. Mutation specific restriction digestion can be applied (figure 4). If the mutation does not change a restriction site, this can be accomplished by introduction of an artificial restriction site. Alternative techniques are allele-specific primer extension (APEX) and allele-specific oligonucleotide (ASO) testing. In general, mutation percentages of less than $1 \%$ are detectable allowing a reliable pre-screening in blood of patients, eliminating the necessity to start with muscle biopsy specimens. 


\section{Pvull digest + \\ Southern blot}

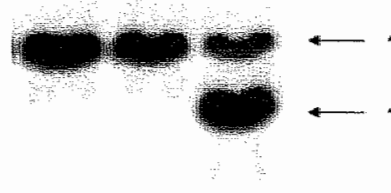

$16.5 \mathrm{~kb}$

$13.1 \mathrm{~kb}$

C C PS

\section{PCR analysis}

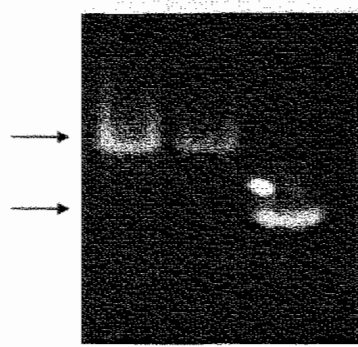

C C PS

Figure 3. Detection of deletions in the mtDNA. The circular mtDNA can either be tested by Southern blot analysis of Pvull-digested DNA or long range PCR and agarose gel electrophoresis. A deletion of $3.4 \mathrm{~kb}$ is visible in the patient with Pearson syndrome (PS) and not in the controls. (C). No normal mtDMA is wisible after PCR aithough the Southern bil ot analysis shows that it is present in substantial amount.

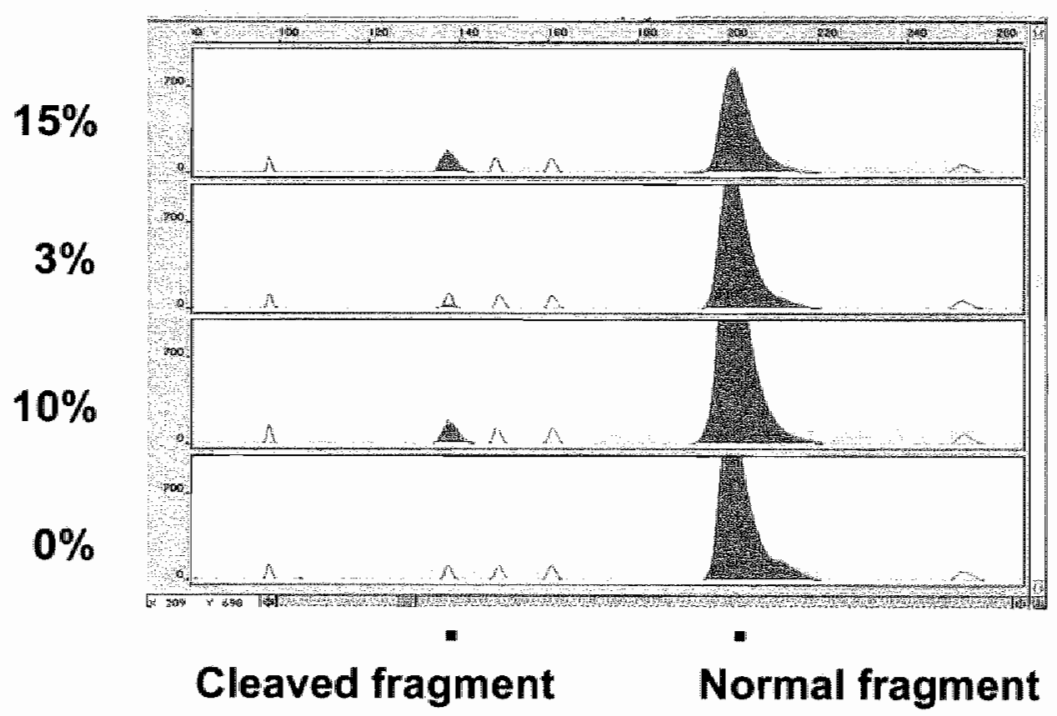

Figure 4. Mutation specific restriction digestion of the $\mathrm{A} 3243 \mathrm{C}$ mutatiom. The mutation creates a restriction site arid when the mutation is present, the PCR fragment will be cleaved in two smaller fragments. One of the PCR primers is labeled and the digested PCR fragments are resolved on an AB13100 automated sequencer. The electropherograms show the intact normal PCR fragment and one of the digestion products (cleawed fragment). The ratio of the peaks gives the amount of mutated mitoNA in relation to the wild type. The negative control (0\%) does not carry the mutation. 


\section{Detection of unknown mtDNA mutations}

Many methods can be used to screen for unknown heteroplasmic mutations. Two methods, i.e. denaturing high-performance liquid chromatography (DHPLC) and denaturing gradient gel electrophoresis (DGGE), can specifically detect heteroduplexes (DNA strands composed of wild type and mutant DNA with a mismatch at the site of the mutation) generated by heteroplasmic mutations. The advantage is that the large number of homoplasmic polymorphisms remains undetected.

A protocol was developed in which the entire mtDNA was amplified in 13 fragments. ${ }^{35}$ The development and validation of this protocol will be described in detail in chapter 3 . Briefly, each fragment is cleaved by restriction enzymes, denatured and renatured. The fragments are then loaded onto the DHPLC column (Transgenomic Inc, San Jose, CA). Elution is performed at temperatures just below the melting temperature of the fragments and a denaturing acetonitrile gradient is applied. Heteroduplexes are less stable than homoduplexes and will be resolved ahead of the homoduplexes (figure 5). The presence of a single peak for each restriction fragment indicates no heteroduplexes, while the presence of an additional peak indicates a heteroduplex and thus a heteroplasmic mutation.

DGGE is also based on differences in melting behavior of homo- and heteroduplexes. Fragments are resolved by electrophoresis through a denaturing gradient of formamide and urea. Heteroduplexes will melt at lower concentrations of denaturing agents than homoduplexes and after the melting, fragments will be stuck in the agarose gel. The presence of 2 fragments with a different mobility is indicative of a mutation. Most other pre-screening methods do not discriminate between homoplasmic and heteroplasmic mutations.

Sequence analysis lacks the sensitivity to detect low amounts of heteroplasmic mutations. However, homoplasmic mutations can be detected best by sequence analysis or, in future, by DNA chips. Any pre-screening method will detect many sequence alterations, which have to be subsequently characterized by sequence analysis. It is often difficult in case of homoplasmic mutations to discriminate genetically between neutral variants and pathogenic mutations. Therefore, functional tests of the mutations or model experiments need to be performed. 


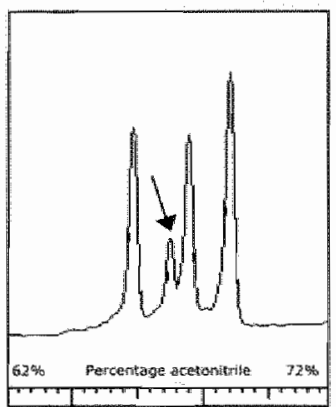

Patient 1

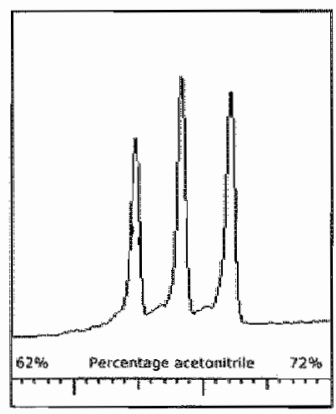

Control

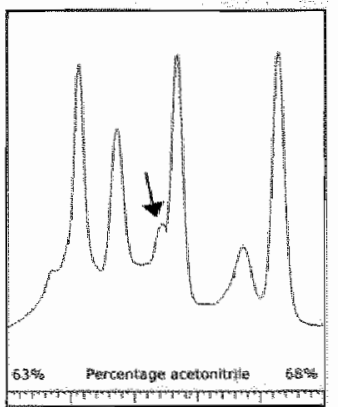

Patient 2

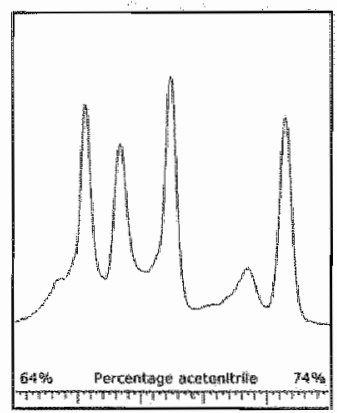

Control

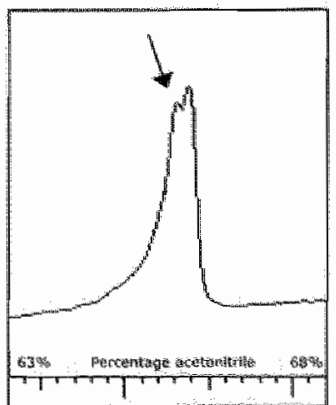

Patient 3

Figure 5. DHPLC analysis of the mtDNA for heteroplasmilc mutations. The circular mtDNA is shiown in figure 1 . The mitDA is amplified in 13 fragments (numbered 1-13), which are digested in multiple fragments by restriction enzymes. The DHPLC patterns of 3 patients and their respective controls are shown. No control was available for the fragments of patient 3 . The arrows indicate the heteroduplex peaks. Sequence analysis revealled that patient 1 Carried the $\mathrm{A} 3302 \mathrm{G}$ mutation with $70 \%$ heteroplasmy (see chapter 4 for more information about this family and this mutation), patient 2 carried the $T 3271 \mathrm{C}$ mutation with $80 \%$ heteroplasimy and patient 3 Carried the T9176C mutation with $93 \%$ heteroplasmy.

\section{Mutations in nuclear genes with a mitochondrial function}

MtDNA defects can also be caused by nuclear gene mutations. Alterations in genes affecting functions such as replication of the mtDNA, may cause multiple deletions in the mtDNA. ${ }^{34}$ Families have been described with an autosomal dominant inheritance pattern of CPEO and DCM and HCM. In 12 families with multiple deletions, more than $1 / 3$ of the patients had cardiac abnormalities. Mutations in similar genes may cause the mIDNA depletion syndrome, which is characterized by a reduced level of the mtDNA in infancy. ${ }^{36}$ This disease can be fatal within the first year of life and HCM has 
been found in some patients. Also, other nuclear genes with a mitochondrial function and defects can be associated with cardiomyopathy, like Friedreich Ataxia. A mouse model in which the Adenine Nucleotide Translocator I gene was knocked out, developed classical HCM followed by DCM. ${ }^{37}$ Another model with a disruption of the mitochondrial transcription factor $\mathrm{A}(\mathrm{Tfam})$ gene developed features similar to Kearns Sayre syndrome, including $\mathrm{DCM}^{38}$ These genes are straightforward candidates for mitochondrial cardiomyopathies and it can be expected that many more genes will follow.

\section{Investigational scheme for mitochondrial disease}

\begin{tabular}{ll}
\hline Clinical investigations & Blood: Creatine Kinase, lactate, glucose \\
Urine: Organic and amino acids \\
Cerebrospinal fluid: Protein and lactate \\
CSR, ECG +/-ECHO \\
EEG/EMG \\
CTMRI
\end{tabular}

DNA investigations can fall in 4 categories:

1. Analysis of specific mutations in the mtDNA

2. Screening for mtDNA deletions

3. Screening the entire mtDNA for point mutations

4. Analysis of nuclear genes, if involvement of mtDNA excluded

Investigations 1 and 2 yield results rapidly, as only a limited number of specific mtDNA mutations are being analyzed. A negative result does not exclude mIDNA involvement. Investigation 3 is quite laborious and takes considerable time. Investigation 4 can be rapid if a good candidate gene is available, but may last several years or may even remain unresolved if this is not the case.

\section{Management of patients}

No cure is yet available for patients with mitochondrial cardiomyopathy due to mtDNA defects. Management can be divided in counseling, supportive therapy (pacemaker) and pharmacological therapy (vitamins and co-factors). Counseling for prognosis, 
presymptomatic testing and inheritance is complex, because of the extreme clinical and genetic variabillity. Prenatal diagnosis is only a limited option for specific mutations.

\section{Conclusion}

Although frequently and increasingly reported, it is at this point unclear whether OXPHOS or mtDNA defects are a common cause of primary cardiomyopathies In a study of 601 endomyocardial biopsy specimens of patients with DCM, $14 \%$ showed ultrastructurally abnormal mitochondria and 3\% harbored likely pathogenic mtDNA mutations and defects in OXPHOS complexes I and IV. ${ }^{39}$ As idiopathic DCM is supposed to be inherited in about $20 \%$ of the cases, a careful search for all potentially affected genes is important, including the mtDNA and nuclear genes involved in mitochondrial functioning. This is especially the case if the cardiomyopathy is already present in the neonate or infant and the involvement of the mitochondria is supported by additional clinical and laboratory investigations or by maternal inheritance. In case of heteroplasmic or homoplasmic mtDNA mutations it can be difficult to judge the pathogenic effect, which may vary from contributing risk factor to primary cause. Insight in this may become especially important as mutations in the mtDNA were more frequently found in heart or muscle of patients with DCM than in control subjects, suggesting a possibly agerelated, cumulative negative effect on heart function.

\section{References}

1. Lightowlers RN, Chinnery PF, Tumbull DM, et al. Mammalian mitochondrial genetics: heredity, heteroplasmy and disease. Trends Gienet. 1997;13:450-455.

2. Santorelli FM, Tessa A, D'Amati $G_{\text {, }}$ et al. The emerging concept of mitochondrial cardiomyopathies. Am Heart J. 2001:141:E1.

3. Marin-Garcia J, Ananthakrishnan R, Goldenthal MJ, et al. Mitochondrial dysfunction in skeletal musche of children with cardiomyopathy. Pediatrics 1999;103:456 4:59.

4. Sornsteim $B$, Huertas $\mathbb{R}$, Ochoa $\mathrm{P}_{n}$ et al. Mitochondrial gerte expression and respiratory enzyme activities in cardiac diseases. Biochim Biophys Acta. 1998;1406:85-90.

5. Towbin IA, Lipshultz SE. Gienetics of neonatal cardiomyopathy. Curr Opin Cardiol. 1999;14:250-262.

6. Marin-Garcia J, Goldenthal MH. Understanding the limpart of mitochondrial diefects in cardiovascular disease: a review. I Card Fail. 2002;8:347-361.

7. Chinnery PF, Tumbull DM. Mitochondriall DNA and disease. Lancet. 1999:354 5upp/ 1:5117-21.

8. Moraes CT. Ciacci F, Silvestri $G$, et al. Atypical dinical presentations associated with the MELAS mutation at position 3243 of human mitochond rial DNA. Neuromuscul Disord $1993: 3: 43-50$.

9. Jean-Francois MJ, Lertrit P, Berkovic SF, et al. Heterogeneity in the phenotypic expression of the mutation in the mitochondrial TRNA gene generally associated with the MELAS subset of mitochondrial encephalomyopathies Aust $N Z$ I Med. 1994:24:188-193.

10. Wan den Ouweland $\mathrm{MM}_{\text {, Maechler } P}$, Wollheim $C B$, et al. Functional and morphological abnormalities of mitochondria harbouring the tRNA mutation in mitochondrial DNA deriwed from patients with maternally inherited diabetes and deafness (MIDD) and progressive kidney disease. Diabetologia. $1999 ; 42: 485-492$.

11. Deschauer $M$, Muller $T$, Weser T, et all. Hearing impaliment is common in warious phenotypes of the mitochondrial DNA A3243C mutation. Arch Neurol. 2001;58:1885-188:. 
Brandon MC, Lott MT, Nguyen KC, et al. MiTOMAP: a human mitochondrial genome database--2004 update. Nucleic Acids Res, 2005,33 Database Issue:D611-613.

Jansen RP, de Boer $K$. The bottleneck mitochondrial imperatives in oogenesis and ovarian follicular fate Mol Cell Endocrinol. 1998;1.45:81-88.

Marchingtorn DR, Hartshome GN, Barlow D, at al. Homopolymeric tract heteroplasmy in mtDNA from tissues and single oocytes: suppont for a genetic bottlenth. Am I Hum Genet. 1997:60:408-416.

Wallace DC. Mitochondrial diseases in man and mouse. Serence, $1999: 283: 1482$ 1488.

Chinnery PF, Turinbull DM. Mittochondrial DNA mutations in the pathogenesis of human disease. Mol Med Today. 2000;6:425-432.

Arbustini $E_{\text {. Fasan }} R_{\text {, Morbin }} \mathrm{P}$, et al. Coexistence of mitochondrial DNA and beta myosin heavy chain mutations in bypertrophic cardiomyopathy with la te congestive heart failure. Heart. 1998,80:5.48-558.

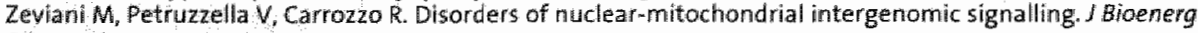
Biomembr. 1997;29:121-130.

MITOMAP: A Human Mitochoindrial Genome Database http://whw mitomap.org. 2003.

Servidei S. Mitochondrial encephallomyopathies:gene mutation. Neuromuscul Disord. 2003:13:848-853.

Mirano M. Pavlakis SG. Mitochondrial myopathy, encephalopathy, lactic acidosis, and strokelike episodes (MELAS): current concepts 1 Chidd Neural 1994;9:4-13.

Zevianil M, Gellera C, Antozzi C, et al. Maternally inherited myopathy and cardiomyopathy: association with mutation in miltochondrial DNA tRNA(Leu)(UUR). Lancet. 1991;338:143-147.

Bruno $C_{,}$KIrby DM, Koga $v$, eal. The mitochondrial DNA C3303T mutation can cause cardiomyopathy and/or skeletal myopathy. I Podiotr. 1999;135:197-202.

Taniike $M_{i}$ Fukushima $H$, Vanagihara $I$, et al. Mitochondrial tRNA(lle) mutation in fatal cardiomyopathy. Blochem Blophys Res Commum. 1992;186:47-53.

Merante F, Myint T, Tein I, et al. Am additional mitochondrial tRNA(lle) point mutation [A-to-G at nucleotide 4295) causing thypertrophic cardiomyopathy. Hum Mutat. 1996;8:216-222.

Casalt C, Santorelli FM, D'Amati $G$, et all. A nowel mt:DNA point mutation in maternally inherited cardiornyopathy. Biochem Biophys Res Commum. 1995:213:588-593.

Shoffrer $\mathrm{M}_{\text {, Lott }} \mathrm{MT}$, thezza $\mathrm{AM}$, et al. Myoclonic eplepsy and ragged-red fiber disease (MERRF) is associated with a mitochondrial DNA ERNA(Lys) mutation. Cell. 1990;61:931-937.

Santorelli FM, Mak SC, El-Schahawi M, et al. Maternally inherited cardiomyapathy and hearing lass associated with a novel mutation in the mitochondrial tRNA $($ Lys) gene (G8363A). Am J Hum Genet. $1996 ; 58: 933-939$.

Merante F. Tein I. Benson L, et al. Maternally inherited mypertrophic cardionyopathy due to a novel T-to-C transition at nucleotide 9997 in the mitochondrial tRNA(glycine) gene. Am J Hum Genet. 1994;55:437-446. Santorel I FM, Tanji K, Manta P, et al. Maternally inherited cardiomyopathy: an atypical presentation of the mtDNA 125 rRNA gene A1555G mutation. Am I Hum Genet. 1999;64:295-300.

Marin Garcia J, Ananthakrishnan R, Korson $M$, et all. Cardiac mitochondrial dysfunction in Leigh syndrome. Pediatr Cardiol 1996;17:387-389.

2. De Coo IF, Renier WO, Ruitenbeek W, et al. A 4-base pair deletion in the mitochondrial cytochrome b gene associated with parkinsonism/MELAS overlap syndrome. Ann Newrol, 1999;45:130-133.

Zeviani $M$. Moraes CT, DiMauro $S_{n}$ et al. Deletions of mitochondrial DNA in Kearns-Sayre syndrome. Neurology. 1988;38:1339-1346.

De CooIf, Gussinklo T, Arts PJ, et al. A PCR test for progressive external ophthalmoplegia and Kearns-Sayre syndirome on DNA from blood samples. 1 Newrol 5 i. 1997; $49: 37-40$.

Wan Den Bosch BI, de Coo RF, Scholte HR, et al. Mutation analysis of the entire mitochondrial genome using denaturing high performance liquid chromatography. Nucleic Acids Res. $2000 ; 28: 89$.

5. Marin-Garcia J, Ananthakrishnar $\mathbb{R}_{8}$ Goldenthal MJ. Hypentrophic cardiomyopathy with mitochondrial DNA depletion and res piratory enzyme defects. Pediatr Cardiol. 1998,19:266-268.

Graham BH, Waymire KG, Cottrell B, et al. A mouse model for mitochondrial myopathy and cardiomyopathy resulting from deficiency in the heart/muscle isoform of the adenine mucleotide translocator. Nat Genet. 1997:16:226-234.

Wang J, Witheimsson $\mathrm{H}_{1}$ Graff $\mathrm{C}$ et al. Dilated cardiomyopathy and atrioventricular conduction blocks induced by heart-specific inactivation of mitochondrial DNA gene expression. Nat Cenet, 1999;21:133-137.

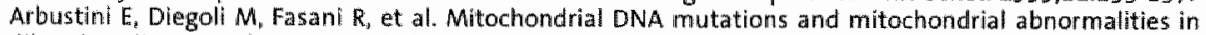
dilated cardiomyopathy. Am I Pathol. 1998;153:1501-1510. 




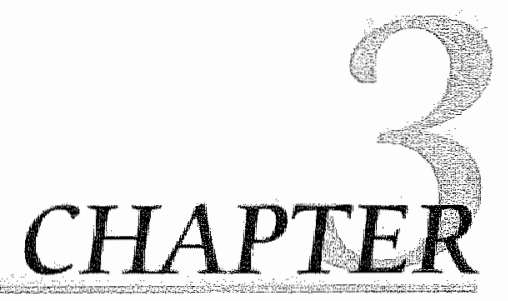

\section{Mutation analysis of the entire mitochondrial genome using denaturing high performance liquid chromatography}

Bianca J.C. van den Bosch"1*, René F.M. de Coo ${ }^{2 *}$, Hans R. Scholte ${ }^{3}$, Jeroen G. Nijland ${ }^{1}$, Ruud van den Bogaard ${ }^{4}$, Marianne de Visser ${ }^{5}$, Christine E.M de DieSmulders ${ }^{1}$, Hubert J.M. Smeets ${ }^{3}$

1 Cardiowascular Research Institute Maastricht (CARIM), Dept, of Genetics \& Cell Biology, Mazstricht University, The Netherlands

Depts of Child Neurology and ${ }^{3}$ Biochemistry, Erasmus MC Rotterdam, The Netherlands

Dept. of Clinical Genetics and "Neurology, Academic Medical Center, Amsterdam, The Netherlands

" These authors contributed equally to this work 


\section{Abstract}

In patients with mitochondrial disease a continuously increasing number of mitochondrial DNA (mtDNA) mutations and polymorphisms have been identified. Most pathogenic mtDNA mutations are heteroplasmic, resulting in heteroduplexes after PCR amplification of mtDNA. To detect these heteroduplexes, we used the technique of Denaturing High Performance Liquid Chromatography (DHPLC). The complete mitochondrial genome was amplified in 13 fragments of $1-2 \mathrm{~kb}$, digested in fragments of 90-600 bp and resolved at their optimal melting temperature. The sensitivity of the DHPLC system was high with a lowest detection of $0.5 \%$ for the A8344G mutation. The muscle mtDNA from six patients with mitochondrial disease was screened and three mutations were identified. The first patient with a limb-girdletype myopathy carried an $A 3302 \mathrm{G}$ substitution in the tRNA ${ }^{\text {Leu(uur) }}$ gene (70\% heteroplasmy), the second patient with mitochondrial myopathy and cardiomyopathy carried a T3271C mutation in the TRNA ${ }^{\text {leu(UuR) }}$ gene ( $80 \%$ heteroplasmy) and the third patient with Leigh syndrome carried a T9176C mutation in the ATPase6 gene $193 \%$ heteroplasmy). We conclude that DHPLC analysis is a sensitive and specific method to detect heteroplasmic mtDNA mutations. The entire automatic procedure can be completed within 2 days and can also be applied to exclude mtDNA involvement, providing a basis for subsequent investigation of nuclear genes.

\section{Introduction}

Energy production in cells by the process of oxidative phosphorylation (OXPHOS) is one of the important functions of mitochondria. Part of the proteins of the OXPHOS complex is encoded by the mitochondrial DNA (mtDNA). This is a maternally inherited 16,569 base pairs long, circular double-stranded molecule with 37 genes, encoding OXPHOS subunits, 2 rRNA genes and 22 tRNA genes. Mutations in the mtDNA as well as mutations in nuclear genes can cause a clinical phenotype of a mitochondrial disorder. In the past 12 years, numerous mtDNA mutations have been described in patients with mitochondrial disease. ${ }^{1}$ These mutations were in herited maternally, or originated de novo. Except for the mtDNA mutations causing Leber Hereditary Optic Neuropathy (LHON), most other pathogenic mutations are in general heteroplasmic (i.e. a mixture of wild type and mutant mtDNA in the same tissue or cell) and the mtDNA mutations become clinically manifest when the percentage of a mutation increases a tissue specific threshold. ${ }^{2}$ Nonpathogenic polymorphisms are normally homoplasmic. ${ }^{3}$ 
Many mtDNA disorders show a wide spectrum of clinical manifestations and variation in the mode of onset, course and progression of the disease: ${ }^{4}$ This is seen between families, but also within families. Maternal relatives can inherit different percentages of mutant mtDNAs and can present with different clinical manifestations. ${ }^{2}$ Patients with a mitochondrial disorder are usually screened for the presence of deletions and specific mtDNA mutations in blood or muscle, based on these symptoms. The protocols are becoming increasingly complex, as the number of mutations in mtDNA accumulates and the specificity of the symptoms lags behind. Furthermore, onlly known mutations are detected with these protocols and unknown mutations remain unresolved. As an alternative, the entire mitochondrial genome can be screened, but these approaches remain laborious (Denaturing Gradient Gel Electrophoresis (DGGE) analysis), lack sufficient sensitivity (sequence analysis) or do not sufficiently discriminate between hetero- and homoplasmic variants (Single stranded Conformation polymorphism (SSCP) analysis). Therefore, we applied the relatively new and automatable Denaturing High Performance Liquid Chromatography (DHPLC) technology $y^{5-7}$, which specifically identifies heteroduplexes that result from heteroplasmic mutations. When known mutations were readily detected even at low levels of heteroplasmy, we developed a protocol to screen the entire mtDNA for mutations by DHPLC in a rapid and sensitive way. A group of six patients with mitochondrial disease was screened for mutations as a test case and three mutations were identified.

\section{Materials and methods}

\section{Patients}

Five patients with $4.5,9,18,55$ and $76 \%$ of the $A 3243 G$ mutation, respectively, and three patients with $0.5,7$ and $19 \%$ of the $A 8344 G$ substitution, respectively, were used to test the sensitivity and specificity of the DHPLC system. Genomic DNA was isolated from blood and (when available) muscle according to the protocol described by Mullenbach et al. ${ }^{8}$ Heteroplasmy was determined, as described below, using PCR primers encompassing the mutations (table 1). Another patient carried a 4 bp deletion in the cytochrome $b$ gene ( $60 \%$ heteroplasmy). The mtDNA of six patients with mitochondrial (encephalo)myopathies, lactic acidosis, OXPHOS deficiencies and ragged red fibers was screened. 


\section{DHPLC analysis of specific mutations}

Primers (Gibco BRL, Life Technologies, Cleveland, $\mathrm{OH}$ ) used for the amplification of fragments containing the $A 3243 \mathrm{G}$ mutation (in tRNA ${ }^{\text {Leu(use) }}$ ) and the $A 8344 G$ mutation (in tRNA ${ }^{\text {Lys }}$ ) are displayed in table 1. Reactions were performed in a $50 \mu$ l volume using 66 ng genomic DNA as template, $8.33 \mu \mathrm{M}$ dNTP each (Pharmacia BioTech, Buckinghamshire, UK), 14 pmol of the forward and reverse primer, 1 U Taq DNA polymerase (PE Applied Biosystems, Foster City, CA) and OptiTaq buffer B (1.5 $\mathrm{mM}$ $\mathrm{MgCl}_{2,}, 50 \mathrm{mM} \mathrm{KCl}, 10 \mathrm{mM}$ Tris- $\mathrm{HCl}, \mathrm{pH}$ 8.4) for tRNA ${ }^{\text {Leu(Uur) }}$ and OptiTaq buffer $\mathrm{G}$ ( $50 \mathrm{mM}$ $\mathrm{NaCl}$ instead of $50 \mathrm{mM} \mathrm{KCl}$ ) for tRNA ${ }^{\text {lys }}$. Using the GeneAmp®) PCR system 9700 (PE Applied Biosystems), PCR conditions for tRNA ${ }^{\text {lew(Uus) }}$ were as follows: first, one cycle of $94^{\circ} \mathrm{C}$ for $5 \mathrm{~min}$, followed by 32 cycles of $94^{\circ} \mathrm{C}$ for $1 \mathrm{~min}, 53^{\circ} \mathrm{C}$ for $1 \mathrm{~min}, 72^{\circ}$ for $45 \mathrm{~s}$, and finally, one cycle of $72^{\circ} \mathrm{C}$ for $7 \mathrm{~min}$ followed by cooling to $4^{\circ} \mathrm{C}$. PCR conditions for tRNA ${ }^{\mathrm{Lys}}$ were similar, except for the annealing temperature of $54^{\circ} \mathrm{C}$ and the number of cycles, which was 35 . PCR products were tested by gel electrophoresis on a $2 \%$ agarose gel stained with ethidium bromide.

Table 1: Primers used to amplify the $A 3243 G, A 8344 G, A 3302 G$, T3271C and the T9176C mutations

\begin{tabular}{|c|c|c|c|c|}
\hline Muit: & Position & Length & Sequence Forward primer & Sequence Reverse primer \\
\hline $\mathrm{A} 3243 \mathrm{C}$ & $3: 189-3,383$ & $195 \mathrm{bp}$ & 5'-CAACTTAGTATTATACCCACAC-3i' & 5'-TTTCGITCGGTAAGCATTAT-3: \\
\hline $\mathrm{A} 8344 \mathrm{C}$ & $8211-8410$ & $200 \mathrm{bp}$ & $5^{*}$-TCG CCIAGAATTAATTCCC- $3^{*}$ & $5^{\prime}$-GGGGGTAATTATGGTGGGCC-3" \\
\hline $\mathrm{A} 33302 \mathrm{C}$ & $3130-3383$ & $254 \mathrm{bp}$ & 5"“AGGACAAGAGAAATAAGGCC-3" & $5^{\prime}$ - TITCGITCGGTAAGCATTAT. $3^{\prime}$ \\
\hline$T 327 \pi \mathrm{C}$ & $3130-3301$ & $172 \mathrm{bp}$ & 5'AGGACAAGAGAMATAAGGCC-3' & 5'-TAAGAAGAGGAATTGAACCTCTGACCTIAA-3' \\
\hline$T 9176 \mathrm{C}$ & $9035-9.203$ & 169 lop & $5^{\circ} \times$ TCATGCACCTAATTC GAAGCG $3^{\prime \prime}$ & 5"GTGTTGTCGTGCAGGTACCAGCTTACT-3" \\
\hline
\end{tabular}

Mismatches are underlined

DHPLC analysis was performed on an automated DHPLC instrument (Transgenomic Inc., San Jase, $C A$ ). The stationary phase consisted of a DNA Sep ${ }^{\circledR}$ column, which binds DNA during analysis. The mobile phase consisted of two eluents ( $\mathrm{pH}$ 7.0). Buffer A contained triethylammonium acetate (TEAA), which interacts with the negatively charged phosphate groups on the DNA as well as with the surface of the column (http://www.transgenomic.com/Pages/Applicationnotes.shtm/\#101).Buffer B contains TEAA with $25 \%$ of the denaturing agent acetonitrile. Fragments were eluted with a linear acetonitrile gradient of $2 \%$ per minute at a flow rate of $0.9 \mathrm{ml} / \mathrm{min}$. Increasing concentrations acetonitrile at a fixed temperature will denature the fragments. Temperatures for successful resolution of heteroduplexes were both calculated by the DHPLC Melt program (http://insertion.stanford.edu/cgi-bin/melt.pl) and also experimentally determined for the fragments containing the $A 3243 G$ and the $A 8344 G$ 
mutation. For this latter purpose, samples were analyzed at increasing column temperatures until a significant decrease in retention time occurred.

\section{DHPLC analysis of the complete mitochondrial genome}

For DHPLC analysis of the mtDNA in small fragments, appropriate restriction sites were selected (Clone Manager 4.0 program, Scientific \& Educational software) to yield fragments between 90 and 600 base pairs. These fragments were generated from longer PCR fragments using the primers shown in table 2 (Gibco BRL, Life Technologies). Reactions were performed in al $50 \mu$ volume using $330 \mathrm{ng}$ genomic DNA as template, $8.33 \mu \mathrm{M}$ dNTP each (Pharmacia BioTech), 14 pmol each primer, 2 U Taq DNA polymerase (PE Applied Biosystems) and OptiTaq buffer B. Fragment 2 was amplified using $14 \mathrm{pmol}$ of the forward and $28 \mathrm{pmol}$ of the reverse primer. Using the GeneAmp( PCR system 9700 (PE Applied Biosystems), PCR conditions are as follows: first, one cycle of $94^{\circ} \mathrm{C}$ for $5 \mathrm{~min}$, followed by 35 cycles of $94^{\circ} \mathrm{C}$ for $1 \mathrm{~min}, 57^{\circ} \mathrm{C}$ for the fragments $1-10$ and $67^{\circ} \mathrm{C}$ for the fragments $11-13$ for $1 \mathrm{~min}, 72^{\circ} \mathrm{C}$ for $2 \mathrm{~min}$, and finally, one cycle of $72^{\circ} \mathrm{C}$ for $7 \mathrm{~min}$ followed by cooling to $4^{\circ} \mathrm{C}$. PCR results were tested by gel electrophoresis on a $1 \%$ agarose gel stained with ethidium bromide.

Table 2: Primer sequences used to amplify the entire mtDNA in 1.3 fragments of $1-2 \mathrm{~kb}$ in length

\begin{tabular}{|c|c|c|c|c|}
\hline Fragm: & Position & Langth & Siequence Forward primer & Sequence Reverse primer \\
\hline 1 & $656-2490$ & 1835 bp & 5'-TGGTCCTAGCCTITCTATAGC-3' & 5'GGGTAAGATTTGCCGAGTTCC-3' \\
\hline 2 & $2433-4224$ & 1792 bp & $5^{\prime}$-CAGGCATGCTCATAAGGAAAGGH' & 5'-GGAGACATATCATATAAGTAATGC-3' \\
\hline 3 & $4.152-57335$ & 1584 bp & $5^{\prime}$-CGACCAACTCATACACCTCC-3' & 5'-GAGAAGTAGATTGAACCCAG-3" \\
\hline 4 & $5470-6908$ & $1439 \mathrm{bp}$ & 5'-CGCTACTCCTACCTATCTCC-3' & 5:AGATCATTTCATATTGCTTCCOT-3' \\
\hline 5 & $6789 \sim 8000$ & $1212 \mathrm{bp}$ & 5'-GGAATAGACGTAGACACACGAG-3' & 5' CAACGTCAAGGAGTCGCAGGT-3' \\
\hline 6 & $7699-87338$ & 1040 bp & 5'-CCTGTATGCCCTITCCTAAC- $)^{\prime}$ & 5-ATAACAGATCAGCTTCGTCCTT-3' \\
\hline 7 & $8577-10407$ & $1831 \mathrm{bp}$ & $5^{-A C C C G C C G C A G T A C T G A T C A T-3 "}$ & S'-CCAATICGGTTCAGTCTAATCC-Z" \\
\hline 8: & $10233 \cdot 11249$ & $1017 \mathrm{bp}$ & 5'“GCTATTACCTTCTTATTATTTGATC-3' & 5'GTGCGATGAGTAGGGGAAGG-3' \\
\hline 9 & $10866-12420$ & $1554 \mathrm{bp}$ & 5"-TCATCCCTCTACTATITTTAACC-3" & 5:-TTTGTTAGGGTTAACGAGGOH 3 \\
\hline 10 & $12175-13708$ & $1534 \mathrm{bp}$ & 5.TGACAACAGAGGCTTACGACC-3" & $5^{\circ}$ CCAGGCGTIIAAATGGGOTITAGI'-3" \\
\hline 11 & $13354 \times 14458$ & $1105 \mathrm{bp}$ & 5'-TITATGTGCTCCGGGTCCATCAT-3" & 5'-GATGGCTATTGAGGAGTATCCI-3' \\
\hline 12 & $14399-15599$ & $1195 \mathrm{bp}$ & 5-ACACTCACCAAGACCICAACC-3" & 5'ATCGGAGAATTGTGTAGCCGAAT-3" \\
\hline 13 & $15498-711$ & $1783 \mathrm{bp}$ & 5 "GCGACCCAGACAATTATACCCT -3" & 5'-AACGGGCATGCITGCATGTGT-3" \\
\hline
\end{tabular}

Fragments were denatured after PCR at $95^{\circ} \mathrm{C}$ for $10 \mathrm{~min}$, reannealed at $65^{\circ} \mathrm{C}$ for 10 minutes and slowly $\left(1^{\circ} \mathrm{C} / \mathrm{sec}\right)$ cooled to $4^{\circ} \mathrm{C}$ to form heteroduplexes. PCR fragments were then cleaved in smaller fragments varying in size from 90 to 560 base pairs by the enzymes shown in table 3 . For each reaction $~ 300 \mathrm{ng}$ of PCR product and 0.8-15 U of the appropriate enzyme (Roche Diagnostics, Mannheim, Germany and New England Biolabs, Beverly, MA) were used in a volume of $50 \mu \mathrm{l}$, according to the conditions given by the manufacturer, leaving out the dithiothreital (DTT), which may be harmful to the 
DNA Sep@column. Digestion results were tested by gel electrophoresis on a $3 \%$ agarose gel stained with ethidium bromide.

The optimal conditions for DHPLC analysis of fragments created by digestion were calculated for each individual fragment using the DHPLC Melt program (http://insertion.stanford.edu/cgi-bin/melt.pl) and the WAVEmaker Utility Software (Transgenomic Inc). The fragments were first analyzed under non-denaturing conditions $\left(50^{\circ} \mathrm{C}\right)$ to test for the presence of aspecific fragments and the resolution. Each vial of 100 ul digestion product is sufficient for analysis at 5 temperatures using 10-20 $\mu \mathrm{l}$ per injection. The injection volume can be adjusted to the signal of the product on agarose.

Table 3: Enzymes used for restrlction digestion (in a volume of 50ul) and DHPLC analysis temperatures

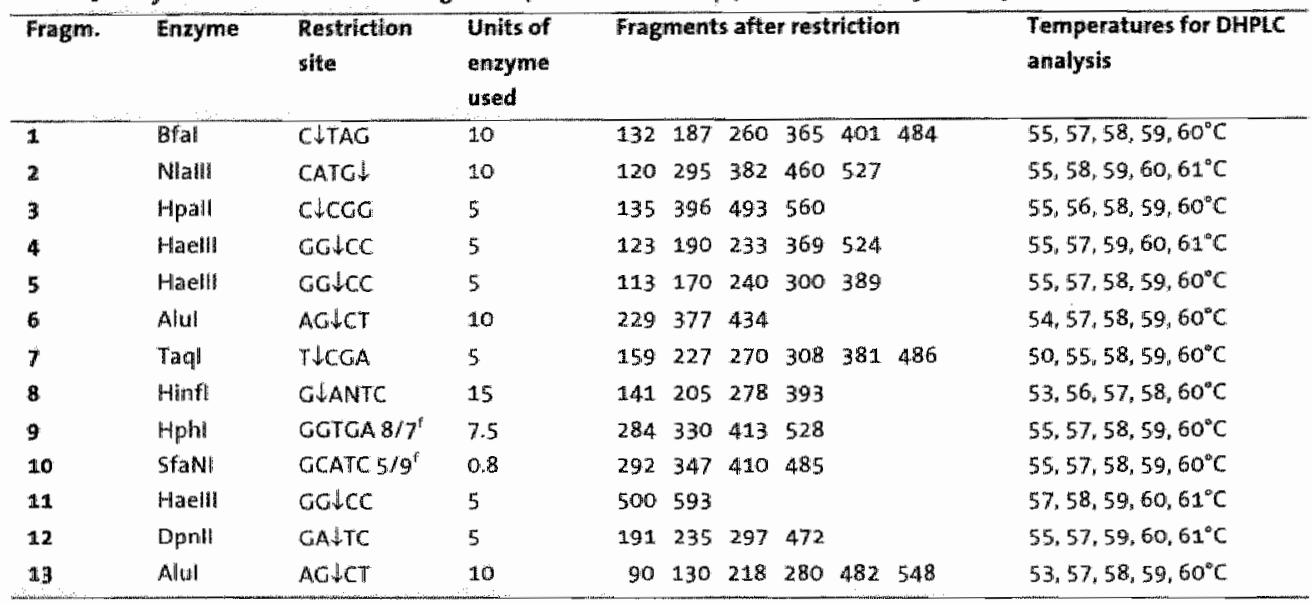

Sequence analysis

PCR fragments were purified with the QIA quick PCR purification Kit protocol IQiagen, Valencia, (A) and cycle sequenced in a volume of $20.0 \mu \mathrm{l}$ using $8.0 \mu l$ BigDye Terminator Ready Reaction Kit (PE Applied Biosystems, Foster City, CA), 3.2 pmol of the forward or reverse primer and $6.0 \mu$ of PCR product. Using a GeneAmp@ PCR system 9700 (PE Applied Biosystems, Foster City, CA), cycle sequence conditions were as followed: 25 cycles of $96^{\circ} \mathrm{C}$ for $10 \mathrm{~s}, 50^{\circ} \mathrm{C}$ for $5 \mathrm{~s}, 60^{\circ} \mathrm{C}$ for $4 \mathrm{~min}$, and finally cooling to $4^{\circ} \mathrm{C}$. Then, DNA was precipitated by mixing $20 \mu \mathrm{l}$ of the product with $74 \mu 170 \%$ ethanol and $0.5 \mathrm{mM} \mathrm{MgCl}_{y_{1}}$ incubated at room temperature for $15 \mathrm{~min}$ and centrifuged at 10 $000 \mathrm{~g}$ for $15 \mathrm{~min}$. Samples were loaded on a denaturing Long Ranger gell (Pharmacia 
BioTech), on the ABI Prism 377 automatic sequencer/genetic analyzer and analyzed with the Sequence(B) 2.1 Analysis Software (PE Applied Biosystems).

\section{Determination of heteroplasmy}

The percentages heteroplasmy of the $\mathrm{A} 3243 \mathrm{G}, \mathrm{A} 8344 \mathrm{G}, \mathrm{A3302G}$, the $\mathrm{T} 3271 \mathrm{C}$ and the T9176C mutations were determined by analyzing fluorescentlly labeled PCR products on a $4 \%$ polyacrylamide gel under non-denaturing conditions. Primers (Gibco BRL, Life Technologies) used for the amplification of fragments containing these five mutations are displayed in table 1. PCR amplification, as described for the A3243G mutation, was followed by a single last cycle, using fluorescent dUTPS (dTTP:fdUTP, 250:1). The PCR fragment with the $A 3243 G$ mutation was digested with Apal (New England Biolabs), yielding two fragments in the presence of the mutation (140 and $60 \mathrm{bp}$ ) and one fragment in the wild-type $(200 \mathrm{bp})$. The PCR fragment with the A8344G mutation was digested with Bgll (New England Biolabs), yielding two fragments in the presence of the mutation (133 and $42 \mathrm{bp}$ ) and one fragment in the wild-type (175 bP). The PCR fragment containing the A3302G mutation was digested with Ddel (New England Biolabs), yielding three fragments $(106,85$ and $63 \mathrm{bp})$ in the patient and two fragments (191 and $63 \mathrm{bp}$ ) in the willd-type. The PCR fragment containing the T3271C mutation was generated with a mismatch primer, creating an AfIII site (New England Biolabs), yielding two fragments in the patient ( 26 and $146 \mathrm{bp}$ ) and one fragment ( 171 $\mathrm{bPl}$ in the wild-type. The PCR fragment containing the T9176C mutation was also generated with a mismatch primer, creating a BstXI site (New England Biolabs), yielding two fragments (148 and $21 \mathrm{bp}$ ) in the patient and one fragment ( $169 \mathrm{bp}$ ) in the wild-type. Digestion products were then analyzed on an ABI Prism 377 automatic genetic analyzer with the Genescan $\circledast 2.1$ Analysis Software (PE Applied Biosystems). The ratio of the mutation peaks versus wild-type was determined. In case not all peaks could be quantified, a correction was made for the size of the fragments and the related incorporation of fdUTP.

\section{Results}

The sensitivity of DHPLC analysis

DHPLC analysis was performed on a variety of percentages of the $A 3243 G$ and $A 8344 G$ mutations in PCR fragments of $200 \mathrm{bP}$ (Fig. 1). In the absence of heteroplasmic mutations, the chromatogram shows only a single homoduplex peak, whereas a heteroplasmic mutation leads to two peaks, the first one representing the heteroduplexes and the second one the homoduplexes. In the case of a low percentage 
of heteroplasmy, heteraduplexes are represented as a "shoulder" in the peak. The A3243C mutation was detected in samples with heteroplasmy ranging from 4.5 to $76 \%$ (Fig. 1B). Figure 1 A shows 9 and 55\% mutated mtDNA compared to 0\% heteroplasmy (wild-type). The A8344G mutation was also detected in samples with $0.5,7$ and $19 \%$ heteroplasmy (Fig. 1D). Figure $1 \mathrm{C}$ shows 0.5 and $19 \%$ mutated mtDNA compared to $0 \%$ heteroplasmy. The sensitivity of the method is thus high for the examples given.

Next we amplified the entire mtDNA in 13 fragments (numbered 1-13, primers in table 2). PCR products were optimized and restriction enzymes were chosen to generate fragments in the DHPLC size range without overlap (table 3). Figure 2 shows chromatograms of the digestion products of fragments 4 and 9 under non-denaturing conditions. Fragment 4 yields Haelll fragments of 123,190,233, 369 and 524 bp in length and fragment $9 \mathrm{Hph} /$ fragments of $284,330,413$ and $528 \mathrm{bp}$. The resolution was good and no additional fragments were observed.

Because polymorphisms in the mtDNA can occur within the restriction sites of the enzymes, sometimes less and sometimes more fragments are observed. Five of such polymorphisms were identified (table 4). At higher temperatures the number of fragments decreased, depending on the melting temperature of the individual fragments. It should be noted that separation of the fragments is based on melting characteristics and that it is not always the largest fragment, which is finally last eluted. Additional digestion reactions were performed to determine which fragment each of the peaks represents. Figure 3A displays the A3243G mutation with 55\% heteroplasmy detected in peak 2 ( $460 \mathrm{bp}$ ) of fragment 2 . Figure $3 \mathrm{C}$ shows the $\mathrm{A} 8344 \mathrm{G}$ mutation with $7 \%$ heteroplasmy at $57^{\circ} \mathrm{C}$. Figure $3 \mathrm{E}$ shows the heteroplasmic 14787 delTTAA mutation ( $60 \%)$ in the cytochrome b gene, present in peak 4 ( $472 \mathrm{bp}$ ) of fragment 12 at $57^{\circ} \mathrm{C}$. The corresponding wild-type fragments are shown in figure $3 \mathrm{~B}_{\text {r }}$ $3 \mathrm{D}$, and $3 \mathrm{~F}$, respectively. All mutations were readily detected in the digestion products, although the patterns can be quite complex, because heteroduplexes of one fragment can overlap with homoduplexes of another fragment. Any alteration, which is either the presence of a heteroduplex or the relative decrease in intensity of the homoduplexes, is an indication for a mutation. 

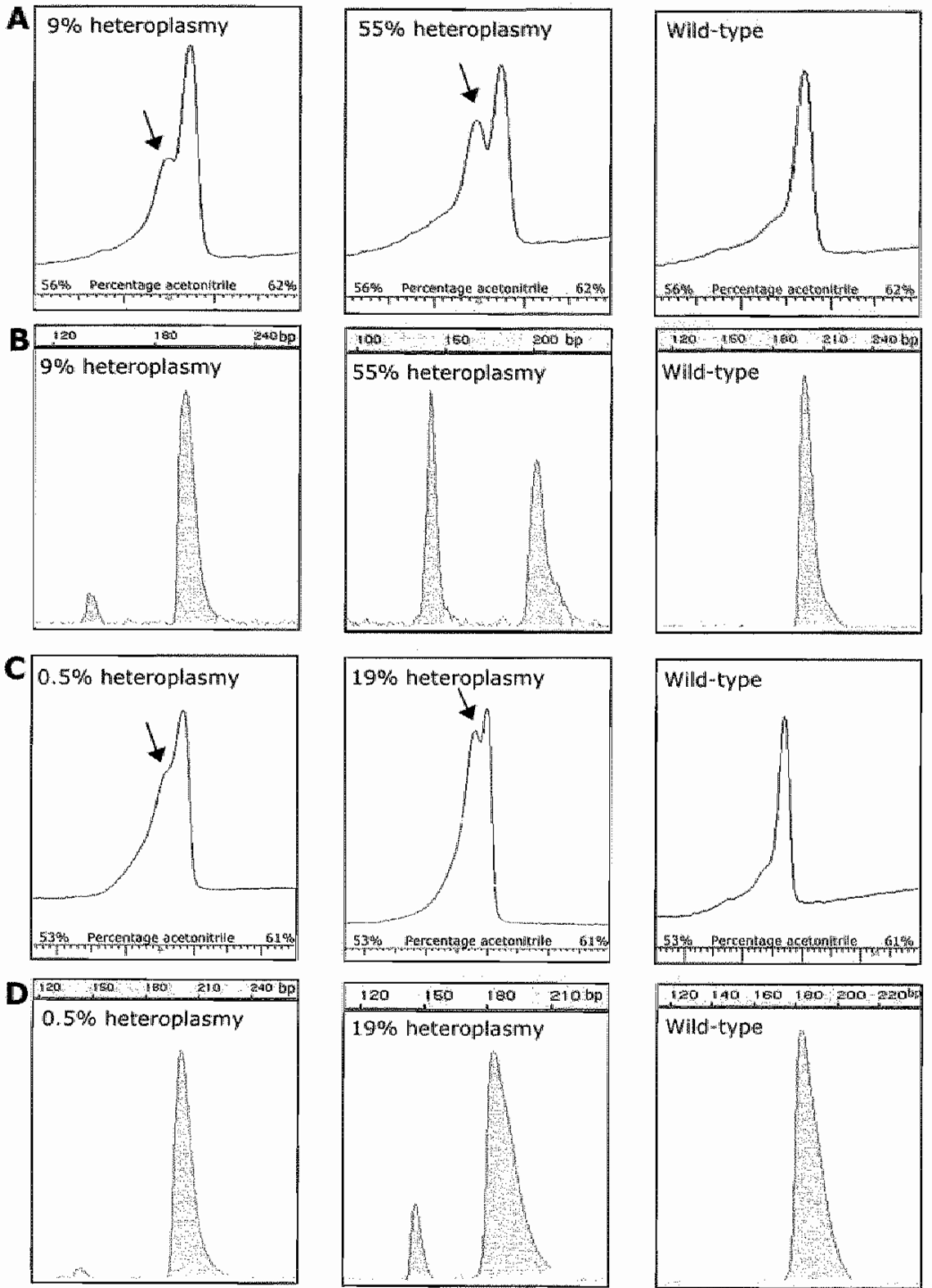

Figure 1. DHPLC analysis of two known mutations with differemt amounts of mutated miDNA. Figure 1a and $c$ show the elution peaks, using increasing amounts of acetonitrile (lower $X$-axis). The $\gamma$-axis represents the intensity of peaks. The arrow indicates the heteroduplexes. Figure $1 b$ and $d$ show the determination of heteroplasmy using lastcycle PCR followed by restriction digestion. The upper $X$-axis shows the length of fragments after digestion. The

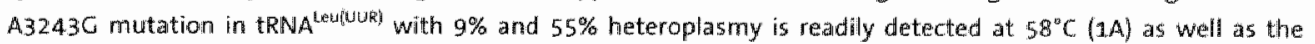
A.8344G mutation in tRNA ${ }^{\text {Lys }}$ with $0.5 \%$ and $19 \%$ at $57^{\circ} \mathrm{C}(1 \mathrm{C})$. 

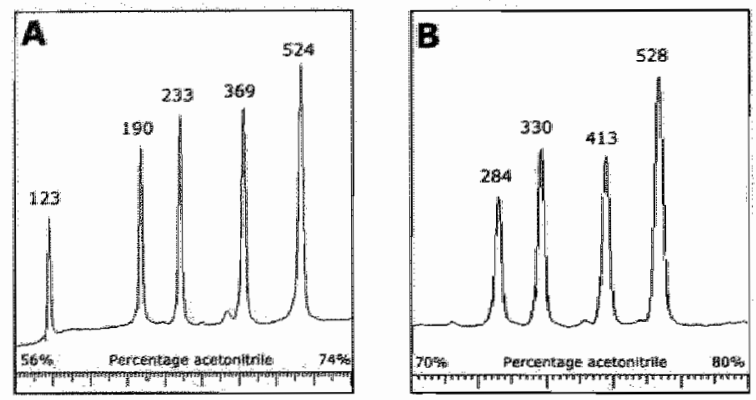

Figure 2. DHPLC analysis of fragment 4 and 9 after digestion with respectively Haelll and Hphl. Fragment 4 is cleaved into fragments of $123,190,233,369$ and 524 bp (2A) and fragment 9 into fragments of $284,330,413$ and $528 \mathrm{bp}(2 \mathrm{~B})$ : Additional digestion reactions were performed to determine which fragment each of the peaks represents. Not all fragments are shown, because both fragment 4 and 9 are representative for the other fragments.

Table 4: Pollymorphisms creating $(+)$ or deleting $(-)$ restriction sites of the enzymes used

\begin{tabular}{llllll}
\hline Polymorphism & Gene & Restriction site & Result & & $\begin{array}{l}\text { No. of patients } \\
\text { (6 in total) }\end{array}$ \\
\hline A2706G & 165 rRNA & + & $295 \mathrm{bp} \quad \rightarrow 146+149 \mathrm{bp}$ & 4 \\
C16260A & COX1 & - & $233+123 \mathrm{bp} \rightarrow 356 \mathrm{bp}$ & 2 \\
C8958A & ATPase 6 & - & $381+486 \mathrm{bp} \rightarrow 867 \mathrm{bp}$ & 1 \\
T11299C & ND4 & + & 528 & $\rightarrow 139+389 \mathrm{bp}$ & 1 \\
A15607G & Cyt b & + & 280 & $\rightarrow 170+110 \mathrm{bp}$ & 2 \\
\hline
\end{tabular}

\section{DHPLC analysis of patients with unknown mutations}

The muscle mtDNA of six patients with evident mitochondrial disease were screened by DHPLC. One patient with a limb girdle type myopathy showed heteroduplexes in the fragment containing the tRNA ${ }^{\text {Lew(Uur) }}$ gene (Fig. 4A). Sequence analysis revealed a heteroplasmic $\mathrm{A} 3302 \mathrm{G}$ substitution. Heteroplasmy was determined to be $\sim 70 \%$ in muscle. A second patient also showed a heteroduplex in the tRNA ${ }^{\text {leul (ur) }}$ gene (Fig. 4C), which by sequence analysis turned out to be the $\mathrm{T} 3271 \mathrm{C}$ mutation. The percentage of the mutation was $80 \%$ in muscle from this patient with mitochondrial myopathy and cardiomyopathy. The pattern is different from the previous patient, because of a NaIII polymorphism. A third patient with signs of Leigh syndrome, showed heteroduplexes in the largest individual fragment of 867 bp (Fig. 4E). Sequence analysis revealed a heteroplasmic T9176C substitution in the ATPase6 gene. The percentage of the mutation in muscle was $\sim 93 \%$. No comparable wild-type pattern is available, because of a polymorphism in a Taql site in this patient. The other three patients did not carry a heteroplasmic mutation in the mtDNA. 


\section{Discussion}

$P C R$ reactions were optimized to amplify the entire mLDNA in 13 overlapping fragments using two different PCR conditions. Restriction digestion conditions were adjusted for each individual fragment. Testing the digestion products on agarose revealed five different polymorphisms. ${ }^{9-12}$ These changes in restriction digestion sites are important to know prior to the analysis, because the melting temperatures from these new fragments may differ from the original fragments. All fragments showed good resolution and no aspecific products were detectable. Digestion of fragment 9 yielded products that eluted after 10 minutes. It is possible to start at a higher acetonitrile concentration to decrease the time required for analysis. However, if the analysis time is too short, the risk of fragments eluting into the first injection peak exists. The optimal temperatures for DHPLC analysis and acetonitrile gradients of all individual fragments can be experimentally determined or using the DHPLC Melt program (http://insertion.stanford.edu/cgi-bin/melt.pl). The predicted temperatures did not differ by more than $1-2^{\circ} \mathrm{C}$ from the experimentally determined temperatures. When fragments are being analyzed at $1^{\circ} \mathrm{C}$ below and above the recommended temperature, this $1-2^{\circ} \mathrm{C}$ difference is within the range of reliable detection of heteroduplexes. For each fragment of $1-2 \mathrm{~kb}$, five temperatures are recommended for analysis, ranging from $50-60^{\circ} \mathrm{C}$. Digestion products should be first analyzed for wildtype fragments at each individual temperature to determine the normal melting behavior. When screening for unknown mutations, it is important to be able to discriminate between peaks which appear as a consequence of the melting process and peaks caused by the presence of heteroduplexes.

Samples with $4.5,9,18,55$ and $76 \%$ of the $A 3243 G$ mutation and $0.5,7$ and $19 \%$ of the A8344G mutation were used to test the sensitivity and accuracy of the DHPLC. All heteroplasmy percentages heteroplasmy were detectable, making DHPLC analysis a very sensitive technology. Mutations were represented as two peaks and mutations with low percentages, such as $0.5 \%$ heteroplasmy, as a "shoulder" in the peak. Apart from the heteroduplex peak, which under some conditions can overlap with (melting) homoduplexes, the reduction in intensity of a peak in comparison with the other peaks is a strong indicator for the presence of a mutation in that specific fragment. 

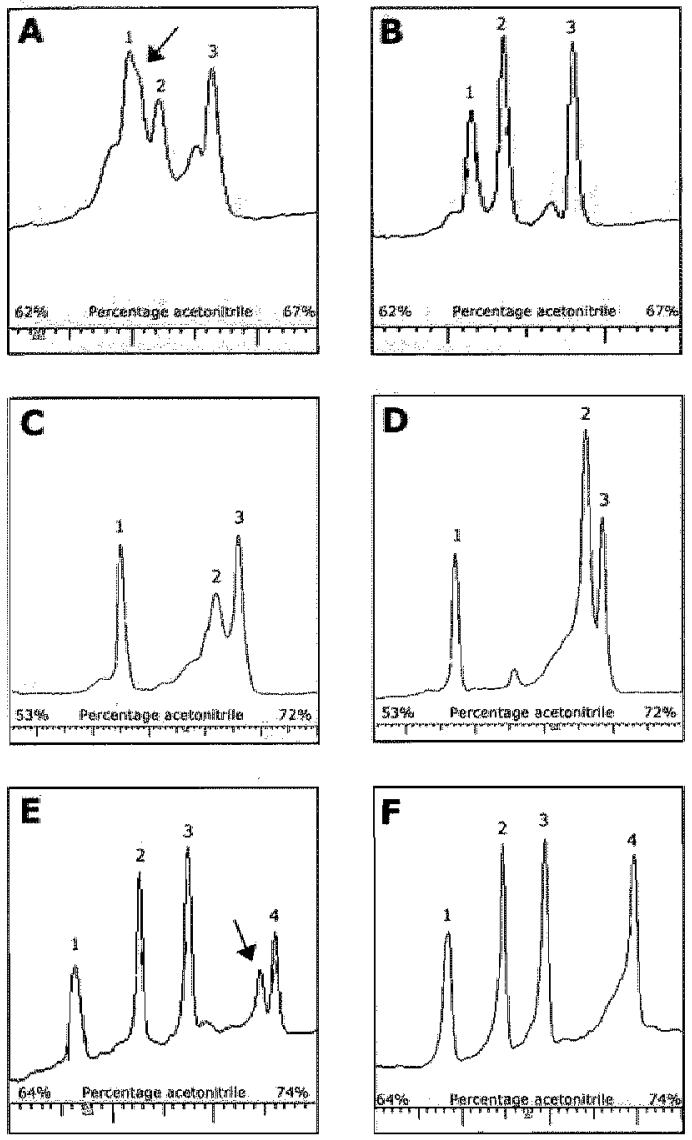

Figure 3. DHPLC analysis of known mutations in digestion products compared with controls. The A32436 mutation ( $55 \%$ heteroplasimy) in $\operatorname{tRNA}$ leututin) $_{(3 A)}$ is compared with the willd-type fragment (3B), representing the 382 bp (peak 1), the $460 \mathrm{bp}$ (peak 2) and the $527 \mathrm{bp}$ (peak 3) Digestion products of fragment 2 at $58^{\circ} \mathrm{C}$. The mutation is present in peak 2 , which decreases in intensity. The arrow indicates the heteroduplexes mierging into peak 1 . The A8344G mutation (7\% heteroplasmy) in $\mathrm{LRNA}^{\mathrm{L} \%}$ (3C) is compared with the wild-type fragment 6 (3D), representing the 229 bp (peak 1), the $434 \mathrm{bp}$ (peak 2) and the 377 bp (peak 3) product of fragment 6 at $57^{\circ} \mathrm{C}$. The mutation is present in peak 2, which decreases in intensity and broadens, whereas the relationship between peak 1 and pealk 3 remains the same. The 14787 delTTAA (60\% heteroplasmy) in cytochrome b (3E) is compared with the wild-type fragment $12(3 \mathrm{~F})$, showing 4 homoduplex peaks at $57^{\circ} \mathrm{C}$ representing the 191 bp (1), the 235 bp (2), the 297 bp (3) and the 42 bp (4) product. The mutation is present in peak 4 . The arrow indicates the heteroduplexes. The numerous peaks in figure 3 f are most likely caused by impurities in this sample and were not seen in ary ather samples. 

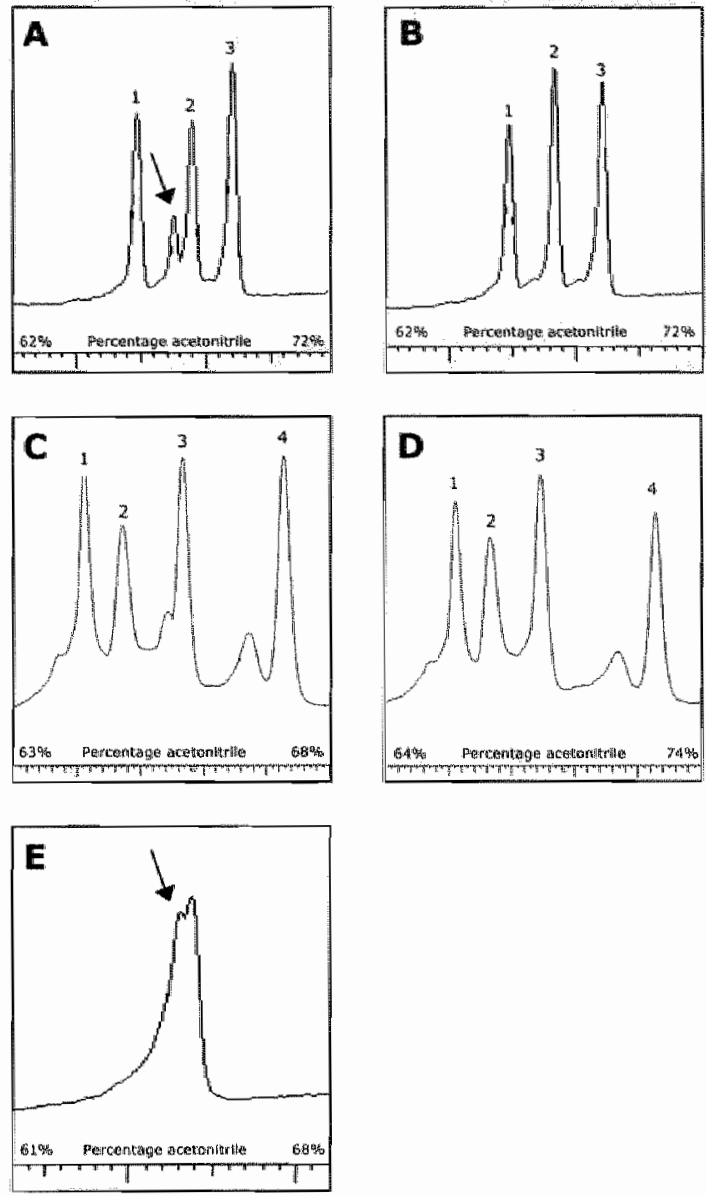

Figure 4. DHPLC amalysils of fragments 2 and 7 of three patients with unknown multations. Fragment 2 of patient 1 (4A) was compared with the wild-type fragment 2 (4B), showing three hornoduplex peaks at $55^{\circ} \mathrm{C}$ representing the $382 \mathrm{bp}$ (peak 1), the 460 bp (peak 2) and the 527 bp (peak 3) product. Patient 1 showed heteroduplexes in peak 2 $(460$ bp) as indicated by the arrow. Sequence analysis revealed the presence of ar 43020 substitution. Fingment 2 of pathent 2 showed a shoulder in peak $3(460 \mathrm{bp})(4 \mathrm{C})$, as indicated by the arrow, compared to the wild-type at $58^{\circ} \mathrm{C}$ (4D). The four peaks represent the 295 bp (peak 1), the 382 bp (peak 2), the 460 bp (peak 3) and the 527 bp (peak 4) fragment. In these two samples the polymorphic restriction site, seen in the other patients, was absent, showing the fragment of 295 bp as the fourth peak. Sequence analysis revealed the presence of a T3271C substitution. Patient 3 showed heteroduplexes in the 867 bp digestion product of fragment $7(4 \mathrm{E})$ as bindicated by the arrow. No similar widd-type fragment was avallable, because of a Taql polymorphism. Sequence analysts revealed the presence of a T9176C substitution. 
mitochondrial ONA A poteritiat dilsease mechanism. D Biol Chem. 1993,268:19559-19564.

15. Goto $y$ Nonaka , Horai 5. new mtow mutation associated with mitochondrial myopathy. enicephalopathy, lactic acidosis and strokealike episodes (MELAS). Bitochim Bnophys Acta. 1991:1097:238. 240 .

16. Thyagarajan $\mathrm{D}$, shanske 5 , vazhuez-Memije M, el al. A novel mittochondral ATPase 6 point mutation in faniliall bilateral striatal necrosis. Ann Neurol $1995338468-472$.

17. Dionis-Vici $C$, sened $S$, Zevan $M$, et al. fulminant leigh syndrome and swdden unexpected death in a farmy with the $19176 \mathrm{C}$ mutation of the mitochomorial ATPase 6 gene I Imherit Metab Dis. 1998.21:2-8.

18. Campos $Y_{\text {, Martin }}$ MA, Rubio JC $C_{i}$ al Leigh syndrome associated with the T9176C mutation in the ATPase G gene of mitochondria DNA. Neurology. 1997;49:595-597.

19. Wong $W_{\text {; }}$ Senadheera D. Direct detection of multiple point mutations in mitochondrial DNA. Clin Chem. $1997: 43: 1857 \cdot 1861$

20. Faser $S_{i}$ Wissinger B. Simultaneous detection of multiple point mutations using fluorescence-coupled competitive primer extension. Biotechniques. $1997 ; 22: 964: 968$.

21. Suomalainen $A_{*}$ Clafaloni $E$, Koga $\psi$, ett al. Ulse of single strand conformation polymorphism analysis to detect point mutations in human mitochondrial DNA. INeurol Sci. 1992;111:222-226.

22. Levin $B C$, Cheng $H_{1}$ Reeder $D$. A human mitochondrial DNA standard reference material for quality contro: in forensic identification, medical diagnosis, and mutation detection. Genomics, 1999;5:5:135*146.

23. Barros F, Lareu MV, Salas A, et aill. Rapid and emhanced detection of mitochondrial DNA variation using single-strand conformation analysis of superposed restriction enzyme fragments from polymerase chain reaction-ampliffed products. Electrophoresis. 1997;18:52-54.

24. van Orsouw NH, Zhing $X$, Wei JW, at all. Mutational scanning of mitochondrial DNA by two-dimensionall electirophoresî́s. Cenomics, 199:5:52:27-36. 




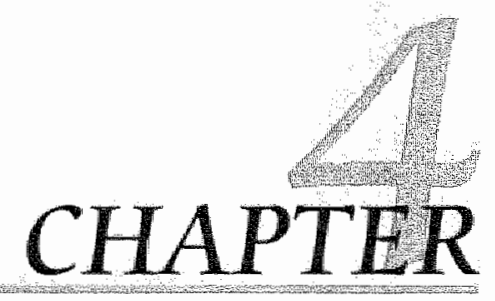

\section{Increased risk for cardiorespiratory failure associated with the $A 3302 \mathrm{G}$ mutation in the mitochondrial DNA encoded tRNA $^{\text {Leu(UUR) }}$ gene}

B.J.C. van den Bosch" I.F.M. de Coo $^{2}$, A.T.M. Hendrickx ${ }^{1}$, H.F.M. Busch ${ }^{3}$, G. de Jong ${ }^{4}$, H.R. Scholte 5 , H.J.M. Smeets ${ }^{1}$

* Gardiovascular Research Institute Masstricht (CARIM), Dept. of Cenetics \& Cell Biology, Maastricht Unversity, The Netherlands

2. Depts of Child Neurology. "Meurology, "Internal Medicine and'Biochemistry, Erasmus MC Rotterdam. The Netherlands 


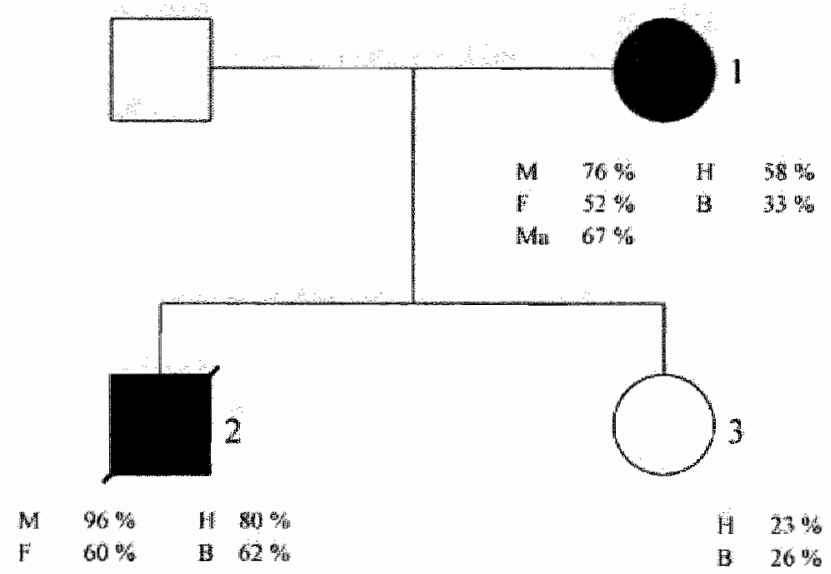

Figure 1. Family pedigree and pencentage of imutant mtDNA in patients with the $A 3302 G$ mutation. $M=m u s c l e ; F=$ fibroblasts; $M a=$ breast tiss we; $H=$ hair roots; $B=$ blood. In patient 1 , the muscle biopsy was taken at the age of 42 , whille the other samples were obtained at the age of 65 . The muscle biopsy in patient 2 was taken at the age of 19 . whereas the other samples were taken at the age of 34 . Hair and blood of patient 3 were taken at the age of 33 . Muttation percentages vary within this family. Patient 2 died of cardiorespiratory failure at age 34.

There were no signs of exercise intolerance or complaints of headaches or abdominall pain. Neurological examination revealed a complete external ophthalmoplegia and a moderate facial diplegia. Apart from the limb girdle type weakness there were no other neurological or psychiatric symptoms. Serum CK $368 \mathrm{U} / \mathrm{l}$ (normal $<270 \mathrm{U} / \mathrm{l}$ ), the $\mathrm{CK}$ heart fraction $40 \mathrm{U} / \mathrm{I}$ (normal $<27 \mathrm{U} / \mathrm{l}$ ) and resting blood lactate $5.5 \mathrm{mM}$ (normal $<1.8 \mathrm{mM}$ ) were all elevated to higher levels than found in his mother. Plasma acylcarnitine profiling did not reveal any abnormalities. He was supplemented with vitamin $B$ and carnitine like his mother, but without any benefit. At the age of 34 his weakness, the ophthalmoplegia and in particular the ptosis, had gradually worsened. Echocardiographic examination and ECG showed no signs of cardiomyopathy. He was having problems with walking stairs and combing his hair, but he had a full time administrative job and was able to walk for two hours. Last summer, he went into the mountains (approximately at $2500 \mathrm{~m}$ altitude) and during this two weeks holiday he became unwell. Whilst staying at a higher altitude, he developed respiratory failure. He was rushed to an emergency clinic, where severe lactic acidosis, ventricular fibrillation and asystole were noted, for which he had to be resuscitated. Due to this incident he suffered from anoxic brain injury with severe permanent brain damage and died. 
Patient 3 (daughter of patient 1) has been investigated because of her familial risk. She has an average stature and weight and an unremarkable medical history showing no abnormalities at neurological examination. Blood lactate and serum CK were in the normal range.

\section{Muscle morphology and biochemistry}

Methods for histochemistry and biochemistry were performed as described by Scholte et al. ${ }^{23}$ Under local analgesia, two muscle biopsies were obtained from the mother (age 41, quadriceps and age 42, biceps) and son (age 15, biceps and age 19, quadriceps). Mitochondria were isolated from a fresh muscle biopsy specimen and homogenates were prepared from frozen muscle and studied as before. ${ }^{22,23}$

\section{Molecular genetic studies}

Total genomic DNA was extracted from muscle, fibroblasts, breast tissue and blood with the Wizard Genomic DNA purification kit (Promega) and from hair roots with the QlAamp DNA Mini Kit (Qiagen). The mtDNA of the patients was amplified in 13 fragments of 1-2 kb, digested in fragments of $90-600 \mathrm{bp}$ and analyzed by Denaturing High Performance Liquid Chromatography (DHPLC) as described before. ${ }^{24}$ The PCR fragment which showed a heteroduplex peak was purified with the QIA quick PCR purification kit protocol (Qiagen) and cycle sequenced using the BigDye Terminator Ready Reaction Kit (Applied Biosystems) with a forward (5'-TACTTCACAAAGCGCCTTCC3') and a reverse (5'-TTTCGTTCGGTAAGCATT AT-3') primer. Samples were analyzed on the ABI Prism 3100 with the Sequencing analysis software 3.7 (Applied Biosystems). The percentage heteroplasmy of the mutation was determined by digestion with a mutation specific restriction enzyme (Ddel, Roche). PCR amplification conditions were the same as performed for sequencing, except for the addition of the same reverse primer with an additional fluorescent label only in the last cycle. In the absence of the mutation, the digestion yields two fragments ( $44 \mathrm{bp}$ and $190 \mathrm{bp}$ ), the largest fragment being fluorescently labeled. Digestion in the presence of the mutation yields three fragments ( $44 \mathrm{bp}, 106 \mathrm{bp}$ and $84 \mathrm{bp}$ ) of which the 84 bp product is fluorescently labeled. Fluorescent digestion products were visualized on the ABI Prism 3100 with the Genescan analysis software 3.7 (Applied Biosystems). 


\section{Results}

\section{Muscle morphology}

In patient 1 , the muscle biopsy obtained at the age of 42 showed variations in fiber size, atrophic fibers and some central nuclei. In many, mainly type I or type llA fibers, an increased subsarcolemmal succinate dehydrogenase activity was found and the Comori trichrome staining disclosed ragged red fibers. The abnormal cells contained excessive lipid droplets. Electron microscopy showed abnormal mitochondria in size and structure with abnormal whorled cristae and crystalline inclusions. ${ }^{22}$ In patient 2, muscle morphology (at the age of 15) and histochemistry findings were similar to patient 1, but the amount of ragged red fibers was even higher.

\section{Biochemical analysis of muscle}

On the basis of muscle mass, complex I activity was lower than the lowest control in both biopsies of patient 1 and 2 (table 1). Carnitine palmitoyltransferase I and II were used as markers for mitochondrial abundance and showed higher activities than the average controls in all four biopsies.

Table 1. Biochemical measurements in muscle homogenates and isolated mitochondria

\begin{tabular}{|c|c|c|c|c|c|c|c|}
\hline \multirow[b]{3}{*}{ Age $(y)$} & \multirow{2}{*}{\multicolumn{2}{|c|}{$\begin{array}{l}\text { Patient } 1 \\
\text { Mother }\end{array}$}} & \multirow{2}{*}{\multicolumn{2}{|c|}{$\begin{array}{c}\text { Patient } 2 \\
\text { son }\end{array}$}} & \multicolumn{3}{|c|}{ Contrals } \\
\hline & & & & & \multirow{2}{*}{$\begin{array}{l}\text { Meanı } \\
-\end{array}$} & \multirow{2}{*}{ Range } & \multirow{2}{*}{$\frac{(n)^{i n}}{-}$} \\
\hline & 41 & 42 & 15 & 19 & & & \\
\hline \multicolumn{8}{|l|}{ Muscle homogenates' ${ }^{6}$} \\
\hline Complex $1(\mu \operatorname{mol} \mathrm{NADH})$ & 1.13 & 0.31 & 0.78 & 1.33 & 3.66 & $1.60-7.30$ & 45 \\
\hline Complex H+llil ( $\mu$ mol cytochirome $d$ ) & 1.53 & 0.56 & 1.93 & 11.8 & 5.20 & $1,60-12.5$ & 54 \\
\hline Complex IV (1st order rate constant $k$ ) & 70 & 34. & 78 & 135 & 95 & $45-161$ & 49 \\
\hline CPT I (nmol L-carnitine) & 211 & 159 & 151 & 143 & 77 & $4 \cdot 3 \cdot 165$ & 55 \\
\hline CPT $\|$ (nirtol L-carniline) & 213 & 139 & 204 & 163 & 96 & $57 \times 174$ & 57 \\
\hline Protein (mg/giget weight) & 141 & 242 & 163 & 132 & 174 & $77-263$ & 53 \\
\hline Totall carnitine (fimol/g wet weight) & 1.42 & 1.45 & 5.16 & 2.93 & 3.96 & $2.57-5.73$ & 59 \\
\hline \multicolumn{8}{|l|}{ Isolated rnuscie mitochondriad } \\
\hline \multicolumn{8}{|l|}{$O_{\text {, }}$-hptake rates + ADP (nmol O, } \\
\hline Pyruvate + malate & - & 12 & 5 & 12 & 35 & $17 \cdot 50$ & 22 \\
\hline Glut atmate is nalate & - & 10 & 4 & 11 & 35 & $19 \cdot 73$ & 22 \\
\hline Palmitoylcarnitine is malate & - & 11 & 6 & 12 & 29 & $17-48$ & 22 \\
\hline Succinate + rotenone & - & 33 & 4.4 & 78 & 45 & $27-84$ & 22 \\
\hline Ascorbate " TMPD" & - & 68 & 78 & 255 & 148 & $99-202$ & 19 \\
\hline Mg'ATPase (nmol ATP) & - & 36 & 64 & $5: 5$ & 44 & $0-175$ & 19 \\
\hline$M_{g^{2}}{ }^{2}$ ATPase + DNP' (nmol AliP) &. & 701 & 1055 & 996 & 603 & $174 \cdot 1003$ & 19 \\
\hline
\end{tabular}

\footnotetext{
" $\mathrm{n}$ is the number of different independent controls

"Activities are expressed in indicated amounts of substratemin? ${ }^{-1}$. (g wet weight) ${ }^{2}$

"CPTI and II is carnitine palmitoyltransferase; used as markers for mitochondirial abundance

"Activities are expressed in indicated amounts of substratemin ${ }^{-1}$. (mg protein) ${ }^{3}$.

"TMPO is tetrametlyl-p-phenylemediamine used in a concentration of 0.6 mmoll

ONP is 2,4-dinitrophenol
} 
The complex I deficiency was confirmed by the functional OXPHOS study in isolated muscle mitochondria. Complex $\|+\| l \|$ activities were decreased in patient 1, while complex IV was normal in the first biopsy and decreased in the second biopsy. The first biopsy of patient 2 showed normal complex II+III and IV activities, which increased to the higher normal range in the second biopsy. This corresponded with the increased oxidation of succinate and ascorbate in isolated mitochondria. Total muscle carnitine levels were deficient but constant in patient 1 . In patient 2 , the levels remained within the normal range, although they were high in the first biopsy and decreased in the second biopsy. Complex $V$ activity was measured in isolated mitochondria as $\mathrm{Mg}^{2+}$ ATPase and stimulated by uncoupler to a normal activity in the second biopsy of patient 1 , and values around the highest control activity in the two biopsies of patient 2.

\section{Mutation analysis}

In patient 1, heteroduplexes were present in the fragment containing the tRNA ${ }^{\text {[euduik] }}$ gene. Sequence analysis revealed a heteroplasmic $A 3302 \mathrm{G}$ substitution, which was also found in both of her children. Figure 2 shows the results of the mutation specific restriction digestion in muscle DNA of patient 1 . Mutation percentages were calculated by dividing the mutant peak area $(M)$ by the sum of the wild-type (Wt) and the mutant peak areas. Mutation loads determined in all three patients are shown in figure 1.

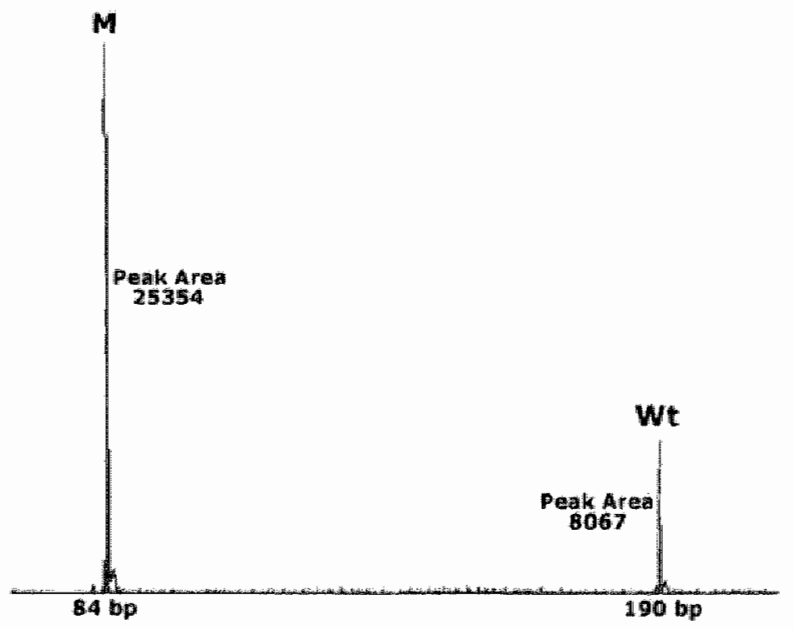

Figure 2. Determination of mutation loads. The two peaks represent the fluorescently labeled mutant $(M)$ fragment and the wild-type (Wt) fragment, Peak areas and fragment lengths are also shown. The mutation percentage in this sample is calculated by dividing the mutant peak area by the total wild-type and mutant peak area: $25354 . /$ (25354 $+8067)=76 \%$ 


\section{Discussion}

In a family with a mitochondrial myopathy and complex I deficiency, in which one patient died of cardiorespiratory failure, we identified the pathogenic $\mathrm{A} 3302 \mathrm{G}$ mutation in the tRNA ${ }^{\text {leutudes }}$ gene..$^{24}$ Patient 2 (son) who was most severely affected and who developed a fatal cardiac arrhythmia, showed the highest percentages of mutated mtDNA in all tissues, indicating a relationship between the mutation percentage and clinical manifestations. This is in line with the absence of clinical symptoms in patient 3 carrying the lowest percentage mutant mtDNA.

Complex I deficiency was present in both biopsies from the mother and son. Complex $I I+I I$ and IV activities were decreased in the mother, although complex IV was normal in her first biopsy. In the son, complex $\|+1\|$ and IV activities remained within the control range in both biopsies, although his second biopsy showed increased activities. This increase cannot be explained by an increase in mitochondrial abundance, as the markers CPT I and II and complex V remained relatively unchanged. As OXPHOS activities in muscle homogenates and isolated mitochondria were found to remain quite stable in multi-biopsied patients with autosomal recessive complex I deficiency ${ }^{23}$, it is tempting to speculate that the findings in the biopsies from this family represent different stages of the disease, also in the light of the high-normal to low-normal carnitine levels in the son and the low levels in the mother. Unfortunately, we were not able to assess corresponding levels of heteroplasmy in the first biopsies of patient 1 and 2, neither did we have biopsies taken with larger intervals at our disposal, which makes it difficult to draw conclusions regarding the possible underlying pathogenic mechanisms. The biochemical changes are nevertheless of interest, because they seem to show that a complex I deficiency may be followed by other defects.

The A3302G mutation has only been reported once before in a 22-year old woman with a mitochondrial myopathy and a profound complex I deficiency, who died of cardiorespiratory failure. ${ }^{21}$ The medical history, muscle cytochemistry and biochemistry of the patient with the mutation have been described previously. ${ }^{20} \mathrm{Her}$ phenotype was quite similar to that in our family, including ragged red fibers with abnormally shaped mitochondria and limb weakness, although she showed a more profound complex 1 and IV deficiency. Percentages mutated mtDNA were nearly homoplasmic in muscle and slightly less high in fibroblasts. The patient and three of her relatives were reported to have died from cardiorespiratory failure. ${ }^{20} \mathrm{~A}$ more extensive investigation of the medical records of the index patient revealed a persistent tachycardia and 
clinical signs of heart failure. More information about the deceased relatives was not available. In our family, patient 2 also developed cardiac problems, in this case under unusual circumstances. His stay at a low oxygen environment during his holiday and the high workload by walking in the mountains, i.e. the combination of lactic acidosis and muscle weakness, most likely caused the fatal cardiorespiratory problems. This suggests that other factors in addition to mutation load, like disturbances in fatty acid oxidation $^{20}$, may determine the outcome of this disease. This specific factor is unlikely to be involved in our family, as plasma acylcarnitine levells were normal.

The A3302G mutation is located clase to the ARNA/ND1 junction and interferes with cleavage of RNA intermediate RNA19, which accumulated in muscle of the patient. ${ }^{21}$ In fibroblasts, RNA19 is also higher than in controls, but the difference is far less marked than in skeletal muscle, indicating that RNA processing is different in these tissues. Pathogenesis was therefore explained by tissue-specific abnormal mitochondrial RNA processing, causing either quantitative or qualitative changes in the ND1 message. ${ }^{21}$ We hypothesize that abnormal RNA processing in heart, similar to muscle, could explain the specific cardiac involvement. A definite answer would come from testing heart RNA for the level of RNA19, but this is not possible at the moment. The A3302G mutation is adjacent to the C3303T mutation, which is associated with cardiomyopathy and/or skelletal myopathy. ${ }^{15,25}$ Recently, analysis of processing intermediates in muscle of a patient with the C3303T mutation showed an accumulation of RNA19 as well. ${ }^{26}$ This was also observed in vitro for both the C3303T and the $\mathrm{A} 3302 \mathrm{G}$ mutation ${ }^{27}$, which suggests a similar pathogenic mechanism for these mutations. Higher levels of mutant mtDNA in the heart can lead to a more severe phenotype. ${ }^{15.28}$ This is supported by the fact that patients with the C.3303T mutation who died at a very young age, showed a nearly homoplasmic percentage of the mutation in the heart and one patient showed a much lower percentage in muscle compared to the heart. ${ }^{28,29}$ A total of six tRNA mutations associated with cardiomyopathies are located in the aminoacyl stem of the TRNA. Four of them are located cllose to the end and probably lead to abnormal and pathogenic RNA processing. ${ }^{28,30,31}$ Alternatively, a deleterious effect on the general cloverleaf structure has been suggested, but other mechanisms have also been postulated. ${ }^{15,32}$

The occurrence of cardiac problems in the two families carrying the A.3302G mutation, the simillarities with the $C 3303 \mathrm{~T}$ mutation and other mutations in the aminoacyl stem of the tRNA emphasize the importance of possible cardiac complications associated with these types of mutations. The severity of the phenotype and complications will 
depend on the position of the mutation within the tRNA structure, the percentage mutated mtDNA and the biochemical phenotype in muscle. Also thorough cardiac examination in these patients is strongly recommended. This information has to be combined for appropriate genetic counseling and treatment, which should certainly be directed towards medical treatment for eventual congestive heart failure, but may also include a backup pacemaker as a support for severely affected patients, as well as advice regarding exposure to low oxygen pressure environments such as stays at high altitude as well as long haul flights in pressurized airplane cabins.

\section{Acknowledgements}

This work was supported by the Netherlands Heart Foundation (99.122) and the Cardiovascular Research Institute Maastricht (CARIM), The Netherlands. We would like to thank Dr. P. Chinnery and Prof. L. Bindoff for their help in the preparation of this manuscript.

\section{References}

1. Wallace DC, Lott MT. MITOMAP: A Human Mitochondrial Genome Database. In: http://www mitomap.org: 2003.

2. Goto $Y$, Nonaka I, Horai S. A mutation in the TRNA gene associated with the MELAS subgroup of mitochandrial encephalomyopathies. Nature. 1990;348:651-653.

3. Zeviani $M, G e l l e r a ~ C$, Antozzi $C$, et al. Maternally inherited myopathy and cardiomyopathy: association with mutation in mitochondrial DNA tRNA ${ }^{-\cdots . . .}$. Lancet. 1991; 338:143-147.

4. Goto Y, Tojo M, Tohyama J, et al. A novel point mutation in the mitochondrial tRNAwa gene in a family with mitochondial myopathy. Ann Neurol. 1992;31:672-675.

5. Ciafaloni E, Ricci E, Shanske 5, et al. MELA5: clinical features, biochemistry, and molecular genetics. Anm Neurol. $1992 ; 31: 391-398$.

6. Mongini T, Doriguzzi C, Chiado.plat L. et al. MERRFIMELAS overlap syndrome in a family with A3243C mLDNA imutation. Clim Newropothol. 2002:21:72-76.

7. Torroni A, Campos $Y$, Remgo $C_{\text {n }}$ et al. Mitochondrial DNA haplogroups do not play a role in the variable phenotypic presentation of the A3243G mutation. Am J Hum Genet. 2003;72:1005-1012.

8. Sciacco M, Prelle A, Comi GP, ent al. Retrospective study of a large population of patients affected with mitochondrial disorders: clinical, morphological and molecular genetic evaluation. J Neurol. 2001;248:778788.

9. Servidei S. Mitochondial encephalomyapathies:gene inutation. Newromuscul Disord, 2003;13:848×853.

10. Moraes $\mathrm{CT}$, Clacci $F$, Silvestri $G$, et al, Atypical clinical presentations associated with the MELAS mutation at position 3243 of human mitochondrial DNA. Newromuscul Disord. 1993:3:43-50.

11. Jean wrancois MI, Lertrit P, Berkovic SF, et al, Heterogeneity in the phenotypic expression of the mutation in the mitochondrial TRNAw gene generaly associated with the MELAS subset of mitochondriall encephalomyopathies Aust NZJMed. 1994:24:188-193.

12. Wan den Ouweland IM, Maechler $P$, Wollheim $C B$, et al. Functional and morphological abnormalities of mitochondria harbouring the TRNA mutation in mitochondrial DNA derived from patients with maternally inherited diabetes and deafness (MIDD) and progressive kidney disease. Diabetologia. $1999 ; 42: 485-492$. 
13. Deschauer $M$, Muller $T$. Wieser $T_{\text {. }}$ et all. Hearing impairment is common in various phenotypes of the mitochondrial DNA A3243G mutation. Arch Neurol. 2004; $\$ 8: 1885$-1888.

14. Zeviani $M$, Mariotti $C$. Antozzi $C$, et al OxpHOS defects and mitochondriall DNA mutations in cardiomyopathy. Muscle Nerwe. 1995:3:5170-174.

15. Bruno $C_{\text {, Kirby DM, Koga }} \%$, et al. The mitochondrial DNA C3303T mutation can cause cardiomyopathy and/or skeletal myopathy. I Pediatr. $1999 ; 135: 197 \% 202$.

16. van den Ouweland $J M$, Lemkes $H H_{4}$, Ruitenbeek $W$, et al Mutation in mitochondrial tRNA gene in al large pedigree with maternally transmitted type ll diabetes mellitus and deafnes5. Nat Genet. 1992;1:368-371.

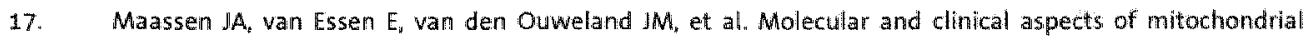
diabetes mellitus. Exp Clin Endocrinol Diabetes. 2001;109:127-134.

18. Jacobs HT, Holt II. The np 3243 MELAS mutation: damned if you aminoa cylate, damined if you don't. Hum Mol Genet. $2000 ; 9: 463-465$.

19. Jacobs HT. Disorders of mitochondrial protein synthesis. Hum Mal Genet. 2003;12:R293-301.

20. Watmough NJ, Bindoff LA, Birch-Machin MA, et al. Impaired mitochondrial beta-oxidation in a patient with an abnormality of the respiratory chain. Studies in sikeletal musclie mitochondria. $J$ Clin Mvest. 1990;85:177. 18.4.

21. Bindoff LA, Howell N, Poulton $\mathrm{d}$, et all, Abnormal RN.A processing associated with a novel tRNA mutation in mitochondrial DNA. A potential disease mechamism. J Biol Chem. 1993;268:19559-19564.

22. Busch HFM, Scholte $\mathrm{HR}_{n}$ Arts WF, et al. A mitochondrial myopathy with a respiratory chain defect and carnitine deficiency. In: Busch HFM, Jeninekens FGI, Scholte HR, eds. Mlitochandria and muscular diseases. Beetsterawaag, The Netherlandls: Mefar B.W.; 1981:207-211.

23. Scholte HR, Busch HFM, Bakker HD, et al. Riboflavin-responsive complex deficiency. Biochim Biophys Acta. $1995 ; 1271: 75-83$.

24. van Den Bosch BJC, de Coo RFM, Scholte HR, et al. Mutation analysis of the entire mitochondrial genome using denaturing high performance liquid chromatography. Nucleic Acids Res. 2000;28:E89.

25. Silvestri G, Santorelli FM, Shanske S, ell a A new mtDNA mutation in the tRNA(Leu(UUR)) gene associated with maternally inherited cardiomyopathy. Hum Mutot. 1994;3:37-43.

26. Koga A, Koga Y, Akita $Y$, et al. Increased mitochondrial processing intermediates associated with three tRNA(Leu(UUR)) gene imutations. Neuromuscul Disord. 2003;13:259-262.

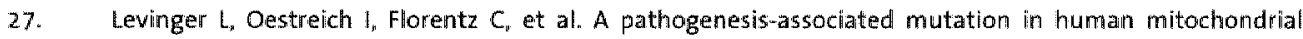
tRNALeu(UUR) leads to reduced 3'wend processing and CCA addition. J Mol Biol. 2004;337:535-544.

28. Santorelli FM, Tessa A, D'Amati $G$, et al. The emerging concept of mitochondrial cardiomyopathies. Am Heart 1. 2001,141:E1.

29. Iwanlaga $R$, Koga $Y$, Aramaki $S$, et al. Inter-andror intra-organ distribution of mitochondrial C $3303 \mathrm{r}$ or A3243G mutation in mitochondrial cytopathy. Acta Neuropathol (Ber)/. 2001;101:179-184.

30. Marin-Garcia J, Goldenthal MJ. Understanding the impact of mitochondrial defects in cardiovascular disiease: a review. J Card Fail. 2002;8:347-361.

31. Marin-Garcia J, Goldenthal M. Fatty acid metabolism in cardiac failure: biochemical, genetic and celfular analysis. Cardiovasc Res. 2002:54:516-527.

32. Sohm $B$, Frugier $M$, Brule $H$, et al. Towards understanding human mitochondrial leucine aminoacylation identity. I Mol Biol. 2003:328:995-1010. 



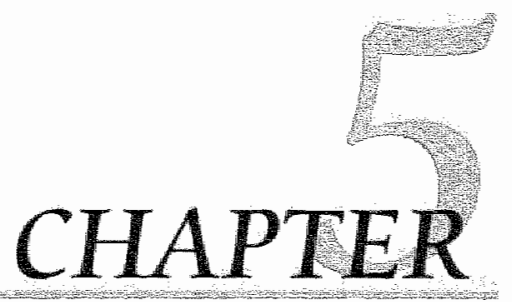

\section{Regional absence of mitochondria causing energy depletion in the myocardium of MLP knockout mice}

Bianca J.C. van den Bosch", Caroline M.M. van den Burg', Kees Schoonderwoerd ${ }^{2.3}$, Patrick J. Lindsey ${ }^{2}$, Hans R. Scholte ${ }^{3}$, René F.M. de Coo', Eva van Rooif ${ }^{1,5}$. Howard A. Rockman ${ }^{5}$, Pieter A. Doevendans ${ }^{5,7}$. Hubert J.M. Smeets ${ }^{1}$

\footnotetext{
1. Cardiovascular Research Institute Maastricht [CARIM], Dept of Genetics \& Cell Biology, Madstricht University, The Netherlands

2. Depts of Clinical Genetics, ${ }^{3}$ Biochemistry and 4 Child Neurology, Erasmus MC Rotterdam, The Netherlands

5 Dept, of Cardiology of the Heart Lung Centre Utrecht (UMCU), The Netherlands

- Dept. of Medicine, Duke University Medical Center, Durham, North Carolina

7 Interuniversity Cardiology Institute of the Netherlands (ICIN), Utrecht, The Netherlands
} 


\section{Abstract}

Defects in myocardial mitochondrial structure and function have been associated with heart failure in humans and animal models. Mice lacking the muscle LIM protein (MLP) develop morphological and clinical signs resembling human dilated cardiomyopathy and heart failure. We tested the hypothesis that defects in the cytoskeleton lead to dilated cardiomyopathy through mitochondrial dysfunction in the MLP mouse model. Oxidative phosphorylation (OXPHOS) activity was determined in left ventricles of MLP $K O$ mice and control littermates by measuring complex activities of the electron transport chain (I-IV) and ATP synthase (complex V). All complexes and citrate synthase (CS) showed decreased activities in the KO mice, although activity per amount of CS, a measure for mitochondrial density, was normal. Light and electron microscopy revealed a disorganization of mitochondria and a dramatic decrease in mitochondrial density, even revealing regions completely lacking mitochondria in the KO hearts. Realtime PCR analysis showed decreased transcript levels of mtDNA and nuclear encoded mitochondrial genes and of peroxisome proliferator activated receptor gamma coactivator $1 \alpha$ (PGC-1 $\alpha$ ), a key regulator of mitochondrial biogenesis. MtDNA copy number (ratio mtDNA/nuclear DNA) was slightly increased in the MLP KO mice. Our results show that the absence of MLP causes a local loss of mitochondria. We hypothesize that this is caused by a disturbed interaction between cytoskeleton and mitochondria, which interferes with energy sensing and energy transfer. Recovery of energy depletion by stimulating mitochondrial biogenesis might be a useful therapeutic strategy for improving the energy imbalance in heart failure.

\section{Introduction}

Defects in mitochondrial structure and function have been associated with cardiovascular diseases such as hypertrophic cardiomyopathy $(\mathrm{HCM})^{1}$, dilated cardiomyopathy $(D C M)^{2}$ and idiopathic cardiomyopathy $(\mathrm{IDC})^{3}$ and primary, causative mutations have been reported in the mitochondrial DNA (mtDNA) and in nuclear genes encoding mitochondrial proteins (nDNA). ${ }^{*}$ Mitochondrial dysfunction in cardiomyopathy can also be secondary to other, often unknown, genetic or environmental causes. ${ }^{5.6}$ Nonetheless, the exact role for mitochondrial dysfunction in different stages of cardiac disease remains to be elucidated. In the heart, energy production mainly relies on mitochondrial oxidative phosphorylation (OXPHOS), consisting of the electron transport chain (complexes I-IV) and the ATP synthase (complex V). These complexes consist of subunits encoded by mtDNA and nDNA. ${ }^{4}$ The 
enzyme activities of the OXPHOS complexes can be either increased, normal of decreased in $H_{C M}, D C M$ and heart failure $(H F){ }^{\text {s.j.8. }}$ One of the major reasons for these discrepancies is that human cardiomyopathy and HF are complex disorders with a heterogeneous etiology, in which a variety of factors, like genetic background, environment and drug treatment, can be involved. "Thus, to get further insight into the role of the OXPHOS system in the transition to HF, it would be advantageous to use an animal model that is more genetically and environmentally homogeneous. Several genetically altered mouse models of cardiac hypertrophy and failure exist, including defects in contractile, cytoskeletal proteins and $\mathrm{Ca2}$-regulatory proteins, cell surface receptors, cell-signaling moleculles, transcription factors, growth factors and mitochondria. ${ }^{10}$

Knocking out cytoskeletal genes in a number of mice models illustrates the importance of the intermediate filament (IF) network in mitochondrial behavior and function. Abnormalities in number, distribution and morphology of mitochondria have been observed in hearts of desmin $\mathrm{KO}$ mice ${ }^{11}$ or skeletal muscle of dystonin $\mathrm{KO}^{12}$ and plectin KO mice. ${ }^{13}$ In addition, downregulation of nuclear encoded mitochondrial transcripts has been reported in patients with Duchenne muscular dystrophy and $\alpha$-sarcoglycan deficiency ${ }^{14}$ and other kinds of myofibrillar myopathy in human skeletal muscle, indicating an important contribution of structural abnormalities to the metabolic crisis in these myopathies. ${ }^{15}$

The cytoskeletal protein MLP (Muscle LIM Protein) is a conserved positive regulator of cardiac muscle development and MLP deficient mice develop DCM with myocyte hypertrophy and HF. ${ }^{16}$ MLP has been found to be an important component of the cardiac mechanical stretch sensing machinery and recently, human MLP mutations were found to be associated with $D C M^{17,18}$ and $H C M^{19}{ }^{19}$ To test the hypothesis that this defect in the cytoskeleton leads to DCM through mitochondrial abnormalities, we studied mitochondria and mitochondrial functioning in the myocardium of MLP KO mice and identified an uncompensated local loss of mitochondria leading to energy depletion.

\section{Methods}

\section{Animal model}

The MLP deficient mice have been extensively described before. ${ }^{16}$ Studies were performed in 8 male MLP KO mice and 5 male control mice at 12 weeks of age. MLP KO 
mice at this age consistently show left ventricular hypertrophy as indicated by an increased LVW (left ventricle weight)/BW (body weight) ratio and an increased mRNA expression of the hypertrophy marker ANF (atrial natriuretic factor). ${ }^{16}$ in addition, 12 weeks KO mice show dilation with reduced cardiac function ${ }^{16}$, which was confirmed by echocardiographic measurements. Wild-type mice of $1295 \mathrm{v} / \mathrm{B} 6$ strain were used as controls. After the mice were sacrificed, hearts were harvested and frozen in liquid nitrogen. Experiments were performed in accordance with the recommendations of the Guide for the Care and Use of Laboratory Animals published by the US National Institutes of Health (NIH publication No. 85-23, revised 1996) and were approved by the Committee for Animal Research of the Maastricht University, The Netherlands.

\section{OXPHOS activities}

Frozen left ventricles from MLP KO mice and controls were grinded in $0.25 \mathrm{M}$ sucrose, $10 \mathrm{mM} \mathrm{N}$-[2-HydroxyEthyl]Piperazine-N'-[2 EthylSulfonic acid] (HEPES) and $1 \mathrm{mM}$ Ethylene Diamine Tetraacetic Acid (EDTA), pH 7.4. Citrate synthase (CS) activity ( $\mu \mathrm{mol} / \mathrm{min} / \mathrm{g}$ muscle) was measured according to Srere ${ }^{20}$ to correct for mitochondrial density and protein ( $\mathrm{mg} / \mathrm{g}$ muscle) was determined using the Lowry method to correct for total protein content. ${ }^{21}$ All enzyme activities were measured at $37^{\circ} \mathrm{C}$ in heart homogenates by spectrophotometric methods as described before..$^{22.25}$

\section{Electron microscopy}

From two MLP KO and control mice, freshly isolated hearts were perfused with $2.5 \%$ glutaraldehyde in $0.1 \mathrm{M}$ phosphate buffer, $\mathrm{pH}$ 7.4. For light microscopic analysis, left ventricle tissue was stained with Toluidine Blue. For electron microscopy, the tissue was postfixed in $1 \%$ osmilum tetroxide, dehydrated in $70-100 \%$ ethanol, incubated in propylene oxide, then embedded in Embed 812 resin (Electronic Microscopic Science). Sections were observed and imaged with a Phillips CM 100 electron microscope. Quantitative analysis of mitochondrial size and regions lacking mitochondria were carried out at a magnification of respectively 23800 and 4550 .

\section{MTDNA copy number}

MtDNA content was determined by comparing the ratio of mtDNA (ND1, NADHubiquinone oxidoreductase subunit 1) to nDNA (185 ribosomal RNA) measured in triplo by real-time quantitative PCR (TaqMan(B) using the SYBRB Green PCR Core Reagents (Applied Biosystems). DNA was amplified in a $20 \mu$ volume reaction mixture containing SYBR Green PCR buffer, $4 \mathrm{mM} \mathrm{MgCl} 2,1.25 \mathrm{mM}$ dNTP mix, $0.25 \mathrm{U}$ 
Amperase@UNG, 0.625 U AmpltTaq GoldB DNA Polymerase and 1.25 prot of the forward or reverse primer. PCR conditions were as follows: first, $50^{\circ} \mathrm{C}$ for $2 \mathrm{~min}, 95 \mathrm{C}$ for $10 \mathrm{~min}$, followed by $40 \mathrm{cycles}$ of $95^{\circ} \mathrm{C}$ for $15 \mathrm{sec} / 60^{\circ} \mathrm{C}$ for $1 \mathrm{~min}$. Immediately atter PCR, samples were heated to $95^{\circ} \mathrm{C}$ for $15 \mathrm{sec}, 60^{\circ} \mathrm{C}$ for $1 \mathrm{~min}$, and then heated to $95^{\circ} \mathrm{C}$ in $20 \mathrm{~min}$, followed by cooling to $4^{\circ} \mathrm{C}$, to create a dissociation curve to check for nonspecific amplification. Primers used for amplification are shown in table 1.

Table 1. Primers used for gene expression studies and determination of mitochondrial IDNA content

\begin{tabular}{|c|c|c|c|}
\hline Gene: & Lengtit: & Siequence Forward primer & Sequence Reverse primer \\
\hline NDI & $184 \mathrm{bp}$ & $5^{*}$ “CAGGATGACCCTCAAACTCC $-3^{\prime}$ & 5'GGTCAGGCTGGCAGAAGTAA-3' \\
\hline $\mathrm{ND2}$ & 204 bp & 5"-AGGGATCCCACTGCACATAC-3" & $5^{\circ}$-CCTATGTGGGCAATTGATGA- $3^{\circ}$ \\
\hline Cytb & $200 \mathrm{bp}$ & $5^{\prime \prime}$-ACGTCCTICCATCAGGACAA-3" & $5^{3}$-GAGGTGAACGATTGCTAGGG-3: \\
\hline Coll & $172 \mathrm{bp}$ & $5^{\circ}$-ACGAAATCAACAACCCCGTA-3' & 5-GGCAGAACGACTCGGTIATC-3" \\
\hline ATPG & $79 \mathrm{bp}$ & 5"-AATTACACGCTTCCGACACAAAC-3" & 5.TGGAATTAGTGAAATTGGAGTICCT-3" \\
\hline SDHC & $69 \mathrm{bp}$ & 5'ACAAATGGTCTCTTCCTATGGCA-3' & $5^{\circ}$-CCCCTCCACTCAAGGCTATTC-3" \\
\hline Coxsa & $72 \mathrm{bp}$ & 5'-CTTTAAATGAATTGGCAATCTCCAC- $3:$ & 5"-GCCCATCOAAGGGAGTTACA 3" \\
\hline Tfam & 204 bp & 5'-GTCCATAGGCACCGTATTGC-3' & $5^{\prime}$-CCCATGCTGGAAAAACACTT-3' \\
\hline PGC-1a & $198 \mathrm{bp}$ & 5"-CAATGAATGCAGCGOTCTTA-3" & 5"GTGTGAGGAGGGTCATCGTI-3" \\
\hline ANT1 & $71 \mathrm{bp}$ & 5'-ACTTCGCCTTCAAAGACAAGTACA-3" & 5“GCGCCALAACTGCTTATGG' \\
\hline Cycllophilin & $71 \mathrm{bp}$ & 5"-CAAATGCTGGACCAAACACAA-3" & 5"-GCCATCCAGCCATTCAGICT-3' \\
\hline 185 rRNA & $61 \mathrm{bp}$ & 5'-TCGAGGCCCTGTAATTGGAA-3' & $5^{\prime}$-CCCICCAATGGATCCTCGT-3' \\
\hline
\end{tabular}

Mitochondrial primers are based on accession AB04.2432 (muls musculus mEDNA), 5DHC on accession NM 007747, Cox5a ony NM_025321, Ifam on NM_009360, PGC-1.a on NM_008904, ANT1 on XM_134169, Cycloptillin on NM_o08907 and 185 IRNA on X00686.

\section{Gene expression}

Total left ventricular RNA was isolated using the TRIzol reagent (Invitrogen) and purified with the RNeasy clean-up kit (Qiagen). Reverse transcription into cDNA was performed in a $40 \mu \mathrm{l}$ volume with $1.25 \mu \mathrm{g}$ total RNA as a template. After denaturing the RNA at $65^{\circ} \mathrm{C}$ for $10 \mathrm{~min}$, a reaction mixture containing first strand buffer, $1.25 \mathrm{mM}$ dNTPs, 200 U Superscript II (Invitrogen), RNAsin and a mixture of $0.75 \mu \mathrm{g}$ oligo(DT) primer and $0.75 \mu \mathrm{g}$ random primers (Invitrogen) was added and incubated for $1 \mathrm{hr}$ at $42^{\circ} \mathrm{C}$ followed by 5 min at $95^{\circ} \mathrm{C}$. Primers were created using Primer Express software (Applied Biosystems). Sequences are presented in table 1. Analysis of gene expression was performed in duplo by real-time quantitative PCR (TaqMan(B)), using the SYBR(B) Green PCR Core Reagents (Applied Biosystems). Real-time PCR conditions for the amplification of CDNA were the same as described for the mIDNA copy number study. Transcription values were normalized to the housekeeping gene cyclophilin. 


\section{Statistical analysis real-time PCR data}

The data collected was modeled using the Gaussian distribution. The inference criterion used for comparing the models is their ability to fit the observed data, i.e. models are compared directly through their minimized minus log-likelihood. When the numbers of parameters in models differ, they are penalized by adding the number of estimated parameters, a form of the Akaike information criterion. ${ }^{26}$ All OXPHOS activity models allowed differences between controls and MLP KO mice. The effect of CS activity, protein content and a different variance for each group was included when necessary. In the gene expression study, cyclophilin was included in all models as a housekeeping gene. A difference between control and knockouts (group effect) was also included. For the mtDNA copy number study, the model included the ratio $m+D N A / n D N A$, control/knockouts (group effect), and differences in mtDNA and nDNA within controls and knockouts.

\section{Results}

Mitochondrial content and enzyme activities

Left ventricles of MLP KO mice were enlarged compared to control littermates (data not shown). The total protein content in $\mathrm{mg} / \mathrm{gram}$ muscle was decreased to $75 \%$ of the controls (statistically not significant), whereas CS activity was significantly decreased to $38 \%$ of the controls, suggesting a strong decrease in mitochondrial number. Mitochondrial enzyme activities for complex I, II, IV and V were significantly decreased to respectively $43 \%, 32 \%, 37 \%$ and $30 \%$ of the controls (figure 1). Complex III was decreased to $69 \%$ of the controls, although not statistically significant. After correction for CS in the MLP KO mice, complex activities were comparable with controls, indicating that the mitochondria have normal OXPHOS activities and that the overall decrease in OXPHOS activity is not due to mitochondrial dysfunction and increased production of oxygen radicals.

\section{Microscopic analysis of mitochondria}

Light microscopic analysis of myocardial structure in controls and MLP KO mice showed a decrease in mitochondrial number and revealed several regions totally lacking mitochondria in the knockouts (figure 2B). Additionally, mitochondria appear to be less well organized than in the control hearts. 

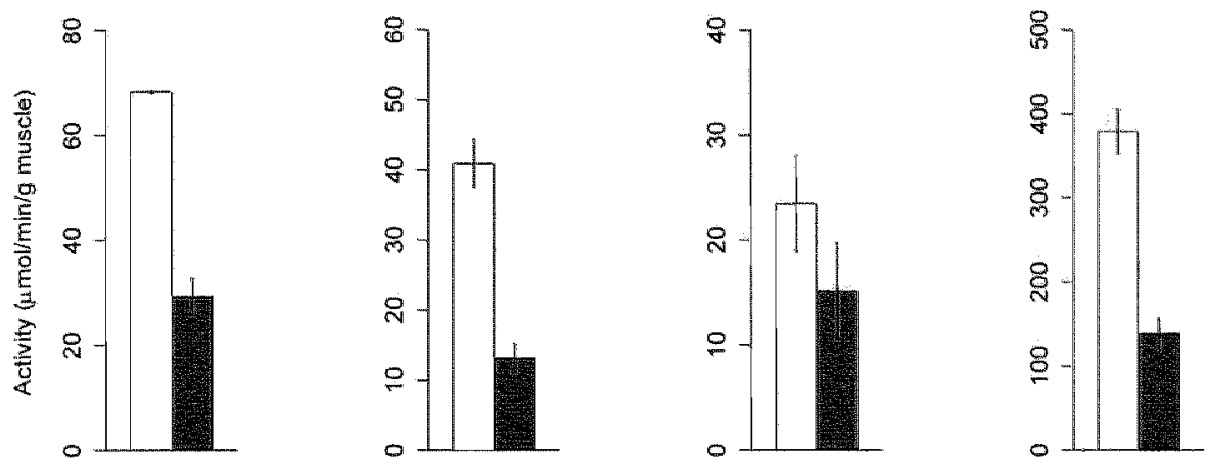

Complex $W$

Citrate synthase

Total protein content
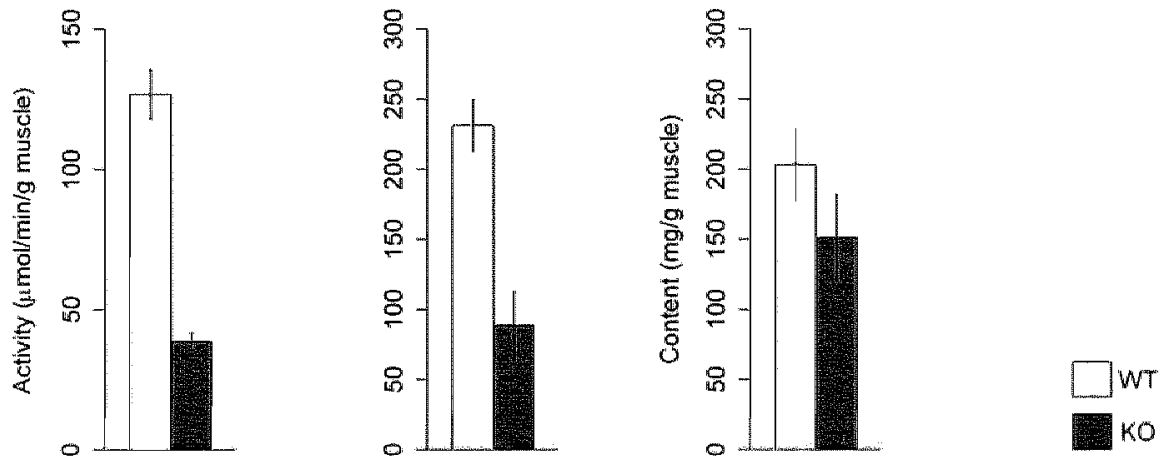

Figure 1. Activities of complex $\|-V$ and citrate synthase (CS) in muscle homogenates from MLP KO and wild-type (WT). All complexes and citrate synthase show decreased activities in the KO mice (n-8) compared to the WT mice $(\mathrm{m}=5)$, ahthough complex lil was mot significant. Protein content ( $\mathrm{mg} / \mathrm{g}$ muscle) is also decreased, but not significant. Data for all activities are expressed as mean absiolute activities in $\mu$ mol/minute/gram muscle ( 5 SD).

Ultrastructural analysis by electron microscopy revealed a disturbed mitochondrial alignment along myofibrils (figure $3 \mathrm{~B}$ and D), although there were also regions present in which the alignment was preserved. Furthermore, the overall size of the mitochondria was significantly decreased in the knockouts compared to controls: 0.48 $\pm 0.04 \mu \mathrm{m} 2$ versus $0.67 \pm 0.07 \mu \mathrm{m} 2$. 

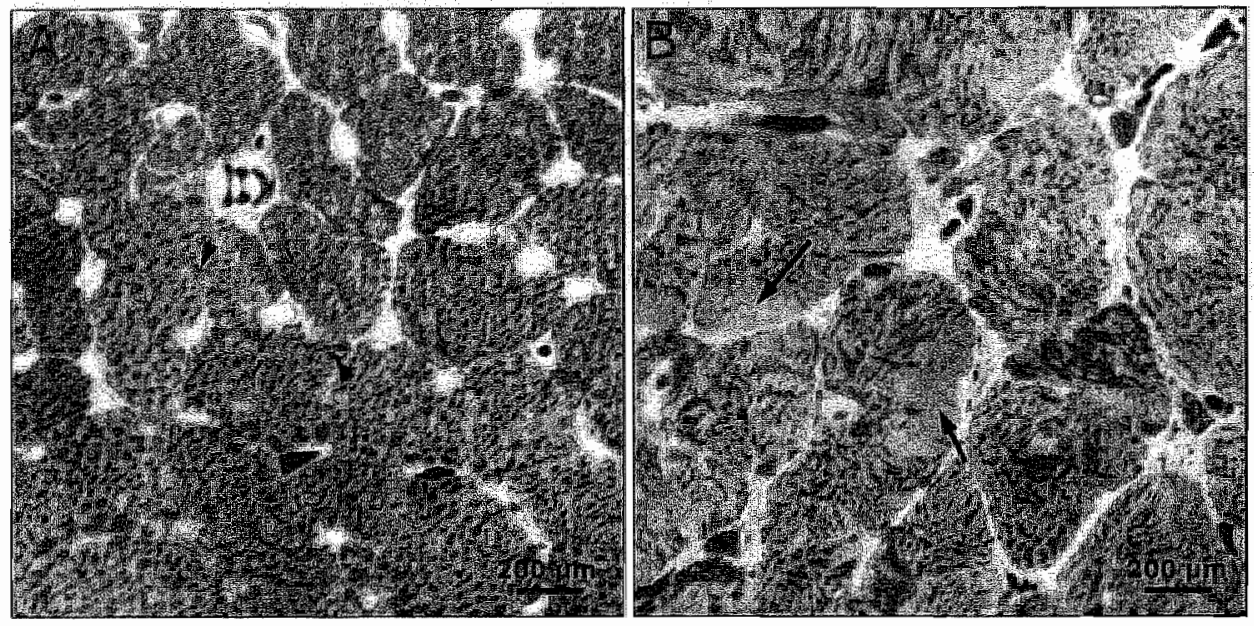

Figure 2. Mitochondrial organization in MLP KO and controls. Transversely sectioned left ventricle tissue from controls (A) and knockouts (B) were stained with Toluidine Blue and observed with a light microscope. The dark spots within cardiomyocytes represent the mitochondria (arrowheads). The mitochondria in the knockouts (B) are less well organized and the cardiomyocytes even show regions lacking mitochondria (airrows). Bar $=200 \mu \mathrm{m}$.

The regional mitochondrial loss was quantified using electron microscopy by comparing 50 healthy cardiomyocytes in the control mice versus 50 cardiomyocytes in the KO mice. Local areas in control cardiomyocytes without mitochondria covered at most $~ 5 \%$ of the total cell area. One third of the cardiomyocytes in the MLP KO mice showed local areas without mitochondria covering at least $\sim 40 \%$ of the total area. The remaining cells showed regions lacking mitochondria of $\sim 10-40 \%$ of the total cell area. Only 5 out of the 50 cardiomyocytes investigated in the MLP KO mice showed similar mitochondrial occupation as in controls, although the disturbed organization was still visible in these cells. The observed OXPHOS deficiency is most likely caused by this local loss of mitochondria.

\section{MTDNA copy number}

To test if the decrease in mitochondrial number in the MLP KO mice is caused by defects in mtDNA replication, we determined the relative mtDNA copy number by comparing the amount of the mitochondrial encoded ND1 gene to the nuclear encoded 185 gene. KO hearts showed an increase in the ratio mtDNA/nDNA by a factor 1.4 compared to control hearts (figure 4). Despite the decrease in the number of mitochondria, the mtDNA content in the knockouts is increased. 

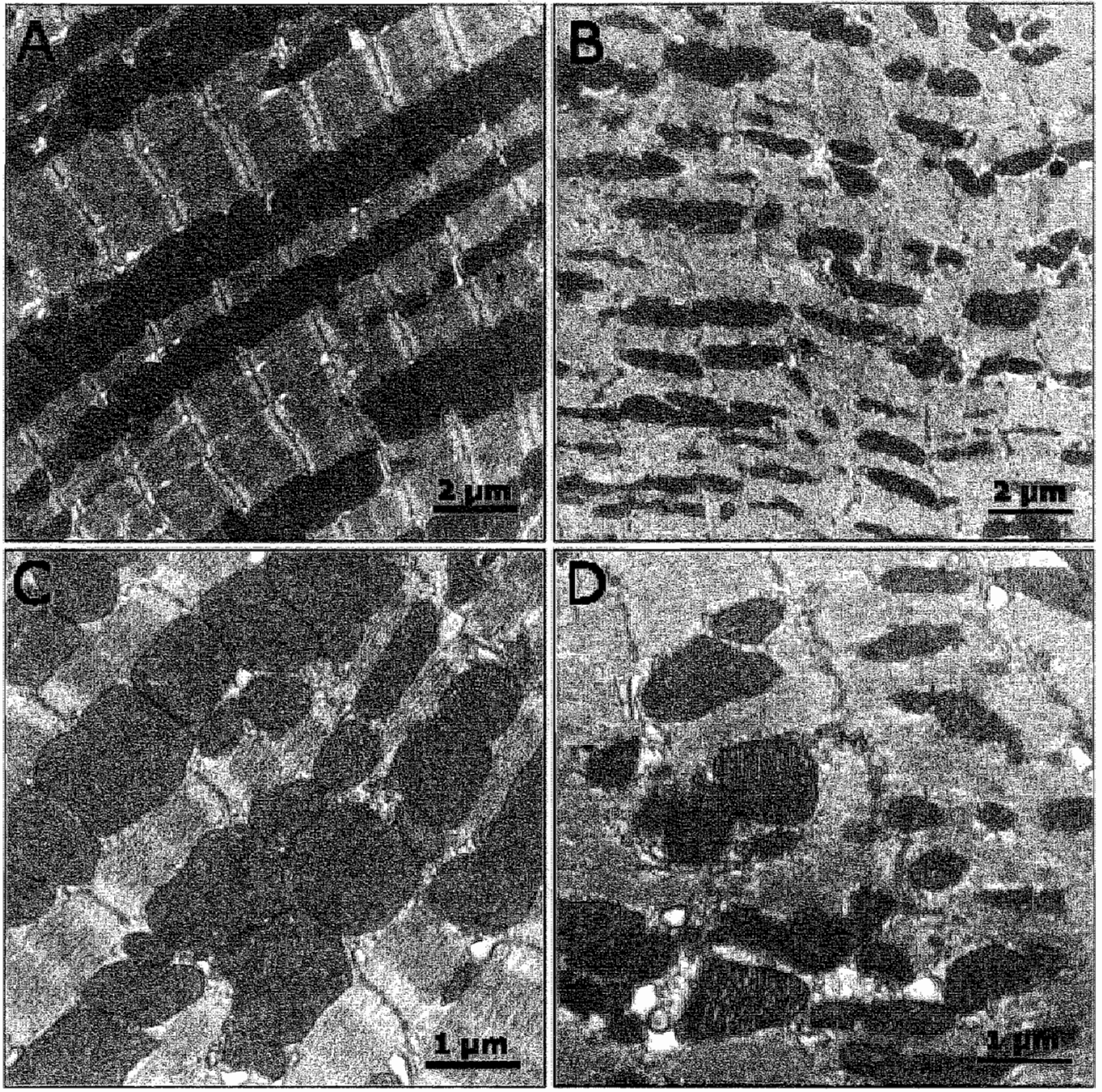

Figure 3. Ultrastructural changes in MLP KO and controls. Electron micrographs represent longitudinally sectioned left wentricles from controls ( $A$ and $C$ ) and knockouts ( $B$ and D). Knockouts reveal a disturbed mitochondrial alignment allong myofibrils and the overall size of the mitochondria is smaller. $B a r=2 \mu \mathrm{m}$ ( $A$ and $B$ ) and 1 fum ( $C$ and D). 


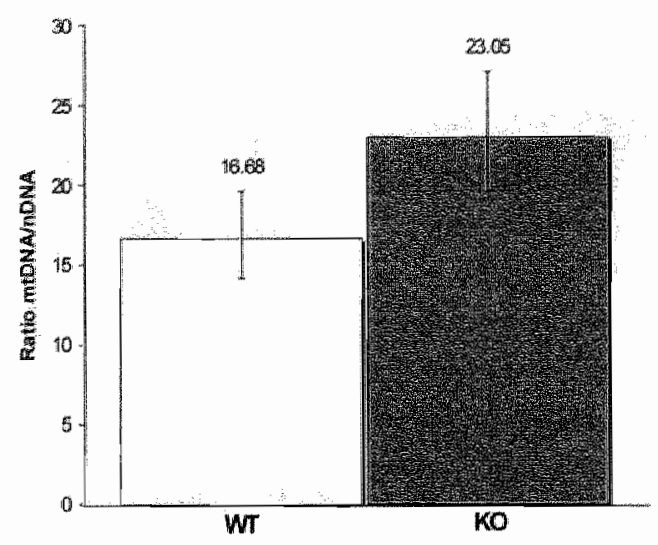

Figure 4. Mitochondrial copy number in MLP KO compared to wild-type (WT). MLP KO mice show an increase in the ratio mLDNA/MONA (ND1/185 rRNA) by a factor 1.4 compared to WT. Measurements were performed by real-time quarititative PCR. Values are presented as fold charige and corresponding confidence intervals.

\section{Gene expression differences}

The decreased mitochondrial content could also be caused by a decrease in mitochondrial protein synthesis. The mitochondrial encoded transcripts for complex!, III, IV and V (NADH-ubiquinone oxidoreductase subunit 2 (ND2), cytochrome b (Cytb), cytochrome $c$ oxidase subunit II (COII) and ATP synthase 6 (ATP6)) were significantly downregulated to $64 \%, 70 \%, 57 \%$ and $73 \%$ of control levels (figure 5 ). Transcript levels of the nuclear encoded mitochondrial genes for complex $\|$ and IV (succinate dehydrogenase $\mathrm{C}$ (SDHC) and cytochrome $\mathrm{c}$ oxidase subunit 5a (Cox5a)) showed a significant decrease to $61 \%$ and $69 \%$ of the controls. Key regulators of mtDNA transcription and regulation, such as mitochondrial transcription factor A (Tfam), peroxisome proliferator activated receptor gamma co-activator 1 (PGC-1 $\alpha$ ) and adenine nucleotide transporter 1 (ANT1) transcripts were also significantly downregulated to respectively $77 \%, 67 \%$ and $55 \%$ of the controls.

\section{Discussion}

In this study we investigated the role of mitochondria and mitochondrial functioning in the MLP KO mouse model. Our results demonstrate an energy deficiency in the myocardium of the MLP KO mice, as indicated by a decrease in overall mitochondrial OXPHOS activity. This is most likely caused by a regional absence of mitochondria in the myocardium of the MLP KO mice. 


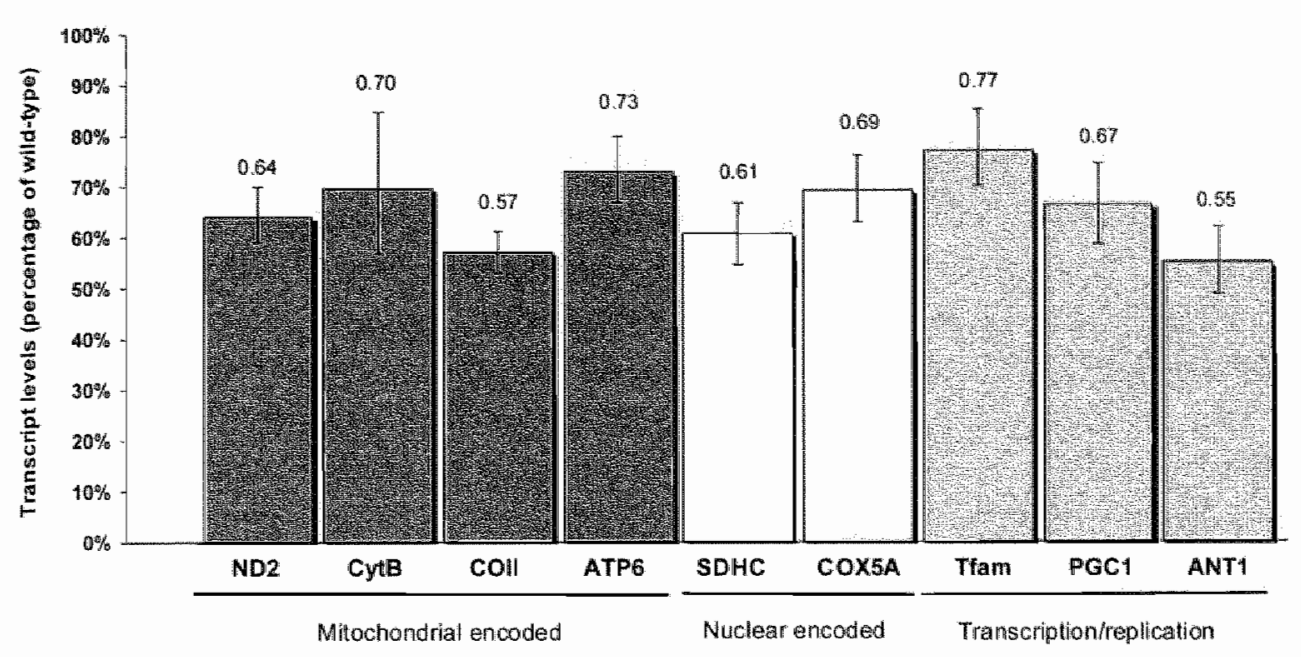

Figure 5. Gene expression data in MLP KO relative to wild-type milce. MLP KO mice show a downregulation of mitochondrial and nuclear encoded transcripts and key regulators of mitochondrilal biogenesis. Transcilipt levels are given as the percentage of will-type (fold change and confidence interval). Values are notmalized to cyclophilin transeription.

Also, the overall size of mitochondria is smaller, although OXPHOS activity per mitochondrion is normal, as indicated by normalization of OXPHOS activities after correction for mitochondrial density. The absence of mitochondria is associated with a downregulation of mitochondrial and nuclear encoded transcripts, indicating a decreased mitochondrial biogenesis. This is corroborated by a downregulation of key regulators of this process, like Tfam, PGC-10 and ANT1. The decrease of Tfam transcripts contrasts with the observed increase in mLDNA content, which may be reminiscent of an initial, physiological increase in mtDNA due to an increased energy demand.

The absence of MLP leads to disorganization of the Z-lines and myofibrils. ${ }^{16}$ The Z-disc is involved in sarcomeric organization, force generation and transmission and acts as an interface between contractile proteins, other cytoskeletal elements and signaling molecules. ${ }^{27.28}$ Muscle mitochondria are present as laterally aligned strands between myofibrils and known to be anchored to the intermediate filament (IF) network of the $Z$-line. The cytoskeleton defects may influence mitochondrial number and function through alterations in the interactions between outer mitochondrial membrane 
proteins and specific cytoskeleton(-associated) proteins. ${ }^{29}$ The integrity of these contact sites $^{30}$ and the associated functional complexes with sarcomeres and sarcoplasmic reticulum (i.e. ICEUs, intracellular energetic units) are important for a variety of mitochondrial functions, such as energy coupling and oxidative metabolism. ${ }^{31.34}$ An increased energy demand usually results in activation of PGC-1 $\alpha$, the key regulator of mitochondrial biogenesis and gene expression in heart and other tissues. ${ }^{35.36}$ It can be expected that loss of proper alignment of mitochondria, as shown in the MLP KO mice, probably in combination with mechanical stretch, results in mitochondrial loss and in interference with the compensatory mechanisms that need to increase energy production to maintain cardiac function, including efficient energy transfer from mitochondria to sites of energy utilization. ${ }^{37}$ Since individual mitochondria were found to still function properly, an excess of free oxygen radicals seems unlikely to have contributed to the deterioration of cardiac function in this stage, which constitutes further support for our hypothesis.

Phospholamban (PLB) ablation ${ }^{38}$ or inhibition of $\beta$-adrenergic receptor kinase ( $\left.\beta A R K 1\right)^{39}$ have been shown to prevent the cardiomyopathic phenotype in the MLP mice. One explanation for the rescue of the MLP phenotype is that the enhanced cardiac relaxation leads to the elimination of the mechanical stretch stimulus. This results in a restoration of the defect in the stretch sensor function, which in normal hearts activates compensatory cardiomyocyte survival and hypertrophy downstream signals. ${ }^{17}$ However, an alternative explanation could be that the cardiac energy status will be recovered by improving the interaction between the cytoskeleton and the mitochondria. This could be tested by evaluation of mitochondria, mitochondrial function and biogenesis in the double MLP/PLB KO mice and MLP KO/ $\beta A R K c t$ mice.

The role of energy imbalance and mitochondrial abnormalities has been implicated in several studies, where mutations in mtDNA or mitochondrial genes have been described in heart failure. ${ }^{6}$ Also, AMP-activated protein kinase (AMPK) mutations were found to result in skeletal and cardiac disease. ${ }^{37,40}$ AMPK regulates expression of both CaMKIV (calcium/calmodulin-dependent protein kinase IV) and PCC-1 $\alpha .{ }^{41}$ Human MLP mutations ${ }^{17-19}$ and the telethonin (T-cap) and $\alpha$-actinin mutations, both disrupting the stable complex with $M L^{17.18}$, lead to $D C M$, presumably by the same mechanism. It would be interesting to test if the transition to heart failure in these patients is due to a defective stretch sensor accompanied by increased wall stress, a defect in energy supply or a combination of these factors. 
In summary, our findings indicate a direct link between cytoskeletal defects and local energy deficiency in affected hearts of the MLP KO mice. Treatment ailmed at recovery of energy depletion might be useful in escaping the vicious cycle of energy mismatch. Furthermore, stimulation of the transcriptional cascades involved in mitochondrial biogenesis may also be an approach for increasing myocardial energetics.

\section{Acknowledgements}

We would like to thank $H$. Roberts and $\mathrm{H}$. Duimel for their assistance in the electron microscopy studies and Prof. P. van Doorn for his additional practical assistance. Dr. F. Verheyen, Prof. M. Borgers and Dr. G. van Eys are acknowledged for their help with the interpiretation of the light and electron microscopy results. This research was supported by the Netherlands Heart Foundation (99.122) and the Cardiovascular Research Institute Maastricht (CARIM), The Netherlands.

\section{References}

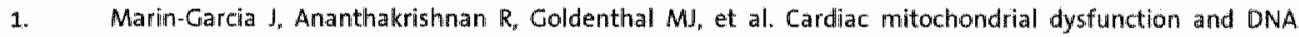
depletion in children with hypertrophic cardiomyopathy. J inherit Metab Dis. 1997;20:674-6i80.

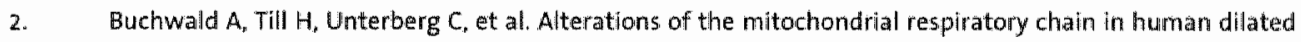
cardiomyopathy. Eur Heart l. 1990;11:509-516.

3. Marin-Carcia J, Goldenthal MJ, Pierpont ME, et al. Impaired mitochondrial function in idiopathic dilated cardiomyopathy: biochemical and molecular analysis. $J$ Card foil. 1995;1:285-291.

4. Santorelli FM, Tessa A, D'Amati $G$, et al. The emerging concept of mitochondrial cardiomyopathies. Am Heart J. 2001;141:E1.

5. Bornstein $B_{n}$ Hluertas $R$, Ochoa $P$, et al. Mitochondrial gene expression and respiratory enzyme activitires in cardiac diseases. Biochim Biophys Acta. 1998;1406:85:90.

6. Marin Garcia 3, Goldenthal MI. Understanding the impact of mitochondrial defects in cardiovascular disea se: a review. 1 Card Faill. $2002 ; 8: 347-361$.

7. Jarreta D, Orus J, Barrientos $A$, et al Mitochondrial function in heart muscle from patients with idiopathic dilated cardiomyopathy. Cardiowasc Res. 2000;45:860-865.

8. Sharow WG, Todor AV, Silveriman N, et al. Abnormal mitochondrial respiration in failed human myocardium. J Mal Cell Cardiol. 2000;32:2361-2367.

9. Marcelis $C$, Doevendans PA, Bonne $G$. Dillated Cardiomyopathy. In: Doevendans. PA, Wilde AA, eds. Cardiovascular Genetics for Clinicians. Dordrecht, The Netheriands: Kluwer Academic Publishers; 2001:155. 168.

10. Che $G$, Haghighi $K$, Kranias $E G$. From mouse to man: understanding heart failure through genetically altered moulse modells. J Card Fail. 2002;8:5432 -449.

11. Miliner DJ, Mavroidis $M$, Weisleder $N$, et al Desmin cytoskeleton linked to musclle mitochondrial distribution and respiratory function. I Cell Biol. 2000,150:1283-1298.

12. Dalpe $G$, Mathieu $M$, Comtois $A$, et al. Dystonin-deficient mice exhibit anintrinsic muscle weakness and an instability of skeletal muscle cytoarchitecture. Dev Biol. 1999;210:367-380.

13. Reipert 5, Steinbock F, fischer I, et al. Association of mitochondria with plectin and desmin intermediate fillaments in striated muscle. Exp Cell Res. 1999:252:479*491. 
14. Chen YW, Zhao P. Borup et al Expression profiling in the muscular dystrophies: identification of novel aisperts of molecullar pathophysiology. CeN B ol. 2000,151:1321-1336.

15. Reimann I, Kunz WS, Vielhaber 5 , at. Mitochondrial dysfunction in myofibrillar myopathy. Neuropathol Appl Neurobiol 2003;29:45*51.

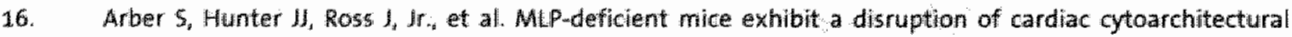
organization, dilated cardiomyopathy, and heart failure. Cell. 1997;88:393-403.

17. Knoll $\mathrm{R}_{v}$ Hoshifima $M_{s}$ Hoffman $H M_{\text {, }}$ et al. The cardiac mechanical stretch sensor machinery involves a $Z$ disc complex that is defective in a subset of human dillated cardiomyopathy. Cell, $2002 ; 111 ; 943-955$.

18. Nohapatra $\mathrm{B}$, Jimenez $S$, Lin $J H$, et all. Mutations in the muscle LIM protein and alpha-actinin-2 genes in dilated cardiomyopathy and endocardial fibroelastosis. Mal Genet Metob. 2003;80:207-215.

19. Weler $C_{*}$ Perrot $A$, Ozcelik $C$, et al. Mutations in the human muscle LM protein gene in families with hypertrophic cardiomyopathy. Circulation. 2003,107:1390-1395.

20. Srere PA. Citrate synthase. In: Lowenstein $\mathrm{IM}_{\mathrm{x}}$ ed. Methods in enzymology, citric acid oyde. New York: Academic Press: 1969:3-11.

21. Lowry OH, Rosebrough NJ, Farr $\mathrm{AL}_{v}$ et al. Protein measurement with the Folin phenol reagent. 1 Biol Chem. $1.951 ; 193: 265-275$.

22. Scholte HR, Busch HF, Luyt-Houwem IE, et al. Defects in oxidative phosphorylation. Biochemical invertigations in skeletal muscle and expression of the lesion in other cells. $J$ inherit Metab Dis. 1987;10 Suppl $1.81-97$.

23. Rustin $P$, Chretien D, Bourgeron $T_{x}$ et al. Biochemical and molecular investigations in respiratory chain deficiencies. Clin Chim Acta. 1994:228:35-51.

24. Scholte HR, Busch HFM, Bakker HD, et al. Riboflavin-responsive complex I deficiency Brochim Biophys Acta. $1995 ; 271775-83$.

25. Trounce $\|$ A, Kim $Y L$, Jun AS, et al, Assessment of mitochondrial oxidative phosphorylation in patient muscle biopsies, lymphoblasts, and transimitochondriall cell lines. Method's Enzymol, 1996;264:484-509.

26. Akaike H. Information theory and an extension of the maximum likelihood principle. In: Petrov BN, Csàki $\mathbb{F}$, eds. Second intemational Symposium on inference Theory. Budapest: Akademiai Kiado; 1973:267-281.

27. Clark KA, MCElhinny AS, Beckerle MC, et al. Striated muscle cytoarchitecture; an intricate web of form and function. Annu Rev Cell Dev Biol. 2002:18:637-706.

28. Ervasti JM. Costameres: the Achilles" heel of Herculean muscle. J Eiol Chem. 2003:278:13591-13594.

29. Rappapoit IL, Oliviero P, Samuel J. Cytoskeleton and mitochondrial morphology and function. Mol Cell Biochem. 1998:184:101-105.

30. Capetanaki $Y$. Desmin cytoskeletom: potential regulator of muscle mitochondrial behavior and function. Trends Cardiovasc Med. 2002;12:339-348.

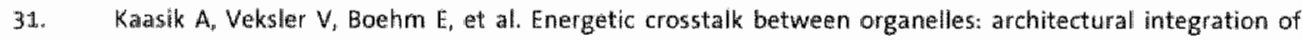
energy production and withlation. Cinc Res. 200:1;89:253-159.

32. Appaix F, Kuznetsov AV, Usson $Y$, et al. Possible role of cytoskeleton in Intracellular arrangement and ragulation of initochondria. Exp Physiol. 2003;88:175-190.

33. Weisleder $N$, Taffet GE, Capetanaki $Y$. BC-2 overexpression corrects rnitochondrial defects and ameliorates inherited desmin null cardiomyopathy. Proc Natl Acad Sci U S.A. 2004;101:769-774.

3.4. Jacobson J, Duchen MR. Interplay between mitochondirian and cellular calcium signalling. Mor Cell Biochem. 2004:256-257:209-218.

35. Wu Z, Puigsenver P, Andersson U, et al. Mechamisms controlling mutochondirial biogenesis and respiration through the thermogenic coactivator $P G C_{-1}$. Cell. 1999:98:115-12.4.

36. Lehmar J., Barger PM, Kovacs $A$, et al. Peroxisome proliferator-activated receptor gamma coactivator-1 promotes cardiac mitachondrial biogenesis J Clin Inwest. 2000;106:847-856.

37. Ventura-Clapier $R$, Garnier $A$, Veksler $V$. Energy metabolism in heart failure. J Physiol. 2004;55:5:1-13.

38. Minamisawa S, Hoshijima M, Chu G, et al. Chronic phospholamban-sarcoplasmic reticulum calcilum ATPase interaction is the critical calcium cycling defect in dilated cardiomyopathy cell. 1999:99:313-322. 


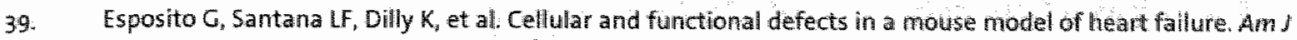
Physiol Heart Circ Physial. 2000;279:43101-3112.

40: Ashrafiam H, Redwood $C_{n}$ Blair $E_{2}$ et al. Hypertiophic cardiomyopativy paradigm for nyocandial energy depletion. Trends Genet. 2003;19:263-268.

4. Zong $H$, Ren .M, Young $\mathrm{LH}$, et al. AMP kinase is required for mitochondrat biogenesis in skeletal musie in response to chronic energy deprivation. Proc Nath Acad Sci U S A. 2002;99:15983-15987. 



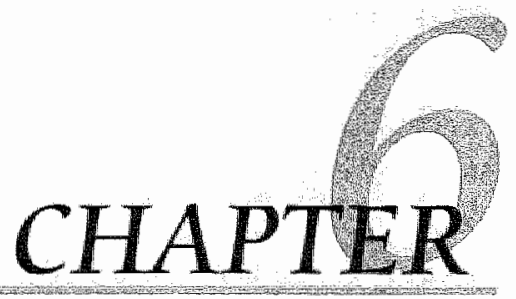

\section{Methods in molecular cardiology: microarray technology}

B. van den Bosch ${ }^{1}$, P.A. Doevendans ${ }^{2,3}$, D. Lips ${ }^{2}$, H.J.M. Smeets ${ }^{1}$

"Cardiowascular Research Institute Maastricht (CARIM), Dept. of Genetics \& Cell Biology, Maastricht University, The Netherlands

" Dept of Cardiology of the Heant Lung Centre Utrectht (UMCU), The Netherlands

* Interuniversity Cardiology Institute of the Netherlands (ICIN), Utrecht, The Netherlands

Netherlands Heart Joumal 2003;11 (5):213-220 


\section{Abstract}

It has become more and more evident that changes in expression levels of genes can play an important role in cardiovascular diseases. Specific gene expression profiles may explain, for example, the pathophysiology of myocardial hypertrophy and pump failure and may provide clues for therapeutic interventions. Knowledge of gene expression patterns can also be applied for diagnostic and prognostic purposes, in which differences in gene activity can be used for classification. DNA microarray technology has become the method of choice to simultaneously study the expression of many different genes in a single assay. Each microarray contains many thousands of different DNA sequences attached to a glass slide. The amount of messenger RNA, which is a measure of gene activity, is compared for each gene on the microarray by labeling the mRNA with different fluorescently labeled nucleotides (Cy3 or Cy5) for the test and reference samples. After hybridization to the microarray the relative amounts of a particular gene transcript in the two samples can be determined by measuring the signal intensities for the fluorescent groups ( $\mathrm{Cy} 3$ and $\mathrm{Cy} 5$ ) and calculating signal ratios. This paper describes the development of in-house microarray technology, using commercially available cDNA collections. Several technical approaches will be compared and an overview of the pitfalls and possibilities will be presented. The technology will be explained in the context of our project to determine gene expression differences between normal, hypertrophic and failing heart.

\section{Introduction}

Genes encoded in the DNA are transcribed into messenger RNA (mRNA), which is then translated into functional proteins (figure 1). ${ }^{1}$ Microarrays detect gene expression (mRNA expression) levels by measuring the hybridization of mRNA present in the tissue of interest to many thousands of genes immobilized on a glass surface (the array). Each single spot on the microarray represents a different gene. The double stranded DNA has to be single stranded when deposited on the slides. In this way, the single-stranded DNA on the array is able to bind to complementary CDNA, to which the mRNA is converted. Both the test and reference MRNA samples are reverse transcribed into CDNA using oligo(dT) priming and fluorescently labeled nucleotides are incorporated. The labeled CDNAs are then mixed together and hybridized to the microarray. After washing, the microarray is scanned to determine the amount of fluorescence for each spotted gene. Since we know which gene each spot represents, and the CDNA (representing the mRNA) only hybridizes to the gene that encodes it, we can determine the expression level of every individual gene. The fluorescence at each 
spot thus represents the expression level of the particular gene. Because one probe is labeled with Cy3 (emits green fluorescence at $532 \mathrm{~nm}$ ) and the other is labeled with Cy5 (emits red fluorescence at $635 \mathrm{~mm}$ ), quantitative comparison of gene expression in both samples is possible. The ratio of Cy5 signal to Cy3 signal can be calculated for each spot on the array and indicates the ratio of gene expression (figure 2$)^{1}$

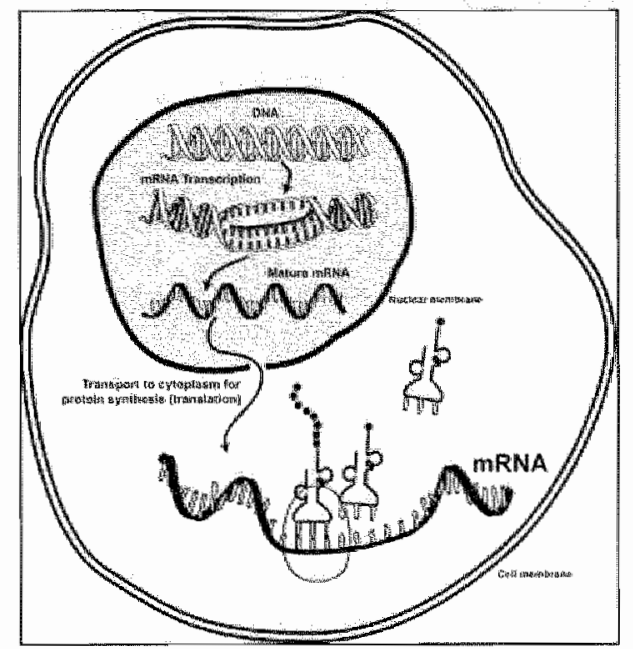

Figure 1. Transcription of DNA into MRNA and translation into proteins. Since we know which gene each spot represents, and the CDNA (representing the mRNA) only hybridizes to the gene that encodes it, we cam determine the expression llevel of every indiwidual gene. The fluorescence at each spot thus represents the expression level of the particular gene. Because one probe is labeled with cy3 (emits green fluorescence at 532 nm) and the other is labeled with Cy5(emits red fluorescence at $635 \mathrm{~nm}$ ), quantitative comparison of gene expression in both samples is. possible. Adapted from "Access Excellence foe the National Heath Museum".

\section{Manufacturing of DNA microarrays}

A number of techniques have been developed for manufacturing DNA microarrays. One of the approaches is called DNA micro-dispensing. Small quantities of DNA solution (with a volume of approximately 50 pl) are dispensed onto a solid surface. Products can be spotted onto the slides using pins, pins and rings, or split pins. The pinand-ring system (figure $3 a)^{2}$ consists of an open ring with a pin centered above. When the ring is dipped into the solution and lifted, it withdraws an aliquot of DNA solution. To spot the sample, the pin is driven through the ring and $50 \mathrm{pl}$ of product is deposited onto the slides. Another way of dispensing the DNA onto the slide is using "split" pins (figure $3 b)^{3}$ which are capable of a multidispensing mode of operation. The sample is 
transferred passively by surface tension as the pin tip touches the slide surface. There are different kinds of robotic systems for microarraying available. ${ }^{4}$ The Affymetrix Genetic Microsystems (GMS) 417 arrayer uses the pin-and-ring system, while the MicroGrid II (Biorobotics) can use the split-pin system.

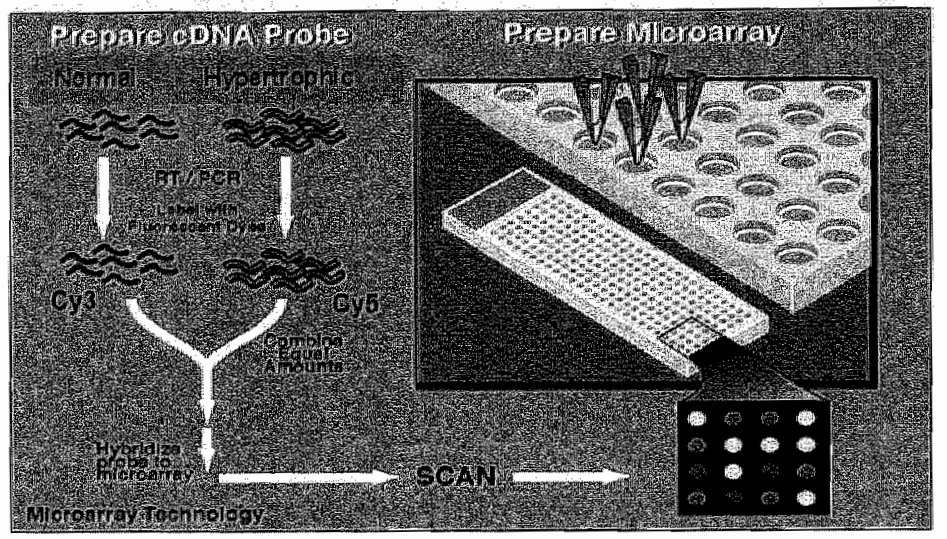

Figure 2. Principle of microarray technology. cDNA probes are prepared by reverse transcription of mRNA samples to CDNA with fluorescently labeled nucleotides (Cy3/Cy5). After hybridization, slides are scanned and signal intersities for the fluorescent growps are measured. The ratio of cys signal to cy 3 signal is calculated for each spot on the array, ind icating the ratio of gene expression between normal and hypertrophic tissue for that gene. Adapted from "Access Excellence @ the National Health Museum".

DNA molecules can be spotted onto different kinds of glass surfaces (Telechem, poly-Llysine [Sigma], aminosilane coated [Sigma, Corning]). Poly-L-lysinecoated slides are commonly used in combination with high-salt buffers, such as $3 \times 55 C$, (saline sodium citrate), as a printing solution. Nowadays, aminosilane-coated glass slides are most commonly used, offering a more consistent surface with lower background fluorescence. CMT-GAPS-aminosilane-coated glass slides (Corning, NY, US) have been shown to give the most consistent results. ${ }^{4} \mathrm{~A}$ variety of spotting solutions have been investigated to determine which would give the best results after hybridization. Highest signal intensities were achieved with $50 \%$ dimethyl sulphoxide (DMSO) as a printing solution. DMSO as a printing buffer has the additional advantage that the polymerase chain reaction ( $\mathrm{PCR}$ ) fragments are denatured better, that evaporation is slower and that spot morphology is improved compared with $3 \times 5 S C .{ }^{4}$ Parameters such as temperature and humidity need to be carefully controlled. Changes have a significant impact on the size and spot morphology and the efficiency of DNA binding to the slides. Best results were obtained by spotting at about $23^{\circ} \mathrm{C}$ and 40 to $45 \%$ 
humidity. ${ }^{4}$ Attachment to the glass surface was achieved by baking at $80^{\circ} \mathrm{C}$ for four hours.
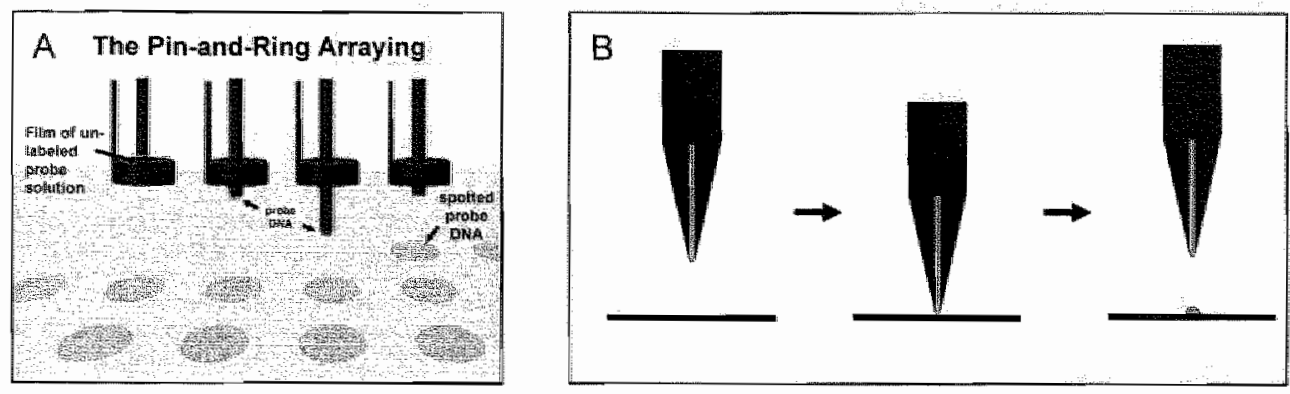

Figure 3. Two ways of depositing DNA solutions onto a glass slide. A: The pin picks up the DNA solution and by driving the pin through the ring, the DNA is deposited onto the slides. B: "Split" pins transfer the sample passively by surface tension as the pin tip touches the slide surface. Modified from "Anatomisches linstitut Tübingen".

The way genes are spotted, the use of positive and negative controls and number of replicates require a carefully designed experiment to allow optimal statistical analysis of the data generated. Many commercially available cDNA clone collections have the disadvantage of being incomplete and of poor quality. This means that to be sure about which gene has been spotted, either all clones have to be sequenced before spotting or additional experiments have to be performed to validate the results. It is, however, obvious that the quality of a cDNA collection is critical to elucidate genetic pathways. Furthermore, cDNAs are often not completely specific, which may lead to cross hybridization, hampering the detection of gene expression differences. Because of the inherent problems with the cDNA sets used, it is also evident that all results from literature have to be taken with great caution. It is a major advantage of the use of gene specific oligonucleotides that these can be designed in a way that they are unique for that gene. BLAST (Basic Local Alignment Search Tool) ${ }^{5}$, a tool to search for sequence homology, is used for this purpose. Potential cross-hybridization can be determined using this method. Now the human, mouse and many other genome sequences have been characterized, ${ }^{6,7}$ it will be only a matter of time before all genes and corresponding exon sequences are known. Given the limitation of the specificity of the CDNA collections, it can be expected that gene- or even exon-specific oligonucleotides will come into general use. The inclusion of control oligonucleotides allows checking for nonspecific hybridization. Furthermore, no PCR steps are required. However, because of the smaller size, signal intensities and the coverage of the gene are less than for CDNAs which may lead to problems in detecting low copy transcripts. 


\section{Clone preparation}

The cDNA collections are usually present as bacterial cultures with plasmids containing the CDNA. The CDNA inserts can be amplified by PCR from the plasmid DNA or directly from clones in culture. The last method is less labour intensive. After amplification, it is essential that unincorporated nucleotides and primers are removed from the reaction products to prevent high background signals on the slides. Several protocols are available for working up large clone collections. ${ }^{4}$ Two examples of a clone collection are presented in this paper. The first is a tissue-specific collection, consisting of about 4000 murine CDNA clones derived from adult and fetal heart ( $4 \mathrm{k} \mathrm{set})^{8.9}$ and the second is a global collection, consisting of about 15000 murine embryonic clones (15k set). ${ }^{10}$ of the 4000 clones in the $4 \mathrm{k}$ set library, about $12 \%$ did not show a product after PCR amplification and about 30\% showed multiple products (figure 4A), comparable with previous reports. ${ }^{11}$ Adjustments of PCR conditions did not lead to an improvement in the results. Sequence analysis of a number of clones with single bands revealed that the inserts were as expected. As we chose to validate all our differentially expressed genes in an independent assay, we decided to spot all fragments irrespective of the presence of multiple bands per clone. The overall quality of the $15 \mathrm{k}$ set was much better than the $4 \mathrm{k}$ set. And all of these clones were sequence verified. ${ }^{12}$

\section{Isolation and purification of RNA}

Total left ventricle RNA was isolated using the TRIzol protocol (Life Technologies), followed by a quality check using the Bioanalyzer (Agilent). ${ }^{12}$ In this system, the samples were electrophoretically separated on a LabChip using nanotechnology, meaning that very low levels of RNA can be measured, preventing the waste of valuable and often limited patient material. The components (the RNA species) are detected by their fluorescence and translated into gel-like images (bands) (figure 5). The purity and quality of the RNA is of utmost importance when performing gene expression studies. Any quality difference will lead to unwanted differences in gene expression. The RNA should not be degraded and no DNA contamination should be present. Figure 5 shows that the RNA is of good quality. Intact total RNA will have sharp, clear 285 and 185 ribosomal RNA (rRNA) bands (eukaryotic samples). The 285 rRNA band should be approximately twice as intense as the 185 rRNA band. Partially degraded RNA will have a smeared appearance, will lack the sharp rRNA bands, or will not exhibit the 2:1 ratio. Completely degraded RNA will appear as a very low molecular weight smear. 


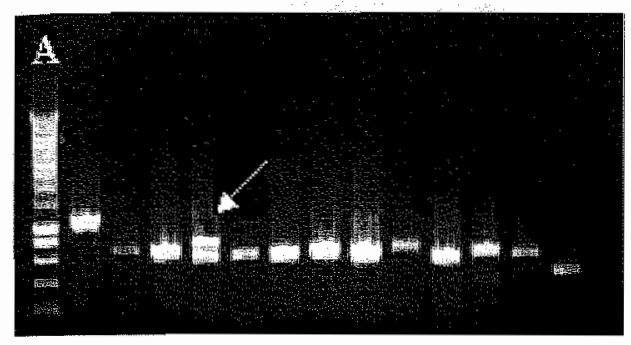

M1 12344567891011121314

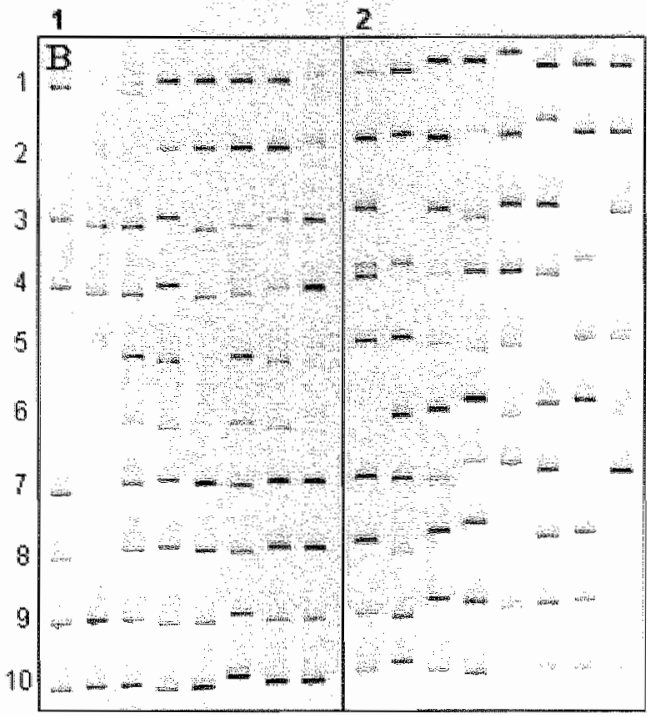

Figure 4. PCR fragments of CDNA clomes. A=Clones from the $4 \mathrm{k}$ set. The total set consists of 40 plates leach containing 96 clones). Products from plate 1 are shown. The products are around 500 bp in size. Hanes 1 to 13 show 13 different cDNA clones; lane 4 contains a contaminated fragment (arrow), mote the differences in PCR efficiency; lane 14 is a negative control; M1 is a molecular weight marker designed for quantification of products and size determination (Eurogentec). The marker produces a pattern of nine regularly spaced bands, ranging from 100 to $1000 \mathrm{bp}$. The 100 and $1000 \mathrm{bp}$ bands have a higher intensity than the others to allow quick and easy identification. $B=C l o n e s$ from the $15 \mathrm{k}$ set. The total set consists of 159 plates (each containing 96 clones). The sizes of the products can vary from 0.5 to $3 \mathrm{~kb}$. Columns. 1 and 2 represent two different plates, of which 80 clones in total are shown here ( 8 clones per horizontal lane). Differences in PCR efficierncy can be observed (lane 1 from plate 1 for example). Also some contaminated fragments are present, containing more than one product, as is indicated by the arrow (plate 2 lane 4 , the first fragment).

\section{Labeling of RNA}

RNA can be fluorescently labeled by direct incorporation of Cy3 and Cy5-labeled deoxycytidine triphosphase (dCTP) nucleotides (NEN) in a first strand CDNA synthesis reaction (RT-PCR, Superscript II RT kit, Life Technologies) or by indirect incorporation of aminoallyl deoxyuridine triphosphates (dUTPS) followed by coupling of the aminoallyl groups to Cy3/Cy5-esters. ${ }^{4}$ Figure 6 shows the principle of the indirect labeling procedure. A comparison between both methods showed that the indirect incorporation had advantages over the direct labeling procedure. 


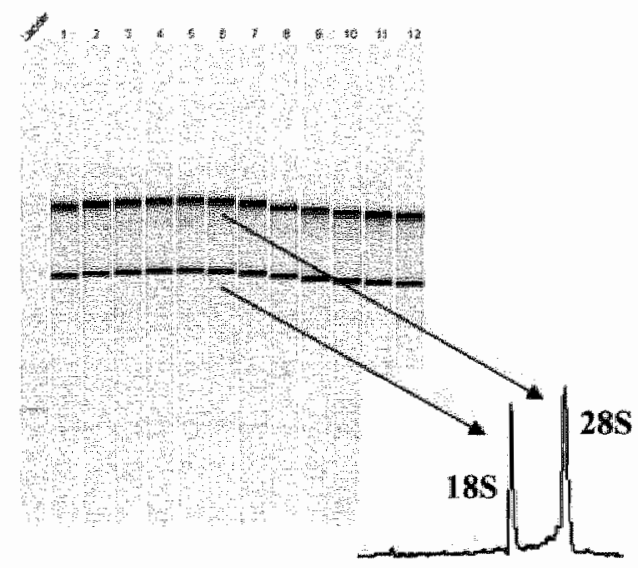

Figure 5. RNA quality check using the Bioanalyzer (Agillent). The two 285 and 185 RNA species are wisible and no degraded fragments are present.

Less starting material was required: $10 \mu \mathrm{g}$ of total RNA in the indirect labeling yields similar signal intensities to $100 \mu \mathrm{g}$ of total RNA in the direct labeling. The indirect labeling procedure also reduced background on the slides by about threefold and is cheaper.

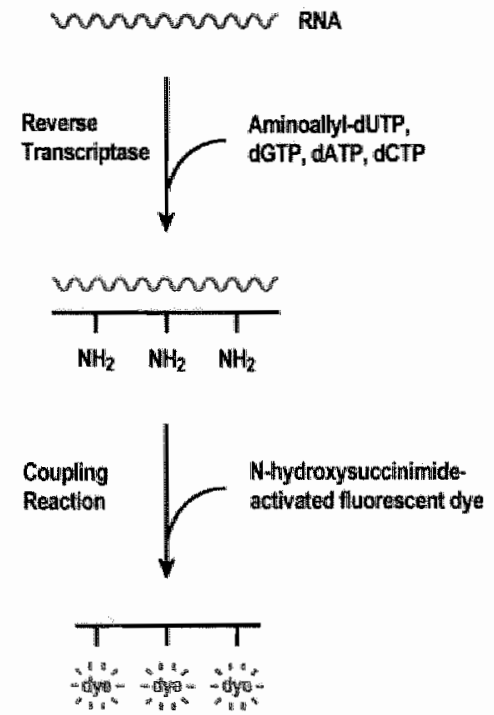

Figure 6. Indinect labeling of cDNA. In the first rournd aminoallyl duTps are incorporated followed by coupling of the aminoallyld dUTPS to Cy3/Cy5-esters. Adapted from Ambion, Inc. 


\section{Prehybridization and hybridization of labeled cDNA to microarray}

Important parameters in the process of hybridization are the hybridization volume, moistness and blocking agents. For each of these parameters, optimal procedures had to be developed. Hybridization of the microarrays was performed according to the updated TIGR (The Institute for Genomic Research) protocol. ${ }^{13}$ The ultimate aim is highly specific and low background fluorescence. Prehybridization is performed to block or inactivate free amine groups on the slide to prevent nonspecific binding of labeled cDNA to the slide. Prehybridization of the microarrays is performed in 5XSSC, $0.1 \%$ sodium dodecyl sulphate (SDS), $1 \%$ bovine serum albumin (BSA) and an end concentration of $50 \%$ formamide. Probe was added in a final concentration of 0.8 $\mu \mathrm{g} / \mathrm{ml}$. Hybridization was performed overnight at $42^{\circ} \mathrm{C}$ in $50 \%$ formamide, $5 \times 5 S \mathrm{C}, 0.1 \%$ SOS.

\section{Washing and scanning of the microarrays}

After hybridization, the slides were washed to remove unbound probe. The slides were washed three times, in $1 \times S S C, 0.2 \%$ SDS for four minutes at $42^{\circ} \mathrm{C}$, in $0.1 \times S S C, 0.2 \%$ SDS for four minutes at room temperature and finally in $0.1 \times S S C$ for four minutes at room temperature. After washing, microarrays were scanned to quantify the signal intensity of the probe bound to the CDNA targets. Data from each fluorescence channel were collected and stored as an image. Because both RNA samples in the experiment were labeled with a different fluorescent group (Cy5 and Cy3 respectively), direct quantitative comparison of gene expression between the two samples is possible. All experiments were performed in triplicate. To correct for a possible confounding effect of dye incorporation (a difference in labeling efficiency between Cy5 and Cy3), 'flip-dye' experiments should be performed, in which one sample is labeled with Cy5 in one experiment and with Cy 3 in the other experiment.

\section{Image processing and data analysis}

The image and spot intensities can be analyzed with image-processing software packages. ${ }^{13-17}$ Figure 7 shows a hybridization image of a $4 \mathrm{k}$ mouse microarray. First, the spots on the microarray have to be identified and distinguished from other signals that are not created by specific hybridization to the DNA on the array, for example hybridization artefacts or dust on the glass surface. The second step is the estimation of the background. The best way to do this is to calculate the local background for each spot ${ }^{4}$ and correct each spot for the local background. Next, the data were normalized 
in both channels to correct for differences in labeling, differences in starting RNA from the two samples and detection efficiencies for the fluorescent labels. ${ }^{4}$ There are different normalization strategies possible to determine the normalization factor. The total fluorescence can be used assuming that the total amount of RNA labeled with Cy5 and Cy3 is equal. Over thousands of spots, possible fluctuations should average out." A number of controls, in which it is known that the expression is equal in both samples (so-called housekeeping genes), should be added to the array. Finally, the differentially expressed genes are characterized. The ratio of Cy5 signal to Cy3 signal is calculated for each spot on the array and indicates the relative ratio of gene expression. Usually a twofold up-or down-regulation is considered significant to define differentially expressed genes."

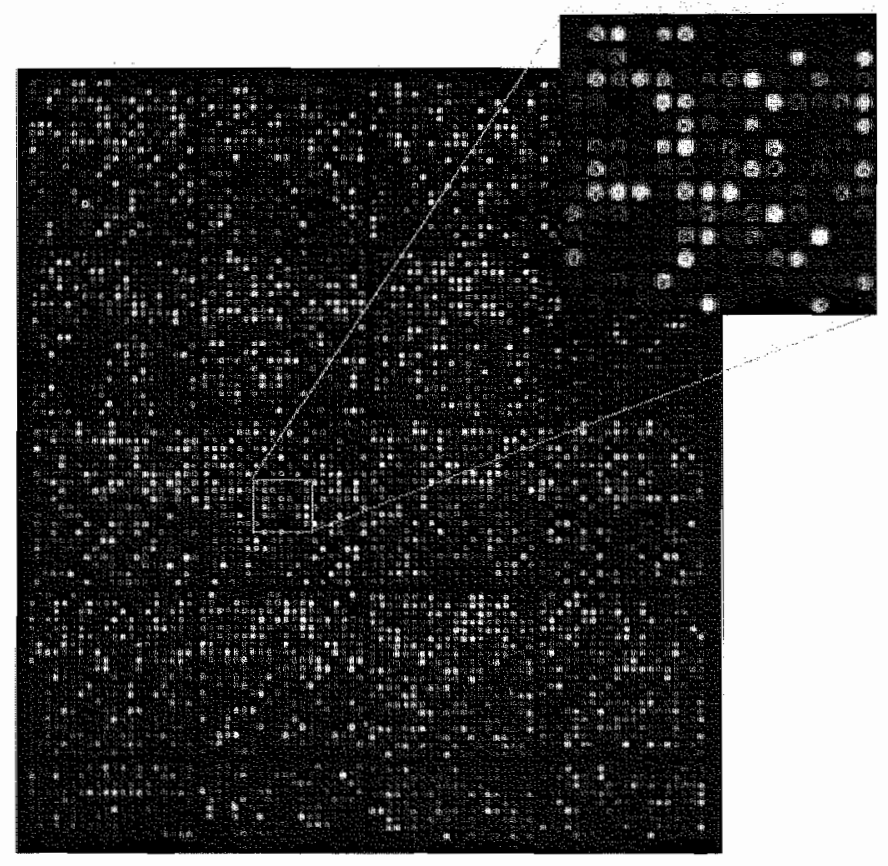

Figure 7. Image of the cDNA nicroarray. Only a part of the cDNA microarray is shown. Clones from the $4 k$ set as well as negative and positive controls were spotted in duplicate on CMT-GAPS ll slides (Coming) using the Microgrid 4 spotter $\{$ Brorobotics).

In large-scale experiments, a broad variety of clustering tools are applied to test the covariance of genes, which may be used for classification or the elucidation of pathophysiological processes. ${ }^{13,14.17 \cdot 19}$ Projects analyzing changes in expression pattern over a certain period of time can be visualized using a time series analysis tool. The kind of follow-up experiments that will be performed to confirm and extend the 
microarray data is dependent on the specific project and the results obtained. In fact, microarray studies are a fishing expedition to identify unknown genetic pathways, which may even involve functionally uncharacterized genes. In the latter case the creation of knockout mice would be a first step.

\section{Microarrays: application in cardiac hypertrophy and pump failure}

The incidence of heart failure has increased in Western countries during the past two decades. Currently, $1.5 \%$ of the population in our society suffers from pump failure. Over the age of 75 years the prevalence rises to $10 \%$. Genetic causes of familial dilated cardiomyopathy, covering about $20 \%$ of all patients with dilated cardiomyopathy, ${ }^{20,21}$ are currently being resolved at a rapid pace and include cytoskeletal, sarcomeric and metabolic genes. ${ }^{22}$ In other families, loci have been identified but the genetic causes largely remain to be resolved. Dilated cardiomyopathy can also occur as part of specific syndromes. ${ }^{23}$ Most patients, however , develop pump failure as end-stage heart disease due to chronic cardiovascular disease, such as hypertensive heart disease and coronary artery disease. Pump failure is then preceded by asymptomatic myocardial hypertrophy. During the development of hypertrophy, a fetal gene programme is restarted, which includes re-expression of atrial natriuretic factor (ANF), skeletal $\alpha$ actin, atrial myosin light chain (MLC-2a) and (in rodents, but not in humans) $\beta$-myosin heavy chain $(\beta-M H C){ }^{24}$

Our studies aim at the identification of the molecular programme underlying myocardial hypertrophy by applying the powerful strategy of gene expression microarrays. Insight into the early pathogenic events of hypertrophy may provide clues for therapeutic interventions. Microarrays have been used to determine gene expression differences between normal, hypertrophic and failing heart. ${ }^{25}$ Because affected human cardiac tissue will display complex expression patterns and cDNA microarrays will identify many alterations in gene expression levels, we started with well-controlled animal models. There are several mouse models for cardiac hypertrophy. Some of them are transgenic mice, mimicking genetic defects in human patients with familial hypertrophic cardiomyopathy (for example $\beta$-MHC (Arg403Glu), $\alpha$-tropomyosin (Asp175Asn), troponin-T (Arg92GIn)) ${ }^{26}$, others involve mechanically (transverse aortic constriction, TAC) ${ }^{31}$ or chemically induced hypertrophy (injections with isoproterenol or angiotensin II) and can be reversed (isoproterenol). ${ }^{25}$ 
In our study we used the TAC mice, in which a stenosis is established in the thoracic aorta, resulting in a pressure overload, which triggers a hypertrophic response in the heart. ${ }^{27}$ Gene expression is studied in mice 48 hours, 1 week, 2 weeks, 3 weeks and 6 weeks after banding. The layout of the microarrays was created using CloneTracker software (Version 1.4, BioDiscovery, Inc.). ${ }^{14}$ Clones in the microtitre wells were mapped to spots on the microarrays for transfer to image analysis programmes. Our initial microarrays contained 4000 I.M.A.G.E. CDNA clones (Incyte Genomics), derived from heart of adult (C57BL/6J, 4 weeks of age) ${ }^{8}$ and fetal mice (NIH/Swiss, 13 day embryo hearts), which were supplied as glycerol stocks. As controls, a number of housekeeping genes are present (Elongation Factor $1 \alpha$ (EF1 $\alpha$ ), $\beta 2$-microglobulin, glyceraldehyde-3-phosphate dehydrogenase (GAPDH), hypoxanthine guanine phosphoribosyltransferase (HPRT), ubiquitin activating enzyme 1 (UBE1), vimentin, keratin 8 , ribosomal protein 59 ). In addition, a number of hypertrophic markers are present as well (atrial natriuretic factor (ANF), sarcoplasmic reticulum $\mathrm{Ca}^{2+}$-ATPase 2 (SERCA2), phospholamban (PLN), $\beta$-myosin heavy chain ( $\beta$-MHC)). In an initial test experiment, total RNA was isolated from wild-type mouse heart and equivalent amounts were labeled with Cy3 and Cy5. Subsequently, Cy3 and Cy5 labeled RNA was cohybridized to a single microarray containing several mouse cDNA clones.

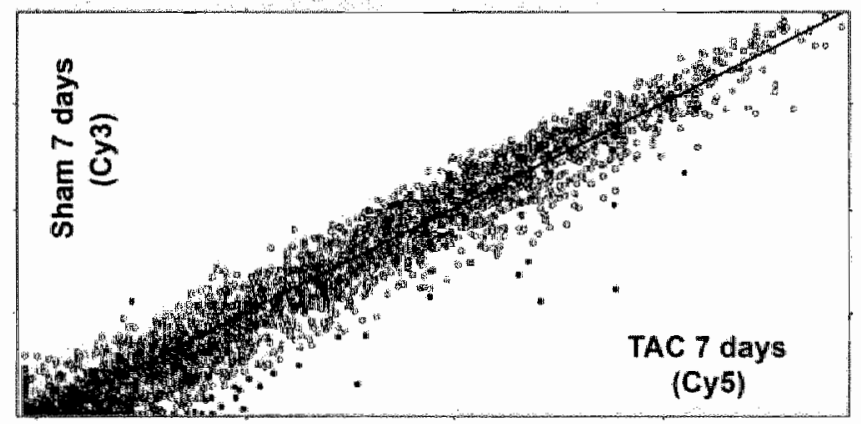

Figure 8. Scatterplot of a TAC and sham-operated mouse 7 days after banding. Signal intensities for both Cy 5 and Cy3 are shown. Most of the genes show no significant difference in gene expression and are distributed around the mean. Genes with more than twofold up or down-regulation in the TAC mouse are depicted as black squares.

As expected, all spots turned yellow, indicating equal expression. Finally, as all parameters had been adjusted and optimized, we prepared microarrays with all 4000 CDNA clones and controls in duplicate and we analyzed RNA from the TAC mouse model, compared with controls. The array was hybridized with labeled total RNA from a TAC mouse (labeled with Cy5-dCTP) and a sham-operated mouse (labeled with Cy3- 
dCTP) 48 hours, 7 days, 14 days and 42 days after induction of hypertrophy. Results of these experiments are represented by scatterplots of the mean ratios as shown in figure 8. Data show an expected distribution around the mean.

\section{Differentially expressed genes}

Initial results showed a greater than twofold altered gene expression of a number of genes, including connective tissue growth factors, imprinted mesoderm specific embryonic genes and calcineurin-interacting proteins in the hypertrophic myocardium after seven days. Mitochondrial genes were downregulated at 42 days after banding. This downregulation was also seen in another mouse model, the MLP knockout. MLP is a muscle specific LIM-only protein, which is an essential regulator of cardiac muscle development. MLP deficient animals develop dilated cardiomyopathy with myocyte hypertrophy and heart failure. ${ }^{28}$ Gene expression changes were confirmed by real-time quantitative PCR, using the SYBR ${ }^{\circledR}$ Green PCR Core Reagents (Applied Biosystems). In this assay, mRNA is first transcribed into CDNA and then a PCR reaction is performed, while the formation of PCR praducts is monitored by measuring the increase in fluorescence caused by binding of SYBR Green Dye to double-stranded DNA. If there is a difference in the expression of a particular gene between the experimental and the control sample, the mRNA quantities (and hence the cDNA quantities) for that gene in both samples will be different. If the gene is downregulated in one sample, the formation of the PCR product needs a higher number of cycles compared with the other sample. To correct for the quantity of starting material in the PCR reaction, housekeeping genes are included as well. The expression of housekeeping genes should be the same in both the experimental and control sample (figure 9).

The late stage at which the downregulation of mitochondrial genes occurs in the TAC mouse and the same observation in the MLP mouse suggests a role for mitochondrial genes in the transition to heart failure. This will be further examined by a new series of experiments, using both the $4 \mathrm{k}$ and $15 \mathrm{k}$ CDNA collections, also including echocardiographic measurements to determine in vivo if the heart is in failure and including enzymatic and other assays to determine respiratory chain activity. Finally, the genes identified in the mouse model will be tested for a role in human pathology. 

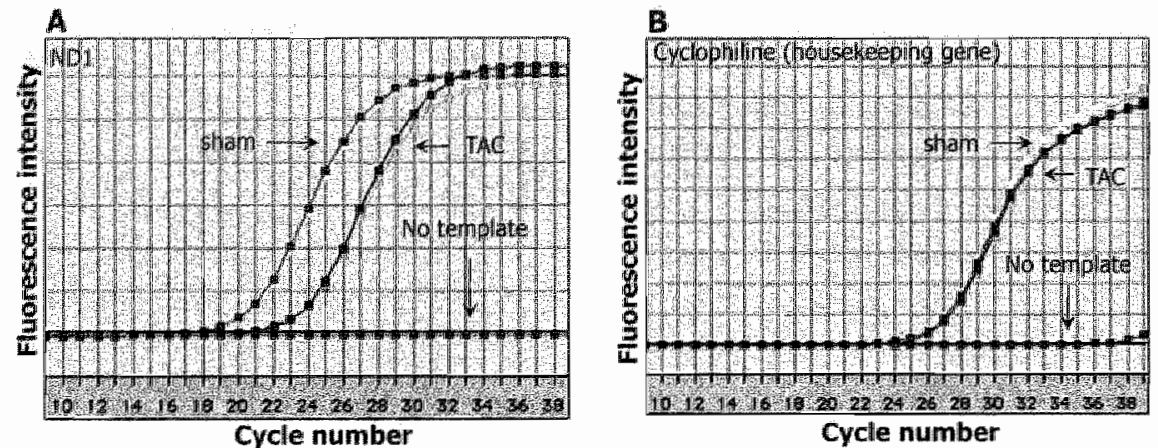

Figure 9. Real-time PCR for a mitochondrial enicoded gene (ND1) and a housekeeping gene cyclophilin) in a TAC mouse versus a sham mice 42 days after surgery. A=The amplification plot for ND1 is shown for a TAC and a sham rivouse. Formation of the PCR product in the TAC mouse starts at a higher number of cycles compared with the sham mouse. This means that there was less mRNA present in the TAC mouse, indicating a down regulation of this gene. A no template control was included as well. $B=$ The amplification plot for the housekeeping gene cyclophilin shows that in both samples the formation of the PCR products starts at the same number of cycles. This means that the quamtities of mRNA are the same in both samples and that there is no difference in gene expression.

\section{Conclusions}

The establishment of an in-house microarray facility requires a major investment in advanced technology, large gene collections and bioinformatics tools. It is essential to combine all three aspects in a genetics and genomics based unit to have the necessary expertise to convert llarge datasets to real genomics and biological knowledge and to functional and pathogenic pathways. The expectations of genomics technologies are high and are currently fulfilled in the classification of tumours, ${ }^{29}$ on which an extremely specific prognosis and therapy can be based. It can be expected that the same development will occur in the field of cardiovascular disease, in which the pathophysiological processes may be more subtle and will require a much more finetuned microarray approach. However, even with our initial experiment we have already identified several previously unknown genetic pathways, which may shed new light on the life-threatening processes of cardiac hypertrophy and pump failure. This is in our view the best illustration of the power of this technology.

\section{Acknowledgements}

This work was supported by grants from the Netherlands Heart Foundation (99.122). 


\section{References}

1. Access Excellence the National Health Museum, http/Www iaccess excellence.org/AB/GG/, 2002 .

2. Anatomisches Institut Tubingen.http:/nero anatom uni-tuebingen.de/orggwhult/forschng chipsoothtm. 2002.

3. wan $\mathrm{Hal}$ NL, Vorst $\mathrm{O}$, van Houwelingen $\mathrm{AM}$, et al. The application of DNA microarras in gene expression analysis. J Biotechnol. 2000;78:271-280.

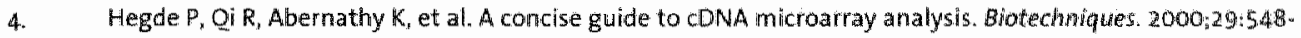
$550,552-544,556$ passim.

5. Altschul SF, Gish W, Miller W, et al. Basic local alignment search tool. J Mlol Biol 1990;215:403-410.

6. Lander ES, Linton LM, Birren B, et all. Initial sequencing and analysis of the human genome. Nature. 2001:409:860-921.

7. Venter JC, Adams MD, Myers EW, et al. The sequence of the humangenome. Science 2001:291:1304-1351.

8. Soares mouse NbMH (dbEST Library ID.855). Www ncbin/m.nilh.gow/UniGene/ lib.cgi?ORC:Mm\&LID=86. 2000.

Stratagene mouse heart (H937316)

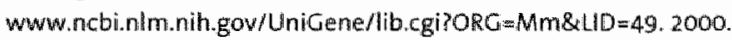

(dBEST Libray $\quad$ (D.509).

10. Tamaka TS, Jaradat SA, Lim MK, et all. Genome-wide expression profiling of nid-gestation placenta ard embryo using a 15,000 mouse developmental cDNA microarray. Proc Nat Acad 5ci U S, A. 2000:97:91279132.

11. Halgren RG, Fielden MR, Fong C, et al Assessment of cilone idlentity and sequence fidelity for 1189 IMAGE cDNA clones. Nucleic Acids Res. 2001;29:58:2-588.

12. Kuschel M AW'. Characterization of RNA quality using the Aglient 2100 Bioanalyzer, Application note Life Sciences. 2000; Publication number 5980-0472E.

13. The Institute for Genomic Research (TIGR). http//wwww.tigrorg/tdb/ microarray/protocolsT/GR.shtml. 2001.

14. Biodiscovery, Inc. http://www biodiscovery.com/. $200 \pi$.

15. Conway $T$, Kraus B, Tucker DL, et al. DNA array analysis in a Microsoft Windows anvironment. Biotechniques. 2002;32:110, 112-114,116, 118-119.

16. National Human Genome Research Institute (NHGRI). http://researchnhgrimih. gov/microarray/image_analysis htmil. 2001.

17. Eisem MB, Spelliman PT, Brown PO, et al. Cluster analysis and display of genome-wide expression pratterns Proc Natl Acad Sci US A. 1998;95:14863-14868.

18. Silicon Genetics. http://www silicongenetics.com//cgi/Sicicgi/Prodlucts/Cuene Spring/index.simf. 2001,

19. Spotfire. http:f/Www spotfire.com/. 2001.

20. Michels VN, Moll PP, Miller FA, et al. The frequency of familial dilated cardiomyopathy in a series of patients with idiopathic dilated cardiomyopathy. N Engl Med, 1992;326:77-82.

21. Marcelis $C$, Doevendans PA, Bonne G. Dilated Cardiomyopathy, In: Daevendans PA, Wilde AA, eds. Cardiowascular Genetics for Clinicions. Dordrecht, The Netherlands: Klumer Academic Publishers; 2001:155. 168.

22. Schonberger J, Seidman CE. Many roads lead to a broken heart: the genetics of dilated cardiomyopathy. Arm Hum Genet, $2001 ; 69: 249-260$.

23. Santorelli FM, Tessa A, D'Amati $G_{r}$ et al. The emerging concept of mitochondrial cardiomyopathies. Am Heart 1. 2001;14:1: E1.

24. Nicol RL, Frey N, Olson EN. From the sarcomere to the nucleus: role of genetics and signaling in structural heart disease. Annu Rev Genomics Hum Genet. 2000;1:179-223.

25. Friddle CJ, Koga $T$, Rubin EM, et al. Expression profiling reveals distinct sets of genes altered during induction and regression of cardiac hypertrophy. Prac NatI Acad SCi U S,A. 2000,97:6745-6750. 
26. Marian A, Roberts R. The mollecular genetic basis for hypertrophic cardiomyopathy. 3 Mof Cell Cardiol. $2001 ; 33655-670$.

27. Rockman H, Ross Rs, Harris AN, et al. Segregation of atrial-specific and inducible expression of an atrial

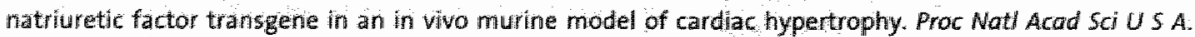
$1991 ; 88: 8277 \times 2881$

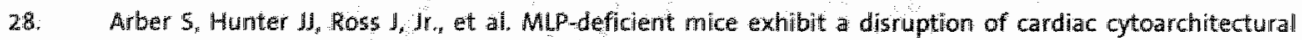
organization, dilated cardiomyopathy, and heart faliure. Cell. 1997:88:393-403.

29. van " $t$ veer $U$, Dai $H$, van de Vijuer $M$, et all Gene expression profiling predicts clinical outcome of breast cancer, Nature. $2002: 415: 530-536$. 



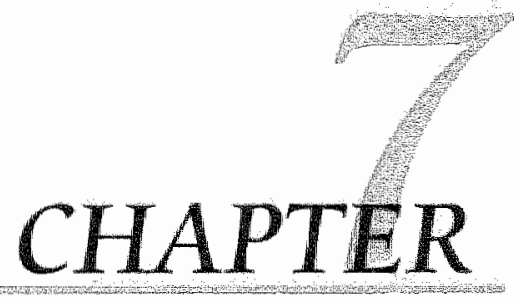

\section{Early and transient changes in gene expression compensate pressure overload induced cardiac hypertrophy in mice}

B.J.C. van den Bosch"1, P.J. Lindsey ${ }^{1}$, C.M.M. van den Burg ${ }^{1}$, S.A. van der Vlies ${ }^{1}$, D.J. Lips $^{3.4}$, G.J. van der Vusse ${ }^{2}$,T.A. Ayoubi ${ }^{1}$, P. A. Doevendans ${ }^{3,4}$, H.J.M. Smeets ${ }^{1 .}$

" Dept. of Genetics and Cell Biology and "Dept. of Physiology, Cardiovascular Research Insthute Maastricht (CARIM). Mastricht University. The Netherlands

3. Dept of Cardiology of the Heart Lung Centre Utrecht (UMCU), The Netherlands

* Interuniversity Cardiology institute of the Netherlands (ICIN), Utrecht, The Netherhands 


\section{Abstract}

Cardiac hypertrophy is an important risk factor for cardiac morbidity and mortality. To unravel the underlying pathogenic genetic pathways, we applied gene expression profiling in a mouse model of cardiac hypertrophy induced by Transverse Aortic Constriction (TAC). At 48 hours, 1 week, 2, 3 and 8 weeks after surgery, left ventricles from white Swiss mice were harvested and RNA was labeled and hybridized on microarrays containing a $15 \mathrm{~K}$ CDNA collection of fetal origin. Using a well-defined array design, we were able to identify small, but significant changes in gene expression for large numbers of genes. Massive changes in gene expression were observed in the TAC mice during the establishment of hypertrophy ( 48 hours and 1 week after banding). Early key processes involved restrictions in metabolism, followed by growth and reactivation of fetal gene expression. Most of these genes returned to basal expression levels during the later phase, in which compensated hypertrophy was maintained. Also, the number of altered genes and gene expression changes were smaller and less specific for certain processes. Our findings suggest that compensated hypertrophy in this mouse model is established by a rapid adaptation of the heart at the cost of metabolic activity. The result is a larger, almost normal heart with respect to gene activity, with no occurrence of the known maladaptive processes. Therefore, the transient early changes may reflect a beneficial response to pressure overload, as these TAC mice do not develop deterioration of cardiac function or progression into heart failure.

\section{Introduction}

The heart is able to adapt to increased workload, injury or defects in contractile performance by increasing muscle mass. ${ }^{1}$ Activation of intracellular signaling cascades results in cardiac hypertrophy, which can be defined as an increase in heart size resulting from the enlargement of existing cardiomyocytes. ${ }^{1,2}$ Whereas compensatory cardiac remodeling seems beneficial at first, myocardial hypertrophy is recognized as an important risk factor for cardiac morbidity and mortality. ${ }^{3,4}$ Much research has focused on the identification of molecular pathways and processes underlying cardiac hypertrophy. ${ }^{5-7}$ A reactivation of fetal genes has been observed, such as natriuretic peptides (ANF, atrial natriuretic factor), Myhc-b (beta myosin heavy chain) and askeletal actin. ${ }^{8,9}$ In addition, intracellular $\mathrm{Ca} 2+$ handling, apoptosis, extracellular matrix deposition and fibrosis also play an important role. ${ }^{6,10,11}$ Furthermore, many experimental and clinical studies in the hypertrophied and failing heart have reported 
changes in energy metabolism. ${ }^{12}$ Aithough a substantial number of processes have been recognized in hypertrophy, it is unclear how they are phased in time and how they are mutually related. We used global gene expression profiling at different time points to monitor thousands of different genes simultaneously. As a model for compensated cardiac hypertrophy, we used a Transverse Aortic Constriction (TAC) mouse model, in which cardiac hypertrophy is induced by pressure overload. Gene expression profiles were determined in left ventricles of TAC and sham-operated mice at $48 \mathrm{~h}, 1 \mathrm{wk}, 2,3$ and $8 \mathrm{wks}$ after banding. Differentially expressed genes were further analyzed using Gene MicroArray Pathway Profiler (GenMapp) ${ }^{1.3}$, MAPPFinder $^{14}$, TXTGate $^{15}$ and Adaptive Quality-Based Clustering ( $\left.A Q B C\right)^{16}$ to identify the mechanisms underlying the development of cardiac hypertrophy induced by pressure overload.

\section{Materials and methods}

\section{TAC mice}

A total of 60 male inbred Swiss mice (10 weeks old, body weight 27-35 g) were randomly allocated to the TAC and sham-operation groups. Mice were anaesthetized with a combination of ketamine (100 mg/ $\mathrm{kg} \mathrm{im})$ and xylazine $(5 \mathrm{mg} / \mathrm{kg} \mathrm{sc})$. TAC was performed as described by Rockman et al. ${ }^{17}$ Sham-operated mice underwent an identical surgical procedure without the actual constriction of the aorta. All procedures were performed in accordance with the recommendations of the Guide for the Care and Use of Laboratory Animals published by the US National Institutes of Health (NIH publication No. 85-23, revised 1996) and were approved by the Committee for Animal Research of Maastricht University. Mice were sacrificed at $48 \mathrm{~h}, 1 \mathrm{wk}, 2,3,8$ and $28 \mathrm{wks}$ after surgery. Hearts were harvested, weighed and frozen in liquid nitrogen. Hypertrophy was assessed by determining the ratio left ventricular weight (LVW)/tibia length (TL).

\section{Microarray preparation}

The CDNA inserts from the NIA Mouse 15K CDNA collection, derived from embryonic and fetal cells and tissues ${ }^{18,19}$, were PCR amplified directly from the glycerol stocks. The insert sizes of eight clones per 96 -wells plate were verified as a quality check. After purification, PCR products were resuspended at a concentration of $200 \mathrm{ng} / \mu \mathrm{l}$ in $50 \%$ DMSO and spotted onto UltraGAPS Coated Slides (Corning, NY) using the Microgrid II arrayer (Biorobotics, UK). This arrayer is mounted with a 16 pin head and slides were printed in three separate runs. Each slide consisted of three meta-grids, subdivided in 16 sub-grids, corresponding to the area printed by each pin. Each sub-grid has 20 rows 
and columns, yielding 400 spots per sub-grid, 6400 per meta-grid. The total of 19200 spots consisted of 15120 cDNA clones and 4080 controls. Five positive controls (i.e. housekeeping genes) were spotted six times by each pin in every meta-grid. Three negative controls (i.e. bacterial genes) and DMSO were spotted four times by every pin in each of the three meta-grids. Finally, 15 spots were left empty in each of the 16 subgrids of the three meta-grids. Each of these products was spotted in positions chosen uniformly across the sub-grid and therefore the slide.

\section{RNA extraction, labeling and hybridization}

Total left ventricular RNA was extracted using the TRIzol reagent (Invitrogen, Carlsbad, (A) and purified with the RNeasy clean-up kit (Qiagen, Valencia, $C A$ ). RNA quality was determined with the Bioanalyser (Agilent, Palo Alto, CA). As the Cy5-dyes have been reported to be unstable due to the amount of atmospheric ozone in summer ${ }^{20}$, we decided to only use Cy3 labeling and compare the samples hybridized on different sllides. Aminoallyl labeling and RNA hybridization were performed according to the protocol by Hegde et al. ${ }^{21}$ and slightly adjusted for use in our own laboratory. Briefly, ten micrograms of total RNA from each sample was reverse transcribed into CDNA using random primers in the presence of aminoallyl dUTP. Following purification, products were coupled to Cy3 NHS-ester (Amersham, Piscataway, NJ). Labeled cDNAs were purified and labeling efficiency was determined. Slides were prehybridized in $1 \%$ BSA (bovine serum albumin), 50\% formamide, $5 \times$ SSC and $0.1 \%$ SDS for 45 min at $42^{\circ}$, and then washed and dried. The labeled CDNA was resuspended in $60 \mathrm{ml}$ hybridization mix, containing 50\% formamide, $5 \times$ SSC, $0.1 \%$ SDS and $8 \mu \mathrm{g}$ mouse CotI-DNA and hybridized to the arrays at $42^{\circ}$ for $16 \mathrm{~h}$. Slides were washed $4 \mathrm{~min}$ at $42^{\circ}$ in $1 \times 5 S \mathrm{C} / 0.2 \%$ SDS, 4 min at room temperature in $0.1 \times$ SSC/0.2\% SDS, and finally $4 \mathrm{~min}$ at room temperature in $0.1 \mathrm{XSSC}$. Slides were dried by centrifugation for $5 \mathrm{~min}$ at $500 \mathrm{rpm}$ and scanned with a dual-laser scanner (Affymetrix/GMS 418, Santa Clare, CA).

\section{Microarray analysis}

Images were quantified with ImaGene software (BioDiscovery, Boston, MA). Any probe that was flagged as empty, negative or poor, or had less than two observations left per TAC or sham group was excluded from further analysis. The remaining genes were analyzed using a Gaussian linear regression including the labeling efficiency and, when necessary, the repeats. The inference criterion used for comparing the models is their ability to predict the observed data, i.e. models are compared directly through their minimized minus log-likelihood. When the numbers of parameters in models differ, they are penalized by adding the number of estimated parameters, a form of the 
Akaike information criterion (AIC). ${ }^{22}$ For each gene, the treatment group was then added to the model. The gene under consideration was found to be differentially expressed if the AIC decreased compared to the model not containing the treatment. We focused on differentially expressed genes with a known LocusLink Identifier (LL ID). The genes analyzed and fold changes were loaded into GenMapp ${ }^{13}$ and MAPPFinder ${ }^{14}$ to evaluate the transcripts in relation to known biological processes, molecular function and cellular component based on Gene Ontology (GO) terms, and to obtain a ranked list (using $P<0.05$ ) of pathways with differentially expressed genes. To reveal unknown relations between genes, we used the TXTGate web-service, which clusters genes using literature based information. ${ }^{15}$ In addition, the expression profile of the differentially expressed genes in time was investigated using Adaptive Quality-Based Clustering. ${ }^{16}$ This interface is intended to find groups of genes that have similar expression profiles.

\section{Real-time $P C R$}

Real-time quantitative PCR (TaqMan(B), Applied Biosystems, Foster City, CA) was performed using the SYBRB Green PCR Core Reagents (Applied Biosystems, Foster City. CA). Reverse transcription into CDNA was performed in a $40 \mathrm{ml}$ volume with $1.25 \mu \mathrm{g}$ total RNA as a template. After denaturing at $65^{\circ} \mathrm{C}$ for $10 \mathrm{~min}$, the RNA, the first strand buffer, 1.25 mM dNTPs, 200 U Superscript /I (Invitrogen, Carlsbad, CA), RNAsin and a mixture of $0.75 \mu \mathrm{g}$ oligo(DT) primer and $0.75 \mu \mathrm{g}$ random primers (Invitrogen, Carlsbad, CA) were incubated for $1 \mathrm{hr}$ at $42^{\circ} \mathrm{C}$ followed by $5 \mathrm{~min}$ at $95^{\circ} \mathrm{C}$. Primers were created using Primer Express $($ software (Applied Biosystems, Foster City, $C A$ ) based on GenBank sequences (Table 1). The CDNA was amplified in duplo in $20 \mu \mathrm{l}$ SYBR Green PCR buffer, with $4 \mathrm{mM} \mathrm{MgCl} 2,1.25 \mathrm{mM}$ dNTP mix, $0.25 \mathrm{U}$ Amperase@UNG, $0.625 \mathrm{U}$ AmpliTaq Gold $B$ DNA Polymerase and 1.25 pmol of the forward or reverse primer. PCR conditions were first, $50^{\circ} \mathrm{C}$ for $2 \mathrm{~min}, 95^{\circ} \mathrm{C}$ for $10 \mathrm{~min}$, followed by 40 cycles of $95^{\circ} \mathrm{C}$ for $15 \mathrm{sec} / 60^{\circ} \mathrm{C}$ for $1 \mathrm{~min}$. Next, samples were heated to $95^{\circ} \mathrm{C}$ for $15 \mathrm{sec}, 60^{\circ} \mathrm{C}$ for $1 \mathrm{~min}$, and then heated to $95^{\circ} \mathrm{C}$ in $20 \mathrm{~min}$, followed by cooling to $4^{\circ} \mathrm{C}$. Transcription values were related to the housekeeping gene cyclophilin. The results were analyzed using a Gaussian linear regression, similar to the microarray analysis, with the adjustment of adding cyclophilin as a housekeeping gene. The AIC was also used to asses whether there was a difference between control and TAC mice (group effect). Hence, the gene under consideration was found to be differentially expressed if the AIC decreased compared to the model not containing the group difference. 
Table 1. Primers used for real-time PCR analystis

\begin{tabular}{|c|c|c|c|}
\hline $\begin{array}{l}\text { Gene } \\
\text { symbol }\end{array}$ & $\begin{array}{l}\text { Cen Rarth } \\
\text { Acc Nic. }\end{array}$ & Sequence Forward primer & Sequence Reverse primer \\
\hline Alvf & Ko278 & 5'AGGAGAAGATGCCGITAGAAGA-3 & $5^{3}$-GCTTCCTCAGTCTGCTCACTCAG-3: \\
\hline Miyhe $b$ & NM 080729 & $3^{\prime}$-ACAACAAACTGAGGCG GGG $3^{\prime \prime}$ & 5 -CCAGTGCCTICCCAACAAT $33^{\prime}$ \\
\hline Plin & $N M: 023129$ & S-GCTTCCTCGCATAATGGAAA-3' & $5^{2}$-CATGITGCAGGTCTGGAGIG-3* \\
\hline Psend & NM 008943 & 5'-TCAAGAAAGCGTTCICCAGC-3' & $5^{\prime}$-CGTGGCGAAGTAGAACACGA-3' \\
\hline App & NM 007471 & 5-AGCTCCTECCGTGAATGG-3' & $5^{\circ}$-ACCCCAAAAGGGTGCCA-3" \\
\hline Nrap & NM_ 008733 & 5'GGCTAGTCCTGICGGAGCC- $3^{*}$ & 5-CTICTGAGIIAAACCTGGCCACAT-3: \\
\hline Idfa $3 a$ & NH_ 029573 & 5' TGCCGACGTGGACCTGAC-3' & $5^{\circ}$ AACACAGGCCCCCGCT $3 '$ \\
\hline Enol & NW 023119 & 5'-AGTGACCAACCCTAAGCGGA-3' & $5^{\prime}-$ GCAAGAGGCAGTTCCAGGAC-3" \\
\hline Umpk & NM 030724 & 5'-TCTCCAAGCGGCACIACG "3' & $5^{*}$-ACGICCTGCCTCTTGCG-3" \\
\hline Tgfb1 & $N M \quad 011577$ & 5'-TGGAAAGCGCCCAGCAC-3" & 5'-GCAATAGTIGGTATCCAGGGCT-3" \\
\hline Plxnby & NN 172775 & 5'TGAGCACGTCACTTCCGAACT $3^{\prime \prime}$ & $5^{\prime \prime}$-GCCACCGTTGCTCCATCT-3' \\
\hline Cyclophiliri & NM 008907 & 5'-CAAATGCTGCACCAAACACAA-3' & $5^{\circ}$ GCCATCCACCCA TTCAGTCT-3* \\
\hline
\end{tabular}

Acc.No, Accession number

\section{Results}

\section{Left ventricular hypertrophy in TAC mice}

Either a TAC or a sham procedure was performed on 60 mice to be able to sacrifice 5 TAC and 5 sham-operated mice at $48 \mathrm{~h}, 1 \mathrm{wk}, 2,3,8$ and $28 \mathrm{wks}$ after surgery. Mortality rates due to the surgical procedure were $8 \%$ for TAC and $16 \%$ for sham-operated mice. We balanced the number of TAC and sham mice for each time point. Unfortunately, at time point $1 \mathrm{wk}$, for technical reasons, only 2 sham-operated mice were available, where for all others at least 3 were. TAC mice at 1 wk, 2, 3 and 8 wks show a reproducible degree of hypertrophy compared to sham mice: mean LVW/TL ratios increased by respectively $40 \%, 33 \%, 28 \%$ and $3.4 \%$ (Table 2). TAC mice at $48 \mathrm{~h}$ do not show any increase. ${ }^{17}$ The hypertrophy model was validated by real-time PCR for 3 genes known to be differentially expressed during hypertrophy ${ }^{23}$ (Figure 1). ANF was upregulated with the highest fold change at 1 wk (13.0-fold). PIn (phospholamban) was downregulated with its peak value also at $1 \mathrm{wk}$ (5.1-fold). Both genes were differentially expressed at all time points, although fold changes decreased towards the later hypertrophic phase. Myhc-b showed a slight upregulation at all time points. Our results show that the hypertrophic response of the TAC mice are comparable with earlier reports on this model. ${ }^{17,24}$ Echocardiographic measurements and determination of lung weight at $28 \mathrm{wks}$ after TAC showed no signs of heart failure (data not shown). The Swiss mice develop compensated cardiac hypertrophy after pressure overload without deterioration of cardiac function. 
Tabie 2. Left ventricular weight and tibia length in TAC and sham mice

\begin{tabular}{|c|c|c|c|c|c|c|c|c|}
\hline \multirow[b]{2}{*}{ Time } & \multicolumn{4}{|c|}{$\overline{T A C}$} & \multicolumn{4}{|c|}{ Sham } \\
\hline & $n$ & LVW (mg) & $\mathrm{Tl}(\mathrm{mm})$ & LWWIL & n & LWW (mg) & The(mm) & LWN/T \\
\hline $48 h$ & 5 & $90 \pm 6$ & $167 \pm 2$ & $0.54 \pm 0.03$ & 4 & $92 \pm 10$ & $166 \pm 5$ & $0.55 \pm 0.05$ \\
\hline $1 w$ & 3 & $134 \pm 11$ & $167 \pm 3$ & $0.80 \pm 0.06$ & 2 & $97 \pm 5$ & $269 \pm 0$ & $0.57 \pm 0.03$ \\
\hline $2 w$ & 3 & $130 \pm 9$ & $171 \pm 2$ & $0.76 \pm 0.04$ & 3 & $99 \pm 4$ & $172 \pm 2$ & $0.57 \pm 0.03$ \\
\hline 3w & 4 & $124 \pm 18$ & $166 \pm 1$ & $0.74 \pm 0.11$ & 4 & $96 \pm 7$ & $167+1$ & $0.58 \pm 0.04$ \\
\hline $8 w$ & 3 & $133 \pm 17$ & $168 \pm 2$ & $0.79 \pm 0.10$ & 3 & 101 & $172+2$ & $0.59 \pm 0.04$ \\
\hline
\end{tabular}

Values are means \pm SD; TAC, Transwerse Aortic Constriction; Time, time point after banding; number of animals in each

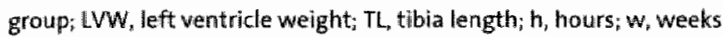

Quality of the microarray data

The positive controls (housekeeping genes), which were spotted in several concentrations, showed consistent intensities throughout the slide. The negative controls (bacterial genes) were negative. Next, we compared different probes on the array representing the same gene (about $25 \%$ of the total number of analyzed probes with a known LL ID). For $~ 98 \%$ of the genes analyzed, expression was similar. This shows the high quality of the arrays and the reliability of the gene expression data. As data from single genes are usually not sufficient to draw a conclusion about the related process, we also tested the consistency with other genes in that process. This will provide evidence for the role of the entire process in the pathology observed. In case genes were inconsistent or were the only genes within a certain process, then the alterations were confirmed by real-time PCR. A total of nine genes was validated this way for all time points. Differential expression of Psen1 (presenilin 1) at 48h was the only gene that could not be confirmed by real-time PCR.

\section{Number of differentially expressed genes in TAC mice}

The total number of probes analyzed at $48 \mathrm{~h}, 1 \mathrm{wk}, 2,3$ and 8 wks was respectively $3066,549,4308,6749$ and 6881 (Figure 2). The low number at 1 wk was due to the availability of only two shams for this time point. As the remaining data still reflect important differentially expressed genes, we decided to keep the data, despite the low number of genes. The number of differentially expressed transcripts was largest at $48 \mathrm{~h}$ (454): $10.4 \%$ up (215) and $13.8 \%$ down (239). Most genes showed a more than 2-fold difference in expression and many genes more than 5 to 10 -fold. At 1 wk, 17.9\% was upregulated (65), whereas $1.1 \%$ was downregulated (2). 


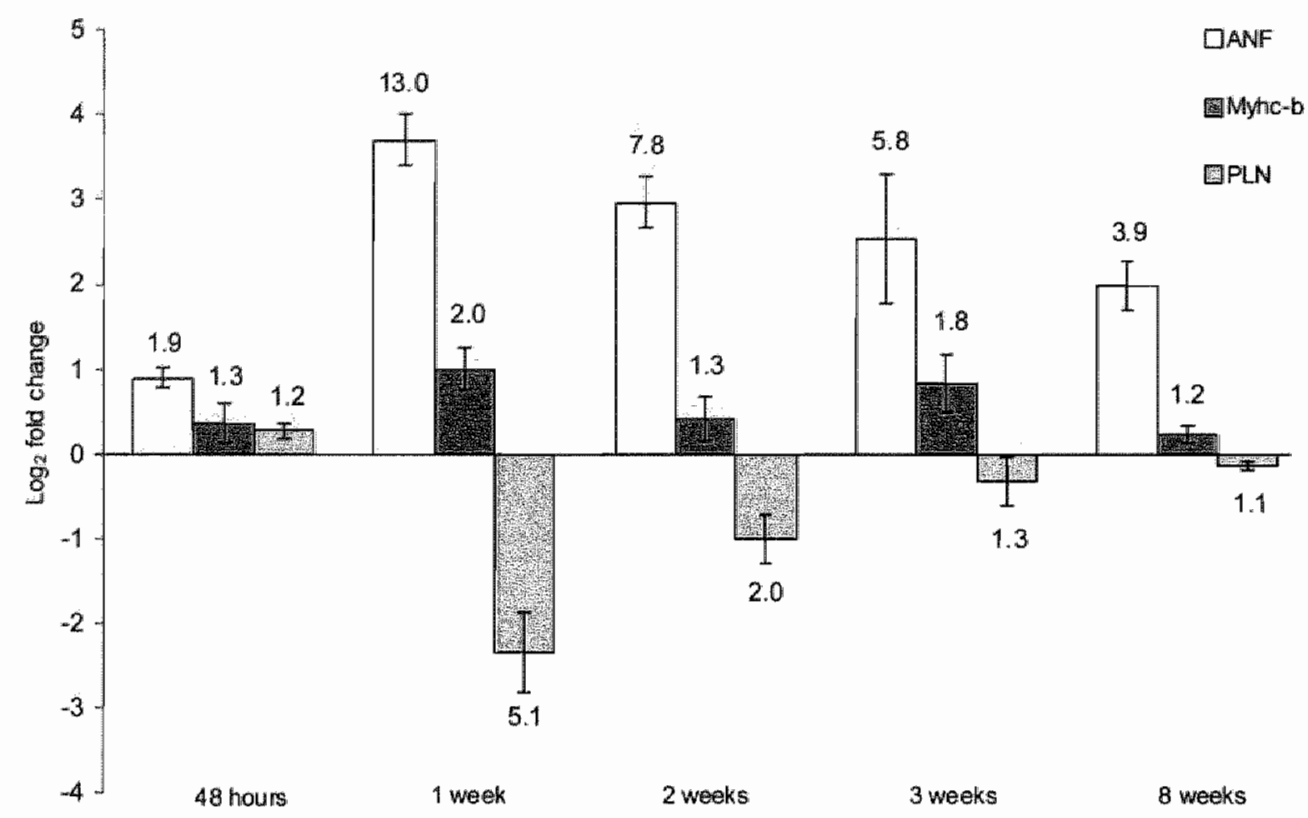

Figure 1. Expression of hypertrophic markers in TAC mice at different time points after banding. Real-time PCR data is shown as the fold change (and confidence interval) in the TAC mice relative to the expression levels of shamoperated mice. All hypertrophic markers were differentially expressed in the TAC mice.

At respectively 2 and 3 weeks, most genes were downregulated: $0.6 \%$ up (18) vs $5.5 \%$ down (162) and $0.8 \%$ up (35) vs $2.7 \%$ down (130). At 8 wks, both up- and downregulated transcripts encompassed $2.8 \%$ of the analyzed transcripts ( 144 up- and 147 down). The majority of genes at 1 wk, 2, 3 and 8 wks showed a less than 2-fold difference in expression. About $71 \%$ of the total number of transcripts analyzed has a known LL ID (Figure 2).

Significant processes in cardiac hypertrophy

The most important processes identified for all time points combining all tools are shown in Table 3 and Figure 3. Results for each analysis tool separately are shown in Table S1 (GenMAPP/MAPPFinder) and Table S2 (TXTGate) of the supplementary data (http://www.personeel.unimaas.nl/Bianca.vandenBosch/thesis.htm) Several previously reported genes and processes involved in cardiac hypertrophy were identified, e.g. Atp2a2 (sarcoplasmic reticulum Ca2+-ATPase), Mapkapk2 (MAP kinase-activated protein kinase 2), MAPK and G-protein signaling. 
$48 \mathrm{h:}$

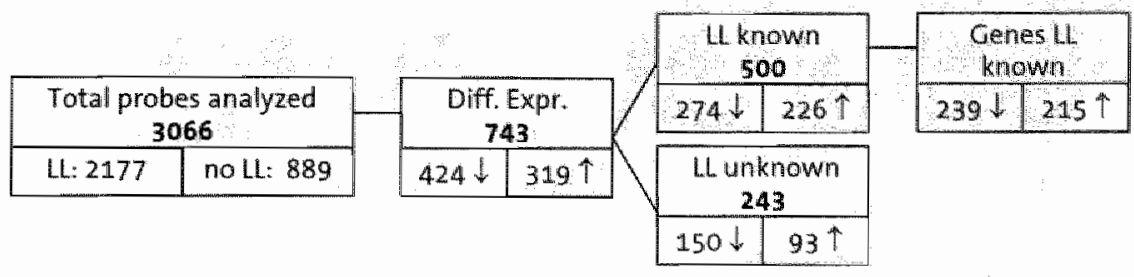

1 wk:

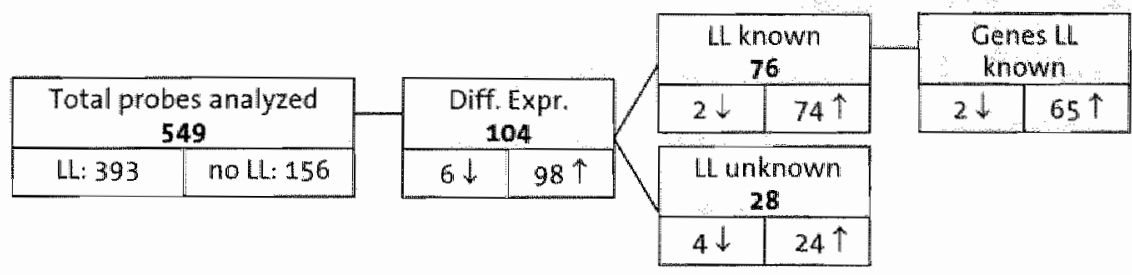

2.wks:
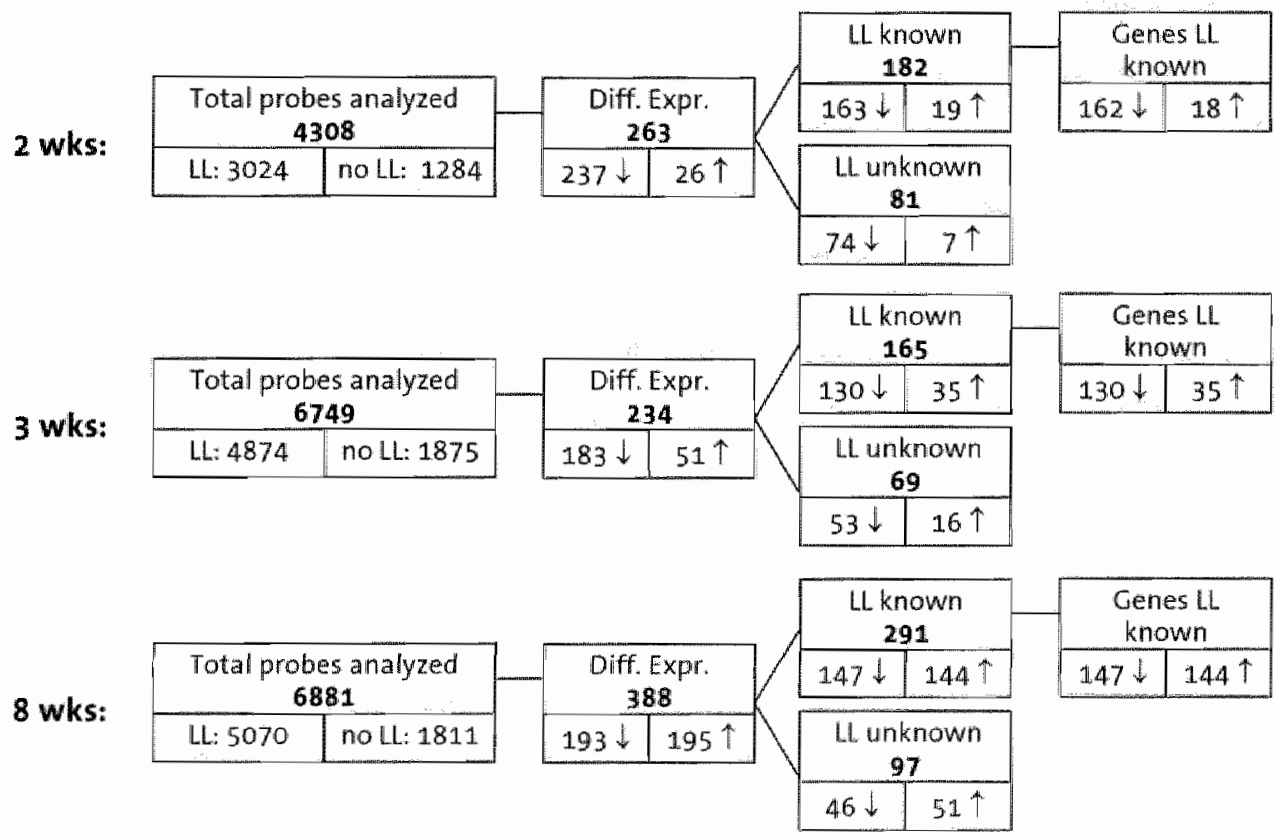

Figure 2. Distribution of the numbers of probes anallyzed per time point. "Total probes analyzed" nepresents 4 he number of transcripts that qualified for analysis diwded into known and unknown Locuslink IDs (LL). "Diff. expr." represents the total number of transcripts that is differentially expressed at each of the time points divided into down- and upregullated genes in the TAC mice. Finally, the actual number of genes represented by the transicripts with a known LL is indicated. 
energy metabolism

(EA, (A, OXPHOS)

TIOTA protein

biosynthesis 1

cyroskeleton / 1 .

Pramyloid

metabolism

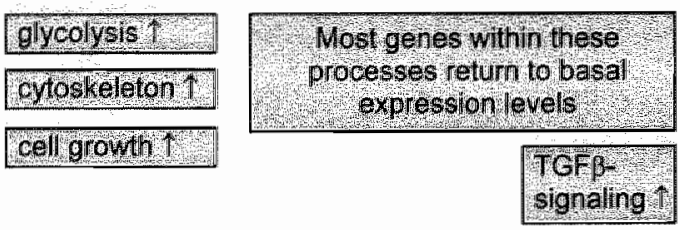

signaling

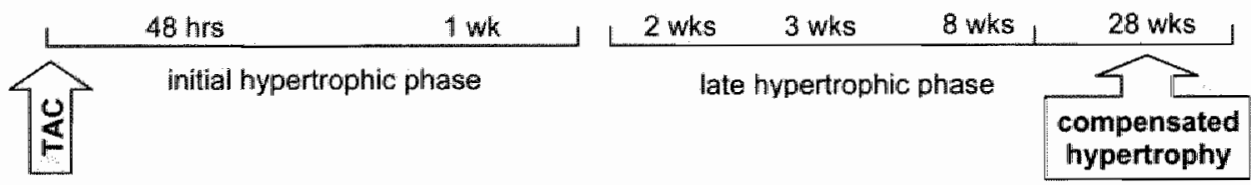

Figure 3. Schematic overview of the most important processes identified at the different time intervals after TAC.

At $48 \mathrm{~h}$, a variety of processes was identified, such as translation, signaling, response to heat and oxidative stress, proteolysis and peptidolysis, fatty acid metabolism, energy pathways as well as cytoskeletal, mitochondrial and ribosomal processes. The downregulation of energy metabolism included genes in fatty acid (FA) metabolism, the tricarboxylic (TCA) cycle and OXPHOS (oxidative phosphorylation). At 1 wk, genes involved in energy metabolism showed a slight increase in activity, which returned to normal at the later stages (Table S3 supplementary data, http://www. personeel.unimaas.nl/Bianca.vandenBosch/thesis.htm). A number of mitochondrial ribosomal genes and translation initiation factors were up- as well as downregulated at $48 \mathrm{~h}$ and 1 wk. Cytoskeletal and sarcomeric genes were partly down and partly upregulated at $48 \mathrm{~h}$, whereas all of these genes analyzed at $1 \mathrm{wk}$ were upregulated. At 2, 3 and 8 wks after banding, genes had returned to basal expression levels agaim "Table S3 supplementary data, http"//www.personeel.unimaas.n|/Bianca.vanden Bosch/thesis.htm). With TXTGate, we identified additionally the downregulation of genes related to $\beta$ amyloid and the upregulation of genes with kinase activity at $48 \mathrm{~h}$ and genes involved in cancer/growth at 1 wk after banding (Table 52 supplementary data, http://www.personeel.unimaas.nl/Bianca.vandenBosch/thesis.htm). At 8 wks, one cluster consisted of genes present in the HUGE (Human Unidentified GeneEncoded) database ${ }^{25}$ and one encoding binding proteins. The relation between genes in clusters was often not clear (except for the $\beta$-amyloid cluster). 


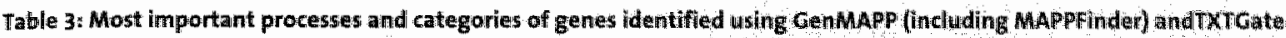

\begin{tabular}{|c|c|c|}
\hline \multirow{2}{*}{ Categaries and processes } & \multicolumn{2}{|c|}{ Tool } \\
\hline & GEMAPP & TXTorate \\
\hline acetyl-CoA metabolism & $x$ & $x$ \\
\hline allcohol metabolism & $x$ & \\
\hline DNA metabolïsm & $x$ & \\
\hline RNA metabolism: & $x$ & \\
\hline protein metabolism & $x$ & \\
\hline carbohydrate metabolism & $x$ & \\
\hline carboxylic acid metabolism & $x$ & \\
\hline fatty acid metabolism & $x$ & \\
\hline glycogen metabolism & $x$ & \\
\hline lipid metabolism & $x$ & \\
\hline glycolysis and gluconeogenesis & $x$ & $x$ \\
\hline mitachondrion & $x$ & $x$ \\
\hline energy pathways & $x$ & $x$ \\
\hline election transport chain (OXPHOS) & $x$ & $x$ \\
\hline tricarboxylic (TCA) cycle & $x$ & $x$ \\
\hline cell proliferation & $x$ & \\
\hline cell cyclen & $x$ & \\
\hline growth & $x$ & $\mathrm{x}$ \\
\hline cancer & & $x$ \\
\hline G-protein signalling & $x$ & \\
\hline TGFB signaling & $x$ & \\
\hline MAPK signaling & $x$ & $x$ \\
\hline Wht signaling & $x$ & \\
\hline transcription & $x$ & \\
\hline Immune response & $x$ & \\
\hline responsie to heat & $x$ & \\
\hline response to oxidative sturess & $x$ & \\
\hline ribosomal & $x$ & $x$ \\
\hline protein biosynthesis & $x$ & \\
\hline transtation & $x$ & $x$ \\
\hline protein degradation & $x$ & $x$ \\
\hline cytoskeleton organization and biogenesis & $x$ & $x$ \\
\hline development & $x$ & \\
\hline B-amyloid metabolism & & $x$ \\
\hline bone remodeling & $x$ & \\
\hline calcium ion binding & $x$ & \\
\hline
\end{tabular}

The most prominent changes in processes as a reaction to TAC occur early and fade out as a compensated stage is reached, i.e. at 2, 3 and 8 wks (Table $\$ 3$ supplementary data, http://www.personeel.unimaas.nl/Bianca.vandenBosch/thesis.htm). Most of the later processes are less drastic as far as alterations in gene activity is concerned. Genes involved in TGF $\beta$ signaling seemed to be particularly involved 8 wks and were mainly 
upregulated. At 48 h ubiquitin-activating and ubiquitin-conjugating enzymes, ubiquitin proteases and ubiquitin ligases were up- and downregulated, while at the later time points these genes were mainly downregulated (Table $\$ 4$ supplementary data, http://www. personeel.unimaas.nl/Bianca.vandenBosch/thesis.htm).

\section{Discussion}

Analysis of gene expression data

Increased left ventricle weight/tibia length (LVW/TL) ratios and differentially expressed hypertrophy markers in the left ventricles of TAC mice, confirmed cardiac hypertrophy due to the banding procedure. After exclusion of all poor, negative and empty spots (flagged by ImaGene), about 7500 probes showed a detectable expression. This is more or less the expected percentage of genes expressed in the heart. ${ }^{24,26}$ The expression values of the genes were judged by strict criteria. At least two values per group (TAC and sham) per time point should be available. Using linear regression analysis, it was possible to detect small changes at a statistically reliable level, even using only cy 3 labeling. Not all of these small changes will be biologically relevant, but if more genes involved in the same process show a similar behavior, this provides additional evidence for a significant role of that process. ${ }^{27}$ Several differentially expressed genes that lack additional information, such as the "Riken cDNA clones" or "expressed sequences" (Table S4 supplementary data, http://www.personeel.unimaas.nl/Bianca.vanden Bosch/thesis.htm), were discarded from further analysis for the moment, but will be studied in the future. The microarray results were validated in a number of ways, such as consistent expression of different transcripts for the same gene and real-time PCR confirmation of differential expression of eight out of the nine genes, which demonstrates the reliability of the microarray data. Comparable results of real-time $P C R$ validation have been reported by others. ${ }^{28,29}$

General description of differentially expressed genes and processes

The high percentage of differentially expressed genes at $48 \mathrm{~h}$ most likely reflects a direct response to the sudden increase in blood pressure. As gene expression in the TAC mice was compared to sham-operated mice, it could be excluded that this response resulted from the surgical procedure. As no change in left ventricle weight was detectable at $48 \mathrm{~h}$, these processes likely reflect anticipation to the pressure overload. At $1 \mathrm{wk}$, the effect was mainly an upregulation of genes with a role in the establishment of cardiac hypertrophy. In the next phase ( 2 and 3 wks after TAC), the 
transition towards stable compensated hypertrophy accurred and the percentage of differentially expressed genes decreased. Genes were mainly downregulated.

During the development of compensated hypertrophy, the most striking differences in gene expression were observed for the processes energy metabolism and cytoskeleton. Also, reexpression of fetal genes was identified. Furthermore, processes such as transcription, cell growth, development, signaling, nucleobase, nucleoside, nucleotide and nucleic acid metabolism (e.g. DNA and RNA metabolism), translation, protein biosynthesis, protein degradation and $\beta$-amyloid metabolism contained a significant number of differentially expressed genes at distinct time intervals after TAC. Striking is the high number of genes that was differentially expressed at only one time point, suggesting that either processes are stage-specific or, more likely, may not be primarily related to the hypertrophy process in the compensated state.

\section{Alterations affecting energy metabolism}

Genes in glycolysis, TCA cycle, FA metabolism, respiratory chain and mitochondrion were mainly downregulated at $48 \mathrm{~h}$, as has been reported previously in hypertrophy. ${ }^{30,31}$ The expression of most mitochondria-related genes, including the respiratory chain, decreased, possibly reflecting an initial downregulation of metabolic processes to prepare for renewed growth. At 1 wk, Eno1 (enolase 1, allpha non-neuron), Gpi1 (glucose phosphate isomerase 1) and Pkm2 (pyruvate kinase, muscle) were upregulated, showing increased glycolytic activity of the heart. These results are consistent with the previously reported shift from FA towards glucose during cardiac hypertrophy. Notably, many studies have also observed this shift in the failing heart, in which the increased glucose utilization is thought to not fully compensate the reduction of FA oxidation. ${ }^{12}$ Recently, overexpression of Glut1 (glucose transporter 1) was reported to prevent the development of heart failure due to chronic pressure overload by increasing insulin-independent myocardia! glucose uptake and thus represents a beneficial adaptation. ${ }^{32}$ Glut1 was not present in the cDNA collection used, but upregulation of Stx4a (syntaxin 4A) in the mice at 1 wk after TAC also supports these findings. St $\times 4 a$ is required for Glut8 (glucose transporter 8) translocation..$^{33}$ Glut8 is a glucose transporter predominantly expressed during mammalian blastocyst development and is essential for cellular glucose uptake during development. ${ }^{3.4}$ Apparently, the initial downregulation of energy metabolism and the subsequent shift in substrate preference in the TAC mice enabled these animals to increase heart size and cope with the new physiological situation, without deterioration of cardiac function. 
Genes involved in mitochondrial protein import and mitochondrial protein synthesis were upregulated. Slc25a19 (solute carrier family 25, mitochondrial deoxynucleotide carrier, member 19) was upregulated 8.1-fold at $48 \mathrm{~h}$. This deoxynucleotide carrier (DNC) supplies the mitochondrial matrix with precursors for mitochondrial DNA synthesis. ${ }^{35}$ It appears that the initial restriction of metabolism is followed by an increased mtDNA synthesis and thus OXPHOS capacity. The simultaneous increase of a number of mitochondrial ribosomal genes and Mtif2 (mitochondrial translational initiation factor 2) at $48 \mathrm{~h}$ supports this and indicates that the first response to TAC also occurs at the level of translation. At 2,3 and 8 wks, all these genes showed basal expression levels again, indicating that energy metabolism in the compensated hypertrophic state is physiologically normal. During the preparation of this manuscript, Wagner et al. published the results of a comparable microarray study in TAC mice. ${ }^{36}$ The changes in metabolism identified are similar to our data, although the time point at which these changes occur is different ( 20 days vs $48 \mathrm{~h}$ ). Also, a different mouse strain is used. The conclusions of these authors are quite different from ours and may be due to the fact that no time series experiment was performed and that therefore, discrimination between transient and chronic processes is not possible. We observed that some of their described changes can eventually return to normal in compensated hypertrophy and not necessarily predispose to heart failure, as the authors suggest. ${ }^{36}$

\section{Alterations related to cardiomyocyte growth}

Results at $48 \mathrm{~h}$ show a switch to renewed growth, which was most evident at 1 wk, consistent with the increase in LVW. Adjustment of structure and size of myofibrils is an early response to deal with the increased workload. Actr1a was one of the cytoskeletal genes upregulated at $48 \mathrm{~h}$. It is an actin-related protein and the mast abundant molecule in the dynactin complex, which activates dynein-driven vesicle movement. ${ }^{37.38}$ Nrap (nebulin-related anchoring protein) was also upregulated at $48 \mathrm{~h}$ and shown to be essential for $\alpha$-actinin organization and organizing actin filaments during myofibril assembly in cultured embryonic chick cardiomyocytes. ${ }^{39}$ Changes in Nrap expression represent an adaptive response to strengthen the link between the myofibrils and the membrane for effective force transmission. ${ }^{40}$ The upregulation of cytoskeletal and sarcomeric genes underlines the physiological changes during early cardiac hypertrophy: the increase in cardiomyocyte size requires an adaptation in cytoarchitecture. 
Cardiomyocyte growth is also demonstrated by the upregulation of several genes associated with cell growth and/or cancer. Increased cardiac protein synthesis can be deduced from the process DNA and RNA metabolism; which falls in the GO category nucleobase, nucleoside, nucleotide and nucleic acid metabolism. One of the genes involved is Umpk (uridine monophosphate kinase), also known as Uck (uridine-cytidine kinase 2), which is 4.8- and 1.2-fold upregulated at, respectively 1 wk and 2 wks and fades out towards the later hypertrophic phase, similar to the hypertrophic marker ANF. Umpk catalyzes the first step in the production of the pyrimidine nucleoside triphosphates required for among others RNA. ${ }^{41}$ Recently, this gene was found to be upregulated in mice during the acute hypertrophic phase after Ang II (angiotensin II) treatment. ${ }^{42}$ increased RNA synthesis and protein content are essential for cardiac hypertrophy.

\section{Reactivation of fetal gene expression}

Apart from differential expression of ANF, Myhc-b, PIn and Nrap at $48 \mathrm{~h}$, several other embryonic genes showed differential expression. Melk (maternal embryonic leucine zipper kinase) is a member of the Snf1/AMPK serine/threonine kinase family and has so far only been implicated during mammalian embryogenesis, with the highest expression during maturation of oocytes and preimplantation development. ${ }^{43}$ In addition, Hoxb3 (homeo box 3), Mfng (manic fringe homolog, Drosophila), Tdgf1 (teratocarcinoma-derived growth factor 1) and Cul1 (cullin 1) were differentially expressed. These findings reflect the activation of fetal gene expression in cardiac hypertrophy, which may be cause or consequence of the renewed growth. ${ }^{8.9}$

\section{Alterations in genes related to $\beta$-amyloid metabolism}

Several genes associated with $\beta$-amyloid metabolism showed a downregulation during the initial hypertrophic phase, such as App (amyloid beta precursor protein) and Aplp2 (amyloid beta (A4) precursor-like protein 2). $\beta$-amyloid is a small piece of the larger protein App, of which the normal function has not yet been determined. Another gene present in the cluster of $\beta$-amyloid related genes was $1 \mathrm{tmb2}$, which has been associated with familial British dementia (FBD), a disorder associated with amyloid deposition and neurodegeneration in the central nervous system. ${ }^{44}$ It has been reported before that coronary artery disease and hypertension may be a forerunner to Alzheimer disease ${ }^{45}$ and recently, another link between hypertrophy and Alzheimer disease has been proposed in hypertrophic mice after treatment with Ang $11 .^{\text {t2 }}$ The precise role of these genes in the hypertrophic process remains to be elucidated. 
Changes occurring at the later (compensated) hypertrophic phase

We identified several other genes not previously reported as hypertrophy-related genes, such as Cetn2 (centrin 2) and Plxnb1 (plexin b), respectively up- and downregulated at 8 wks. Activation of signaling pathways such as G-protein signaling, MAPK signaling, Wrt signaling and TGF $\beta$ signaling was identified at the different time points, although genes related to TCF $\beta$ signaling were slightly upregulated only at 8 weeks after banding. Differences in gene expression were only modest and the differentially expressed genes could less easily be grouped into certain processes. A direct relation to the hypertrophic process is therefore questionable.

\section{Conclusions}

Compensated hypertrophy is characterized in our study by a restriction in metabolism in the early hypertrophic phase associated with an investment in the construction of the cytoskeletal and sarcomeric apparatus to deal with the increased workload. The establishment of cardiac hypertrophy is associated with an upregulation of genes involved in glycolytic activity and activation of fetal gene expression. The fact that these changes are transient indicates that the heart is able to compensate by hypertrophy and that progression into heart failure is prevented. In case this compensated phase cannot be reached, alterations in energy metabolism sustain and can be observed in the failing heart.

\section{Acknowledgements}

We thank the Leids Universitair Medisch Centrum (LUMC) for the distribution of the NIA 15k set. Dr. Jeroen Aerssens, Rob Janssen and Erika Timmer are acknowledged for their assistance with the microarray experiments and Ton Derix for his contribution to the data analysis. This research was supported by the Netherlands Heart Foundation (99.122) and the Cardiovascular Research Institute Maastricht (CARIM), The Netherlands.

\section{References}

1. Hunter $H_{1}$ Chien KR. Signaling pathways for cardiac hypertrophy and failure. Wngl/ Med. 1999:341:12761283 .

2. Dorn GW, 2nd, Robbins $J$, Sugden PH. Phenotyping hypertrophy: eschew obfuscation. Circ Res $2003,92: 1171-1175$

3. Agabiti-Rosei E, Muiesan ML. Prognostic significance of left ventricular hypertrophy regression. Adv Exp Med Biol 1997:432:199-205. 
4. Brown DW, Giles WH, Croft 18 . Left ventrienlar hypertrophy as a predictor of coronary heart disease mortality and the effect of hypertension. Am Meart 1.2000;140:848-856.

5. Tarone $G$. Lembo $G$. Molecular interplay between mechanical and humoral signalling in cardiac hypertirophy: Trents Mal Med. 2003;9:376-382.

6. Ritter $O$, Neyses $L$. The molecular basis of myocardial hypertrophy and heart fallure. Trends Mal Med. 2003:9:313-321.

7. Frey N, OIson EN. Cardiac hypertrophys the good, the bad, and the ugly. Amw Rev Physiod, 2003;65:45-79.

8. Chien KR, Knowlton KU: Zhu H, Chien S. Regulation of cardiac gene expression during myocal dial growth and hypertrophy: nolecular studies of an adaptive physiologic response. Foseb 1. 1991;5:3037-3046.

9. Komuro I, Yazaki $Y$. Control of cardiac gene expression by mechanical stress. Anmu Rev Physiol. 1993.55:55. 75 .

10. Lips DJ, deWindt L, wan Kraal] DI, Doevendans PA. Molecular determinants of myocandial bypertrophy and failure: alternative pathways for beneficial and maladaptive hypertrophy. Eur Heart 1.2003;24:883-896.

11. Selvetella $G$, Hirsch $E$, Notte $A$, Tarone $G$, Lembo $G$. Adaptive and maladaptive hypertrophic pathways: points of convergence and divergence. Cardiowasc Res. 200:4:63:373-380. vam Bilsen $M$, Smeets PJ, Gilde A, van der Vusse GJ. Metabolic remodelling of the failing heart: the cardiac burn-out syndrome? Cardiovasc Res. 2004;61:218-226.

13. Dahlquist KD, Salomomis N, Vranizan K, Lawlor SC, Conklin BR. GenMAPP, a new tool for viewing and analyzing mïcroarray data on biological pathways. Nat Genet, 2002;31:19-20.

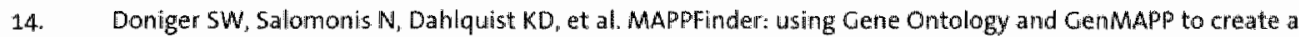
global gene-expression profile from micraaray data. Genome Biol. 2003:4: R.7.

15. Glemisson P, Coessens B, Van Vooren S, wal. TXTGate: profiling gene groups with text-based information. Cenome Biol. 2004;5:R43.

16. De Sinet F, Mathys 1, Marchal K, et al. Adaptive quality-based clustering of gene expression profiles. Bioinformatics. 2002:18:735-746.

17. Rackman HA, Ross RS, Harris AN, et al. Segregation of atrial-specific aind inducible expression of an atrial matriuretic factor transgene in an in vivo murine model of cardiac hypertrophy. Proc Natl Acod Sci USA. $1991-88: 8277-8281$

18. Tanaka TS, laradat SA, Lim MK, et al. Genome-wide expression profiling of mid-gestation placenta and embryo using a 15,000 mouse developmental cDNA microarray. Proc Natl Acad Sci U 5 A. 2000;97:91279132.

19. Kargull G., Dudiekula $D B$, Qian $Y$, el all. Verification and initiali annotation of the NiA mouse 15K CDNA clone set. Nat Genet. $2001 ; 2817-18$.

20. Fare $T L$, Coffey EM, Dai $H$, et all. Effects of atmospheric ozone on microarray data qualty. Anal Chem. $2003: 75: 4672-4675$

21. Hegde P. QI $R$, Abernathy K, et al A concise guide to cDNA micnaarray analysis. Biotechntques. 2000;29:548. $550,552-544,556$ passim.

22. Akaike H. Information theory and an extension of the maximum likelihood principle. In: Petrov BN. Csaki F. eds. Second intermational Symposium on waference Theory. Bud apest: Akad émiai Kiado; $1973: 267-281$.

23. Sadashima , tzumo 5. The cellular and molecular response of cardiac myocytes to mechanical stress. Anmu Rev Physiol 1997,59:551-571.

24. Zhao M. Chow A, Powers J, Fajardo G, Bernstein D. Microarray Analysis of Gene Expression after Transwerse Aortic Constriction in Mice. Physiol Genomics. 2004

25. Kikuno $R_{*}$ Nagase T, Waki M. Onara O. HUGE: a database for human large proteins identified in the Kazusa CDNA sequencing project. Nucleic Acids Res. 2002,30:166-168.

26. Friddie CJ. Koga T, Rubin EM, Bristow J. Expression profiling reveals distinct sets of genes altered during induction and regression of cardiachypertrophy. Proc Nat! Acad SCi US A. 2000:97:6745-6750.

27. Mootha VK, Lindgren CM. Erikson KF, et al. PGC-1alpha-responsive genes inwolwed in oxidative phosphorylation are coordinately downregulated in human diabetes. Nat Genet, 2003;34:267-273. 
28. Hashimoto $M$, koda $M$, no $H_{2}$ et al Gene expression profiling of cathepsin $D_{r}$ metallothioneins-1 and -2 , oxteopontin, and tenascin-C in a mouse spinal coid anjury model by CDNA microarray analysis. Acto Meuropothof (Berl). 2004.

29. Duque $G$, Macaritto $M$, Kremer $R$. Vitamin $D$ treatment of senescence accelerated mice (SAM-P/6) induces several regulators of stromal cell plastichty. Biogerontology. 2004,5:421 429.

30. Allard MF, Schonekess BO, Henning $\$ L$, English DR, Lopaschuk $G D$. Contribution of oxidative metabolism and glycolysis to ATP production in hypertrophied hearts. Am / Physiol. 1994;267:4742-750.

31. Sambandam $N_{,}$Lopaschuk GD, Brownsey RW, Allard MF. Energy metabolism in the hypertirophied heart. Heart Fail Rev. 2002;7:161-173.

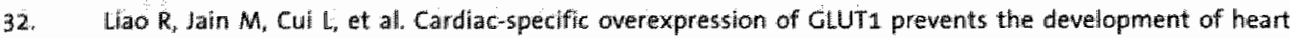
failure attributable to pressure overioad in mice. Circulation 2002;106:2125-2131.

33. Wyman $A H$, Chi M, Riley d, et al. Syntaxir 4 expression affects glucose transporter 8 translocation and embryo surviwal. Mol Endocrinol. 2003:17:2096:2102.

34. Pinto AB, Garayannopoulos MO. Hoehn A, Dowd L, Moley KH. Glucose transporter 8 expression and translocation are critical for murine blastocyst survival. Biol Reprod. 2002;66:1729-1733.

35. Dolce $V$. Fiermonte $G$, Runswick MJ, Palmieri F, Walker JE. The human mitochondrial deoxynucleotide carrer and its role in the toxicity of nucleoside antivirals. Proc Natl Acad Sci U S A. 2001:98:2284-2288.

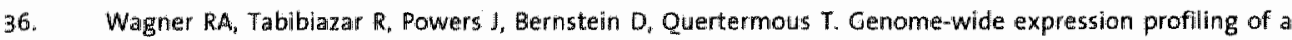
cardiac pressure overload model identifies major metabolic and signalling pathway responses. $\mathrm{Mol}$ Cell Cardiol. 2004;37:1159-1170

37. Les-Miller IP. Helfman DM, Schroer TA. A vertebrate actin-related protein is a component of a multisubunit complex involved in microtubule-based vesicle motility. Nature. 1992;359:244-246.

38. Clark SW, Meyer DI. Centractin is an actin homologue associated with the centrosome. Nature. $1992 ; 359: 246-250$.

39. Carroll S, Lu S, Herrera AH, Horowits R. N-RAP scaffolds $\mid-Z$ - 4 assembly during myofibrillogenesis in cultured chick cardiomyocytes. 1 Cell Sci. 2004;117:105-114.

40. Ehler E, Horowits R, Zuppinger $C_{r}$ et all. Alterations at the intercallated disk associated with the absence of muscle LIM protein. J Cell Biol. 2001;153:763-772.

41. Suzuki NN, Koizumi K, Fukushima M, Matsuda A, Inagaki F. Crystallization and preliminary X, ray analysis of human uridine-cytidine kinase 2. Acta Crystallogr D Biol Crystallogr. 2003;59:1477-1478.

42. Larkin JE, Frank BC, Gaspard RM, et al. Cardiac transcriptional response to acute and chronic angiotensin II treatiments. Physiol Genomics. 2004:18:152-166.

43. Heyer BS, Warsowe I, Solter D, Knowles BB, Ackerman SL. New member of the Snf1/AMPK kinase famlly. Melk, is axpressed in the mouse egg and preimplantation embryo. Mol Reprod Dev. 1997;47:148:156.

44. Mead $\$_{3}$ James-Calton $M$, Revesz $T_{2}$ et al. Familial Biritish dementia with amyloid anglopathy: early clinical, meuropsychologlcal and imaging findings. Bram. 2000;123 ( Ft 5):975-991.

45. Sparks DL, Martin TA, Gross DR, Hunsaker JC, 3rd, Link between heant disease, cholesterol, and Alzheimer's disease: a review. Microsc Res Tech. 2000;50:287-290. 



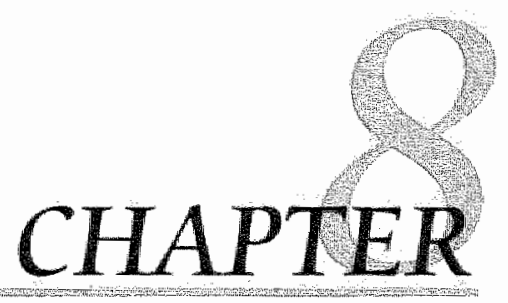

\section{The early genetic profile of maladaptive hypertrophy in cMyBP-C knockout mice}

L.M.T. Eijssen ${ }^{3 *}$, B.J.C. van den Bosch ${ }^{1 *}$, N. Vignier ${ }^{2}$, P.J. Lindsey ${ }^{2}$, C.M.M. van den Burg $^{3}$, L. Carrier 2.3 , P. A. Doevendans ${ }^{4.5}$, H.J.M. Smeets ${ }^{2}$

1 Cardiovascular Research institute Mastricht (CARIM), Dept of Genetics \& Cell Biology, Maastricht University. The Netherlands

2. INSERM, U582, Paris, F-75013 France

3 Imstitute of Experimental and Clinical Pharmacology, University-Hospital Hamburg Fppendorf. Hamburg, Germany

4 Dept. of Cardiology of the Heart lung Centre Utrecht (UMCU), The Netherlands Interuniversity Cardiology Institute of the Netherlands (ICIN), Utrechl, The Netherlands These authors contributed equally to this work 


\section{Abstract}

Familial hypertrophic cardiomyopathy (FHC) is an autosomal dominant disease, which predominantly involves the interventricular septum, and is characterized by left ventricular hypertrophy (LVH) with myocardial disarray and interstitial fibrosis. Cardiac myosin binding protein $\mathrm{C}$ (CMyBP-C) mutations are the most common cause of $\mathrm{FHC}$, accounting for about $20 \%$ or more of all mutations linked to it. A CMyBP-C knockout (KO) mouse model has been developed, in which heterozygotes display asymmetric septal hypertrophy as in FHC, and homozygotes develop eccentric LVH. Gene expression profiling was performed on left ventricular RNA from 9-weeks-old mice to identify the molecular processes in the pre-hypertrophic and early hypertrophic phase. Gaussian models were fit for each probe to determine differential expression in any or both of the KO groups versus wild-type (WT) mice. Differential genes were annotated with several statistical, literature mining and database tools. The most prominently changed processes were MAP kinases/signaling, apoptosis, energy generation, cell structure/sarcomere, RNA regulation and protein turnover. Similar processes occurred in heterozygotes and homozygotes, but the effects were more pronounced in homozygotes. Especially genes related to energy generation, the sarcomere and regulation were more affected in this group than in the heterozygotes. Several genes were only differentially expressed in one of both groups, or even showed opposite effects, but the significance of this remains to be determined. A clear and important observation in both groups was that the molecular changes related to maladaptive hypertrophy were already emerging or present in the early stage mice. The molecular processes leading to deterioration of cardiac function were already initiated very early, which may enable possible strategies for (preventive) therapy.

\section{Introduction}

Familial hypertrophic cardiomyopathy (FHC) is an autosomal dominant disease, which predominantly involves the interventricular septum, and is characterized by left ventricular hypertrophy (LVH) with myocardial disarray and interstitial fibrosis." Cardiac myosin binding protein $\mathrm{C}(\mathrm{CMyBP}-\mathrm{C})$ mutations are the most common cause of FHC, accounting for about $20 \%$ or more of all mutations.$^{2.6}$ Cardiac MyBP-C is a large and abundant myofibrillar protein, which interacts with myosin heads, actin and titin, indicating its important structural and functional role during cardiac contraction. ${ }^{7.8}$ In contrast to other sarcomeric proteins in which mutations have been found to cause $F H C$, considerably less is known about the precise structure and function of this protein, and the molecular mechanism by which $\mathrm{CMyBP}-\mathrm{C}$ gene mutations lead to 
FHC. ${ }^{8}$ A suitable model to study human FHC would be a heterozygous CMyBP-C null mouse carrying only one functional allele. Two cMyBP-C mutant mouse models recently developed showed no evidence of asymmetric septal hypertrophy", which is a key phenotypic feature of human FHC. ${ }^{10}$ However, inactivation of one mouse $\mathrm{CMyBP}-\mathrm{C}$ allele by targeted deletion of exons 1 and 2, resulted in asymmetric septal hypertrophy associated with fibrosis at ten to eleven months of age. Inactivation of two alleles led to the development of eccentric LVH with decreased fractional shortening at three to four months of age and impaired relaxation after nine months. ${ }^{11}$ Elucidation of the molecular events involved in heterozygous and homozygous CMyBP-C null mice will provide insight into the development of LVH in human FHC related to CMyBP-C mutations.

The application of microarray technology enables us to screen thousands of different genes simultaneously and to compare gene expression patterns during the development and progression of diseases. Moreover, new genes and processes can be characterized using this strategy. To identify gene expression profiles of presymptomatic and early phase hypertrophy, we performed microarray analysis, comparing early stage CMYBP-C KO mice to WT mice. Left ventricular RNA of heterozygous and homozygous CMyBP-C KO mice was hybridized to microarrays containing a $15 \mathrm{~K}$ cDNA collection of embryonic origin. ${ }^{12}$ For each gene, we fitted Gaussian models to determine the differential expression. The differentially expressed genes were further evaluated using GenMAPP ${ }^{13}$ and MAPPfinder ${ }^{14}$, online databases at the NCBI website and the PubMatrix tool ${ }^{15}$, to gain more insight into the mechanisms underlying the differences in phenotype between heterozygous, homozygous $\mathrm{CMyBP}-\mathrm{C}$ KO mice and control littermates.

\section{Materials and methods}

\section{CMYBP-CKO mice}

Heterozygous and homozygous CMYBP-C KO mice develop a non-lethal cardiomyopathy, but the specific phenotype and disease progression differs. ${ }^{11}$ Heterozygotes develop asymmetric septal hypertrophy at ten to eleven months, symptoms that correspond to the human phenotype in FHC, and homozygotes develop eccentric LVH at three to four months. Animals were sacrificed at nine weeks of age and the hypertrophy status of $5 \mathrm{KO}$ and $6 \mathrm{WT}$ mice was determined by calculating the LV weight to body weight ratio. LV heart samples were prepared from 1 male WT and 1 
male heterozygous $K O$ mouse, 2 male homozygous $K O, 2$ female $W T$ and 2 female heterozygous $\mathrm{kO}$ mice, and 1 female homozygous $\mathrm{kO}$ mouse.

\section{Microarray preparation}

Inserts of the NIA Mouse 15K cDNA Collection, containing 15000 different CDNA clones derived from embryonic and fetal cells and tissues ${ }^{12}$ were PCR amplified directly from the glycerol stocks. The insert sizes of eight clones per 96-well plate were verified as a quality check. After purification, PCR products were resuspended at a concentration of $200 \mathrm{ng} / \mathrm{\mu l}$ in 50\% DMSO and spotted onto UltraGAPS (Gamma Amino Propyl Silane) ${ }^{\mathrm{rm}}$ Coated Slides (Corning, NY) using the Microgrid II arrayer (Biorobotics, UK). This arrayer is mounted with a 16 pin head and slides were printed in three separate runs. Each slide consisted of three meta-grids, subdivided in 16 sub-grids, corresponding to the area printed by each pin. Each sub-grid has 20 rows and columns, yielding 400 spots per sub-grid and 6400 per meta-grid.

Out of the total of 19200 spots, 15120 spots corresponded to the CDNA clones. The remaining 4080 spots were allocated to spikes, positive and negative controls, DMSO, or remained empty. Eight different spikes were printed four times by each of the 16 pins in all three meta-grids. Five positive controls were spotted six times by each pin in every meta-grid. Three negative controls and DMSO were spotted four times by every pin in each of the three meta-grids. Finally, seven spots were left empty in each of the 16 sub-grids of the three meta-grids. Each of these products was spotted in positions chosen uniformly across the sub-grid and therefore the slide. Because of the spikes, possible variations between slides can be taken into account during the data amalysis, allowing precise estimation of the differences in gene expression between the groups of mice.

\section{RNA extraction, labeling and hybridization}

Total LV RNA was extracted using TRIzol reagent (Invitrogen, Carlsbad, CA) according to the manufacturer's protocol, followed by purification with the RNeasy clean-up kit (Qiagen, Valencia, CA). RNA quality was determined using the Bioanalyser (Agilent, Palo Alto, CA). As the Cy5-dyes have been reported to be unstable due to the amount of atmospheric ozone in summer ${ }^{16}$, we decided to only use Cy3 labeling and compare the samples hybridized on different slides. Aminoallyl labeling and cDNA hybridization were performed according to the protocol by Hegde et al. ${ }^{17}$ and slightly adjusted for use in our own laboratory. In short, ten micrograms of total RNA from each sample was reverse transcribed into cDNA using random primers in the presence of aminoallyl 
dUTP. Following purification, products were coupled to Cy3 NHS-ester (Amersham; Piscataway, NJ). Labeled CDNAs were purified and labeling efficiency was determined. Slides were prehybridized in $1 \%$ BSA (bovine serum albumin), 50\% formamide, $5 \times$ SSC and $0.1 \%$ SDS for $45 \mathrm{~min}$ at $42^{\circ}$. Slides were then washed and dried. Labeled CDNA was resuspended in $60 \mu$ l hybridization mix, containing 50\% formamide, $5 \times$ SSC, $0.1 \%$ SDS and $8 \mu \mathrm{g}$ mouse Cotl-DNA and hybridized to the arrays at $42^{\circ}$ for 16 hours. After hybridization, slides were washed for 4 min at $42^{\circ}$ in 1 XSC $/ 0.2 \%$ SDS, followed by a 4 min wash at room temperature in 0.1 XSC $/ 0.2 \%$ SDS and finally washed manually for $4 \mathrm{~min}$ at room temperature in $0.1 \times$ SSC. Slides were then dried by centrifugation for 5 $\min$ at $500 \mathrm{rpm}$ and scanned with a dual-laser scanner (Affymetrix/ GMS 418, Santa Clara, CA).

\section{Microarray data analysis}

The scanned microarray images were processed and quantified using ImaGene software (BioDiscovery, Boston, MA). Spots flagged by this program as being empty, negative, or poor were excluded from further analysis. The remaining probes were analyzed using a Gaussian linear regression including labeling efficiency and, depending on the number of repetitions available, sex of the animals and one or more of the eight spikes were added to the model. Fitness of the models was evaluated by the Akaike Information Criterium (AIC).$^{18}$ This criterion selects the least complex model that fits the data by summing the minus log-likelihood of the model with the number of parameters it contains. For each gene, several models with and without effects for each of the groups were built and the one with the lowest AIC was selected. This resulted in several possibilities: no effect (non-differential gene), a common effect in both KO groups versus the WT mice, an effect in heterozygotes only, an effect in homozygotes only, or an effect between all groups in the analysis. The last possibility means that both homozygotes and heterozygotes were differential with respect to the WT mice, but with significantly different effect sizes. If only one of the KO groups could be analyzed, the gene was included for that group only. In the analyses, onlly genes that were differentially expressed in one or both of the KO groups were considered.

First, GenMAPP was used to evaluate which GO (Gene Ontology) categories were overrepresented in the set of genes that could be analyzed as compared to the a priori expectations. For genes with consistent effects for all of their probes, the murine gene name and description were retrieved using Locuslink at the NCBI website. "Homologene" was used to find human homologues for the genes. Then, gene descriptions were extended by information from the Nucleotide- and, if necessary, 
$\mathrm{MeSH}$ and OMIM-entries of both the mouse genes and their human homologues (NCBI). Annotations were further completed by performing automatic PubMed searches using PubMatrix to find literature links between the genes in the list and several processes of interest that came up in the previous steps. Incorrect links were excluded from the results, like abstracts in which a gene and a process are both mentioned, but not in relation to each other.

\section{Results}

From probes to differential genes

For both WT and homozygous KO mice, LV weight to body weight ratios were determined. These were significantly different with $p=0.00003$ using a student $t$-test ( $p=0.005$ using Mann-Whitney test). The mean and standard deviation of the WT group were 4.34 and 0.43 . For the homozygotes, these figures were respectively 6.44 and 0.46 . This confirmed that the CMyBP-C homozygotes already developed considerable hypertrophy at 9 wks of age. Increase of the LV weight to body weight ratio in homozygotes starts at birth. The heterozygotes show no hypertrophy up to age 11 months. ${ }^{11}$

Because of the different number of mice within the groups and the flagging of spots, the number of samples - and as such degrees of freedom - might differ for each gene. Therefore, the maximum number of covariates possible was used. A list of 8188 probes could be analyzed, of which 870 were differentially expressed in at least one of the KO groups. Locuslink Identifiers (LL IDs) were retrieved and the probes with known IDs were retained. A few genes were represented by more than one probe and were removed in case not all probes were significant or if the effect was inconsistent. Genes were also removed if the intensities were near the saturation value for all groups. These pre-processing steps ensured good quality of the expression data for the genes selected. In addition, the variation in the expression of the eight spikes was low, both within and between slides. For the genes that could be analyzed in both $\mathrm{KO}$ groups, a reliable list of 53 genes with differential expression between WT and KO mice was obtained, consisting of 15 up- and 38 downregulated genes. A total of 92 genes was differentially expressed with a different effect for heterozygotes and homozygotes. Amongst these, 8 demonstrated opposite effects in heterozygotes and homozygotes, 66 were only differentially expressed in one of both groups, with most upregulated in homozygotes, and 18 showed consistent effects in both KO groups, but of a different range, as otherwise they would have been in the first group. Figure 1 gives an overview of the number of genes after each step and in each group for the entire procedure. 


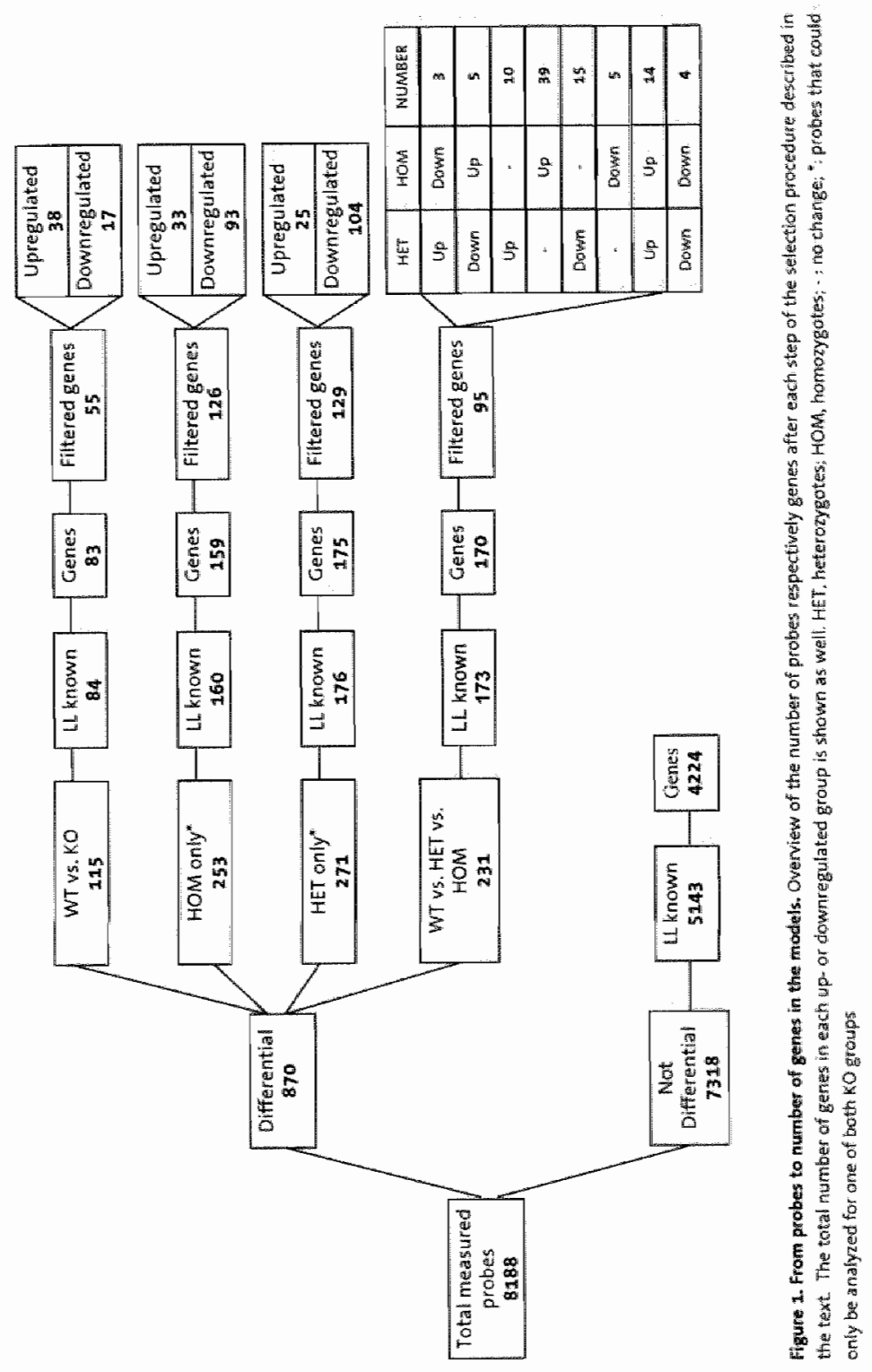


Overall, the number of downregulated genes was higher than the number of upregulated genes in heterozygotes (145 vs 90) and more or less equal in homozygotes (12.2 vs 129). The total number of differentially expressed genes was slightly higher in the homozygous group. The fold changes tended not to be very large in this data set. For the genes with a common effect in both $\mathrm{KO}$ groups, only one had a fold change below 0.33 (with value 0.27 ), and none above 3 (maximum of 2.60). For the ones with different effects, in heterozygotes, none showed a fold change below 0.33 (minimum of 0.35 ) and two genes above 3 (values 7.87 and 11.50). For the homozygotes these were respectively two (values 0.26 and 0.32 ) and four genes (maximum 43.69 , second highest 5.04). For the genes analyzable for heterozygotes or homozygotes only, in total 13 had a value below 0.33 and two above 3. For all differential genes and their associated fold changes, see Supplementary Data Table 1 (http://www.personeel. unimaas.n//Bianca.vandenBosch/thesis.htm).

\section{Overview of processes present}

The top list of most significant Local MAPPs for the comparison between WT and KO mice, according to GenMAPP, contained processes related to translation, cell replication, and Wnt- and G-protein signaling (Supplementary Data Table 2, http://www.personeel.unimaas.nl/Bianca.vandenBosch/thesis.htm). Considering GO annotations, processes related to cell structure and cell-environment interaction, RNA handling, protein ubiquitination and -folding, energy, oxygen transport, GTPases, and calcium, were identified. For both $\mathrm{KO}$ groups, the significant processes were similar. To obtain more detailed information on the functions of the differentially expressed genes, Nucleotide-, MeSH- and OMIM-entries were evaluated. Some processes that were frequently present in the resulting gene list were apoptosis, cell structure and attachment, mitosis and mitogen, mitochondrial, serine/threonine kinases, ubiquitination, and zinc finger proteins. For these processes and functions the list of all differential gene names was loaded into PubMatrix with keywords representing them: 'apoptosis', "myosin' and 'actin', 'mitosis', 'mitochondrion", 'serine threonine kinase', 'ubiquitin', and 'zinc finger' and 'ring finger' respectively. Overall, for the genes with literature links to these keywords according to PubMatrix, nearly $50 \%$ were correct. From these genes, those that provided sufficient evidence for the association under consideration were selected, further reducing the list. As there were still some annotations obtained using PubMatrix and missed by hand and the other way around, both lists were merged to retrieve a list of annotations as complete as possible. The genes in the most prominent processes are presented in Table 1. 
Table 1. Genes identified in most prominent processes

MITOSIS I MAP KINASES

\begin{tabular}{|c|c|c|c|}
\hline Mouse Gene Name & Description & HET. & HOM \\
\hline ligtp & interferon-gammanducible GTPase & \multicolumn{2}{|c|}{ down } \\
\hline Mphosphy & M-phase phosphoprotein 9 & \multicolumn{2}{|c|}{ dowm } \\
\hline C430014ML2Rik & RIKEN CDNA C 430014 MO2 gene & \multicolumn{2}{|c|}{ up } \\
\hline $\operatorname{cd} k 2$ & cyclin-dependent kinase 2 & \multicolumn{2}{|c|}{ up } \\
\hline Pbk & $P O Z$ binding kinase & \multicolumn{2}{|c|}{ up } \\
\hline Rad1s & RAD18 homolog (5. gerevisiae) & \multicolumn{2}{|c|}{ up } \\
\hline Btrc & Betavtransducin repeat containimg proteim & mat & down \\
\hline G:ap43 & Growth associated protein 43 & ma & down \\
\hline Gnais & guanine nucleotide binding protein, alpha inhibiting 3 & na & down \\
\hline Taces & ransforming, acidic coiled-coil containing protein 3 & na & down \\
\hline Kit & akit oncogene & na & up \\
\hline slk & STE20-like kinase & na & up \\
\hline Madzlibp & MAD2L1 tuinding protein & กล & up \\
\hline Etsa & E26 avian leukemia oncogene $1,5^{2}$ domain & ma & up \\
\hline combi & cyctin $B 1$ & down & ma \\
\hline sfobl & Splicing factor $3 b_{*}$ subunit $\mathbb{I}$ & down & ma \\
\hline Runx 2 & runt related transcription factor 2 & down & na \\
\hline Fyn & Fyn proto-oncogene & down & 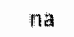 \\
\hline Mapk8ip3 & mitogen-activated protein kinase 8 interacting protein 3 & down & ma \\
\hline Spred1 & Sprouty protein with EVH-1 domain 1, related sequence & down & nat \\
\hline $\operatorname{cdc} 37$ & cell division cycle 37 homolog (S. cerrevisiae) & . & up \\
\hline Bag2 & Bcl2-associated athamogene 2 & $*$ & uр \\
\hline Fhl1 & four and a half LIM domains 1 & - & up \\
\hline $5 k b 1$. & 5KB1 homolog (S. pombe) & - & up \\
\hline Tbrg4 & transforming growt hactor beta fregulated gene & - & up \\
\hline $\operatorname{Trim} 25$ & tripartite motif protein 25 & - & up \\
\hline Fin & F11 recepitor & down & * \\
\hline D19ErtdH44e & DNA siegment, Chr 19, ERATO Doi 144, expressed & up & - \\
\hline Ets.2 & E2.6 avian leukemia o-ogene $2,3^{\prime}$ domain & up & . \\
\hline Csie1L & CAS, chromosome segregation 1-like & up & up \\
\hline Mapks & JNK, mitogen actiwated protein kinase 9 & up & $u \bar{p}$ \\
\hline Xpon & exportin 1 , CRMI homolog (yeast) & $u p$ & up \\
\hline
\end{tabular}

HET, heterozygotes; $40 M$, homozygotes; na: not analyzed, - no change

A.POPTOSIIS

\begin{tabular}{|c|c|c|c|}
\hline Mouse Gene Name & Description & HET & HOM \\
\hline Foxa3 & forkhead box 03 & \multicolumn{2}{|c|}{ down } \\
\hline lgtp & interferon-gamma inducible GTPase & \multicolumn{2}{|c|}{ down } \\
\hline Txndc 5 & thioredoxin domain contaiming 5 & \multicolumn{2}{|c|}{ up } \\
\hline Wdr 3 & WD repeat & na & down \\
\hline $5100 a 6$ & 5200 calcium binding protein A6 (calcycli m) & n目 & down \\
\hline Taccs & transforming acidic coiled-coll containing protein 3 & na & dowin \\
\hline $\operatorname{Txn} 2$ & thioredoxin 2 & $\mathrm{na}$ & down \\
\hline Prdms & PR domain containings & na & down \\
\hline Slk & STE20-Hke kinase & nat & up \\
\hline Kitt & c-Kit oncogene & na & up \\
\hline
\end{tabular}




\begin{tabular}{|c|c|c|c|}
\hline Mouse Cene Name & Description & HET & HOM \\
\hline Etsi & E 6 awan les kemia oncogene 1.5 domain & ma & up \\
\hline Runk2 2 & runt related transciption factor 2 & down & na \\
\hline Fyn & Fyn proto-oncogerale & down & na \\
\hline RabGip2 & Rabo interacting protein 2 & down & na \\
\hline crnobl & catenin, butallike 1 & up & na \\
\hline Pacsin2 & protein kinase C and casein kinase substrate in neurons 2 & up & na \\
\hline Birc6 & baculoviral IAP repeat-containing 6 & down & up \\
\hline Cugbp2 & ETR-3, CUG triplet repeat, RNA Binding protein 2 & down & up \\
\hline Plagla & pleiomorphic adenoma gene-like 1 & down & $u p$ \\
\hline $\mathrm{Bag} 2$ & Bcliz-associated athanogene 2 & - & up \\
\hline BHI & basic transcription factor 3 &. & up \\
\hline $\operatorname{cdc} 37$ & cell divisian cycle 37 homolog (s. cerevisiae) & - & up \\
\hline Perp & PERP, TP53 apoptosis effector & * & up \\
\hline Ppíc & peptidylprolyl isomerase C & - & up \\
\hline Stk17b & apoptosis-inducing serine/thireonime kinase $17 \mathrm{~b}$ & * & up \\
\hline Anxas & amnexin $A 5$ & down & - \\
\hline Fmr1 & fragile $X$ mental retardation syndrome 1 hamolog & down & " \\
\hline Csedl & CAS, chromosome segregation 1- like & up & $u p$ \\
\hline Mapkg & NMK, mitogen activatted protein kinase 9 & up & up \\
\hline Uquarh & wbiquinolwcytochrome cireductase thinge protein & up & up \\
\hline $\mathbb{E t s} 2$ & E26 avian le ukemia o-ogene $2,3^{\prime}$ domain & up & $*$ \\
\hline
\end{tabular}

HET heterozygotes; HOM, homozygotes; na: mat analyzed ; - no change:

MITOCHONDRIAL

\begin{tabular}{|c|c|c|c|}
\hline Mouse Gene Name & Description & HET & HOM \\
\hline D10Ertd214e & DNA segment, Chr 10, ERATO Doi 214 , expressed & \multicolumn{2}{|c|}{ down } \\
\hline Mipl19 & mitochondrial ribosomal protein $L 19$ & \multicolumn{2}{|c|}{ down } \\
\hline Acads & acyl-Coenzyme A dehydrogenase, short chain & \multicolumn{2}{|c|}{ up } \\
\hline Echs1 & enoyl Coenzyme A hydratase, short chain, 1 , mitochondrial & \multicolumn{2}{|c|}{ up } \\
\hline Ndufc2 & NADH dehydrogenase (ubiquinone) 1 , subcomplex unknown, 2 & \multicolumn{2}{|c|}{ up } \\
\hline Mrplis & mitochondrial ribosomal protein L15 & \multicolumn{2}{|c|}{ up } \\
\hline Stuclg 2 & succinate-Coenzyme A ligase, CDP forming beta subunit & \multicolumn{2}{|c|}{ up } \\
\hline Timm22: & translocase of inner mitochondrial membrane 22 homollog (veast) & na & down \\
\hline $\operatorname{Tin} 2$ & thioredoxin 2 & ria & dowth \\
\hline Afgila & AFGi3(ATPase family gene 3)-Iik 2 byeast) paraplegin-velated & na & up \\
\hline Alats 2 & anninolevulinic acid synthase 2 , erythroid & down & ma \\
\hline Nuturs 3 & NADH dehydrogenase (ubiquinone) Fe-s protein 3 & dowm & ma: \\
\hline Ppargenata & peroxisome prolif. active. receptor.gamma,coactivator 1 alpha & down & 镂 \\
\hline Mrpls2 & mitochondrial ribosomal protein $\mathrm{L} 52$ & up & $\operatorname{ma}$ \\
\hline Pdhx & pyruvate dehydrogenase complex, component $X$ & up & na \\
\hline $1810063 B 05 R K$ & RIKEN CDNA 1810063605 gene & down & 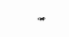 \\
\hline Aldoc & aldolase $3, \mathrm{C}$ isoform & . & upi \\
\hline Ckmta & creatine kinase, mitochond rial 1 , ubiquitous & - & up \\
\hline Perp & PERP, TP53 apoptosils effector & 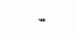 & up \\
\hline Btf3 & basic transcription factor 3 & - & up \\
\hline Uacrh & ublquinol-cytochrame c reductase hinge protein & up & up \\
\hline Acad8 & acyl-Coenzyme Adehydrogenase family, member 8 & up & - \\
\hline
\end{tabular}

HET, heterozygotes; HOM, homozygottes; ma: rot analyzed: - : no change: 


\begin{tabular}{|c|c|c|c|}
\hline Mouse Gene Name & Description & HET & HOM \\
\hline Ifrdil. & interfieron-related developmentall regulattor 1 & \multicolumn{2}{|c|}{ down } \\
\hline Fndes & fibronect in type tll domain containing 5 & \multicolumn{2}{|c|}{ dowlin } \\
\hline Mapt & microtubule associated protein tau & \multicolumn{2}{|c|}{ dowir } \\
\hline $\mathrm{BCO} 21523$ & CDNNIA seque-e BCO21523 & \multicolumn{2}{|c|}{ down } \\
\hline Actiba & actinn-like $6 \mathrm{~A}$ & \multicolumn{2}{|c|}{ down } \\
\hline Foxo3 & forkhead box $\mathrm{O}_{3}$ & \multicolumn{2}{|c|}{ down } \\
\hline Abiz & abl-interactor 2 & \multicolumn{2}{|c|}{ up } \\
\hline PA2 pop & Myb protein P4,2POP & \multicolumn{2}{|c|}{ wp } \\
\hline Mastl & microtubule as sociated serine/threonine kinasenalike & na & down \\
\hline 5730409 F24Rik & RIKEN $\mathrm{DDNA} 5730409 \mathrm{~F} 24$ geme & na & down \\
\hline $8 b s 4$ & Bardet-Biedl syndrome 4 homolog (humany) & na & down \\
\hline Waspip & Wiskott-Aldrich syndrome protein interasting protein & กี & down \\
\hline Spg. 4 & spastic paraplegia 4 homolog (human) & กต & up \\
\hline Spred1 & sprouty protein with EVH-1 domain 1, related sequence & down & na \\
\hline Smoc1 & SPARC related modular calcium binding $\mathbb{1}$ & up & ma \\
\hline Pdimi & PDZ and $U M$ domain 1 (elfim) & up & na: \\
\hline Cugbp2 & CUG triplet repeat $\mathrm{R}_{i} N \mathrm{~b}$ binding protein 2 & dowr: & up \\
\hline Fmr1 & fragile X mental retardation syndrome 1 homolog & diown & 。 \\
\hline F11r & F11 receptor & down & 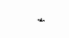 \\
\hline Smarce1 & $\begin{array}{l}\text { SWI/SNF related, matrix associated, actin dependent regulatior of } \\
\text { chromatin, subfamily e, member } 1\end{array}$ & down & $=$ \\
\hline $2310057 \mathrm{H} 16 \mathrm{Rik}$ & RIKEN CDNA $2310057 \mathrm{H} 16$ gene & down & 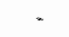 \\
\hline Arhgap 21 & Rho GTPase activating protein 21 & down & . \\
\hline Lad1 & ladinin & down & down \\
\hline Abiit & abl-interactol 1 & 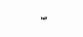 & up \\
\hline Fhl 1 & four and a half LliM domains 1 & - & up \\
\hline Smin & smoothelin & * & up \\
\hline D2Ertd435e & DNA segment, Chr 2, ERATO Doi 435, expressed & - & up \\
\hline Actin 4 & actinin alpha 4 & - & up \\
\hline 1.200009HO6Rik & RIKEN ICDNA 1200009106 gene & - & up \\
\hline Myh10: & myosin heavy chailn 10 , mon-muscle & - & up \\
\hline Stk17b & apoptosis-inducing serine/threonine kinase $17 \mathrm{~b}$ & " & up \\
\hline Bage 2 & Bichlzassociated athanogene 2 & - & up \\
\hline $\lg a$ is 4 & lectin, galactose binding, soluble 4 & up & down \\
\hline D19Ertd 144e & DNA segment, Chr 19, ERATO Doi 144, expressed & up & . \\
\hline
\end{tabular}

HET, heterozygotes: HOM, homozygotes; na: not analyzed; - no change

\section{SERINE/THREONINE PROTEINE KINASE}

\begin{tabular}{|c|c|c|c|}
\hline Mouse Gene Name & Description & HET & HOM \\
\hline Pok & POZ binding knase & \multicolumn{2}{|c|}{ Uip } \\
\hline cdk2 & cyclin-dependent kinase 2 & \multicolumn{2}{|c|}{ up } \\
\hline lkbke & inhibitor of kappab kinase epsilon & natio & down \\
\hline Masti & microtubule associated serine/threonine kinase-vke & na & dlown \\
\hline Kit & c-Kit ancogene & na & up \\
\hline$\$ \| k$ & STE20-like kinase & na & up \\
\hline Stk $1>b$ & apoptosis-inducing serine/thureonine kimase $17 \mathrm{~b}$ & - & $u p$ \\
\hline Mapkg & NNK mitogen activated protein kinase 9 & up & up \\
\hline Rp/37 & ribosomal proteinn $\mathrm{L} 37$ & up & . \\
\hline
\end{tabular}

HET, heterozygotes; HOM, homozygotes; na: not anialyzed; * no change 


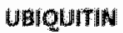

\begin{tabular}{|c|c|c|c|}
\hline Mouse Cene Name & Description & HET & HOM \\
\hline $203 h d c 5$ & zine finget CCCH type domatn containing 5 & \multicolumn{2}{|c|}{ down: } \\
\hline Ubeajz & ubiquitin-conjugating enzyme $1 \mathrm{Z}, 12$ homolog (yeast) & \multicolumn{2}{|c|}{ up } \\
\hline Ubers 212 & ubiquitin-conjugating enzyme E.R. 2 & \multicolumn{2}{|c|}{ up } \\
\hline Rinfisa & ring finger protein 139 & \multicolumn{2}{|c|}{ up } \\
\hline $\operatorname{sg}$ & golgi assoc, gamma adaptin ear containing, ARF binding protein 3 & na & down \\
\hline Btre & betha-trangducin repeat containing protein & ma & down \\
\hline 50006 & S100 calcium binding protein AG (calcyclin) & nata & down \\
\hline Vpsas & wacuolair protein sorting 28 (yeast) & na & up \\
\hline Usp3: & ubiquitin specific protease 38 & na & up \\
\hline Tcebis. & transcription elongation factor B (SMI), polypeptide 1 & na & up \\
\hline gigat & golgi asisoc.gamma adaptin ear containing, ARF binding protein 2 & down & na \\
\hline $\sec 63$ & SEC63:Hke (S. cereviliae) & up & na \\
\hline Birco & baculoviral IAP repeat-contalning 6 & down & up \\
\hline Asb6 & ankyrin repeat and 5005 box-comtaining protein 6 & down & - \\
\hline $\operatorname{Rnf} 24$ & ring finger protetn 24 & 。 & $u p$ \\
\hline Trim:5 & tripartite motif protein 25 & - & up \\
\hline Mapks & $J N K_{x}$ mitogen activated protein kinase 9 & up & up \\
\hline
\end{tabular}

HET, heterozygotes; HOM, homozygotes; na: not analyzed; : no change

ZINC- FINGER PROTERN

\begin{tabular}{|c|c|c|c|}
\hline Moulse Gene Narrie & Description & HET & HOM \\
\hline Zcindes & zinc finger CCCH type domain containing 5 & \multicolumn{2}{|c|}{ dowr } \\
\hline $2 f p 281$ & zinc finger protein 281 & \multicolumn{2}{|c|}{ dowri } \\
\hline Zfpis 51 & zinc finger protein 51 & \multicolumn{2}{|c|}{ up } \\
\hline Rad18 & RAD18 thomolog (S. cerevisilae) & \multicolumn{2}{|c|}{ up } \\
\hline $\operatorname{Rnf139}$ & ring finger protein 139 & \multicolumn{2}{|c|}{ up } \\
\hline DSErtd689e & DNA segment, Chr 5, ERATO Doi 689, expressed & na & down \\
\hline 5430400NoLRik & RIKIEN CDNA 5430400 NO5 gene & na & down \\
\hline $\operatorname{Rnf} 41$ & ring finger protein 41 & na & down \\
\hline Zfp 334 & zinc finger protein 334 & na & down \\
\hline $\operatorname{Rn} \operatorname{li}_{3}$ & ring finger pratein 35 & na & down \\
\hline $5100 \mathrm{a} 6$ & S100 calcium binding protein A6 (calcyclin) & na & down \\
\hline Akap8 & A kinase (PRKA) anchor protein \& & na & down \\
\hline Prdins & PR domán containing & na & down \\
\hline Zfp 503 & zinc fingel prottein 503 & $\mathrm{na}$ & up \\
\hline $22 \times 23$ & zinc finger, $Z 2$ domail containirag 3 & down & na \\
\hline $2 f p 367$ & zink finger protein 367 & down & na \\
\hline Pcló & piccolo (presynaptic cytomatrïx protein) & down & na \\
\hline Zdhathes & zinc finger, DHHC domain containing 5 & up & na \\
\hline Pdilma & PDZ and LIM domain 1 (elfin) & up & na \\
\hline Plagld & pleiomorphic adenoma gene-like 1 & down & up \\
\hline 08114266 & expressed sequence BB114266 & down & - \\
\hline Acbp: & AE binding protein 2 & - & up \\
\hline whl1 & four and a half LIM domvains 1 & - & up \\
\hline Rnf 24 & ring finger protein 24 & - & up \\
\hline Trimes & tripartite motif protein 25 & . & up \\
\hline $2 f p 219$ & zinc finger protein 219 & - & dowr \\
\hline Phf13 & PHD finger pratein 13 & up & up \\
\hline Rpl37 & ribosomal pratein 137 & up & - \\
\hline
\end{tabular}

HET, haterozygotes; HOM, homozygotes; ina: mot analyzed; - no change 
For some of the genes described, there was only data available for one of the KO groups: heterozygotes (HET) or homozygotes (HOM). If this was the case, the group is indicated between brackets.

\section{The MAP kinase system}

MAPK9 or JNK2 (mitogen activated protein kinase 9) was upregulated in all KO mice. In addition, several other genes were differentially expressed in both groups. In heterozygotes, D19Ertd144e (homologous to human Doc1r), a MAP kinase substrate that controls microtubule organization ${ }^{19}$, was upregulated. Also, Ets2 (E26 avian leukemia o-ogene $2,3^{\prime}$ domain), that stimulates the CD13/aminopeptidase $N$ complex in a Ras/MAPK mediated way, which is a potent regulator of angiogenesis ${ }^{20}$, was upregulated. On the other hand, F11r ( $F 11$ receptor), required for the integrin mediated angiogenic activity of $\mathrm{bFGF}^{21}$ and functioning through the ERK system ${ }^{22}$, was downregulated. This was also the case for Runx2 (runt related transcription factor 2), which is mainly linked to the ERK system and angiogenesis (HET). ${ }^{23}$ Another gene related to ERK activation, Fyn (Fyn proto-oncogene) ${ }^{24}$, was downregulated (HET), just like Gnai3 (guanine nucleotide binding protein, alpha inhibiting 3) with the same function (HOM). ${ }^{25}$ The Ets1 gene, of which the product is activated by ERK1/2 $2^{26}$, was upregulated (HOM). In homozygotes, Bag2 (Bcl2-associated athanogene 2) which encodes a nuclear fiber containing SERCA isoforms and mitochondria ${ }^{27}$ and is positively regulated by the $\mathrm{p} 38$ system ${ }^{28}$, was upregulated. Fhl1 (four and a half LIM domains 1) that inhibits Erk $2^{29}$, was also upregulated, which has been previously reported in (integrin mediated) cardiomyopathy. ${ }^{30,31} \mathrm{Cdc} 37$ (cell division cycle 37 homolog, S. cerevisiae) was also upregulated and known to be part of complexes related to TNFinduced induction of IKK and NF-kappaB ${ }^{32}$, involved in hypertrophy ${ }^{33}$ and MAPK signaling. ${ }^{34}$ Consistent with this finding was the upregulation of the receptor Trpc4ap (transient receptor potential cation channel - subfamily $C$ - member 4 associated protein), also related to TNF, IKK and NF-KappaB activation ${ }^{35}$ in both groups, although more in homozygotes. Furthermore, in both groups, $\mathrm{Pbk}$ (PDZ binding kinase), another MAPKK family related protein ${ }^{35}$, was upregulated, just like XPO1 that regulates export of Hog1 MAPK from the nucleus. ${ }^{37}$ However, Mapk8ip3 (mitogen-activated protein kinase 8 interacting protein 3), related to $\mathrm{NNK}^{38}$, was downregulated (HET), just like the ERK and cell migration inhibitor Spred1 (sprouty protein with EVH-1 domain 1, related sequence). ${ }^{39}$ Gap43, found to be related to reduced MAPK activation ${ }^{40}$, was downregulated (HOM). In summary, the MAP kinase system, except for the ERK pathway, was stimulated in both KO groups. 
Also, Wnt signaling is involved in the occurrence of cardiac hypertrophy. Wnt4 (wingless-related MMTV integration site 4) was upregulated (HOM). Cdk2 (cyclindependent kinase 2), upregulated in both groups, tunes the levels of the Wnt downstream component $\beta$-catenin over the course of the cell cycle and regulates its interaction with $A x i n{ }^{41,42}$ Finally, Btrc (beta-transducin repeat containing protein) that promotes degradation of I kappa B and $\beta$-catenin ${ }^{43}$, was downregulated (HOM). This gene is activated by JNK, but not at a transcriptional level. ${ }^{44}$ Other mitosis-related genes, which showed a clear upregulation especially in the homozygotes, include cell cycle progression genes and several checkpoint and control genes.

\section{Apoptosis}

One of the major apoptotic routes was upregulated in both heterozygotes and homozygotes. Uqcrh (ubiquinol-cytachrome $c$ reductase hinge protein) was upregulated, a gene that accelerates apoptosis by enhancing the release of cytochrome $c$ from mitochondria. ${ }^{45}$ This was further enhanced by upregulation of Mapk9, absence of which is known to cause a defect in this release. ${ }^{46}$ Contributing to the initiation of the proteolytic activity of caspase- 3 by release of cytochrome $c^{47}$, the anti-apoptotic gene Igtp (interferon-gamma-inducible GTPase) was downregulated, relieving its inhibition of caspase 3 and $9 .{ }^{48}$ One of the proteins cleaved by caspase 3 and upregulated (HOM) was $S \mid k^{49}$, that initiates apoptosis through actin disassembly and cell adhesion modification. ${ }^{50}$ Bag2, mentioned before, is also a member of a family that is related to this apoptotic route. ${ }^{51}$ Additionally upregulated was Txndc5 (thioredoxin domain containing 5), which is known to protect endothelial cells under hypoxia against apoptosis..$^{52}$ Some genes behaved differently in both groups though. It was remarkable that from the genes with known annotations, three out of four from the genes downregulated in heterozygotes and upregulated in homozygotes, were somehow linked to apoptosis. This group contained Birc6 (baculoviral IAP repeatcontaining 6), which has an important function in preventing apoptosis by ubiquination of SMAC (second mitochondria-derived activator of caspase) and caspase$9^{53}$, and Plagl1 (pleiomorphic adenoma gene-like 1), which is expressed transiently in myocardium ${ }^{54}$ and can concurrently induce apoptosis and cell cycle arrest. .5.56 $^{\text {There }}$ were three other genes only upregulated in homozygotes: Stk17b (apoptosis-inducing serine/threonine kinase 17b), which can phosphorylate myosin light chain and is expressed in heart and involved in apoptotic signaling ${ }^{57}$, Perp (PERP, TP53 apoptosis effector), which is highly expressed in apoptotic cells as compared to cell-cycle arrested cells and a target of $p 53^{58}$, and Ppic (Cyclophilin C), which is related to DNA degradation in apoptosis ${ }^{59}$ and may have some relation to calcineurin, a known 
regulator of (maladaptive) hypertrophy. The anti-apoptotic lkappaB kinase regulatory subunit Rab6ip2 (Rab6 interacting protein 2) ${ }^{60}$ was downregullated (HET), just like the anti-apoptotic gene Run $\times 2^{51}$ and Ctnnbl1 (catenin, beta like 1), that was found to be linked to induction of apoptosis ${ }^{62}$ was upregulated in this group. The gene Tacc3, a centrosome component whose absence triggers p53-mediated apoptosis ${ }^{63}$, was downregulated (HOM), just like the anti-apoptotic mitochondrial gene Txn2 (thioredoxin 2). The homozygous mice clearly showed an upregulation of apoptosis and the heterozygotes showed upregulation of a major apoptotic pathway.

\section{Mitochondrial energy production}

Both Acads (acyl-Coenzyme A dehydrogenase, short chain) and Echs1 (enoyl Coenzyme A hydratase, short chain, 1 , mitochondrial) were upregulated in both groups of KO mice. These enzymes catalyze the first, respectively second intramitochondrial reaction in the $\beta$-oxidation of fatty acids (FA). Acad8 (acyl-Coenzyme A dehydrogenase family, member 8 ) catalyzes the first dehydrogenation step in the $\beta$-oxidation of fatty acylCOA derivatives and was upregulated in heterozygotes. Increased energy demand was also reflected in the upregulation of Ndufc2 (NADH dehydrogenase (ubiquinone) 1 , subcomplex unknown, 2), Suclg2 (succinate-Coenzyme A ligase, GDP-forming, beta subunit), and Aldoc (aldolase 3, C isoform), the latter only in homozygotes. In the homozygotes, Ckmt1 (creatine kinase, mitochondrial 1, ubiquitous) was upregulated. This gene functions in the creatine/phosphocreatine shuttle system, a system that can generate energy much faster than glycolysis and oxidative phosphorylation. Also some mitochondrial genes (like ribosomall proteins) not directly related to energy production showed differential expression.

\section{Cell structure}

Apart from changes in genes related to the sarcomere, actin and microtubuli, changes were also found in genes related to cell adhesion, migration and sensoring. In signaling, the integrin-mediated LIM domain-containing gene Fhl1 was upregulated in the homozygous mice. F11r, also integrin-mediated, was downregulated in heterozygotes. Several sarcomere-related proteins were upregulated in the homozygotes, including Smtn (smoothelin), an actin binding smooth muscle-cell gene, present in vascuralized organs and at the Z-disc level of cardiomyocytes ${ }^{64.66}$, Actn4 (actinin alpha 4), an actin-binding protein that is found to regulate cell motility ${ }^{67.58}$, and Myh10 (myosin heavy chain 10, non-muscle), the latter more than three-fold. Downregulated in both groups was the transcription factor Foxo3 (forkhead box O3), that activates sarcomeric atrogin- $1^{69}$, and finally, Cugbp2 or ETR-3 (CUC triplet repeat, 
RNA binding protein 2), a cardiac gene related to cardiac troponin T (CTNT). The

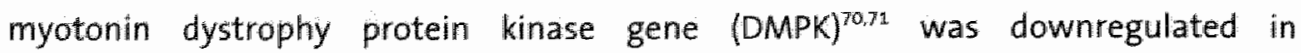
heterozygotes. Except for these sarcomeric genes, several other cell structure related genes were differentially expressed. Interestingly, both Abil1 and 2 (abl-interactor 1 and 2) were upregulated, the first only in homozygotes. These proteins are related to Rac induced cytoskeleton reorganization in reaction to growth factors and to cell motility. ${ }^{72.73}$ In all KO mice, Lad1 (ladinin), related to the basement membrane ${ }^{74}$, was downregulated, similar to the microtubule-related protein Mapt (microtubuleassociated protein tau), and Fndc5 (fibronectin type III domain containing 5), strongly expressed in adult heart. ${ }^{75}$ Smoc1 (SPARC related modular calcium binding 1), a calcium-binding basement membrane protein ${ }^{76}$, was upregulated (HET). Mastl (microtubule associated serine/threonine kinase-like) was downregulated (HOM). In heterozygotes only, Fmr1, again thought to be linked to the Rac1 GTPase pathway and cytoskeleton remodeling ${ }^{77}$, Arhgap21 (Rho GTPase activating protein 21), a potentially cytoskeletal Rho-GTPase activating protein important for cell differentiation ${ }^{78}$, and 2310057H16Rik, involved in microtubule-based movement, were all downregulated. SWIISNF-related proteins as ActI6A (actin-like 6A) and Smarce1 (SWI/SNF related, matrix associated, actin dependent regulator of chromatin, subfamily e, member 1 ), linking matrix and chromatin, were downregulated as well, the first also in homozygotes. Finally, Lgals4 (lectin, galactose binding, soluble 4), a member of a cellcell and matrix interaction protein family, was upregulated in heterozygotes and downregulated in homozygotes. Both groups show up- and downregulation in cell structure genes, with more prominent upregulation of sarcomeric ones in the hypertrophic homozygous mice.

\section{Other noticeable changes}

In homozygotes, many zinc finger proteins were differentially regulated, indicating changed gene expression, which was also indicated by upregulation of RNA processing factors like Cpsf 1 and 2 (cleavage and polyadenylation specific factor 1 en 2) and Tceb1 (transcription elongation factor B (SIII), polypeptide 1). In heterozygotes, changes in gene expression were evident, but the effect was somewhat smaller. Also, several ubiquitination genes came up in our list, showing again a mixed effect in heterozygotes, but an upregulation in homozygotes, indicating increased protein turnover. Among the genes upregulated in both groups were Ube2j2 (ubiquitinconjugating enzyme E2, J2 homolog), and Ube2r2 (ubiquitin-conjugating enzyme E2R 2), a member of the same familly that regulates $\beta$-catenin function. Downregulation of Zc3hde5 may counteract this effect though. Asb6 (ankyrin repeat and SOCS box- 
containing protein 6) was downregulated in heterozygotes and contains a SOCS box, that inhibits cytokine signaling ${ }^{79}$ and targets proteins for ubiquination by ubiquitin protein ligases. ${ }^{80}$ Another SOCS box-containing protein, Socs3, is known to be an inhibitor of JAK/STAT signaling. ${ }^{81}$ Finally, the calcium-binding protein genes Nucb (nucleobindin 1) and Rcn2 (reticulocalbin 2) were upregulated in homozygotes.

Several other genes showed opposite effects in heterozygotes and homozygotes: Atp6voa2 (ATPase, $\mathrm{H}+$ transporting, lysosomal Vo subunit a isoform 2) and Mospd1 (motile sperm domain containing 1) were both upregulated in heterozygotes and downregulated in homozygotes. The opposite was true for D8Ertd769e. The genes analyzable in both groups with the most extreme downregulation were Zc3hdc5 (zifinger $\mathrm{CCCH}$ type domain containing 5), and, in homozygotes, BC003993. Finally, strongly upregulated in both groups (but with different factors) were 2010005013Rik, Phf13 (PHD finger protein 13), and - most extremely - C80171.

\section{Discussion}

GenMAPP results provided a good first indication of the most significant processes in the set of genes with reliable differential expression. It was clear, however, that the number of differential genes per pathway was often small, two or three, even for the best scoring ones. Also, the number of genes within each ontology was smaller than the list of genes obtained by the next step, i.e. the NCBI website combined with PubMatrix results. This indicates that the $G O$ annotations are not as extensive as those abtained by the other metho

ds used. Two other GO-based tools evaluated were David/Ease ${ }^{82}$ and TXTGate ${ }^{83}$, although both could not extract enough information from this dataset. Another issue is that the GO information presented differs between websites and tools and must be interpreted with care. PubMatrix results need to be examined by hand, which means checking whether abstracts are really linked to the gene of interest. Also, names of genes are not always recognized, which means that some genes are missed. Still, some links were added that would have been missed by using the NCBI website. However, it was still most useful to manually check the website if possible for the number of genes involved.

Some genes were missed because of the somewhat conservative approach to remove genes with probes with an inconsistent result, most frequently concerning genes with both differentially expressed probes and non-differential ones. The fact that more 
down than upregulated genes could only be analyzed for one KO group, can be explained by flagging of negative spots. This means that the gene may well have been downregulated in the other group as well, but below detection llimit. As CDNA arrays were used, cross hybridization could have occurred, i.e. increased detection of Myh10 (myosin heavy chain 10, non-muscle), a $\beta-M H C_{\text {, }}$ could be caused by upregulation of other myosins. Nevertheless, it is known from haemodynamic overload studies in rodents that $\alpha-M H C$ switches to $\beta-M H C^{84}$ A few genes, such as Map3k7 (mitogen activated protein kinase kinase kinase 7) and Actg1 (actin, gamma, cytoplasmic 1), had saturated intensities, obscuring the actual correct fold change. However, the conservative approach used ensured that the genes found to be differentially expressed were reliable. The reliability of the slides spotted was confirmed by low spike intensity variation. Finally, the same clone set and microarray platform was used by others, who confirmed their array results with real-time $P C{ }^{55-87}$, indicating the quality of the procedure.

The CMyBP-C KO mouse model enabled us to study the early stage molecular changes occurring on the route to maladaptive hypertrophy. We especially focused on similarities and differences between homozygotes and heterozygotes, which will eventually develop different forms of hypertrophy. ${ }^{11}$ At 9 weeks of age, the homozygotes had already developed hypertrophy, in contrast to the heterozygotes. Many genes related to processes that are known to be involved in hypertrophy were differentially expressed. These included the MAP kinase system, Wht signaling, apoptosis, mitochondrial energy production, regulation of transcription, protein breakdown, and (sarcomeric) cell structure and matrix interaction genes. Biochemically, many serine/threonine kinases and several SWI/SNF complex, GTP, and calcium related genes, were present. In the homozygotes, somewhat more genes showed differential expression compared to wild-types than in the heterozygotes. In general, all KO mice show differential expression for all of these processes, with a slightly stronger effect in the homozygotes.

Genes from the MAPK system showed obvious changes in expression at this early stage of hypertrophy. In both homozygotes and heterozygotes, the JNK and p38 pathways were upregulated and parts of the ERK pathway downregulated. Also, a few genes that are regulated by JNKs or ERKs at protein level are regulated in compensatory direction. Indeed, upregulation of the MAPK system, is known to lead to hypertrophy instead of proliferation in cardiomyocytes ${ }^{84}$ and for its three subsystems, INKs, p38, and ERKs ${ }^{88}$, overexpression of the third is thought to be related to beneficial 
hypertrophy and the other two to maladaptive hypertrophy. ${ }^{5.89}$ This indicates that from the beginning, the mice appeared to be destined for a maladaptive outcome. Also, upregulation of other mitosis-related genes was observed, such as cell cycle progression genes and several checkpoint and control genes, indicating cell division activity. This may be caused by proliferation of other cell types than cardiomyocytes, such as fibroblasts and endothelial cells, indicating the probable occurrence of fibrosis, present in maladaptive hypertrophy and failure..$^{51}$ Moreover, in heterozygotes, angiogenesis was stimulated, indicating that the process may preferentially occur in the pre-hypertrophic phase or reflect different pathology. On the other hand, F11r, a stimulator of angiogenic activity, which functions through the ERK system ${ }^{22}$, was downregulated in heterozygotes consistent with the fate of the hearts. In both groups, protection of endothelial cells under hypoxia against apoptosis was increased "which may be to protect endothelial cells that spread to form new vessels.

For both homozygotes and heterozygotes, a major apoptotic route, i.e. the release of cytochrome c from mitochondria and the activity of caspases, was enhanced by activation of several steps in the underlying pathways. Also several other pro-apoptotic genes were upregulated, especially in the homozygous $\mathrm{KO}$ mice, and several antiapoptotic genes were downregulated in both groups. This activation of apoptosis is consistent with its known role in maladaptive hypertrophy, as has been recently reviewed. ${ }^{33}$ in the presymptomatic and early stages of hypertrophy, the energy need was increased and the oxidation of FA, the primary cardiac fuel under normal circumstances, was found to be increased as such. Even in the heterozygotes, that do not have a phenotype at this stage, the effect could clearly be observed. This upregulation of FA oxidation contrasts with the later stages of hypertrophy and especially failure, in which the heart switches to glucose as primary fuel. ${ }^{90.91}$ Also several other mitochondrial energy related genes were upregulated in both KO groups. In the homozygotes, the creatine/phosphocreatine shuttle system was upregulated, indicating a severe defect in cardiac function at this stage. Heterozygotes also showed an increased need. Apparently, KO hearts are trying to find ways to increase energy production. The adaptations in cell structure to make up for the loss of CMyBP-C likely not entirely suffice, leading to less efficient cardiac functioning, especially in homozygous KO mice.

The remodeling and increased cellular activity might also require extra energy. These were reflected by upregulation of transcription factors such as zinc finger proteins in both groups, especially in homozygotes, leading to increased protein production. Also, 
genes encoding proteins involved in ubiquitination were mainly upregulated, with the noticeable exception of Zc3hdc5, indicating extra breakdown of proteins. We hypothesize that there is an increased turnover of proteins that are replaced by others for restructuring activities. And perhaps, the increased production of proteins might also lead to the generation of more erroneous ones, that subsequently need to be removed. Many cell structure and adhesion related genes showed changes in expression. Genes related to cytoskeleton (re)organization, cell motility, cell-matrix interaction, dystrophy, and cardiomyopathies were differentially expressed. Several sarcomeric genes were upregulated in the homozygous KO mice. Genes related to integrins and MLP (muscle LIM domain protein), that have been suggested to act as biochemical sensors in the development of hypertrophy ${ }^{84}$, were also differentially expressed. The myodystrophy gene Large (like-glycosyltransferase) was downregulated (HET). Clues for reactivation of the embryonic program were present in the downregulation of the adult gene Fndc5 in both groups, and upregulation in homozygotes of Cugbp2, which is known to bind to a splicing motif in cardiac troponin $T$ (CTNT) and so positively regulating expression of the embryonic form. ${ }^{70,71}$ Downregulation of Fox03 in both groups inhibited prevention of calcineurindependent hypertrophy by atrogin-1. ${ }^{69,92}$

Interesting to mention are the genes that showed opposite effects in heterozygotes and homozygotes, such as Lgals4, Atp6voa2, Mospd1, Birc6, Cugbp2, Plagl1 and D8Ertd769e. Remarkable was that three of them were related to apoptosis. These genes may either be stage-specific, reflecting different stages of comparable pathology or they may reflect different pathology between heterozygotes and homozygotes. Time course experiments can provide the answer to this. Finally, the completely analyzable genes with the most extreme fold genes were Zc3hdc5, BC003993, 2010005013Rik, Phf13 and C80171. These genes may be novel biomarkers for maladaptive hypertrophy, but should be tested in patients first. Several of these were relatively unknown clones, which make them interesting candidates to investigate and further elucidate potential new molecular mechanisms.

In conclusion, the differentially regulated processes in both homozygotes and heterozygotes were similar. Already, several well-known hypertrophy-related processes could be identified at this early (pre)symptomatic stage. The effect was more prominent in homozygotes though. In heterozygotes, the situation appeared more as a perturbed system searching for equilibrium, with changes in several directions. In a previous study, it was also shown that the number of genes changed correlated to the 
severity of pathology. ${ }^{93}$ It was clear from our results that several molecular changes related to the maladaptive type of hypertrophy were already present in both groups. This indicates that the fate of the heart is likely already determined in the early hypertrophic homozygotes and the phenotypically pre-hypertrophic heterozygotes and perhaps even earlier. In some mouse models for heart failure, it has also been suggested that early changes in gene expression may set the outcome at a later age. ${ }^{93.94}$ This may be important for therapeutic strategies, offering possibilities for early or even preventive therapy.

\section{Acknowledgements}

We thank the Leids Universitair Medisch Centrum (LUMC) for the distribution of the NIA 15k set. Dr. Jeroen Aerssens, Rob Janssen and Erika Timmer are acknowledged for their assistance with the microarray experiments and Ton Derix for his contribution to the data analysis. This research was supported by the Netherlands Heart Foundation (99.122) and the Cardiovascular Research Institute Maastricht (CARIM), The Netherlands.

\section{References}

1. Bashyam MD, Savithri GR, Ktmmar MS, et al. Molecular genetics of familial hypertrophic cardiomyopathy (FHC) i Hum Genet. 2003;48:55-64.

2. Carrier $L$, Bonne $G$, Bahrend $E_{2}$ et al. Orgamization and sequence of human cardiac myosin binding protein $C$ gene (MYBPC3) and identification of mutations predicted to produce truncated proteins in familial hypertrophic cardiomyopathy. Circ Res. 1997;80:427-434.

3. Niimura $H_{1}$ Bachinski $L$, Sangwatanaroj 5 , et al. Mutations in the gene for cardiac myosin-binding protein $C$ and latemonset famallial hypertrophic cardiomyopathy. N Engl/ Med. 1998:338:1248-1257.

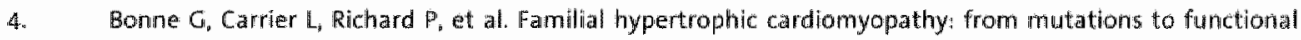
defects. Circ Res. 1998:83:580-593.

5. Aldets $M$, Jongblaed $R_{r}$ Deelen $W$, et al. The 2373 ins C mutation in the MYBPC 3 gene is a founder mutation, which accounts for nearly one-fourth of the HCM cases in the Netherlands. Fur Heart J. 2003:24:1848. 1853 .

6. Richard P, Charron P, Carrier L, et all Hypertrophic cardiomyopathy: distribution of disease genes, spectrum of mutations, and implications for a molecular diagrosis strategy. Circulation. 2003:107:2227-2232.

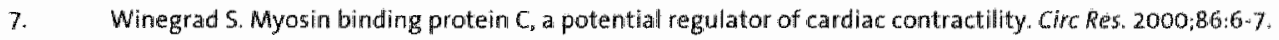

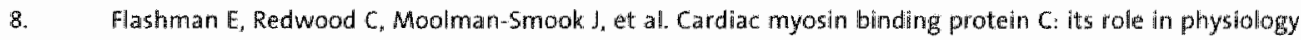
and disease. Circ Res. 2004:94:1279-1289.

Harris SP, Bartley CR, Hacker TA, et al. Hypertrophic cardiomyopathy in cardiac myosin binding protein $\mathrm{C}$ knockout mice. Circ Res. 2002:90:594-601. Carrier L, Knoll R, Vignier $N$, et al. Asymmetric septal hypertrophy in heterozygous cMyBP $\mathrm{C}$ nuil mice. Cardiovase Res. 2004:63:293-304.

12. Tamaka TS, Jaradat SA, Lim MK, ett al. Genomewide expression profiling of mid-gestation placenta and embryo using a 15,000 mouse dewelopmental cDNA miciroarray. Proc Natl Acad SCi U S A. 2000:97:9127. 9132 . 
13. Dahlquist $\mathrm{KD}$, Salomonis $\mathrm{N}$, Vramilain $K_{\text {, }}$ et al. GenMAPP, a new tool for viewing and analyzing microarray data on bilologicall pathways. Wat Genet. 2002;31:19-20.

14. Donger SW, Salomonis 1 , Dahquist KO et al. MAPPFindeir: using Gene Ontology and GenMAPP to create a global gene expression profle from microariay data. Cenome Biol. 2003 : $4: R 7$.

15. Becker $K G$, Hosack DA, Deninis $G$, li., al. PubMatrix a tool for multiplex literature mining: BMC Bionformatice. $2003 ; 4: 61$.

16. Fare TL, Coffey EM, Daf H, et al. Effects of atmospheric ozone on microarray data quality. Anal Chem. $2003775: 4672-4675$

17. Hegde $P$, Qi $\mathrm{R}$, Abernathy $K$, et al. A concise guide to cDNA microarray analysis. Biotechniques. 2000;29:548$550,552-544,556$ passim.

18. Akake $H$. Information theory and an extension of the maximum likelihood principle. In: Petrov BN, Csaki F, edis. Second International symposium on Inference Theary. Budapest: Akadẻmïli Kiadô; 1973:267*281.

19. Terret ME, Lefebvre $C$. Djlane $A$, al. DOC1R: a MAP kinase substrate that controf microtubule organization of metaphase ll mouse oocytes. Development. 2003;130:5169-5177.

20. Pettrovic N, Bhagwat SW, Ratzan WJ, et al. CD13/APN transcription is induced by RAS/MAPK-medilated phosphorylation of Ets-2 in activated endothelial cells. J Biol Chem. 2003"278:49358-49368:

21. Naik MU, Mousa SA, Parkos CA, et al. Signaling through JAM-1 and alphawbeta3 is required for the angiogenic action of bFGiF: dilssociation of the JAM-1 and alphavbetas complex. Blood. 2003:102:2108. 2114.

22. Naik MU, Vuppalanchi D, Naik UP. Essential role of junctional adheston molecule-1 in basic fibroblast growth factor-induced endothelial cell migration. Arterioscler Thromb Vasc Bial. $2003 ; 23: 2165-2171$.

23. Qiao $M$, Shapiro $P$, Kumbar $R$, et all. Imsulih-like growth factor-1 regulates endogenous RUNX2 activity in endothelial cells through a phosphatidylinositol 3-kimase/ERKodependent and Akt-independent signaling paithway. I Bial Chem. 2004;279:42709-42718.

24. Kawabe 1 , Okumura 5 , Lee MC, et al. Tiranslocation of caveolin regulates stretch-induced IERK activity in vascular smooth musele cells. Am I Physiol Heart Circ Physiol. 2004;286:H1845-1852.

25. Bao $X$, LUi C, Frangos JA. Mechanism of temporal gradients in shear-induced ERK1/2 activation and proliferation in endothelial cells. Am I Physiol Heart Circ Physiol. 2001;281:H22-29.

26. Dittmer J. The biology of the Ets1 prota-oncogene. Mol Cancer. 2003;2:29.

27. Ogata T, Yamasiaki Y. Ultra-high-resolution scanning electron microscopic studies on the sarcoplasmic reticulum and mitochondria of the rat intrafusal muscle fibers. Part II: The extracapsular region. Arch Histol cytol. $1992 ; 55 ; 117-124$.

28. Ueda K, Kosako H Fukui $Y$, et al. Proteomic identification of Bcl2-associated athanogene 2 as a novel MAPKactivated proteili kinase 2 substrate. I Biof Chem. 2004;279:41815-41821.

29. Purcell NH, Darwis D, Bueno of, et al. Extracellular signal-regulated kinase 2 interacts with and is negathely regulated by the LM-only protein FHL2 in cardiomyocytes. Mol Cell Biol. 2004;24:1081-1095.

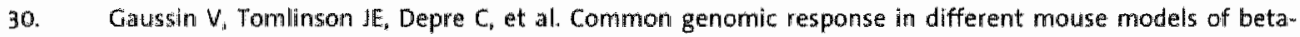
adrenargic.induced cardiomyopathy. Circulation. 2003:108:2926-2933.

31. Chu PH, Ruiz-Lozano $P$, Zhou $Q$, et al. Expression patterns of FHL/SLM family members suggest important functional roles in skeletall muscle and cardiovascular system. Mech Dev. 2000:95:2:59-265.

32. Chen $G$, Cao P. Goeddel DW. TNF-induced recruttment and activation of the $1 K K$ complex require Cde37 and Hsp90. Mol Cell. 2002;9:401-410.

33. Van Empel VP, De Windt U. Ayocyte hypertrophy and apoptosis: a balancing act Cardiowasc Res. $2004 ; 63: 487-499$.

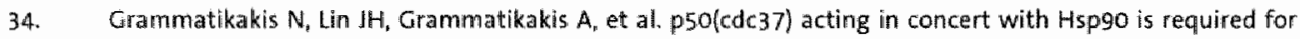
Raf-1 function. Mol Cell Biol. 1999;19:1661-1672.

35. Soond SM, Terry IL, Colbert JD, et al. TRUSS, a novel tumor necrosis factor receptor 1 scaffolding protein that mediates activation of the transcription factor NF-kappaB. Mal CeN Bial. 2003;23:833.4-8344. 
36. Gaudet S, Branton D, Lue RA. Characterization of PDZ-binding kinase, a mitotic kinase. Proc Not Acod 5 ci D S. A. 2000:97:5167-5172.

37. Ferrigno P, Posas F, KoepP D, et al. Regulated nucleo/cytoplasmic exchange of HOC1 MAPK requires the importin beta homologs NMD5 and XPO1. Embo 1. 1998;17:5606-5614.

31. Matsuura $H$, Nishitoh $H$, Takeda K, et al. Phosphorylationdependent scaffolding role of ISAPY/JP3 In the ASK1.JNK signaling pathway. A new mode of regulation of the MAP kinase cascade. B Bol Chem. 2002;277:40703:40709.

39. Miyoshi $K_{n}$ Wakioka $T_{n}$ Nishinakamura $H_{s}$ et all. The Sprouty-related protein, Spred, inhibits cell motillty, metastasins, and Rho-mediated actin reorganization. Oncogene. $2004,23.5567-5576$.

40. Huang $Z Y$, Wu $Y$, Burke SP, et al. The 43000 growth-associated protein functions as a negative growwth regulator in glioma. Cancer Res. 2003;63:2933-2939.

41. Park CS, Kim S1, Lee MS, et all. Modulation of beta-catenin phosphorylationidegradation by cyclindependent kimase 2. I Biol Chem. 2004;279:19592-19599.

42. Kim 51, Park CS, Lee MS, et al. Cyclin-dependent kinase 2 regulates the interaction of Axin with betacatenin. Biochem Biophys Res Commun. 2004;317:478-483.

43. Nakayama K, Hatakeyama 5, Maruyama S, et al. Impaired degradation of inhibitory subunit of NF-kappa B ( 1 kappa B) and beta-catenin as a result of targeted disruption of the beta-TrCP1 gene. Proc Notl Acad Sci $U$ 5. A. 2003; $100: 8752-8757$.

44. Spiegelman VS, Stawropoulos. P, Latres $E$, et al. Induction of beta-transducin repeat-containing protein by INK signaling and its role in the activation of NF-kappaB. J Biol Chem, 2001:276:27152-27158.

45. Okazaki $M$, Ishibashi $Y$, Asoh $S$, et all. Overexpressed mitochondrial hinge protein, a cytochrome c-binding protein, accelerates apoptosis by enhancing the release of cytochrome $c$ from mitochondria. Biochem Biophys Res Commun. 1998:243:131-136.

46. Tournier C, Hess P, Yang DD, et al. Requirement of JNK for stress-induced activation of the cytochrome $c$ mediated death pathway. Sicience, 2000;288:870-874.

47. Adams JW, Pagel AL, Means CK, et al. Cardiomyocyte apoptosis induced by Galphaq sigmaling is mediated by permeability transition pore formation and activation of the mitochondrial death pathway. Circ Res. $2000 ; 87: 1180-1187$.

48. Zhang $H M$, Yuan J Cheung $P$, et al. Overexpression of interferon-gammanducible GTPase inluibits coxsackievirus B3-induced apoptosis through the activation of the phosphatidylinositol 3-kinase/Akt pathway and inhibition of viral replication. J Biol Chem. 2003:278:33011-33019.

49. Sabourin LA, Tamai $K_{u}$ Seale $P_{y}$ et al. Caspase 3 cleavage of the Stezo-rellated kinase SLK releases and activates an apoptosis-inducing kirase domain and an actin-disassiembling region. Mol cell Biol. 2000,20:684-695.

50. Wagner 5, Flood TA, O'Reilly $P_{*}$ et al. Association of the Ste20-llke kinase (SLK) with the microtubule. Role in Ract-mediated regulation of actin dynamics during cell adlhesion and spreading $I$ biol chem. $2002: 277: 37685-37692$.

51. Lips DJ, deWindt U, van Kraaij DJ, et al. Molecular determinants of myocardial hypertrophy and failure: alternative pathways for beneficial and maladaptive hypertrophy. Eur Meart $1.2003 ; 2,4: 883-896$.

52. Sulliwan DC. Huminiecki $\mathbb{L}$, Moore JW, et al. EndoPDI, a novel proteim-disulfide isomerase-like protein that is preferentially expressed in endothelial cells acts as a stress surwival factor. I Biol Chem. 2003;278:47079. 47088 .

53. Hauser HP, Bardroff $M$, Pyrowolakis $G$, et al. A giant ubiquitin-conjugating enzyme related to IAP apoptosis inhibitors. / Cell Biol. 1998; 141:14:15-142.

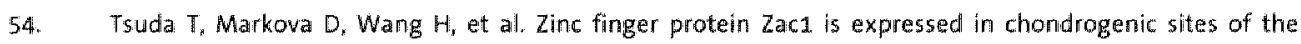
mouse. Dev Dyn. 2004;229:340-348.

55

Spengler $D$, Villalba M, Hoffmann A, et al. Regulation of apoptosis and cell cycle arresit by Zaic 1 , a nowel zinc finger protein expressed in the pituitary gland and the brain. Embo J. 1997;16:2814:-28:25. 
56. Hoffmanin A, Ciani E, Boeckardt 1 , al. Transcriptional activities of the zinc finger protein Zac are differentially controlled by DWA binding. Mol Cell Biol. 2003;23,988-1003.

57. Sanjo H. Kawai T, Akira S. DRAK5, novel sernedthreonine kinases related to death-associated protein kinase that trigger apoptosis. J Biol Chem. 1998;273:29066-29071.

58. Attardi $L D$, Reczek EE, Cosmas $C$, et al. PERP, an apoptosis-associated target of p53, is a novel member of the PMP-22/gas 3 fiamilly, Genes Dev. 2000;14:704-718.

59. Montague IW, Hughes FM, Jr. Cidlowski JA Native recombinant cyclophilins $A, B$, and $C$ degrade DNA independently of peptidylprolyll cis-trans-isomerase activity. Potential roles of cyclophiths in apoptosis. $J$ Biol Chem. 1997;272:6677-6684.

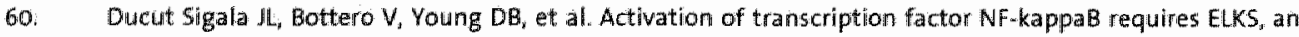
kappab kinase regulatory subunit. Science, 2004;304:1963\%1967.

61. Sun $\mathrm{L}_{\text {. }}$ Vitolo MI, Qiao $\mathrm{M}$, et al. Regulation of TGFbetal-mediated growth inhibition and apoptosis by RUNX2 isoforms in endlotheliall cells. Oncogene. 2004:23:4722-4734.

62. Jabbour $L$, Welter $J F$, Kollar $J$, et ali, Sequence, gene structure, and expression pattern of CTNNBL1, a minorclass intron-containing gene-ewidence for a role in apoptosis. Genomics. 2003:81:2:92-303.

63. Piekorz RP, Hoffmeyer $A_{A}$ Duntsch CD, et al. The centrosomal protein TACC3 is essential for hematopaietic stem cell function aind genetically interfiaces with p53-regulated a poptosils. Embo s. 2002:21:653-664.

64. Kramer I, Aguirre-Arteta AM, Thiel $C_{3}$ et al. A novel isoform of the smooth muscle cell differentiation marker smoothelin. J Mol Med. 1999;77:294-298.

65. Johansson 1 , Eriksson A, Ramaekers $F$, et al. Smoothelin in adult and developing human arteries and myocardium. Histochem Cell Biol. 1999;112:291-299.

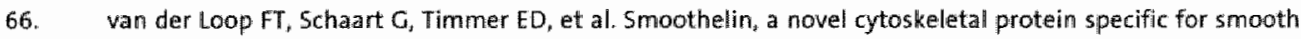
muscle cells, 1 Cell Biol, 1996; $340: 40 \%-411$.

67. Menez J, Le Maux Chansac $B$, Dorothee $G$, et all. Mutant alpha-actinim-4 promotes tumorigenicity and regulates cell motility of a human lung carcinoma. Oncogeme. 2004:23:2630-2639.

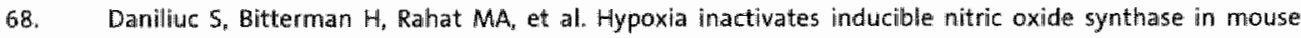
macrophages by disrupting its interaction with alpha-actimin 4. $1 / \mathrm{mm}$ unol $2003 ; 171: 3225-3232$.

69. Sandri M, Sandri C, Gilibert A, et all. Foxo transcription factors induce the atrophy-related ubiquitin ligiase atrogin-1 and cause skeletall muscle atrophy. Cell. 2004;117:399-412.

7o. Ladid AN, Charlet N, Cooper TA. The CELF family of RNA binding protelins is implicated in cell-specific and developmentally regulated alternative splicing. Mol Cell Biol. 2001;21:1285*1296.

77. I L X Timrbenko NA Timchenko LT. Cardac elav-type RNA-binding protein (ETR-3) binds to RNA CUG repeats expanded in myotonic dystrophy. Hum Mol Genet. 1999;8:53-60.

72. Courtney $\mathrm{KD}$, Grove $M$, Varidongen $H$, et al. Localization and phosphorylation of Ablinteractor proteins, Abi-1 and Abi-2, in the developing nerwous system. Mol Cell Neurosci. 2000; 16:244-257.

73. Stradal T, Courtney $\mathrm{KD}$, Rottner $\mathrm{K}$, at. The Abl interactor proteins localize to sites of actin polymerizat at the tips of lamellipodia and filopodia. Curr Biol. 2001;11:891-895.

74. Motok: K, Megahed $M$, LaForgia $S_{p}$ et al. Cloning and chromosomal mapping of mouse ladinin, a novel basement membrane zone component, Genomics. 1997;39:323-330.

75. Ferrer-Martinez A, Ruiz‘lozano P, Chien KR. Mouse PeP: a novel peroxisomal protein linked to myoblast differentiation and developiment. Dev Dym. 2002:224:154-167.

76. Vamahme C. Smyth N, Mosge N, et al. Characterization of SMOC-1, a nowel modular calcium-birading protein in basement meimbranes. $J$ Biol Chem. 2002;277:37977-37986.

77. Schenck $A_{4}$ Bardoni B, Langmann $C_{3}$ et al. CYFIP/S $19-1$ controls neuronall connectivity in Drosophila and links the Racy GTPase pathway to the fragile X protein. Newron. 2003:38:887-898.

78. Basseres DS, Tizzei EV, Duarte AA, at al. ARHGAP10, a novel human gene coding for a potentially cytoskeletal Rho.GTPase activating protein. Biochem Biophys Res Commun. 2002;294:579-585.

79. Kile BT, Metcalf D, Mifsud 5 , et al. Functional anallysis of Asb-1 using genetic modification in mice. Mol Cell Biol. $2001: 21: 6189-6197$. 
80. Kille 8T, Schulman BA, Alexander WS, et al. The SOCS box: a tale of destruction and degrodation. Trends Biochem Sci. 2002; 27:235-241.

81. Vasukawa $H_{*}$. Hosthijima $M_{3}$ Gu $Y_{\text {: }}$ et al. Suppressor of cytokune signalling-3 is a biomechanical stress. inducible gene that suppresses gp130 mediated cardiac myocyte hypertrophy and survival pathways. I Clin invest. $2001 ; 108: 1459-1467$.

82. Hosack DA, Dennis $G$, Mr., Sherman BT, et al. ldentifying biological themes within lists of genes with EASE. Genome Biol. $2003 ; 4: R 70$.

83. Glenisson P, Coessens B, Van Wooren S, et al. TXTGate: profiling gene groups with text-based information. Genome Brol. 2004;5: R43.

84. Ritter $O$, Neyses $L$. The molecular basis of myocardial hypertrophy and heart fallure. Trends Mol Med. $2003: 9 * 313-321$.

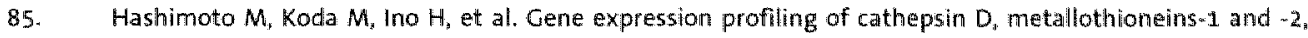
osteopontin, and tenascin $C$ in a mouse spinal cord injury model by CDNA microarray analysis. Acta Neuropothol (Ber). 2004.

86. Duque G, Macoritto M, Kremer R. Vitamin D treatment of senescence accelerated mice (SAM-P/6) induces several regulators of stromal cell plasticity. Biogerontology. 2004;5:421-429.

87. MuX, Zhao 5, Pershad $R$, et al. Gene expression in the developing mouse retina by EST sequencing and microarray analysils. Nucleic Acids Res. 2001;29:4983-4993.

88. Garrington TP, Johnson GL. Organization and regulation of mitogen-activated protein kinase signaling pathways. Curr Opin Cell Biol' 1999:11:211-218.

89. Selwetella $G$. Hirsch $E_{\mathrm{p}}$ Notte $A$, et al. Adaptive and malladaptive hypertrophic pathways points of convergence and divergence. Cardiowasc Res. 2004;63:373-380.

90. Frey N, Olson EN. Cardiac hypertrophy: the good, the bad, and the ugly. Annu Rev Physiol. 2003;65:45-79.

91. Stanley WC, Chandlef MP. Energy metabolism in the normal and failing heart: potential for therapeutic interventions. Heart Fail Rev. 2002; 7:115,-130.

92. Li $\mathrm{HH}$, Kedar $V$, Zhang $C$, et al. Atrogin-1/muscle atrophy F-box inhibits calcineurin-dependerit cardiac hypertrophy by participating in an SCF ubiquitim ligase complex. J Clin Invest. 2004;114:1058-1074.

93. Blaxall BC, Spang R, Rockman HA, et al. Differential myocardial gene expression in the developmenta and rescue of murine theart failure. Physiol Genomics, $2003 ; 15: 105-114$.

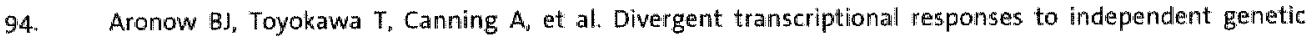
causes of cardliac hypertrophy. Physiol Genomics, 2001:6:19-28. 


\section{General discussion}


Many of the pathogenic molecular processes that play a role in cardiac hypertrophy and heart failure $(\mathrm{HF})$ are still unknown and most of them have been examined on a process-by-process basis only. Therefore, we applied the powerful approach of gene expression profiling to elucidate the processes involved in an unbiased manner and at a global scale. To reduce genetic heterogeneity we used (transgenic) mouse models with different causes of HCM or DCM and possible transition to HF. Dissection of the processes involved in different mouse models will unravel different pathogenic mechanisms and interactions between genome and (manipulated) environment. Our first result from a small microarray study revealed a clear downregulation of OXPHOS (oxidative phosphorylation) genes associated with HF. To determine the functional significance of our data, we carried out biochemical and morphological studies in a DCM model (MLP KO mice) and showed that the OXPHOS defects were caused by a reduction in the number of mitochondria and reduced expression of mitochondrial genes. OXPHOS defects related to HF have been reported in literature as well..$^{1-4}$ To investigate OXPHOS defects due to mtDNA defects as a possible cause of inherited cardiomyopathies, we screened the mtDNA for mutations in patients with mitochondrial myopathy and/or cardiomyopathy. A number of defects was identified, also in patients showing evident cardiac problems, indicating that mtDNA defects were a cause, although not a frequent one, of (congenital) cardiomyopathies. This example shows that gene expression profiling is a valid tool to identify pathogenic molecular processes and that results obtained in mice have significance for patients. So we extended our global gene expression studies in mouse models to identify other, possibly novel, genes and processes. Our results revealed similar and different molecular mechanisms related to mouse strain and pathology. This chapter will focus on the significance of gene expression profiling as a tool to unravel pathogenic molecular pathways, the compatibility of mouse model data for the human situation and the role of defects in energy metabolism in cardiac disease.

\section{Using microarray analysis for the identification of pathogenic processes}

Microarray technology was already in use during the $19805^{5}$, but only just mid 1990 s did it emerge as an exciting tool for gene expression profiling ${ }^{6.7}$ This technology enables the investigation of expression levels of thousands of genes simultaneously and generates a wealth of data, which has to be subsequently converted to biological relevant information. Nowadays, microarrays have a widespread use in genomic research, with various applications in biology and medicine, like classification of tumors ${ }^{8}$, unraveling the pathogenesis of several diseases ${ }^{9,10}$, the development of 
therapeutic targets ${ }^{11}$ or the assessment of cancer prognosis.12 However, before achieving these goals, there are several issues to be considered on the quality and reproducibility of the data. This has been recognized by the Scientific Community and microarray experiments have to be MIAME compliant nowadays. ${ }^{13}$ MIAME describes the Minimum Information About a Microarray Experiment necessary to enable the interpretation of the results of a certain experiment unambiguously and the potential reproduction of the experiment, thus to make microarray data available to the community in a useful way. MIAME is not a formal specification, but more a guideline to create a standard for recording and reporting microarray data. This will facilitate the establishment of public databases and also enable the development of appropriate data analysis tools. The MIAME guidelines also include information regarding an adequate experimental and microarray design, which is an absolute prerequisite to successfully perform a microarray experiment and exploit the results produced.

For our experiments on home-made microarrays, the design was such that relevant sources of variation, such as labeling efficiency, between and within slide variations, metagrid differences, pin effects, quality of the slides and instrumental variations, could be corrected for, even when performing single color experiments (chapter 7 and 8). As essential as the microarray design itself is the experimental design to answer the scientific questions or hypothesis, as biological differences are often the most prominent source of variation. This design is easier to set up in single color experiments than in dual color experiments. In the former, every slide can be compared with every other slide, while in the latter, one has to correct for dye differences as well. A specific design, e.g. a loop-design, is required when comparing multiple samples with multiple controls, because one particular control sample is always linked to a particular test sample (hybridized to the same slide). The quality of the RNA is a crucial factor as well. A recent study showed decreased data quality when moderately degraded RNA samples were used. Severely degraded RNA samples demonstrated low overall quality and poor correlation with their intact sample counterparts. ${ }^{14}$ The clone collections used can influence the results as well. The detection level of CDNA microarrays is higher than of oligonucleotide microarrays, but the specificity is less due to potential crass hybridization, complicating the determination of actual gene expression differences for the gene of interest. In general, gene expression data has to be validated within the microarray experiment itself (e.g. consistency between probes representing the same genes and between genes in the same process), and partly experimentally by real-time PCR (chapter 7 and 8). Confirmation of specific processes by functional studies or the generation of 
transgenic animals should be the next step to evaluate the biological relevance of findings.

\section{Translation of microarray data to biological and functional information}

A major challenge for scientists, who produce huge data sets by microarray experiments, is to determine the proper statistical and bioinformatic methods to use. With all the methods available for data analysis, the challenge lies in generating evidence for hypotheses by the application of the appropriate bioinformatics tools. The analyticall approach depends on the information required, i.e. the identification of a diagnostic signature requires a different kind of analysis than the construction of a list of differentially expressed genes to unravel underlying pathogenic processes. ${ }^{15}$ Before integration of multiple microarray measurements into a single analysis, basic statistics has to be performed to normalize the measurements and possibly correct them to make them comparable. Next, several approaches can be used, e.g. supervised, which search for genes that fit a predetermined pattern (training set), or unsupervised methods. Examples of the former are nearest neighbor analysis and support vector machines. Unsupervised methods are commonly used to characterize the components of a data set without the a priori input or knowledge. Examples are hierarchical clustering, self-organizing maps or principal components analysis. ${ }^{15}$ Many software packages can be used that can perform these analytical tasks, but there is no golden standard available at this point (reviewed by A. Butte et al.). ${ }^{15}$

The rate-limiting step in functional genomics experiments is the post-analytical interpretation of the results. Microarrays can both be used to investigate the role of known genes and processes in the pathology under investigation or to determine the role of unknown genes by alterations in gene expression level related to tissues, pathology or other genes. Several helpful tools exist to translate lists of differentially expressed genes into biological information, such as GenMAPP and MAPPFinder ${ }^{16,17}$, DAVID ${ }^{18}$, Pubmatrix ${ }^{19}$ and TXTGate. ${ }^{20}$ GenMAPP and MAPPFinder are used to visualize gene expression on maps representing biological pathways and groupings of genes, whereas DAVID allows access to a relational database of functional annotation and links Genbank, Unigene, and Affymetrix identifiers to biological annotations including gene names and aliases, functional summaries, Gene Ontologies (GO), protein domains, and biochemical and signal transduction pathways. Pubmatrix performs automatic PubMed searches for a list of genes and keywords and gives a result table with links to associated abstracts. TXTGate, finally, determines whether genes cluster into certain groups using literature based information. 
A major problem is that the tools used in genome projects are very good at the identification of genes, but that functional studies on the role of each of these genes lags behind. Many tools use the Locus Link identifiers (LL ID), which provide a single query interface to curated sequence and descriptive information about genetic loci. It presents information on for example official nomenclature, aliases, sequence accessions, phenotypes, thomology and map locations. Approximately $71 \%$ of the total number of transcripts analyzed in our experiments has a known LL ID, although for several of these genes there is still no additional information available, i.e. only the annotations "expressed sequence" or "Riken cDNA clone". Also, available information on genes can still be rather general, as the Gene Ontology (GO) term "metabolism" may be the most specific term available for a certain gene, while this term can actually be subdivided into many other, more specific, terms. This means that the function of many genes identified as being differentially expressed, can remain unknown for months or years and that microarray data sets remain a valid and often not fully exploited resource for future investigations. A problem particularly related to the use of murine LL IDs as starting-point for TXTGate analysis is that quite a lot of associations between genes were only based on their presence within one data set, such as the $15 \mathrm{~K}$ CDNA collection. On the other hand, the use of human gene names in animal research as starting-point may lead to lack of information regarding relationships between the genes identified. Moreover, every association identified should be verified by hand, which is also the case for Pubmatrix analysis, because the proposed relation between genes is not aiways relevant. The limitations of the analysis tools and the ambiguous annotation and functional information that is not available for all genes, complicate the interpretation of the results. It is obvious that this will change in the future and that microarray experiments will be among the driving forces in this respect.

\section{Successful examples of microarray technology in humans}

Microarray analysis has already proved to be valuable for diagnostics, elucidation of pathogenic mechanisms, and the discovery and evaluation of therapeutic targets. Transcript profiling has been frequently used on tumor tissues. The ease of access to the affected tissue, the clinical importance and the role of genetic derangement in its pathogenesis may provide a less complex starting point for microarray analysis. For example, in a microarray study in primary breast tumors, a gene expression signature was identified, strongly predicting the formation of distant metastases ("poor prognosis" signature) in patients diagnosed as lymph node negative. This signature consisted of genes regulating cell cycle, invasion, metastasis and angiogenesis. These findings provide a strategy to select patients who would benefit from adjuvant 
therapy. Similar approaches are probably more difficult when applied to other diseases. Cardiovascular diseases may not involve such gross transcriptional changes to the degree observed in cancer and access to tissue is often more problematic. Nevertheless, gene expression results in cardiac hypertrophy and the progression to HF have also provided valuable information about genes and processes involved.

Examination of human mRNA from left ventricular (LV) tissues of patients with IDC revealed several genes upregulated in muscle contraction, signaling and apoptosis. ${ }^{21}$ One of the cytoskeletal genes that was found to be upregulated in IDC patients was ZASP (Z-band alternatively spliced PDZ motif), suggesting this gene as a putative DCMassociated candidate gene. ZASP KO mice developed a severe myopathy and DCM. ${ }^{22}$ Subsequent mutation analysis in patients with familial or sporadic DCM or INLVM (isolated non-compaction of the left ventricular myocardium) revealed mutations in this gene in $6 \%$ of the patients. ${ }^{23} \mathrm{~A}$ second study revealed several genes differentially expressed in both DCM and HCM when compared to controls, which suggests different underlying remodeling and molecular pathways for HCM and DCM.24 Moreover, microarray technology has a great potential for the identification and evaluation of therapeutics in cardiovascular disease. For instance, evaluation of the effects of captopril on myocardial remodeling after infarction in the rat showed that early ACE (angiotensin converting enzyme) inhibition could prevent some of the changes in gene expression induced by $\mathrm{MI}$ (myocardial infarction). Some genes appeared to be unaffected by the treatment and thus may reveal novel targets in remodeling not presently affected by ACE inhibitors. ${ }^{25}$ Another example is the identification of specific gene expression patterns in pre- and post-LVAD (left ventricular assist device) hearts ${ }^{26-}$ ${ }_{28}$ and the significant alterations in gene expression resulting from LVAD support dependent on starting with either a failing ischemic or non-ischemic heart. This suggests different mechanisms of LVAD-mediated recovery dependent on HF etiology. In this way, it may be determined a priori which patients would benefit most from long-term LVAD. ${ }^{25}$

For the identification of pathogenic pathways, it is important to realize that microarray technology should be regarded as an explorative hypothesis-generating tool. A comparison with microarray results from other studies may be helpful to gain a better and more complete understanding of the molecular pathways that play a role in the disease under investigation. Nowadays, more and more microarray data are becoming publicly available through publications in journals, but also through the internet containing downloadable array data, for example by NCBI (www.ncbi.nlm.nih.gov/geo) 
or the CardioGenomics group (www.cardiogenomics.org). Although this availability is a good initiative, in practice it is often difficult to directly compare public data. There are many differences in the experimental approaches with respect to animal models (and mouse strains), patients, array types, and CDNA or oligonucleotide collections used. In addition, other parameters may vary as well, such as the time points studied during the course of a disease. Also, the presentation of the data can complicate comparisons, as data have frequently been processed up to a certain point (clustered data, groups of genes). On the other hand, if only the raw data are presented, then this requires additional data analysis to evaluate the actual results. Nevertheless, valuable information and potential discoveries will be present in existing data sets and therefore investments in meta-analysis to compare data sets from different labs and different experiments are worthwhile. For cardiovascular disease, integrating existing expression data of human tissue samples may enable the identification of distinct expression signatures associated with disease subtypes. Importantly, additional data on time experiments of animal models may help us to gain a broader view of how the transcriptional network of the cardiovascular system reacts in response to different genetic and environmental stimuli.

\section{Genomic profiling in mouse models of cardiac hypertrophy and heart failure}

Recent advantages in transgenic and gene-targeting approaches, mouse genetics and microsurgical technology have resulted in a revolution in cardiac research on the development of cardiac hypertrophy and the transition to $H F$, and has led to the identification of previously unknown molecular initiators, transducers and effectors. ${ }^{29}$ ${ }^{31}$ The clinical relevance of these models for human disease is a recurrent discussion. Although mice and men share a subset of highly conserved genes regulating fundamental aspects of the cardiovascular system, their physiological, dietary and environmental differences suggest that species variability may be a critical factor in the evaluation of mouse models for human cardiac disease. Moreover, as human hypertrophy and HF are complex diseases with regard to course, progress and outcome, genetic manipulation of a single mouse gene is thus unlikely to result in a phenotype completely reflecting the human clinical phenotype. As mouse strainspecific characteristics and genetic background influence the phenotype observed, conclusions drawn from studies using mouse models are not always directly valid for humans. Therefore, the role of the gene of interest in the pathogenesis of the cardiac phenotype should be interpreted with caution. Nevertheless, numerous murine molecular mechanisms underlying cardiac abnormalities have been proposed to play 
an important role in hypertrophy and $\mathrm{HF}$, including changes in cardiac metabolism, cytoskeletal, contractile and $\mathrm{Ca}^{2+}$-regulatory proteins, apoptosis, alterations in excitation-contraction coupling, the signal transduction system and many others. All these mechanisms have been confirmed in human pathology ${ }^{32,33}$, which demonstrates that in spite of all differences, investigation of these mouse models allowed a comprehensible dissection of pathogenic processes involved in hypertrophy and $\mathrm{HF}$ and the identification of the underlying molecular pathways.

\section{Compensated hypertrophy}

A number of mouse studies have been performed to identify key processes in compensated cardiac hypertrophy (increased cardiac mass without pulmonary congestion and deterioration of cardiac function) using a global gene expression microarray approach. Friddle et al. examined the expression of 4000 CDNA clones over a time course of (pharmacological) hypertrophy induction and regression in mice and found several genes differentially expressed either specific for the induction or the regression of hypertrophy. Induction of hypertrophy mainly involved changes in genes related to signaling, structure (mainly increased) and energy metabolism (mainly decreased), while most genes that changed during the regression phase were unknown. ${ }^{34}$ Similar changes were identified in our mice after induction of hypertrophy (chapter 7) and in a mouse model of cardiac hypertrophy induced by acute ( 24 hours) and chronic (14 days) ANG II (angiotensin II) treatment. ${ }^{35}$ Microarray analysis ( 22000 transcript probes) in these mice revealed overlapping differences in gene expression, i.e. changes in genes related to mitochondrial metabolism (mainly decreased), protein translation, ribosomal activity, but also distinct profiles, i.e. changes involving oxidative stress and amino acid metabolism in the acute treatment, and changes in genes related to the cytoskeleton (mainly increased), amyloidosis and the extracellular matrix after chronic treatment. ${ }^{35}$ Acute and chronic responses to hypertrophy were also assessed by Weïnberg et al. using high density microarray analysis ( 12500 genes) in both male and female mice at 1 day (acute) and 30 weeks (chronic) after banding. They revealed temporal- and sex-dependent expression profiles, with genes found to be either regulated in the acute response or in both acute and chronic overload hypertrophy. Distinct genes related to inflammation, stress response, extracellular matrix and cytoskeleton showed increased expression in either the acute or chronic condition. ${ }^{36}$ We also observed temporal changes in gene expression, showing a more pronounced response during the acute phase (chapter 7 ). Zhao et al. investigated mice at 48 hours, 10 days and 3 weeks after TAC and mainly identified changes in the expression of genes related to metabolism, cell growth and cell communication. They 
found many differential changes in gene expression between time points ${ }^{3 \%}$, which we also observed (chapter 7). The group of Weinberg et al. and Zhao et al. used FVB mice, which together with our white Swiss mice, seem to be among the mouse strains which remain in a hypertrophic state without LV decompensation until many weeks after TAC, with a similar increase in heart weight.

During the preparation of chapter 7 describing the changes occurring in LV of mice after aortic banding, Wagner et al. reported their findings in LV and LA (left atrium) from TAC mice at 20 days after banding. Significant alterations in cytoskeletal remodeling and energy metabolism were found, including a downregulation of genes encoding multiple components of the respiratory chain complexes and FA metabolism in TAC mice. ${ }^{38}$ In addition, they identified changes in cell cycle regulation and signal transduction. They consider the processes identified in their study as maladaptive, since cardiac hypertrophy often leads to HF and several studies have reported a shift in substrate preference from fatty acids to glucose in mice that develop HF. ${ }^{39,40}$ In this case, it is proposed that the reduction of FA oxidation is not fully compensated for by the increased glucose oxidation, implicating a reduced overall rate of ATP regeneration, eventually leading to functional deterioration. ${ }^{41}$ However, other groups have not identified this shift or even showed an increase in the use of fatty acids (for a review, see van Bilsen et al. ..$^{41}$ Moreover, cardiac-specific overexpression of Glut1 (glucose transporter 1) in mice was found to prevent the development of HF due to chronic pressure overload by increasing myocardial glucose uptake. These findings suggest that enhanced glucose uptake can support the heart to sustain the high workload during chronic pressure overload, although the glucose uptake and glycolysis exceeds the level that can be achieved in the normal situation. ${ }^{42}$ The results from Wagner's group regarding changes in energy metabolism and cytoskeletal remodeling are similar to ours, but by investigating more than one time point, we demonstrated that during the later hypertrophic phases, gene expression in these processes returns to basal levels again. Moreover, FVB mice used in their study seem to develop hypertrophy without decompensation ${ }^{36.37}$, just like our white swiss mice. Most likely, the observed changes in energy metabolism in these mice reflect a transition to temporary growth of the myocardium as an adaptation to the increase in pressure overload and do not necessarily represent a maladaptive process. The increased expression of structural and sarcomeric genes may provide important cytoskeletal support for these TAC models, such that hypertrophy does not progress to failure, not even on the long term. Time series experiments are very useful for investigation of genes and processes in hypertrophy or HF, especially when drawing conclusions 
regarding their adaptive or maladaptive nature. If our TAC mice would have been studied at the early time points only and would not have been examined many weeks after banding, we would not have observed the transient nature of some gene expression changes and linked this to adaptive cardiac hypertrophy.

Mirotsou et al. also compared gene expression profiles between TAC mice and MI mice 1 week after surgery. They identified distinct regional expression profiles in these two models of cardiac hypertrophy, involving mainly an upregulation of genes related to immune response (LV/septum in TAC), extracellular matrix and cell communication (LV/septum in TAC, LV in MI), cell cycle (LV/septum in MI) and a downregulation of enzyme encoding genes (LV/septum in TAC/MI). The regional differences likely represent the different insults to the heart, as following $\mathrm{MI}$, the effect is local at the beginning and gradually will extend to the whole ventricle, while TAC exerts a global effect from the start. ${ }^{43}$ No decompensation was observed in these mice at the time point investigated. However, a time series experiment is required to determine whether these mice eventually progress to HF, as this has been described previously for this mouse strain (C57BL/6 mice). ${ }^{44,45}$ Divergent transcriptional changes were also seen in phenotypically similar but pathophysiologically different genetic models of cardiac hypertrophy. All mice were investigated at a state of non-failing or compensated hypertrophy, although some of the mouse models are known to eventually develop HF. These findings suggest the presence of transcriptional effects that are unique to a certain hypertrophic stimulus, rather than the existence of a general stress response to the induction of hypertrophy. ${ }^{46}$ The absolute number of genes changed and the nature of some of them in the models corresponded approximately with the severity of the pathology observed, suggesting that early changes in gene expression may already set the outcome at a later age (see also Blaxall et all. and our findings in the CMyBP-C KO mice, further down).

\section{Decompensated hypertrophy}

Murine microarray studies addressing the transition to HF were among others performed by Blaxall et al., who compared gene expression in controls, HF MLP KO mice, HF CSQ (calsequestrin) overexpressing mice and rescued mice (HF + BARKCt). They showed significant differences between all groups and demonstrated that the phenotypic rescue by $\beta A R K c t$ returned gene expression towards normal. They also showed that mice with a mildly diminished cardiac function (mild HF mice) were classified correctly as having a HF phenotype when blindly subjected to their predictive model, indicating that a HF-specific gene expression profile appears to be already set in 
the early stages of $\mathrm{HF}$ progression. Among the differentially expressed genes between normal and HF were several previously reported HF-associated genes, such as BNP (brain natriuretic peptide), and extracellular matrix and heat shock related genes. They mainly emphasized the identified novel statistical and predictive analyses, which demonstrate the potential for using multifactoral gene expression profiling. ${ }^{47}$ Expression profiling in 4-9 weeks old mice deficient for cardiac specific Tfam (mitochondrial transcription factor A), which develop progressive DCM, revealed an early switch in metabolism indicated by increased expression of glycolytic enzymes and decreased expression of genes encoding FA oxidation enzymes. ${ }^{4 \&}$ To our knowledge, few microarray profiling experiments have been performed in mice with $\mathrm{HF}$ due to pressure overload, such as $\mathrm{C} 57 \mathrm{BL} / 6$ mice, which have been reported previously to develop HF after aortic banding. ${ }^{44}$ These mice are mostly studied when still at a state of compensated hypertrophy. ${ }^{43}$

No time range experiment was performed for the two KO mouse models used in this thesis characterized by an uncompensated cardiomyopathy. Nonetheless, both the heterozygous and homozygous CMyBP-C KO mice showed an increased expression of mitochondrial encoded genes and genes involved in FA metabolism. This was at an age prior to the onset of hypertrophy for the heterozygotes and before impairment of cardiac function for the homozygotes. Previous findings in patients with HCM caused by sarcomeric mutations also suggest an increased energy demand ${ }^{49}$, which supports the notion that HCM caused by sarcomeric mutations is characterized by impaired energy metabolism. Recently, this was demonstrated in HCM mutation carriers without hypertrophy ${ }^{50}$, suggesting that sarcomeric mutations could primarily lead to energetic abnormalities and that they do not only occur secondarily to the hypertrophy. In addition, several genes involved in MAPK (mitogen activated protein kinase) signaling were upregulated, as well as sarcomeric, cytoskeletal and apoptosisrelated genes (chapter 8 ). Notably, most alterations were more pronounced in the homozygous KO mice. Based on a single time point observation, it is difficult to judge if these differences relate to different genetic pathways or to different stages of disease. Comparable with the human situation. carriers of two mutated alleles, such as compound heterozygotes (patients with two different abnormal alleles for $\mathrm{cMyBP}-\mathrm{C}$ ) and double heterozygotes (patients with one mutated CMyBP-C allele and an additional mutated HCM allele), develop a more severe cardiac phenotype. ${ }^{51-53}$ Moreover, alterations in processes occurring in both homo- and heterozygous KO mice reveal that the early molecular response to hypertrophy may be an important determinant of later remodeling, prior to the clinical or pathophysiological 
manifestations of compensated or decompensated hypertrophy. This has also been suggested previously in mouse models for HF. .66.47

The second model for uncompensated hypertrophy investigated in this thesis, the MLP $K O$ mice (chapter 5$)^{54}$, showed a downregulation of mitochondrial encoded genes and PGC-1 $\alpha$ (peroxisome proliferator activated receptor gamma co-activator 1a), which is a key regulator of mitochondrial biogenesis and gene expression in heart and other

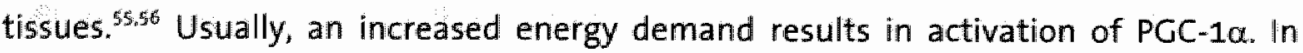
both homozygous and heterozygous CMyBP-C mice, PGC- $1 \alpha$ expression was also found to be downregulated (unpublished data). Downregulation of PGC-1 $\alpha$ has previously been reported in rats with $\mathrm{HF}^{57}$ and has been associated with loss of mitochondria. ${ }^{58} \mathrm{In}$ the MLP KO mice, a regional loss of mitochondria was identified. ${ }^{54}$ Recently, mice overexpressing Cdkg (cyclin-dependent kinase 9), a mediator of mRNA synthesis, exhibited not only myocyte enlargement, but also selective suppression of PGC-1 $\alpha$ after challenge by mechanical stress, culminating in mitochondrial defects, enhanced myoctye apoptosis, predisposition to $\mathrm{HF}$ and early demise. ${ }^{59}$ Interestingly, in compensated cardiac hypertrophy (mice 1 and 8 weeks after TAC, unpublished observations), an upregulation of PGC-1 $\alpha$ was observed. Additional increased expression of genes involved in mtDNA synthesis and mitochondrial protein biosynthesis early after induction of hypertrophy (chapter 7) show that some mice strains are rather flexible in altering their energy status in response to TAC, which may not be the case in mouse models developing cardiac hypertrophy caused by a genetic defect. These results confirm the important role of PGC-1 $\alpha$ in maintaining the balance required between mitochondrial energy production and cardiac energy demand.

Several of the aforementioned studies show overlapping results, while also different processes have been identified for the different mouse models. Both the similarities and differences identified will be meaningful, as the first may unravel core pathways, while the second may indicate more pathology or strain specific processes. When comparing different murine microarray studies, it is difficult to clearly identify processes that seem to be distinctive for compensated and decompensated cardiac hypertrophy. Changes of genes involved in protein synthesis, extracellular matrix proteins, oxidative stress and calcium handling have been described in several rodent microarray studies. ${ }^{34-36,60-62}$ However, it is still unclear which genes or mechanisms can distinguish adaptive from maladaptive cardiac hypertrophy. Some signaling routes have been suggested to be maladaptive in nature, such as the calcineurin/NFAT 
(nuclear factor of activated $T$ cells) route, Gq-signaling and $\rho 38$ signaling ${ }^{63}$ and apoptosis is thought to play an important role in the transition to $\mathrm{HF}^{63,64}$ Upregulation of apoptotic genes in the CMYBP-C KO mice also suggest a role for this process in maladaptive cardiac hypertrophy, as hardly any apoptotic genes were found to be differentially expressed in the TAC mouse model for compensated hypertrophy. We also observed other changes and similarities when comparing results from our and other mouse models. Differential expression of mitochondrial metabolic genes, particularly those involved in OXPHOS and FA oxidation, and structural remodeling seem to be essential in both compensated and decompensated hypertrophy. However in compensated hypertrophy, changes in (mitochondrial) energy metabolism seem to be transient and adaptive when the hypertrophic stimulus itself does not interfere with compensation mechanisms to match the increased energy demand ${ }^{34.35 .38}$ (and chapter 7), i.e. that there are no primary abnormalities in energy metabolism and that cytoarchitecture is still intact. If these abnormalities are present, it can be expected that the initial structural adaptations and energy generation of the heart will not be sufficient, leading to further energy depletion and impaired cardiac function with progression to HF. in other words, the cost of the continuous stress with respect to energy demands becomes too high compared to essential processes in the mouse that can counteract the effects of the primary defect that triggers cardiac hypertrophy. Further cross-comparisons of different mouse models will allow a greater insight into these underlying processes and pathways depending on the genetic or etiologic origins of hypertrophy and HF. Time series experiments are an important aspect in these comparisons, as the eventual outcome will determine the conclusions regarding the adaptive or maladaptive nature of certain genes or processes. Moreover, comparisons of different mouse strains may reveal modifier genes that could increase our knowledge with respect to the variability in the phenotypic expression of hypertrophy and HF in patients.

\section{Relevance of the findings in the mouse models for human pathology}

HCM and DCM can be caused by environmental factors, but also by genetic defects within the cardiomyocyte itself, like mutations in genes encoding sarcomeric proteins, as well as non-sarcomeric genes (see chapter 1). One of the key processes identified in our and other studies is (mitochondrial) energy metabolism. $2,49.57,65.67 \%$ To determine the functional relevance of these findings, we directed part of our investigation to genetic and functional studies of the OXPHOS system. The human heart mainly relies on mitochondrial OXPHOS for its energy production and cardiomyopathies can occur due 
to inherited or acquired pathogenic mutations in the mtDNA. This has been reported in cardiac disease, such as DCM, HCM, cardiac conduction defects, sudden death, ischemic and alcoholic cardiomyopathy, and myocarditis. ${ }^{68}$ For example, cardiac involvement (mostly a hypertrophic phenotype) has been reported in 20-30\% of patients with MELAS syndrome caused by the A3243G mutation, although a cardiac phenotype has also been described as a partial or an isolated phenotype in patients carrying this mutation. ${ }^{69}$ Primary mitochondrial dysfunction and morphological abnormalities leading to cardiomyopathy have been reported in several animal models, such as ANT1 (adenosine nucleotide translocator) KO mice which develop cardiac hypertrophy ultimately leading to $\mathrm{DCM}^{70}$ and cardiac specific Tfam KO mice, which develop progressive DCM. In addition, many diseases that limit myocardial energy production, such as Friedreich's ataxia, defects in fatty acid (FA) uptake and mitochondrial FA oxidation, can lead to cardiac hypertrophy clinically indistinguishable from $\mathrm{HCM}^{71-74}$ Furthermore, mutations in the 12 -regulatory subunit of AMP-activated protein kinase (PRKAG2), a sensor and orchestrator of cellular energy homeostasis, were found to result in HCM..$^{67.75}$ Recently, it was found that LAMP2 (lysosomal membrane glycoprotein 2) mutations, which typically cause multisystem glycogen storage disease, can also present as a primary cardiomyopathy. ${ }^{75}$ The glycogen storage cardiomyopathies produced by LAMP2 and PRKAG2 mutations resemble HCM, but can be distinguished by electrophysiological abnormalities. This suggests that patients with unexplained LVH and preexcitation patterns on ECG may be suffering from glycogen storage disease. ${ }^{\text {s }}$

Our results and existing reports on non-sarcomeric energy metabolism-related causes of HCM and DCM suggest that cardiac energetic abnormalities, including OXPHOS abnormalities, play an important role in the pathogenic mechanism of these diseases. To validate this, we tested patients with presumed cardiomyopathy with or without myopathy for defects in OXPHOS function and mutations in the entire mtDNA. ${ }^{76}$ Reduced activities of one or more OXPHOS complexes were identified in $48 \%$ of the skeletal muscle and $57 \%$ of myocardium samples of these patients (Scholte, unpublished data). The entire mtDNA of 64 patients has been screened, in which 11 mutations were identified. In 27 patients, part of the mtDNA was only just screened, which revealed 3 mutations. Several mutations were found to be associated with cardiac abnormalities, such as the A3260C and T3271C in the tRNA ${ }^{\text {leuluur) }}$ gene, the G12192A in tRNA ${ }^{\text {His }}$, the A12308G mutation in tRNA ${ }^{\text {leulCUN) }}$ and the G13513A mutation in ND5. The DHPLC method to screen the entire mtDNA has recently been adjusted and converted to a diagnostic kit by Transgenomic Inc. ${ }^{77}$ At the moment, the mtDNA from 
more patients with and without signs of cardiomyopathies are being screened. One of the patients (a 64-year-old woman) screened by this method revealed the tRNA ${ }^{\text {(eul(uv) }}$ A3302G mutation (chapter 4). Her son carried $96 \%$ of the mutation in muscle and died of cardiac arrhythmia. This mutation had been reported before in another family, in which one patient died of cardiorespiratory failure. Another patient carrying the T14484C LHON (Leber hereditary optic neuropathy) mutation presented with additional neurological symptoms next to the central visual loss. Screening the mtDNA of this patient revealed the $A 4269 G$ mutation in RRNA $^{\text {lle }}$ (case report in preparation by spruijt et al.), which might explain the neurological symptoms, but which has previously been reported associated with cardiomyopathy. Subsequent cardiological examination of this patient revealed cardiac abnormalities, although symptoms were not clinically manifest. Our findings show that OXPHOS and mtDNA defects are a cause, although not a frequent one, of (congenital) cardiomyopathies. However, our results emphasize the importance of possible cardiac complications associated with mtDNA mutations and the need for appropriate cardiac investigations in case of OXPHOS defects. This is currently not performed on a routine basis and might indicate an underdiagnosis of mitochondrial cardiomyopathies. Also, genetic counseling should be provided and advice concerning the avoidance of possible risk factors for cardiorespiratory failure, such as traveling by airplane or staying at high altitudes (i.e. low oxygen pressure environments).

\section{Conclusions}

Our approach of gene expression profiling in mouse models of cardiomyopathies has unraveled a myriad of potential pathogenic pathways. Alterations in energy metabolism, and more specific OXPHOS, are common in both compensated (transient downregulation) and decompensated (structural downregulation) cardiomyopathy. The observed downregulation can be induced by primary genetic factors, like mtDNA defects, or secondary factors, like defects in cytoskeletal proteins, or they can be induced by environmental factors, like TAC or ageing. All processes lead to OXPHOS deficiencies. Primary defects in TRNA genes interfere with proper translation of the mitochondrial RNA and will affect the mtDNA encoded subunits. Secondary, cytoskeietal defects result in a disorganized myofibrillar structure, which may lead to loss of the mitochondria. The relation between a cytoskeletal defect and local mitochondrial depletion can provide clues for a therapeutic strategy to improve the energy balance in HF by stimulating mitochondrial biogenesis. This also applies to the situation in type 2 diabetes, in which PGC-1 $\alpha$ and subsequently the OXPHOS genes are 
downregulated, resulting in a reduced ATP-production. ${ }^{78}$ it is not said that every pathogenic pathway identified will have a similar significance, but we have clearly shown that gene expression profiling in mice is a powerful approach to identify pathogenic processes with significance in human pathology, and can provide clues for therapeutic interventions. This was the main aim of our work. The use of different mouse models with different pathology allows dissection of the processes to be general or specific for the pathology observed. Whether the processes identified will be useful for prognosis in patients remains to be determined. However, confirmation is hampered by the lack of heart tissue of patients and controls.

The remainder of the processes and genes identified in compensated as well as in noncompensated hypertrophy require additional functional studies to establish their biological relevance. Part of these studies has already been performed as we have also detected previously known and characterized pathways. ${ }^{29,3 \dot{3}, 33}$ An interesting group of genes are the functionally uncharacterized genes, which show altered gene expression levels in our models and which behave similarly to the pathogenic processes identified. Further characterization of these genes would be a first step to get an idea of their function and possible role in cardiac pathology. Tools that link unknown genes to known biological pathways, or that enable the discovery of new pathways, have been improved substantially in the last couple of years, although they are still far from complete. In case information remains insufficient, the generation of animal models, in which the specific gene is knocked out or overexpressed, might be the only approach to provide clues regarding the function. Our results and results from other groups have revealed only a small, but still promising part of the complex orchestrated transcriptional responses of the heart to stimuli causing the onset of cardiac hypertrophy and the possible tramsition to HF. Each of these newly identified genes and processes will increase our knowledge and may ultimately lead to new effective treatment strategies.

\section{References}

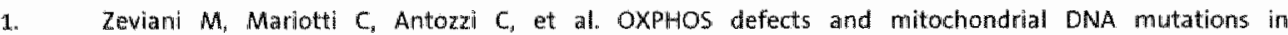
cardiomyopathy, Muscle Nerve. 1995;3:5170m.174.

2. Bornstein B, Huertas $R$, Ochoa $P$, et al. Mitochondriall gene expression and respiratory enzyme activities in cardilac diseases. Biochim Biophys Acta. 1998;1406:85-90.

3. Jarreta D, Orus J, Barrientos $A_{\text {a }}$ et al. Mitochondrial function in heart muscle from patients with idiopathic dilated cardiomyopathy. Cardiowasc Res. 2000;45:860-865.

4. Sharow VG, Todor A'V, Silwerman $N$, al. Abnormal mitochondrial respiration in failed human myocardium. I Mol Cell Cardiol. 2000;32:2361-2367. 
5. Augenlicht LH, Kobrin D, Pavlovec A, et al. Elevated expression of an enidogenous retroviral iong termunal repeat in a mouse colon tumor. J Biol Chem. 1984;259:1842-1847.

6. DeRisi $J_{8}$ Penland $L$, Brown PO, et al. Use of a CDNA microarray to analyse gene expression patterins in human cancer. Nat Genet. $1996 ; 14,457-460$.

7. Lockhart DI. Dong, H; Byme MC, et all. Expression monitoring by hybridization to high-density oligonucleotide arrays. Nat Biotechnol 1996;14:1675 1680 .

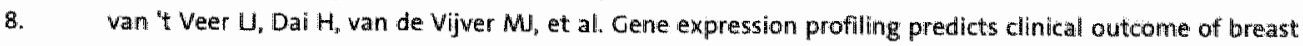
cancer. Nature. 2002;415:530-536.

9. Lim DS, Roberts $\mathbb{R}$, Marian Al. Expression profiling of cardiac genes in human hypertrophic cardionyopathy: insight into the pathogenesis of phenotypes. $\mathrm{Am}$. Coll Cardiol 2001:38:1175-1180.

10. Ning W, LI C, Kaminski N, et al. Comprehensive gene expression profilles reveal pathways related to the pathogenesis of chronic obstructive pulmonary disease. Proc Nat Acad Sci U 5 A. 2004,101:14895-1.4900.

11. Gaiger $A_{x}$ Heintel $D_{n}$ lager $U$. Novel molecular diagnostic and therapeutic targets in cluronic lymphocytic lewkaemia. Eur J Clin invest 2004;34 5uppl 2:25-30.

12. ZOW M, Famulski KS, Parhar RS, et al. Microarray analysis of metastasis wassociated gene expression profining in a murine model of thyroid carcinoma pulmonary metastasis: identification of $5100 \mathrm{A4}$ (Mts1) gene overexpression as a poor prognostic marker for thyroid carcinoma. I Clin Endocrinol Metab. 2004;89:61466.154.

13. Brazma A, Hingamp P, Quackenbush J, et al. Minimum information about a microarray experimernt (MIAME)-toward standards for microarray data. Nat Genet. 2001,29:365-371.

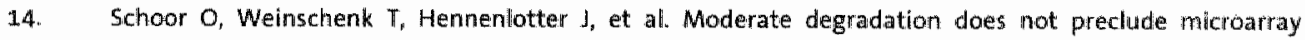
analysis of simall amounts of RNA. Biotechniques. 2003;35:1192-1196, 1198-1201.

15. Butte A. The use and analysis of microarray data. Not Rev Drug Discov, 2:002; $1: 951-960$.

16. Dahlquist $K D$, Salomonis $N$, Vranizan $K$, et al. GenMAPP, a new tool for viewing and analyzing microarray data on biological pathways. Nat Genet. 2002;31:19-20.

17. Doniger $5 W$, Salomonis $N_{\text {; }}$ Dahlquist $K$, et al. MAPpFinder: using Gene Ontology and GenMAPP to create a global gene-expression proflie from micraarray data. Genome Biol. 2003;4:R7.

18. Dennis $G$. Jr., Sherman BT, Hosack DA, et al. DAVID. Database for Annotation, Visualization, and Integrated Discowery. Genome Biol. 2003;4:P3.

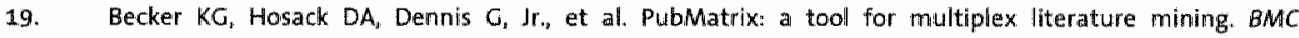
Bioinformatics. 2003:4:61.

20. Glenisson P, Caessens B, Van Vooren S, et al. TXTGate: profiling gene groups with text-based information. Genome Biol. 2004:5:R43.

21. Grzeskowiak $R_{\text {, Witt }} H_{\text {s }}$ Drungowski $M$, et al. Expression profiling of human idiopathic dilated cardiomyopathy. Cardiovase Res. 2003:59:400-411.

22. Huang $\mathrm{C}_{\text {, }}$ thou $\mathrm{Q}$, Liang $\mathrm{P}$, et al. Characterization and in viwo functional analysis of splice variants of cypher. Biol Chem. 2003;278:7360m7365.

23. Vatta Mohapatra $\mathrm{B}_{\text {, Nimenez }}$, et al. Mutations in Cyplmer/ZASP in patients with dilated cardiomyopathy and left ventricular non-compaction. I Am Coll Cardiol. 2003:42:2014-2027.

24. Hwang J., Allen PD, Tseng GC, et al Microarray gene expression profiles in dilated and hypertrophic cardiomyopattic end-stage heart failure. Physiol Genomics. 2002;10:31-44.

25. $\operatorname{lin} H_{*}$ Yang $R$, Awad $T A$, et al. Effects of early angiotensinmconwerting enzyme inhibition on cardiac gene axpression after acute myocardiall infarction. Circulation, 2001; 103:736-7.42

26. Blaxall BC, Tschannen-Maran BM, Milano CA, et al. Differential gene expression and genomíc patient: stratification following lefi ventricular assist device support. I Am Coll Cardiol. 2003;41:1096-1106.

27. Chen $\%$, Park $S_{4}$ Li $\%$, et al. Alterations of gene expression in failing myocardium following left ventricular assist device siupport. Physiol Genomics. $2003 ; 14: 251-260$. 


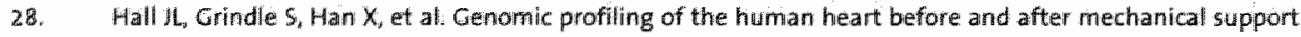
with vertricular assist device reveals alterations in vascular signaling networks. Physiol Genomics. $2004 ; 17: 283-291$ :

29. Hunter J, Chien KR. Signaling pathways for cardiac hypertrophy and failure. N Engl J Med. 1999;341:12761283.

30. Chien KR. Stress pathways and heart failure Cell 1999:98:555-558.

3. Molkentin JD, Dorn $1 G_{n}$ znd. Cytoplasmic signaling pathways that regulate cardiac hypertrophy. Annu Rev Physiol $2001 ; 63: 391-426$.

32. Frey N, Olson EN. Cardiac hypertrophy: the good, the bad, and the uglly. Ammu Rew Physiol 2003:65:45-79.

33. Lips DI, deWindt $\mathrm{U}$, varn Kratij Dt, et all. Molecular determinants of myocardiall hypertrophy and failure: alternative pathways for beneficial and maladaptive hypertrophy. Eur Heart 1.2003;24:883-896.

34. Friddle $C J$, Koga T, Rubin EM, et all. Expression profiling reveals distinct sets of genes aitered during induction and regression of cardiac hypertrophy. Proc Nati Acad SCI U S.A. 2000;97:6745-6750.

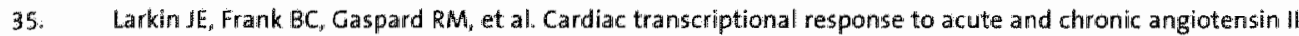
treatments, Physiol Genomics, 2004;18:152-166.

36. Weinberg. EO, Mirotsou $M_{n}$ Gannon I, et al. Sex dependence and temporal dependence of the lleft wentricular genomic response to pressure overload. Physiol Cenomics. 2003:12:113-127.

37. Zhao $M$. Chow $A_{i}$ Powers $J_{\text {, }}$ et al. Microarray Analysis of Gene Expression after Transverse Aortic Constriction in Mice. Physiol Genomics. 2004.

38. Wagner $R A$, Tabibiazar $R$, Powers J, et all. Genome-wide expression profiling of a cardiac pressure overtoad model identifies major metabolic and signaling pathway responses. $J$ Mol Cell Cardiol. 2004;37:1159-1170

39. Barger PM. Brandt JM, Leone TC, et al. Deactivation of peroxisome proliferator-activated receptor-alpha during cardiac hypertrophic growth. J Clin invest. 2000:105:1723-1730.

40. Lehman 11, Kelly DP. Gene regulatory mechanisms governing energy metabolism during cardiac hypertrophic growth. Heart Fall Rew, 2002;7:175-185.

41. van Bilsen $M$, smeets $P J_{\text {, Glide }} \mathrm{AJ}$, et al. Metabolic remodelling of the failing heart: the cardiac burn-out syndrome? Cardiovasic Res. 2004;61:218-226.

42. Liao $R_{i}$ Jain $M$, Cui $L$, et al. Cardiac-specific overexpression of GLUT1 prevents the development of heart fallure attributable to pressure overload in mice. Circulation. 2002;106:2125-2131.

43. Mirotsou $M_{n}$ Watanabe $C M$, schultz $P C$, et al. Elucidating the molecular mechanism of cardiac remodeling using a comparative genomic approach. Physiol Genomics. 2003;1: 5:115-126.

44. Okada K, Mimamino T, Tsukamoto Y, et al. Prolonged endoplasmic reticulum stress in hypertraphic and falling heart after aortic constriction: possible contribution of endoplasmic reticulum stress to cardiac myocyte apoptosis. Circination. 2004:120:705-712.

45. Liao $Y$, Takashima $S_{n}$ Asano $\gamma$, et al. Actiwation of adenosine A1 receptor attenuates cardiac hypertrophy and prevents heart failure in murine left ventricular pressure-overload model. Circ Res. 2003;93:759-766.

46. Aronow Bi, Toyokawa $\mathrm{T}$. Caming A, et all. Divergent transcriptional responses to independent genetic causes of cardiac hypertrophy. Physiol Genomics. 2001:6:19-28.

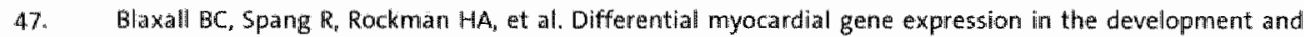
rescue of murine heart failures physiol cienomics. 2003:15:105-114.

48. Hansson A, Hance $N$, Dufour $E_{v}$ et al. A switch in metabolism precedes increased mitochondrial biogenesis in respiratory thain-deficient mouse hearts. Proc Nat Acad Sci U S A. 2004;101:3136-31.41.

49. Ashrafian H, Redwood C, Blair E, at al. Hypertrophic cardiomyopathy: paradigm for myocardial energy depletion. Trends Genet. 2003:119:263:268.

50. Crilley $J G_{1}$ Boehm EA, Blair $E$, et al. Hypertiophic cardiomyopathy due to sarcomeric gene mutations is characterized by impaired anergy metabolism irrespective of the degree of hypertrophy. $J$ An Coll Cardiol. $2003 ; 41: 1776-1782$ 


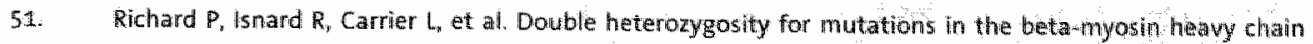
and in the cardiac myosin binding protein $C$ genes in a family wh h hypertrophic cardomyopatly. $1 \mathrm{Med}$ Genet. $1999: 36: 542-545$.

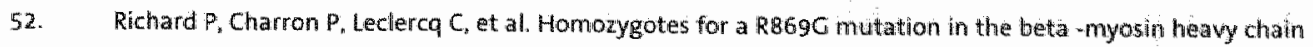

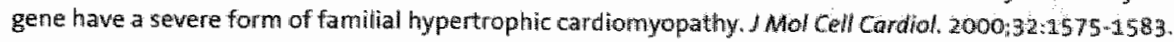

53. Richard $P_{\text {, Charron }} \mathrm{P}_{\mathrm{n}}$ Carrier $\mathrm{L}$, et al. Hypertrophic cardiomyopathy: distribution of disease gehes spectrum of mutations, and implications for a molecular diagnosis strategy. Circulation. 2003,107:2227-2232.

54. Van den Bosch $B$, van den Burg CM. Schoonderwoerd $K_{3}$ et al. Regional absence of mitochondria causting energy depletion in the myocardium of muscle l.M proteln knockout mice. Cardiowasc Res. 2005.65.411. 418 .

55. Wu $Z_{\text {, }}$ Pugserver $P$, Andersson U, et al. Mechanisms controlling mitochondrial biogehesis and respiration through the thermogenic coactivator PGC-1. Cell. 1999:98:115-124.

56. Lehman J, Barger PM, Kowacs A, et al. Peroxisome proliferatoractivated receptor gamma coactivator-1 promotes cardiac mitochondrial biogenesis. I Clin invest. 2000;106:847-856.

57. Garnier A, Fortin D, Delomenie $C_{\text {, }}$ et all. Depressed mitochondrial transcription factors and oxidative capacity in rat falling cardiac and skeletal muscles. I Physiol. 2003:551:491 -501.

58. Czubryt MP, MCAnally J, Fishman Gl, et al. Regulation of peroxisome proliferator-activated receptor gamma coactivator 1 aipha (PGC.1 alpha) and mitochondrial function by MEF2 and HDAC5. Proc Nall ACad SeiU S A. $2003 ; 100: 1711-1716$.

59. Sano $M$, Wang SC, Shira: $M$, et al. Activation of cardiac Cdk9 represses PGC-1 and confers a predisposition to heart failure. Embo 1. 2004;23:3559-3569.

60. Kong SW, Bodyak N, Yue P, et al. Genetic Expression Profiles During Physiologic and Pathollogic Cardilac Hypertrophy and Heart Failure in Rats. Physiol Genamics. 2004.

61. Schroen B, Heymans 5, Sharma $U$, et al. Thrombospondin-2 is assential for myocardial matrix integrity: increased expression identifies failure-prone cardiac hypertrophy. Circ Re5. 2004:95:515-522.

62. Chen $H$, Huang $X N$, Stewart $A F$, et al. Gene expression changes associated with fibronectim-induced cardiac myocyte hypertrophy. Physiol Genamics. 2004:18:273-283.

63. Selwetelia G. Hirsch E, Notte A, et al, Adaptive and maladaptive hypertrophic pathways: points of convergence and divergence Cardiawasc Res. 2004;63:373-380.

64. van Empel VP. De Windt U. Myocyte hypertrophy and apoptosis: a balancing act. Cardiovasc Res. $2004 ; 63: 487-499$.

65. Arbustini E, Diegali M, Fasani $R$, e* al. Mitochondrial DNA mutations and mitochondrial abnormalities in dilated tardiomyopathy. Am I Pathol. 1998:153:1501-1510.

66. Lehmam $j_{\text {s }}$ Kelly DP. Transcriptional activation of energy metabolic switches in the developing and hypertrophied heart. Clin Exp Pharmacal Physiol. 2002;29:339-3.45.

67. Ventura-Clapier R, Garmier A, Veksler V. Energy metabolism in heart fallure 1 Physiol 2004:55:1-13.

68. Marin Garcia " Coldentha! M. Understanding the impact of mitochondrial defects in cardiowascular disease: a review. I Cord Fail. 2002;8:347-361.

69. Lodi R, Rajagopalan B, Blamire AM, et al. Abnormal cardiac energetics in patients carrying the A32 430 mtDNA mutation measured in wivo using phosphorus MR spectroscopy. Biochim Biophys Acta. $2004 ; 1657: 146-150$.

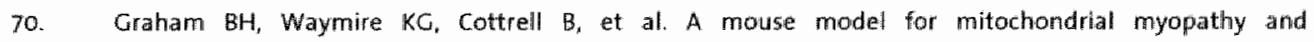
carciomyopathy resulting from a deficiency in the heart/muscle isoform of the ademine nucleatide trams:ocator. Nat Cenet. $1997: 16: 226-234$.

71. Merante F, Tein I, Benson L, et al. Maternally inherited hypertrophic cardiomyopathy due to a nowel Twow $\mathrm{C}$ tramsition at nucleotide 9997 in the mitochond rial tRNA(glycinel gene. Am S Hum Genet. 1994;55:437-446.

72. Lodi $R$, Cooper J $M$, Bradley $I L$, et al. Deficit of in vivo mitochondrial ATP production in patients with Friedreich ataxia. Proc Nath Acad Sci U S A. 1999:96:11492-11495. 
73. Tanaka $T$, sohmiya $K$, Kawamura $K$ is $C 036$ deficiency an etiology of hereditary hypertrophic cardiominopathy? I Mol Cell Cardiol $1997 ; 29: 121-127$.

74. Aoyama $T$, Sour $M$, Ushikubo $S$, et al. Purification of human very-long-chain acyl-coenzyme $A$ dehydrogenase and characterization of its deficiency in seven patients I clin trvest 1995:95:2465-2473.

75. Arad $M$, Maron Bj, Goham $M$, et al Glycogen storage diseases presenting as hypertrophic cardiomyopathy. N Engl/ Med 2005;352:362-372.

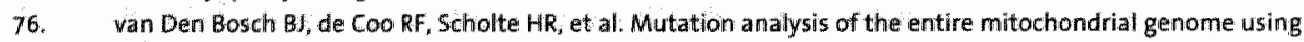
deraturing high performance liquid chromatography. Nucleic Acids Res. 2000:28.E89.

77. Transgenomic I. Mitoscreen Assay Kit: for rapid screening of the entire mitochondrial genome using mult plex DHPLC. Product specification sheet. 2003.

78. Lowell BB, Shulman GI. Mitochondrial dysfunction and type 2 diabetes. Science, 2005;307:384-387. 


\section{Summary}

Cardiovascular disease is already for many years the leading cause of death in modern Western societies, including the Netherlands. About $11 \%$ of the total number of deaths is due to HF, which is associated with high morbidity and mortality. Deciphering the pathophysiology of myocardial hypertrophy and pump failure is therefore one of the most important challenges in cardiovascular disease. Chapter 1 introduces a variety of causes and consequences of cardiac hypertrophy and $\mathrm{HF}$, indicating the complexity of these diseases. Important progress has been made in the past years with respect to the underlying pathogenic processes, although many questions still remain unanswered. Cardiomyopathies in humans are extremely heterogeneous with respect to cause and etiology and therefore mouse models, which are genetically and environmentally more homogeneous, are better suited to resolve the pathogenic mechanisms. This chapter includes an overview of the existing hypertrophy and HF mouse models and introduces microarray technology as a gene expression profiling tool for the dissection of pathogenic pathways.

Microarray studies yield a broad spectrum of potential pathways involved which need further investigation. As the first results of our microarray studies pointed among otheres to a role of OXPHOS defects in HF, we decided to validate these results by a variety of functional approaches and to judge the significance of primary OXPHOS defects in human pathology. Chapter 2 reviews the specific features of mitochondrial cardiomyopathies and the characteristics of mtDNA, which differ from those of the nuclear DNA in a number of aspects. For example, the mutation rate is about 10-20 times higher than in the nuclear DNA, due to reactive oxygen species generated by the OXPHOS system and the lack of sufficient repair mechanisms. MtDNA mutations mainly affect organs with a high energy consumption, such as the central nervous system, skeletal muscle and the heart. Both inherited and acquired mtDNA mutations play a role in cardiomyopathies. The former can be pathogenic heteroplasmic mutations or homoplasmic risk factors, while the latter are associated with the agerelated decline of OXPHOS function in the heart. Also, mitochondrial cardiomyopathies are frequently associated with (encephalo)myopathies, which are often the prominent features. To determine the role of primary mtDNA mutations in cardiomyopathies, we developed a method to screen the entire mIDNA for heteroplasmic mutations (Chapter 3). DHPLC analysis of PCR fragments specifically detects heteroduplexes resulting from heteroplasmic mutations with a sensitivity of 1-5\%. Several mutations were identified in patients with a cardiomyopathy with or without myopathy and muscle of one 
female with mitochondrial myopathy revealed the $A 3302 G$ mutation in tRNALeu ${ }^{\text {(und: }}$ Muscle of her affected son carried $96 \%$ mutated mtDNA and he died of cardiorespiratory failure at the age of 34 . Chapter 4 discusses a possible relationship between this mutation and cardiac problems. The mutation has onlly been described once before, also associated with cardiorespiratory failure. It is located at the end of the aminoacyl stem adjacent to the C3303T mutation, which has previously been related to cardiomyopathy. Also, other cardiomyopathy mutations have been reported in this part of tRNA genes. Although the affected son did not reveal signs of cardiomyopathy on examination, the combination of exercise and staying at a high altitude resulted in cardiorespiratory failure. Our findings suggest that cardiac examination should be performed in patients with pathogenic mtDNA mutations, but also that carriers should be informed regarding the possible risks of exposure to low oxygen pressure environments. An important role of mitochondrial abnormalities secondary to a cytoskeletal defect in cardiac disease is illustrated by our findings in the MLP mouse model for DCM (Chapter 5). Gene expression, biochemical and morphological studies showed reduced OXPHOS activity caused by a decreased mitochondrial density, even revealing regions completely lacking mitochondria in the MLP KO hearts. We hypothesize that the mitochondrial abnormalities identified are caused by the observed disturbed interaction between cytoskeleton and mitochondria, which interferes with energy sensing and energy transfer. Consequently, an energy defect is not compensated for by an increased production of mitochondria. This can be concluded from the downregulation of $\mathrm{PGC}-1 \alpha$, further contributing to energy depletion and deterioration of cardiac function.

Our first microarray experiments were performed before the human genome project was completed. Since then, the number of characterized human and mouse genes increased considerably and genome technology for transcriptomics changed and improved rapidly. The second part of this thesis (chapter 6,7 and 8) discusses microarray technology and its use for gene expression profiling in the identification of pathogenic processes in hypertrophy and HF. Chapter 6 reports on the initial development of in-house microarray technology using cDNA collections. Several technical approaches and protocols are compared and an overview of possible pitfalls is presented. Also, the application in cardiac hypertrophy and HF is briefly discussed and some preliminary results of the first microarray experiments are shown. Since then, technology has progressed and many adjustments were made regarding the microarray and experimental designs, technical protocols and data analysis described in this chapter. This has led to further improvement of data quality and enabled a 
more extensive and valid microarray data analysis. These improvements were applied to the global gene expression studies on microarrays containing a 15K cDNA collection of fetal origin in two genetic mouse models; i.e. the TAC model for cardiac hypertrophy induced by pressure overload and the CMYBP-C KO model for HCM. Chapter 7 describes the results of the gene expression study in left ventricles from TAC mice compared to sham-operated mice at different stages after banding, i.e. 48 hours, 1 week, 2, 3 and 8 weeks. Our results demonstrated an initial restriction in metabolism, associated with an investment in growth. Most of the genes involved in these processes returned to basal expression levels as from time point 3 weeks, in which a state of compensated hypertrophy was maintained. If these compensation mechanisms fail to match the increased energy demand, alterations in energy metabolism may sustain and may ultimately become detrimental, as has been reported in HF. The findings in this study also underline the importance of performing time series experiments, as certain alterations may be transient or coincidental. Although no actual time series experiment was performed in the CMyBP-C KO mice, comparison of heterozygous and homozygous KO mice revealed important clues regarding the possible adaptive and maladaptive processes involved in HCM. Chapter 8 reveals similar differentially regulated processes in both heterozygous as homozygous mice, of which the latter demonstrated a more pronounced effect. Some previously proposed maladaptive processes (e.g. apoptosis) were identified very early, before the development of cardiac hypertrophy in heterozygotes and before onset of impaired cardiac function in the homozygotes with hypertrophy. This suggest that an early molecular response may be an important determinant of later remodeling, which means that the benign or maladaptive outcome may already be set at this early stage.

Chapter 9 discusses three key issues raised in the previous chapters related to the use of gene expression profiling, the significance of the data from mouse models for human pathology and the role of OXPHOS defects in cardiomyopathies. The value, but also the limitations of microarray expression profiling for the elucidation of pathogenic genetic processes is discussed and several successful applications of genomic profiling in humans are shown. Part of the chapter discusses the translation of microarray data to biological significance. Also, data from murine studies using a similar approach as ours are compared with our own observations. When comparing these data, some important aspects should be kept in mind, like the use of different mouse strains, the different pathology in the mouse models (compensated vs. decompensated hypertrophy), time series experiments, experimental design and presentation of microarray data. Not only previous reports from literature, but also our 
own results indicate that mice are a valid model for studying both cardiac hypertrophy and $H F$ in humans. The final part of this chapter discusses the key role for mitochondrial energy metabolism in hypertrophy and failure, identified in the mouse models used as well as in patients. The chapter concludes with possible future steps to further unravel the molecular changes involved in hypertrophy and $\mathrm{HF}$. 


\section{Samenvatting}

Hart- en vaatziekten vormen al jaren de belangrijkste doodsoorzaak in Westerse landen, ook in Nederland. Ongeveer $11 \%$ van het totaal aantal sterfgevallen zijn het gevolg van hartfalen, dat geassocieerd is met een hoge morbiditeit en mortaliteit. Hartfalen wordt vaak voorafgegaan door hypertrofie van de hartspier. Het ontrafelen van de pathofysiologie van cardiale hypertrofie en pompfalen is een van de belangrijkste uitdagingen op het gebied van hart- en vaatziekten. Hoofdstuk 1 introduceert een breed scalla aan oorzaken en gevolgen van hypertrofie en hartfalen, waaruit blijkt dat deze aandoeningen zeer complex zijn. De afgelopen jaren is belangrijke vooruitgang geboekt in het onderzoek naar de onderliggende pathogene processen, maar er zijn nog steeds veel vragen die onbeantwoord blijven. Humane cardiomyopathieën zijn zeer heterogeen wat betreft hun oorzaak en manifestatie en daarom zijn muizenmodellen genetisch gezien en wat betreft omgevingsinvloeden homogener en dus beter geschikt voor de opheldering van de pathogene mechanismen. Dit hoofdstuk geeft een overzicht van bestaande muizenmodellen van hypertrofie en hartfalen en introduceert de microarray technologie als een middel voor het ontrafellen van pathogene processen door middel van genexpressie studies.

Microarray studies leveren een breed spectum aan pathways op die mogelijk betrokken zijn en verder onderzoek behoeven. Omdat onze eerste microarray resultaten 0.a. duiden op een rol van OXPHOS defecten in hartfalen, is besloten om deze resultaten te valideren met behulp van een aantal verschillende functionele benaderingen om zo de rol van primaire OXPHOS defecten in de humane pathologie te achterhalen. Hoofdstuk 2 bespreekt de specifieke kenmerken van mitochondriële cardiomyopathieën en de karakteristieken van het mtDNA, die in een aantal opzichten verschillen van die van het nucleaire DNA. De mutatiesnelheid in het mtDNA is bv. ongeveer 10-20 maal hoger als gevolg van de productie van zuurstofradicalen door het OXPHOS-systeem en de afwezigheid van DNA repair systemen. MLDNA mutaties hebben met name effect op organen met een hoge energieproductie, zoals het centrale zenuwstelsel, de skeletspier en het hart. Zowel erfelijke als verkregen mtDNA mutaties spelen een rol in het ontstaan van cardiomyopathieën. De eerste kunnen pathogene heteroplasmische mutaties of homoplasmische risicofactoren zijn, terwijl de laatste geassocieerd zijn met een leeftijd-gerelateerde verslechtering in cardiale OXPHOS-functie. Ook zijn mitochondriële cardiomyopathieën vaak geassocieerd met (encephalo)myopathieën, die vaalk de meest prominente manifestatie vormen. Om de rol te bepalen van primaire mtDNA mutaties in cardiomyopathieën, hebben we een 
methode ontwikkeld om het gehele mtDNA te screenen op heteroplasmische mutaties (Hoofdstuk 3). DHPLC analyse van PCR fragmenten detecteert met een gevoeligheid van $1-5 \%$ specifiek de heteroduplexen die ontstaan door heteroplasmische mutaties. Verschillende mutaties werden gevonden in patiënten met een cardiomyopathie met of zonder myopathie. In spier van een vrouw met een mitochondriële myopathie werd de $\mathrm{A} 3302 \mathrm{G}$ mutatie in tRNALeu(uUk) gevonden. Spier van haar aangedane zoon bevatte $96 \%$ gemuteerd mtDNA en deze man is op 34-jarige leeftijd overleden ten gevolge van cardiorespiratoir falen. Hoofdstuk 4 bespreekt een mogelijke relatie tussen deze mutatie en het optreden van hartproblemen. De mutatie is slechts eenmaal eerder beschreven, ook in relatie tot cardiorespiratoir falen, en is gelocaliseerd aan het einde van de aminoacylstam grenzend aan de C3303T mutatie, voorheen gerelateerd aan cardiomyopathie. Tevens zijn er andere cardiomyopathie-mutaties beschreven in dit deel van de tRNA genen. Hoewel de aangedane zoon geen tekenen vertoonde van een cardiomyopathie, resulteerde de combinatie van inspanning en een verblijf op grote hoogte in cardiorespiratoir falen. Onze resultaten suggereren dat cardiologisch onderzoek van belang is in patiënten met pathogene mtDNA mutaties, maar ook dat dragers geïnformeerd moeten worden over de mogelijke risico's met betrekking tot het verblijven in een omgeving met lage zuurstofdruk. Een belangrijke rol voor secundaire mitochondriële afwijkingen als gevolg van bv. een cytoskelet defect in het hart, blijkt uit onze resultaten in het MLP muizenmodel voor DCM (Hoofdstuk 5). Genexpressie, biochemisch en morfologisch onderzoek lieten een verminderde OXPHOS-activiteit zien als gevolg van een verlaagde mitochondriële dichtheid, met zelfs gebieden in het hart van de MLP KO muizen waarin de mitochondria geheel ontbraken. Wij veronderstellen dat deze mitochondriële afwijkingen veroorzaakt worden door een verstoorde interactie tussen het cytoskelet en de mitochondria, die interfereert met het bewaken van de energiebalans. Als gevolg hiervan wordt een energiedefect niet meer gecompenseerd door de aanmaak van meer mitochondria. Dit valt af te leiden uit de downregulatie van PGC-1 $\alpha$ wat verder bijdraagt aan de energiedepletie en verslechtering van hartfunctie.

Onze initiële microarray experimenten werden uitgevoerd voordat het humane genoom project was afgerond. Sindsdien is het aantal gekarakteriseerde humane en muizengenen behoorlijk toegenomen en zijn de genoomtechnologieën voor transcriptomics veranderd en sterk verbeterd. Het tweede deel van dit proefschrift (hoofdstuk 6,7 en 8) bespreekt het gebruik en de waarde van microarray technologie voor de identificatie van pathogene processen die een rol spelen in hypertrofie en hartfallen. Hoofdstuk 6 vertelt over de eerste ontwikkelingen van "in-house" 
microarray technologie waarbij gebruikt wordt gemaakt van CDNA collecties. Verschillende technische benaderingen en protocollen worden vergeleken en er wordt een overzicht gegeven van mogelijke valkuilen. Ook wordt de toepassing in cardiale hypertrofie en hartfalen kort besproken en worden een aantal preliminaire resultaten van de eerste microarray experimenten getoond. Sindsdien is de technologie vooruitgegaan en zijn veel aanpassingen gedaan wat betreft de microarray en experimentele designs, de technische protocollen en data-analyse die beschreven zijn in dit hoofdstuk. Dit heeft geleid tot een verdere verbetering van de kwaliteit van de data, waardoor een uitgebreidere en meer valide data-analyse mogelijk is. Deze verbeteringen zijn toegepast in de globale genexpressie studies waarin microarrays met een 15K cDNA collectie van foetale afkomst in twee genetische muizenmodellen werden gebruikt, namelijk het TAC model voor cardiale hypertrofie geïnduceerd door "pressure overload" en het CMyBP-C model voor HCM. Hoofdstuk 7 beschrijft de resultaten van de genexpressie studie in linker ventrikels van TAC muizen vergeleken met sham-geopereerde muizen op verschillende tijdstippen na constrictie, namelijk op 48 uur, 1 week, 2, 3 en 8 weken. Onze resultaten duiden op een initiële beperking in metabolisme geassocieerd met een investering in vergroting van de hartspier. De meeste van de genen die betrokken zijn bij deze processen keren weer terug naar hun basale expressie niveaus vanaf tijdstip 3 weken wanneer sprake is van gecompenseerde hypertrofie. Wanneer dit compensatiemechanisme niet meer tegemoet komt aan de toename in energiebehoefte, zouden de veranderingen in energiemetabolisme in stand kunnen blijven en uiteindelijk nadelig kunnen zijn, zoals ook al eerder is beschreven in hartfalen. Onze bevindingen benadrukken tevens het belang van het uitvoeren van experimenten in de tijd, omdat bepaalde veranderingen voorbijgaand of toevallig kunnen zijn. Hoewel dit soort experimenten feitelijk niet werden uitgevoerd in de $\mathrm{CMYBP-C}$ muizen, leverde vergelijking tussen heterozygote en homozygote $K O$ muizen interessante aanwijzigingen op met betrekking tot mogelijke adaptieve en maladaptieve processen in HCM. Hoofdstuk 8 lat soortgelijke differentieel gereguleerde processen zien in zowel de heterozygote en homozygote muizen, waarvan de laatste een meer uitgesproken effect vertonen. Enkele eerder geopperde maladaptieve processen (bv. apoptose) werden al vroeg gezien, voorafgaand aan de ontwikkeling van cardiale hypertrofie in de heterozygoten en alvorens het ontstaan van een verslechterde hartfunctie in de homozygoten met hypertrofie. Deze resultaten suggereren dat een vroege moleculaire respons een belangrijke voorspeller kan zijn van de later optredende "remodeling", wat betekent dat de benigne of maladaptieve afloop al in het vroege stadium zou kunnen vastliggen. 
Hoofdstuk 9 bespreekt drie belangrijke thema's met betrekking tot het gebruik van genexpressie studies, de betekenis van muizenmodellen voor de humane pathologie en de rol van OXPHOS defecten in cardiomyopathieën. De waarde, maar ook de beperkingen van het bepalen van genexpressie profielen met behulp van microarray technologie voor de opheldering van pathogene genetische processen worden beschreven en een aantal succeswolle toepassingen in humane studies wordt beschreven. Een deel van het hoofdstuk gaat over het vertalen van microarray data naar informatie van biologische betekenis. Ook worden gegevens uit muizenstudies die een soortgelijke benadering dan de onze gebruiken vergeleken met onze eigen resultaten. Wanneer men data uit verschillende studies vergelijkt, is het belangrijk om met een aantal zaken rekening te houden, zoals het gebruik van verschillende muizenstammen, de verschillende pathologie in de muizenmodellen (gecompenseerde vs niet-gecompenseerde hypertrofie), tijdserie-experimenten, experimenteel design en de presentatie van microarray data. De betekenis van bevindingen in de muis voor de humane pathologie blijkt niet alleen uit de literatuur, maar ook uit onze eigen bevindingen, waarin is bewezen dat de muis een geschikt model is voor het bestuderen van zowel cardiale hypertrofie als hartfalen. Het laatste deel van dit hoofdstuk bespreekt de sleutelrol voor het mitochondriële energiemetabolisme in hypertrofie en falen die is gevonden in zowel de gebruikte muizenmodellen als in patiënten. Het hoofdstuk eindigt met mogelijke toekomstplannen om verder de moleculaire veranderingen te ontrafelen die betrokken zijn bij hypertrofie en hartfalen. 



\section{Dankwoord}

Hier zit ik dan, voor de afwisseling weer 's achter mijn laptop...maar nu met een glimlach, want ik ben écht mijn dankwoord aan het schrijven en de rest van het boekje is klaar! lk heb me de afgelopen tijd regelmatig afgevraagd hoe dit zou voeien en zelfs toen het einde al in zicht was, leek dit moment nog ver weg te zijn. Als ik terugdenk aan de afgelopen jaren, dan is er zoveel gebeurd! Er zijn dan ook heel wat mensen die me op de een of andere manier hebben bijgestaan en die wil ik graag bedanken.

Als eerste wil ik Dr. H. Smeets bedanken, mijn co-promotor en directe begeleider die een zeer belangrijke rol heeft gespeeld bij de totstandkoming van mijn boekje. Beste Bert, ik vond het erg leuk dat ik na mijn stage bij jou ook de kans kreeg om te promoveren. I $\mathrm{k}$ heb de afgelopen jaren heel veel geleerd en met veel plezier en enthousiasme gewerkt, maar er waren ook periodes waarin niets goed leek te gaan en ik me niet kon voorstellen dat ik ooit een proefschrift bij elkaar geschreven zou krijgen...In "goede tijden" was je op jouw eigen manier enthousiast (met een "netjes" was ik erg blij) en als ik het niet meer zag zitten - ik wist zó zeker dat de resultaten alleen maar slecht waren - zag jij altijd nog een lichtpuntje en samen maakten we dan weer nieuwe plannen. Daar ben ik je zo dankbaar voor! Ook was het fijn dat je begrip had voor elke situatie en dat ik steeds bij je terecht kon (net als in New Orleans, haha!). De wereld van de mitochondria interesseert ons allebei en ik vind het dan ook erg fijn om de komende 3 jaar als postdoc bij je te werken samen met de andere "mitomensen"! Mijn dank gaat verder uit naar mijn twee promotores, Prof. Dr. J. Geraedts en Prof. Dr. P. Doevendans. Beste Joep, jouw kritische vragen en adviezen waren zeer verhelderend voor mij, bedankt! Beste Pieter, bedankt voor al je hulp gedurende het project, met name voor je inzet om materiaal te verzamelen voor onze (toekomstige) studies!

Toen ik als AlO begon, waren ons groepje en de labs verspreid over verschillende verdiepingen (de 4-daagse lopen was er niks bij!). Uiteindelijk zijn we toch allemaal bij elkaar komen te zitten, wat behalve gemakkelijker, ook een stuk gezelliger was (met het kippenhok en een echte koffiekamer)! De eerste 2 jaar was jij, Saskia, analist op mijn project en hebt steeds meegedacht en keihard gewerkt. Dankjewel voor alle leuke en hilarische momenten (je weet wel, haha) en ook voor je steun in de moeilijkere tijden toen...Ook wil ik jou, Katinka, bedanken voor de gezelligheid en assistentie op het lab toen en voor het met me meeleven tot op de dag van vandaag. Joost, jij ook bedankt voor de hulp (en gezelligheild natuurlijk) tijdens je stage en veel succes met 
jouw promotieonderzoek! Ik will ook Frank, Kirsten, Jan Geurts en Jeroen Aerssens bedanken voor de leuke samenwerking destijds. Ook de mensen van DNA diagnostilek mag ik niet vergeten: Judith, Jeroen (ja, je AljO gaat eindelijk promoveren!), Diane, Wil, Alexandra, Lien, Crool, Patricia, Sabine, Lars, Dimitri, Rien, Kees, JosH en Arthur. Francis, bedankt voor de poster-hulp en het vastleggen op foto op deze belangrijke dag voor mij! Ook de overige mensen van Klinische Genetica, Cytogenetica en Metabole Stoornissen, bedankt allemaal.

Natuurllijk een speciaal woord van dank voor de mensen van onze eigen afdeling voor hun hulp op welke manier dan ook, voor hun interesse en natuurlijk voor de gezelligheid op het lab, in de koffiekamer, tijdens labuitjes etc.: Marion (denk je aan me in het vliegtuig?), Jos, Mike (toch maar gewoon Bianca op de kaft gezet...), Ellen, Bieke, Anja, Aimeé en Roselie (wanneer gaan we weer??), Marij, Torik (fijn dat ik altijd binnen kon komen lopen!), Bob, Florence, Liesbeth, Fons (meneer Stassen bedoel ik), en de stagaires, bedankt! In het bijzonder wil ik jou, Caroline, bedanken voor de praktische ondersteuning de laatste 2 jaar (zoals o.a. de lange wandelingen met de kloontjes...).॥ would like to thank you, Patrick, for all the hours (evenings and nights!) you spent on analyzing our data. Ton "jou wil ik bedanken voor je redding en kalme optreden tijdens mijn PC-drama('s)! Lieve Rosy, met vragen (of voor ridders en Gandalfs), om ff gezellig te kletsen, maar ook als het even niet meezat, kon (en kan) ik altijd bij jou terecht, dankjewell Echt älles komt uiteindelijk toch goed! Lieve Rob, lieve Erika, we hebben elkaar leren kennen vlak voordat ik hier als AlO begon en jullie hebben me gedurende mijn hele pramotietijd bijgestaan. Vooral om de microarray aan de praat te krijgen hebben we de nodige uurtjes samen doorgebracht, met goede momenten (jippie, spotjes!), en minder goede (uh, waar blijven ze nou?!). Niet alleen wat het werk betreft, maar ook daarbuiten hebben we veel leuke dingen gedaan en heb ik heel veel steun aan jullie gehad. Ik hoefde dan ook niet lang na te denken over wie ik als paranimfen graag naast me zou willen zien staan! Jullie zijn schatten...dankjewel! In het bijzonder wil ik mijn mede-AlO's en kamergenoten bedanken voor de osmose (jaja), gezelligheid, hulp, de nodige klaaguurtjes en mentale steun gedurende de afgelopen jaren! Lorraine (wat hebben wij llanggelaufen hè...), Lars (lang leve de supportsessies op MSN tot in de late (voor mij dan) uurtjes!), Roedi (mien Mestreechs wierd noch waal 's get, hè! En misschien Photoshop ook nog 's...). Nicole (samen toch's naar Dorien gaan??) en Ruben (tiswa met al die Limbo's op de kamer hè): heel veel succes de komende tijd! Ik zall ons missen als we ooit niet meer op dezelfde kamer zitten... 
Ook wil ik o.a. de mede-(ex)AlO's bedanken voor de gezelligheid look tijdens onze cursussen) en hulp door de jaren heen: Sander en Petra, Joris, Victor, Marjollein, 5 tijn, Anne (was leuk altijd in A'dam!), Mathijs, Daniëlle, Jop, Eva, Fawzi, Daan (zonder jou geen TACs...), Debby, Susan, Danny, Roy, Yart, Maurice en Danielle (help, ik hoop dat ik niemand vergeet nu...). Guillaume, bedankt dat ik altijd binnen kon stormen om even liets te vragen, Marcel Borgers en Fons Verheyen, bedankt voor jullie huip met de microscopie-resultaten. Tevens de overige collega's van Moleculaire Genetica en Moleculaire Celbiologie, bedankt! En Blanche, dankjewel voor alle keren dat je op de goele momenten even binnen kwam lopen om te kletsen, jij ook succes met alles! Simone, als microarray-lotgenoten hebben we elkaar het laatste jaar beter leren kennen, maar door omstandigheden nog te weinig leuke dingen gedaan! Ik stel voor dat we daar snel iets aan gaan doen! Tijl, ontzettend bedankt voor al je muïzen-eerstehulp, jij ook veel succes met alles! Ook Jacques, alle andere collega's van Farmacologie en de mensen van het CPV wil ik bedanken voor hun assistentie bij de muizenexperimenten. Petra, bedankt voor je assistentie bij de WAVE en de gezelligheid op jullie lab. Hans, het was altijd leuk op het lab bij Celbiologie vroeger en ook om zo even met je te kletsen tussendoor op de gang. Bedankt voor het uitvoeren van alle ELMI experimenten! in het bijzonder will ik ook Ger van der Vusse bedanken voor de nuttige en verhelderende discussies over onze resultaten, fijn dat je altijd tijd voor me vrij maakte!

I would also like to thank the people we have been (and still are) collaborating with: Howard Rockman and Holly Roberts from Duke University Medical Center in North Carolina and Lucy Carrier from University-Hospital Hamburg-Eppendorf in Germany. Een speciaal woord van dank wil ik richten tot onze collega's uit Rotterdam: Jasper, René, Gerard, Wim en Kees. Beste Jasper, je interesse voor ons onderzoek en alle adviezen en hulp daarbij heb ik altijd enorm gewaardeerd. Ook naar jouw enthousiaste verhalen, zowel op wetenschappelijk als op ander gebied, luister ik (nog) altijd graag. Ook dank ik jou en je vrouw voor de gastvrijheid bij jullie thuis, het eten was altijd heerlijk! Beste René, eindelijk is het dan zover hè, je was me enkele maanden voor en je weet dus precies hoe ik me nu voel tijdens het schrijven van mijn dankwoord (en op 7 oktober om 12.00 uur)...lk heb onze samenwerking altijd als prettig ervaren en ik hoop dat we de komende jaren nog veel samen gaan werken. Beste Kees, bedankt voor het meten van de OXPHOS complexen en de gastvrijheid bij jullie op het lab. Behalve leerzaam waren die uirtjes ook gezellig! Net als onze RoMa-meetings, die er helaas de laatste tijd een beetje bij ingeschoten zijn. Laten we de draad vanaf nu weer oppakken en weer snel een nieuwe meeting plannen! 
Natuurlijk wil ik ook mijn familie en vrienden bedanken voor alle steun en begrip in de tijden dat ik weer 's niet meeging, moeilijk afspraken kon maken en redelijk wat gezellige uurtjes moest missen...gaan we inhalen! Roberto, thanx voor de mouse, hebben "we" mooi gedaan hè! Thea en Nana, bedlankt voor jullie interesse altijd en steun, en Peter, dankjewel voor je bezorgdheid en je vertrouwen in mij...Nelleke, ik vond het heel fijn dat je altijd met me meegeleefd hebt en ik vind het erg jammer dat ik niet bij jullie bruiloft kan zijn. Een hele mooie dag gewenst! Lieve Annick, ik ben zo dankbaar dat je er altijd voor me bent! Als het goed ging kon ik het met je delen, maar ook als het minder ging was je daar...lk heb zoveel van je geleerd (jaja, iedereen is ve...haha), je bent mijn maatje voor altijd! Verder wil ik ook iedereen bedanken die ik toch nog vergeten ben....sorry!

Lieve papa, lieve mama, zonder jullie onvoorwaardelijke vertrouwen en steun was ik nooit zover gekomen. Jullie hebben altijd achter me gestaan, welke keuzes ik ook heb gemaakt. Daar ben ik jullie heel erg dankbaar voor! We hebben allemaal wat moeilijke momenten gehad de afgelopen jaren, maar gelukkig gaat het nu weer wat beter allemaal. Mam, bedankt voor alle ohzo belangrijke dingen die je voor me hebt gedaan: van Shiatsu (wat is dat toch heerlijk...) tot lekker koken tot...och, gewoon voor álles! Pap, dankjewel voor alles wat je voor me hebt gedaan en dat je altijd in me bent blijven geloven, ik ben heel blij dat je er bij kunt zijn vandaag! Lieve Demis, jij hebt ervoor gezorgd dat die laatste loodjes (maar ook die daarvoor hoor) niet té zwaar waren. Ik heb heel wat avonden zitten werken, waardoor we weinig samen konden doen in die tijd, maar gelukkig heb je altijd achter me gestaan (vaak letterlijk met thee en chocolade...). Je sprak me ook altijd moed in op momenten dat ik het even niet meer zag zitten. Fijn dat je altijd zo geduldig was en me ook weer steeds aan het lachen kon maken! Zonder jou waren de afgelopen jaren zoveel moeilijker geweest...dankjewel! Samen maken we er iets moois van hèl

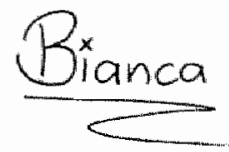




\section{Curriculum Vitae}

Bianca Jozefina Catharina van den Bosch werd geboren op 23 oktober 1976 te Heerlen en is opgegroeid in Brunssum. Van 1989 tot 1995 doorliep zij het Voortgezet Wetenschappelijk Onderwijs (VWO) aan het St. Janscollege in Hoensbroek en vervolgens begon ze aan haar opleiding Biologische Gezondheidkunde aan de Universiteit Maastricht. Ze was altijd al geïnteresseerd in de genetica en daarom was. ze erg blij dat het gelukt was om haar afstudeerstage te volgen binnen de afdeling Klinische Genetica in Maastricht. Het doen van onderzoek beviel haar erg goed en met name het onderwerp "mitochondriële ziekten" trok haar aandacht. In 1999 behaalde ze haar doctoraal examen en begon ze haar promotieonderzoek als assistent in opleiding (AIO) op de afdeling Genetica en Celbiologie, verbonden aan het Cardiovascular Research Institute Maastricht (CARIM) aan de Faculteit der Geneeskunde, Universiteit Maastricht. Het doel van haar onderzoek was het ontrafelen van pathofysiologische processen in hypertrofie en hartfalen. Gedurende deze periode heeft zij verschillende cursussen gevolgd en certificaten behaald, zoals o.a. "Artikel 9 functionaris" voor het werken met proefdieren, "Veilige Microbiologische Technieken" voor het werken met genetisch gemodificeerde organismen, "Deskundigheidsniveau

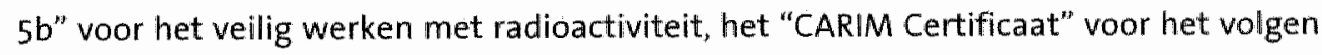
van het AIO-cursustraject van CARIM en een certificaat voor het volgen van de "Mouse Genetics Course" in het Karolinska Institute in Stockholm. Sinds 1 januari 2005 is ze werkzaam als postdoc binnen de afdeling Genetica en Celbiologie, teruggekeerd naar haar favoriete onderwerp: de mitochondria. Het MITOCIRCLE project wordt uitgevoerd in samenwerking met verschillende groepen binnen Europa die gespecialiseerd zijn in mitochondriële ziekten. 


\section{Publications}

B.J.C. wan den Bosch, I.F.M. de Coo, H.R. Scholte, J.G. Nijland, R.van den Bogaard, M.de Visser, C.E.M. de Die-Smulders, H.J.M. Smeets. Mutation analysis of the entire mitochondrial genome using denaturing high performance liquid chromatography (DHPLC). Nucleic Acids Research... 2000; 28 (20): e89.

R.J.E. Jongbloed, B.J.C. van den Bosch, I.F.M. de Coo, H.J.M. Smeets. Mitochondrial Cardiomyopathy. In: Doevendans PA, Wilde AA, eds. Cardiovascular Genetics for Clinicians. Dordrecht, The Netherlands: Kluwer Academic Publishers; 2001:127-137.

B.J.C. van den Bosch, P.A.F.M. Doevendans, I.M.W. Geurts, H.J.M. Smeets. Towards elucidation of pathogenic genetic pathways in cardiac hypertrophy: a technical report on making in-house gene expression microarrays. In Cardiovascular Genomics: New pathophysiological concepts. Proceedings of the 2001 European Science Foundation Workshop in Maastricht. Edited by P. Doevendans en S. Kääb. 2002. Klluwer Academic Publishers.

B.J.C. van den Bosch, P.A.F.M. Doevendans, D.J. Lips, H.J.M. 5 meets. Methods in molecular cardiology: microarray technology. Netherlands Heart Journal. 2003, 11 (5), 213-220.

B.J.C. van den Bosch, I.F.M. de Coo, A.T.M. Hendrickx, H.F.M. Busch, G. de Jong, H.R. Scholte, H.J.M. Smeets. Increased risk for cardiorespiratory failure associated with the $A 3302 \mathrm{G}$ mutation in the mitochondrial DNA encoded TRNALeu(UUR) gene. Neuromuscular Disorders. $2004 ; 14: 683-688$.

B.J.C. van den Bosch, C.M.M. van den Burg, K. Schoonderwoerd, P.J. Lindsey, H.R. Scholte, I.F.M. de Coo, E. van Rooij, H.A. Rockman, P.A.F.M. Doevendans, H.J.M. Smeets. Regional absence of mitochondria causing energy depletion in the myocardium of MLP knockout mice. Cardiavascular Research. 2005; 65: 411-418.

B.J.C. van den Bosch, P.J. Lindsey, C.M.M. van den Burg, 5.A. van der Vlies, D.J. Lips, G.J. van der Vusse, T.A. Ayoubi, P.A.F.M. Doevendans, H.J.M. Smeets. Early and transient changes in gene expression compensate pressure overload induced cardiac hypertrophy in mice. Submitted.

L.M.T. Eijssen, B.J.C. van den Bosch, N. Vignier, P.J. Lindsey "C.M.M. van den Burg, L. Carrier, P. A. Doevendans, H.J.M. Smeets. The early genetic profile of maladaptive hypertrophy in CMyBP.C knockout mice. In preparation. 


\section{Abbreviations}

ACE

ACTRIA

AIC

ALP

AMPK

ANF/ANP

ANG

ANT1

APEX

APP

APLP2

$A R$

ARK

ARVD

ASO

ATP

AT1-R

ATP6

AQBC

AV

6-ARK1

BLAST

B-MHC/MyHC-b/MYH7

BNP

BSA

BW

CaMKIV

CDK9

CDNA

CETN2

$\mathrm{CH}$

$\mathrm{CK}$

$\operatorname{cox}$

$\operatorname{cox} 5 \mathrm{a}$

coll

CMYBP-C/MYBPC/MYBPC3

CPEO

CPT

CREB

CS

CSD

$\operatorname{CSQ}$ angiotensin converting enzyme

ARP1 actin-related protein 1 homolog $A$

Akaike information criterion

actinin-associated LM protein

AMPactivated protein kinase

atrial natriuretic factor/atrial natriuretic peptide

angiotensin II

adenine nucleotide translocator 1

allele-specific primer extension

amyloid beta precursor protein

amyloid beta (A.4) precursor-like protein 2

adrenergic receptor

adrenergic receptor kinase

arrhytmogenic right ventricular dysplasia

allele-specific oligonucleotide

adenosine tri-phosphate

angiotensin 11 type- 1 receptor

ATP synthase 6

Adaptive Quality-Based Clustering

atrioventricular

$\beta$-adrenergic receptor kinase

Basic Local Alignment Search Tool

3-myosin heavy chain

brain natriuretic peptide

bovine serum albumin

body weight

calcium/calmodulin-dependent protein kinase IV

cyclin-dependent kinase 9

copy DNA

centrin 2

cardiac hypertrophy

creatine kinase

cytochrome c oxidase

cytachrome c oxidase subunit 5 a

cytochrome coxidase subunit II

cardiac myosin binding protein $C$

chronic progressive external opthalmoplegia

carnitine palmitoyltransferase

cyclic adenosine monophios phate regulatory element-binding protein

citrate synthase

conduction-system disease

calsequestrin 


\begin{tabular}{|c|c|}
\hline $\operatorname{CSR}$ & Cheyre-Stokes respiration \\
\hline$C T$ & computerized tomography \\
\hline CUL1 & cullin 1 \\
\hline CVD & cardiovascular disease \\
\hline CYTB & cytochrome b \\
\hline DAVID & Database for Annotation ${ }_{i}$ Visualization and Integrated Discovery \\
\hline DCM & dillated cardiamyopathy \\
\hline dCTP & deoxycytidine triphosphase \\
\hline DGGE & denaturing gradient gel electrophoresis \\
\hline DHPLC & denaturing high-performance liquild chromatography \\
\hline DMSO & dimethyl sulphoxide \\
\hline BNC & deoxymucleotide carrier \\
\hline DNP & 2,4-dinitrophenol \\
\hline dNTP & deoxynucleotide triphosphate \\
\hline DTt & dithiothreitol \\
\hline dUTP & deoxyuridine triphosphate \\
\hline $\mathbb{E C G}$ & electrocardiogram \\
\hline $\mathrm{ECHO}$ & echocardiography \\
\hline EEG & electro-encephalogram \\
\hline EF1a & elongation factor $1 \alpha$ \\
\hline $\mathbb{E L C}$ & essential myosin light chain \\
\hline EMG & electromyogram \\
\hline ENO1 & enolase 1 , alpha noin-neuron \\
\hline FA & fatty acid \\
\hline FBD & Familial British dementia \\
\hline FHC & familial hypertrophic cardiomyopathy \\
\hline FKBBP122 & FK506 binding protein-12 \\
\hline F5 & fractional shortening \\
\hline GAPDH & glyceraldehyde-3-phosphate \\
\hline GenMapp & Gene MicroArray Pathway Profiler \\
\hline GLUT & glucose transporter \\
\hline GO & Gene Ontology \\
\hline GPI1 & glucose phosphate isomerase $\mathbb{1}$ \\
\hline $\mathrm{HCM}$ & hypertrophic cardiamyopathy \\
\hline HEPES & $\mathbb{N}-[2-$ Hydroxy[thyl] Piperazine-N'-[2 EthylSulfonic acid] \\
\hline $\mathrm{HF}$ & heart failure \\
\hline HOXB3 & homeo box 3 \\
\hline HPRT & hypoxanthine guanine phorsphoribosyltransferase \\
\hline HUGE & Human Unidentified Gene-Encoded \\
\hline ICEU & intracellular energetic units. \\
\hline IDC & idiopathic cardiomyopathy \\
\hline IDH3A. & isocitrate dehydrogenase 3 , alpha subunit \\
\hline IF & intermediate filament \\
\hline $1 G F$ & insulin-like growth factor \\
\hline
\end{tabular}


II

INLVM

ISO

KO

LAMP2

LHON

LL. ID

LV

LVAD

LVH

LVW

MAPK

MEK5

MELAS

MELK

MERFF

MFNG

MHC

$\mathrm{MI}$

MIAME

MLC2

MLP

MMP

MnSOD

mRNA

mtDNA

MEIF2

METFA

MRI

NCBI

NCX

ND1/ND2

nDNA

NFAT

NIA

NIH

NMHC-IIB

NRAP

OMIM

OXPHOS

PCR

PGC-1C.

PI3K

PKA interleukin

isolated non-compaction of the left ventricular myocardium isoproterennol

knorkout

lysosome-associated membrane protein 2

Leber hereditary optic neuropathy

LocusLink Identifier

left ventricle

left ventricular assist device

left wentricular hypertrophy

left ventricle weight

mitogen-activated protein kinase

MAPK kinase- 5

mitochondrial encephalopathy lactic acidosis and stroke-lilke episodes maternal embryonic leucine zipper kinase

myoclonic epilepsy with ragged red fibers

manic fringe homolog

myasin heavy chain

myocardial infarction

Minimum Information About a Microarray Experiment

myosin light chain 2

muscle LIM protein

metalloproteinase

manganese superoxide dismutase

messenger RNA

mitochondrial DNA

mitochond rial translational initiation factor 2

mitochondrial transcription factorA

magnetic resonance imaging

National Center for Biotechnology Information

sodium-calcium exchange

NADH-ubiquinone oxidoreductase 1 and 2

nuclear DNA

nuclear factor of activated T cells

Nationall Institute on Aging

National Institute of Health

nonmuscle myosin heavy chain-llB

nebulin-related anchoring protein

Online Mendelian Inheritance

axidative phosphorylation

polymerase chain reaction

peroxisome proliferator activated receptor gamma co-activator 1a

phosphatidylinositol 3-kinase

protein kinase A 
PKC

\section{PKML}

PLBIPLN

PLXNB1

PRKAC2/AMPKY 2

PSEN1

RAR

RCM

IRNA

RT-PCR

RXR

RyR-2

SD

SDHC

SDS

SERCA2 /ATPZA2

SGCB

SGCD

SGCG

SRF

$5 S C$

$55 \mathrm{CP}$

SLC25a19

STAT

STX4A

TAC

TAK1

TCA cycle

TDGF 1

TEAA

TFAM

TGF

TIGR

TL.

TMPD

TNF

tRNA

UBE1

UITraGAPS

UMPK/UCK

VEGF

WPW

$W T$

ZASP protein kinase $C$

pyruvate kinase

phospholamban

plexin b

protein kinase, amp activated, noncatalytic, gamma 2

presenulin 1

retinoid acid receptór

restrictive cardiomyopathy

ribosomall RNA

reverse transcriptase $\mathrm{PCR}$

retinoid $X$ receptor

ryanodine receptor-2

standard deviation

succinate dehydrogenase $C$

sodium dodecyl sulphate

sarco/endo-plasmic reticulum Ca-ATPase type 2 isoform

sarcoglycan beta

sarcoglycan delta

sarcoglycan gamma

serum response factor

salline sodium citrate

single stranded conformation polymorphism

solute carrier family 25 , mitoch deaxynucleotide carrier, member 19

signal transducer and activator of transcription

syntaxin $4 \mathrm{~A}$

transverse aortic constriction

transforming growth factor-activated kinase $\mathbb{1}$

tiricarboxylic cycle

teratocarcinoma-derived growth factor 1

triethyllammonium acetate

mitochondrial transcription factor $\mathrm{A}$

transforming growth factor

The Institute for Genomic Research

tibia length

tetramethyl-p-phenylenediamine

tumor necrosis factor

transfer RNIA

ubiquitin activating enzyme 1

Llltra Gamma Amino Propyl Silane

uridine monophosphate kinase

vascular endothelial growth factor

Wolff-Parkinson-White

wild-type

Z-band alternatively spliced PDZ motif 